SILVIA HONDA TAKADA

\title{
MORTE NEURAL E NEUROGÊNESE NO HIPOCAMPO DE RATOS APÓS ANÓXIA NEONATAL
}

Tese apresentada ao Programa de PósGraduação em Ciências Morfofuncionais do Instituto de Ciências Biomédicas da Universidade de São Paulo, para obtenção do Título de Doutor em Ciências.

São Paulo 2013 


\section{MORTE NEURAL E NEUROGÊNESE NO HIPOCAMPO DE RATOS APÓS ANÓXIA NEONATAL}

Tese apresentada ao Departamento de Anatomia do Instituto de Ciências Biomédicas da Universidade de São Paulo, para obtenção do Título de Doutor em Ciências.

Área de concentração: Ciências Morfofuncionais

Orientadora: Profa. Dra. Maria Inês Nogueira Versão Original 
DADOS DE CATALOGAÇÃO NA PUBLICAÇÃO (CIP)

Serviço de Biblioteca e Informação Biomédica do

Instituto de Ciências Biomédicas da Universidade de São Paulo

reproduçẫo nâo autorizada pelo autor

Takada, Silvia Honda.

Morte neural e neurogênese no hipocampo de ratos após anóxia neonatal / Silvia Honda Takada. -- São Paulo, 2013.

Orientador: Profa. Dra. Maria Inês Nogueira.

Tese (Doutorado) - Universidade de São Paulo. Instituto de Ciências Biomédicas. Departamento de Anatomia. Área de concentração:

Ciências Morfofuncionais. Linha de pesquisa: Plasticidade e hodologia de sistemas neurais envolvidos em reflexos e ritmos.

Versão do título para o inglês: Cell death and neurogenesis in rat hippocampus following neonatal anoxia.

1. Asfixia neonatal 2. Necrose 3. Apoptose 4. Proliferação celular 5. Diferenciação celular 6. Anóxia I. Nogueira, Profa. Dra. Maria In ês II. Universidade de São Paulo. Instituto de Ciên cias Biomédicas.

Programa de Pós-Graduação em Ciências Morfofuncionais III. Título. 
Candidato(a):

Título da Tese:
Silvia Honda Takada.

Morte neural e neurogênese no hipocampo de ratos após anóxia neonatal.

Orientador(a):

Profa. Dra. Maria Inês Nogueira.

A Comissão Julgadora dos trabalhos de Defesa da Tese de Doutorado, em sessão pública realizada a I. I... considerou

( ) Aprovado(a)

( ) Reprovado(a)

\begin{tabular}{|c|c|}
\hline Examinador(a): & $\begin{array}{l}\text { Assinatura: } \\
\text { Nome: ....... } \\
\text { Instituição: }\end{array}$ \\
\hline Examinador(a): & $\begin{array}{l}\text { Assinatura: } \\
\text { Nome: ....... } \\
\text { Instituição: }\end{array}$ \\
\hline Examinador(a): & $\begin{array}{l}\text { Assinatura: } \\
\text { Nome: ....... } \\
\text { Instituição: }\end{array}$ \\
\hline Examinador(a): & $\begin{array}{l}\text { Assinatura: } \\
\text { Nome: ....... } \\
\text { Instituição: }\end{array}$ \\
\hline Presidente: & $\begin{array}{l}\text { Assinatura: } \\
\text { Nome: ....... } \\
\text { Instituição: }\end{array}$ \\
\hline
\end{tabular}




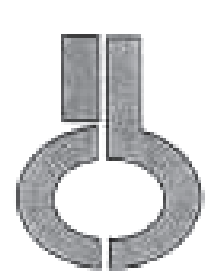

UNIVERSIDADE DE SÃO PAULO

INSTITUTO DE CIENCLAS BIOMEDICAS

Cidade Universitäria "Armando de Salles Oliveira"

Av. Prof. Lineu Prestes, 2415 - CEP. 05508-000 Săo Paulo, SP Brasil

Telefone :55) (011) 3091.7733 - e-mail: cep@icb.usp.br

\section{Certificado}

Certificamos que o protocolo registrado sob n ${ }^{\circ} 190$ nas fls. 139 do livro 02 para uso de animais em experimentação, sob a responsabilidade do Prof(a) Dr(a)) Maria Inês Nogueira, Coordenador (a) da Linha de pesquisa "Estudo da organização e dinămica neural: no encéfalo de ratos após anóxia neonatal ${ }^{*}$ do qual participam o(s) aluno(s), Silvia Honda Takada, Mike Yoshio Hamasaki, Vitor Yonamine Lee, está de acordo com os Princípios Éticos de Experimentaçăo Animal adotado pela Sociedade Brasileira de Ciência de Animais de Laboratório (SBCAL) e foi aprovado pela COMISSÃO DE ÉTICA NO USO DE ANIMAIS (CEUA) em 12.12.2012, com validade de 4 anos.

Såo Paulo, 14 de dezembro de 2012.

P) Q Qunes

Prof. Dr. WOTHAN TAVARES DE LIMA Coordenador-CEUA - ICB/USP

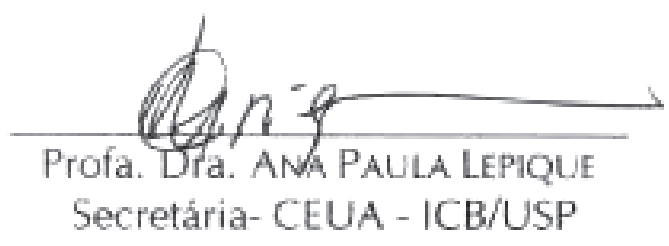


Dedico este trabalho aos portadores de paralisia cerebral e outras sequelas de anóxia neonatal, os quais me inspiraram e me motivaram durante a realização do mesmo. 


\section{AGRADECIMENTOS}

Aos meus pais, por apoiarem minhas escolhas, hoje e sempre, contribuindo e torcendo para minha realização pessoal e profissional e por terem me fornecido todas as ferramentas necessárias para isso.

Ao meu marido e filhos, por inigualável apoio, amor, carinho e compreensão e por terem sido meus alicerces em momentos mais difíceis.

À orientadora Profa. Dra. Maria Inês Nogueira, pela orientação, convivência, amizade e por dar o exemplo de como fazer ciência com humanidade e em sua totalidade.

Aos amigos Leila, Lívia, Daniella, Carlos Haemmerle, Vitor e Mike, pela amizade sincera, apoio, por dividir comigo alegrias e frustrações da vida e dos experimentos e pelas preciosas discussões.

Aos amigos queridos do Laboratório de Neurociências do Departamento de Anatomia: Bárbara, Roberto Tangoa, Renné, Wilma, Rômulo, Muniz, Cauê, Carlos Sampaio e Amrita, pela amizade e convivência enriquecedora.

Ao Professor Dr. Luiz Fernando Takase, idealizador e colaborador de parte da tese, pelos ensinamentos e apoio.

Ao Professor Dr. li-Sei Watanabe, Marta, Sônia, Boleta, Kelly e alunos Carlos, Diego, Fernando e Adriano, por todo o auxílio e colaboração com o espaço, equipamentos e com a microscopia eletrônica.

Ao Professor Dr. Jackson Cioni Bittencourt, seus alunos Daniella e Giovanne e à Jô, meus sinceros agradecimentos por todo o apoio e auxílio prestado na utilização dos equipamentos, imprescindíveis para a realização deste estudo.

Ao Professor Dr. Roelf Cruz-Rizzolo, pela ajuda inestimável com a estereologia e pelo grande exemplo como pesquisador e ser humano.

Ao Professor Dr. Gilberto Xavier, técnico Manuel e alunos do laboratório de Neurociência e Comportamento (IB-USP), por todo o apoio e facilidades no uso do espaço e equipamentos.

Ao Professor Dr. Sidhartha Tan e sua equipe, por ter proporcionado rico aprendizado e pela confiança depositada em meu trabalho.

Ao Professor Dr. Alexandre Hiroaki Kihara, pelas discussões que permitiram outras visões e abordagens valiosas neste estudo.

À Rosana Prisco, meus agradecimentos especiais, pelo profissionalismo e eficiência. 
Aos funcionários do Instituto de Ciências Biomédicas, por toda a assistência prestada durante a realização deste trabalho.

À Coordenadoria de Aperfeiçoamento Pessoal de Nível Superior, pelo apoio financeiro no início do desenvolvimento do projeto.

À Fundação à Pesquisa do Estado de São Paulo, pelo apoio financeiro (processos 2009/51557-0 e 2010/01488-9).

Ao Programa de Ciências Morfofuncionais, pela oportunidade e facilidades oferecidas.

Ao Departamento de Anatomia e ao Instituto de Ciências Biomédicas, pela utilização de seus espaços e recursos.

Á Pró-reitoria de Pós-Graduação da Universidade de São Paulo, pelo auxílio financeiro concedido. 
"O que destrói a humanidade: a política, sem princípios; o prazer, sem compromisso; a riqueza, sem trabalho; a sabedoria, sem caráter; os negócios, sem moral; a ciência, sem humanidade; a oração, sem caridade."

Mohandas Karamchand Gandhi 


\section{RESUMO}

Takada SH.Morte neural e neurogênese no hipocampo de ratos após anóxia neonatal. [tese (Doutorado em Ciências Morfofuncionais)]. São Paulo: Instituto de Ciências Biomédicas, Universidade de São Paulo; 2013.

A anóxia neonatal, considerada problema clínico mundial, é uma das mais importantes causas de lesão encefálica em neonatos que pode apresentar consequências graves e permanentes na vida adulta, como déficits cognitivos e comportamentais, paralisia cerebral, epilepsia, deficiências auditivas e visuais. $\mathrm{O}$ presente estudo tem como objetivo analisar longitudinalmente possíveis alterações na morte, proliferação e diferenciação neuronais no hipocampo de ratos submetidos à anóxia neonatal. Para tanto, utilizamos modelo adaptado e validado em nosso laboratório (TAKADA et al., 2011), o qual foi efetivo em ocasionar alterações neuronais, gliais e comportamentais em ratos. Para o estudo da morte neuronal, foram utilizados anticorpos contra Caspase-3 ativada, TUNEL, Fluoro-Jade B® (FJB) e microscopia eletrônica. A metodologia escolhida para o estudo da proliferação e neurogênese consistiu na análise do volume das subregiões hipocampais por análise estereológica, nas técnicas de imunoreatividade para Ki-67, marcadora de proliferação celular e dupla imunofluorescência para BrdU e NeuN, para estudo da neurogênese hipocampal adulta. Os seguintes resultados foram observados: 24 horas após a anóxia (P3), ocorreu maior marcação TUNEL+ em CA1 e CA2-3, enquanto houve maior marcação $\mathrm{FJB}+$ em $\mathrm{CA} 3$; a análise estereológica da densidade da Caspase-3 ativada, porém, não mostrou diferenças entre os grupos anóxia e controle em nenhuma das idades estudadas (P3, P14, P21 e P60). Também não foram encontradas diferenças na proliferação celular da camada subgranular do hipocampo nestas idades. A análise da diferenciação neuronal, contudo, mostrou estar diminuída nos animais adultos (P60) submetidos à anóxia neonatal. Em relação ao volume das subregiões hipocampais, houve aumento de volume na região CA1 de ratos $\mathrm{P} 14$ submetidos à anóxia neonatal. A análise por microscopia eletrônica de transmissão evidenciou ainda neurônios com características de morte por necrose e continuum em CA1 e GD de animais P3 submetidos à anóxia, além de indícios que outros tipos de morte, como autofagia, necroptose e morte por excitotoxicidade estavam também presentes nestes animais. Portanto, estes resultados mostraram que o presente modelo de anóxia neonatal causa morte neural em CA1 e CA2-3, além de diferentes tipos de morte neuronal nas subregiões do hipocampo de ratos 24 horas após a anóxia, levando ao aumento de volume em P14 na região CA1, retornando ao seu volume original em seguida e, apesar de não alterar o padrão de proliferação celular na zona subgranular nas idades estudadas, a anóxia neonatal promove a diminuição da neurogênese no giro denteado de ratos adultos.

Palavras-chave: Anóxia neonatal. Hipocampo. Morte neuronal. Neurodegeneração. Neurogênese. 


\begin{abstract}
Takada SH. Cell death and neurogenesis in rat hippocampus following neonatal anoxia.[Ph. D. thesis (Morphofunctional Sciences)]. São Paulo: Instituto de Ciências Biomédicas, Universidade de São Paulo; 2013.

Neonatal anoxia, considered a worldwide clinical problem, is one of the most important causes of brain injury in neonates; it may present serious and permanent consequences in adulthood, such as cognitive and behavioral deficits, cerebral palsy, epilepsy, hearing and visual impairment. The present study aims to analyze possible longitudinal changes in neural death, cell proliferation and neuronal differentiation in the hippocampus of rats submitted to neonatal anoxia. We used an adapted model that was validated in our laboratory (TAKADA et al., 2011), which is effective to cause neuronal, glial and behavioral sequelae in rats. For the study of neural death, we used antibodies against cleaved Caspase-3, TUNEL, Fluoro-Jade $®$ B (FJB) and electron microscopy. The methodology chosen for the study of proliferation and volume of subregions were stereological analysis and immunoreactivity for Ki-67, a marker of cell proliferation; to study hippocampal neurogenesis, immunofluorescence for BrdU and NeuN was used. The following results were observed: 24 hours after anoxia (P3), there was higher quantity of TUNEL+ cells in CA1 and CA2-3 and a higher quantity of FJB+ cells in CA2-3; otherwise, the stereological analysis of cleaved caspase- 3 density showed no difference between groups anoxia and control in any of the studied ages (P3, P14, P21 and P60). Analysis by electron microscopy showed neurons with features of death by necrosis and continuum in CA1 and DG of P3 animals subjected to anoxia, as well as evidence that other types of death, such as autophagy, necroptosis and death by excitotoxicity were also present in these animals. We also found no differences in cell proliferation of subgranular layer of the hippocampus in these ages. The analysis of neuronal differentiation, however, proved to be reduced in adult animals. Therefore, these results showed that this model of neonatal anoxia promotes cell death in CA1 and CA2-3, and different types of neuronal death in subregions of the hippocampus of rats 24 hours after anoxia, leading to the volume increase in P14 in the CA1 region, returning to its original size and then, despite do not alter cell proliferation pattern in subgranular zone of studied ages, neonatal anoxia promotes decreased neurogenesis in the dentate gyrus of adult rats.
\end{abstract}

Keywords: Neonatal anoxia. Hippocampus.Neuronal death. Neurodegeneration. Neurogenesis. 


\section{LISTA DE FIGURAS}

Figura 1- Sistema utilizado para provocar anóxia em ratos neonatos. .28

Figura 2 - Vias de ativação da apoptose 34

Figura 3 - Subregiões do hipocampo de rato em P3.

Figura 4 - Delimitação das áreas de interesse para análise estereológica do hipocampo de ratos submetidos à anóxia neonatal.

Figura 5 - Células IR-Casp3 no hipocampo de rato neonato submetido à anóxia neonatal.

Figura 6 - Degeneração neuronal no hipocampo de ratos 24 horas após anóxia neonatal

Figura 7 - Células FJB+ no hipocampo de rato 24 horas após anóxia neonatal.

Figura 8 - Células TUNEL+ no hipocampo de ratos 24 horas após anóxia neonatal.

Figura 9 - Células TUNEL+ na região CA1 do hipocampo de ratos 24 horas após anóxia neonatal.

Figura 10 - Células TUNEL+ no hipocampo de ratos 24 horas após anóxia neonatal.

Figura 11 - Análise estereológica da quantidade absoluta e relativa (células $/ \mathrm{mm}^{3}$ ) de células IR-Casp3 no hipocampo de ratos após anóxia neonatal.

Figura 12 - Padrão de marcação de células IR-Casp3 no hipocampo de ratos submetidos à anóxia neonatal.

Figura 13 - Padrão de marcação de células IR-Casp3 nas subregiões CA1, CA2-3 e GD do hipocampo de ratos após anóxia neonatal, ao longo das idades.

Figura 14 - Apoptose em micrografias eletrônicas de neurônios do hipocampo de ratos neonatos submetidos à anóxia neonatal 24 horas antes. .58

Figura 15 - Micrografias eletrônicas de neurônios em CA1 do hipocampo de ratos 24 horas após a anóxia neonatal em diferentes processos de morte.

Figura 16 - Micrografias eletrônicas de neurônios do hipocampo de ratos 24 horas após a anóxia neonatal possivelmente em necroptose e excitotoxicidade.

Figura 17 - Micrografias eletrônicas de neurônios das subregiões CA1 e GD do hipocampo de ratos neonatos submetidos à anóxia neonatal 24 horas antes em possível autofagia. 
Figura 18 - Estudo longitudinal dos efeitos da anóxia neonatal na proliferação neural, neurogênese e morte neuronal no hipocampo de ratos.

Figura 19 - Proliferação celular no giro denteado de rato adulto (IR-Ki67)................78

Figura 20 - Dupla marcação BrdU-NeuN no hipocampo de ratos de 60 dias.............79

Figura 21 - Confirmação da co-localização da dupla marcação BrdU-NeuN na camada granular do giro denteado do hipocampo de ratos

Figura 22 - Análise longitudinal da influência da anóxia neonatal na proliferação celular da zona subgranular do giro denteado de ratos.

Figura 23 - Diminuição da neurogênese no giro denteado do hipocampo de ratos adultos submetidos à anóxia neonatal.

Figura 24 - Padrão de neurogênese no GD do hipocampo de ratos de 60 dias de vida após anóxia neonatal.

Figura 25 - Co-localização da dupla marcação BrdU-NeuN na camada granular e hilo do giro denteado do hipocampo de ratos adultos.

Figura 26 - Variação dos volumes das subregiões hipocampais após anóxia neonatal. 


\section{LISTA DE TABELAS}

Tabela 1 - Parâmetros utilizados para análise por estereologia das células IR-Casp3 e volume no hipocampo de ratos submetidos à anóxia neonatal.

Tabela 2 - Quantidade de células FJB+ no hipocampo de ratos submetidos à anóxia neonatal.

Tabela 3 - Quantidade de células TUNEL+ no hipocampo de ratos submetidos à anóxia neonatal.

Tabela 4 - Quantidade de células IR-Casp3 após anóxia neonatal. .52

Tabela 5 -Densidade de células IR-Casp3 por volume $\left(\mathrm{mm}^{3}\right)$ após anóxia neonatal.

Tabela 6 - Quantificação de células imunorreativas e Ki-67 na zona subgranular do giro denteado do hipocampo de ratos em diferentes idades.

Tabela 7 - Volume do hipocampo de ratos submetidos à anóxia neonatal, mensurado por estereologia $\left(\mathrm{em} \mathrm{mm}^{3}\right)$. 


\section{LISTA DE ABREVIATURAS E SIGLAS}

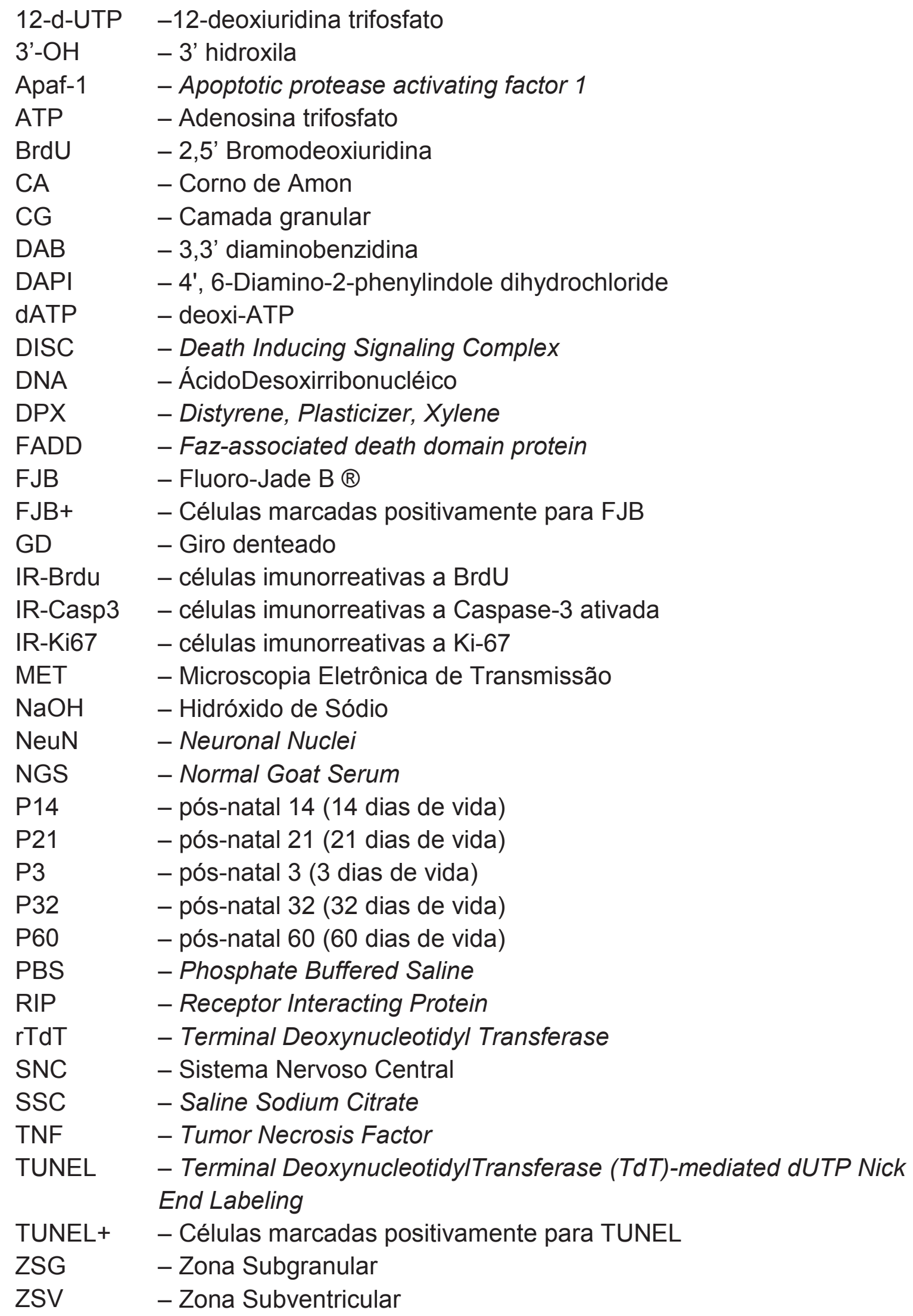




\section{SUMÁRIO}

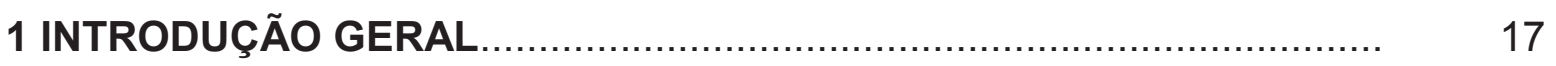

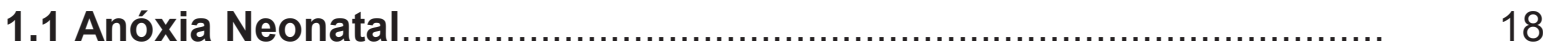

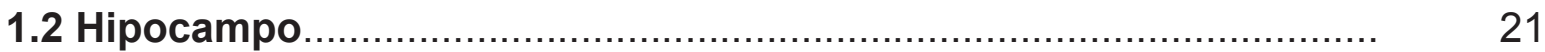

1.2.1 Características morfológicas do hipocampo....................................... 21

1.2.2 Hipocampo e a privação de oxigênio.................................................. 23

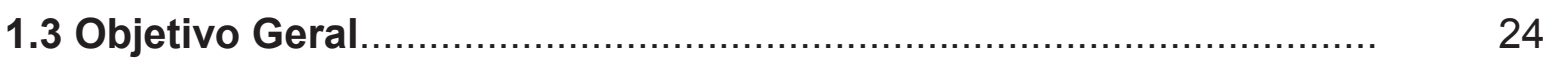

1.4 Objetivos Específicos ................................................................ 24

2 MATERIAIS E MÉTODOS GERAIS ..................................................... 26

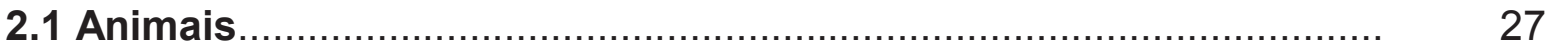

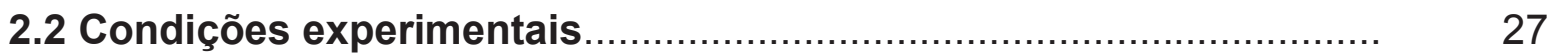

2.3 Processamento do material biológico................................................ 29

3 CAPÍTULO 1: ESTUDO DAS IMPLICAÇÕES DA ANÓXIA NEONATAL À MORTE CELULAR NO HIPOCAMPO DE RATOS................................... 30

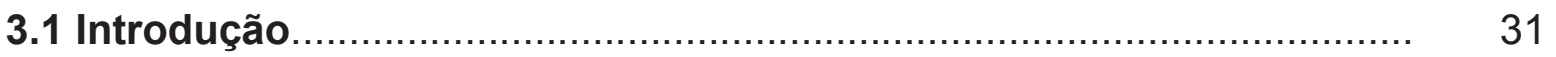

3.1.1 Morte neuronal após privação de oxigênio........................................... 31

3.1.1.1 Apoptose

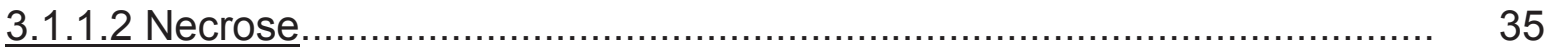

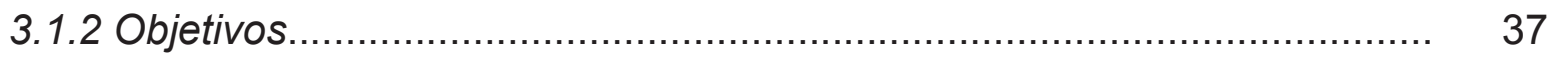

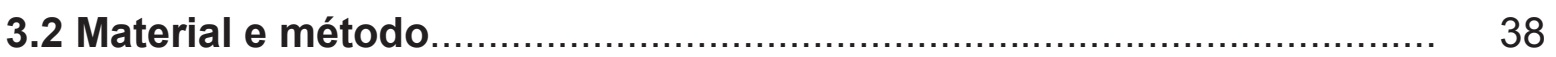

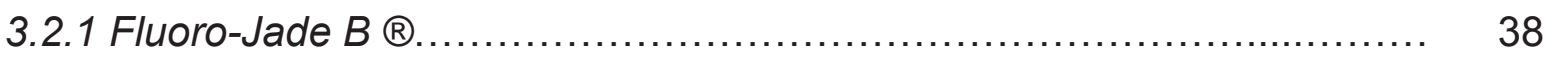

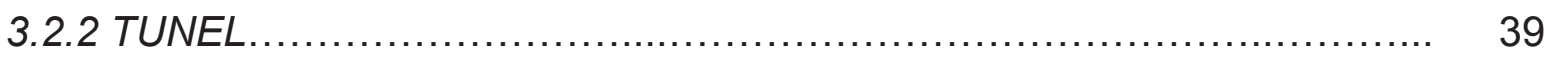

3.2.3 Imunoistoquímica - Caspase-3 ativada............................................... 40

3.2.4 Microscopia Eletrônica de Transmissão (MET) .................................. 40

3.2.5 Técnicas de análise dos resultados................................................... 42

3.2.5.1 Fluoro-Jade B $®$ e TUNEL ........................................................... 42

3.2.5.2 Caspase-3 ativada e volume hipocampal........................................ 43

3.2.5.3 Análise estatística..................................................................... 43

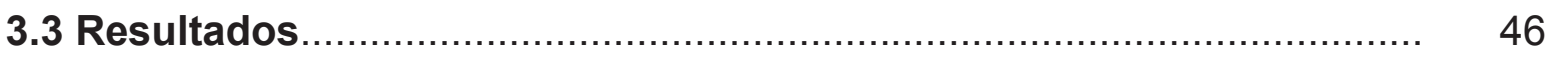

3.3.1 Fluoro-Jade $B \otimes$ e TUNEL.............................................................. 46

3.3.2 Caspase-3 ativada......................................................................... 51

3.3.3 Microscopia eletrônica..................................................................... 56 
3.4 Discussão

4 CAPÍTULO 2: ESTUDO DA DINÂMICA ESTRUTURAL DO HIPOCAMPO QUANTO AO VOLUME, PROLIFERAÇÃO E DIFERENCIAÇÃO NEURAIS NO GIRO DENTEADO DE RATOS APÓS ANÓXIA NEONATAL.

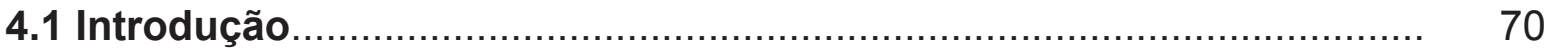

4.1.1 Proliferação............................................................................ 70

4.1.2 Ontogênese e neurogênese hipocampal pós-natal................................ 71

4.1.3 Neurogênese hipocampal adulta...................................................... 73

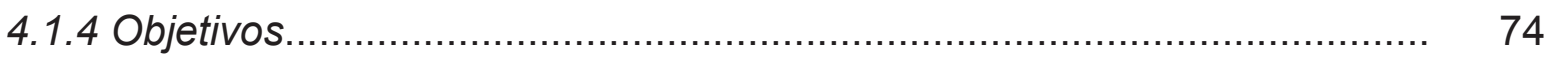

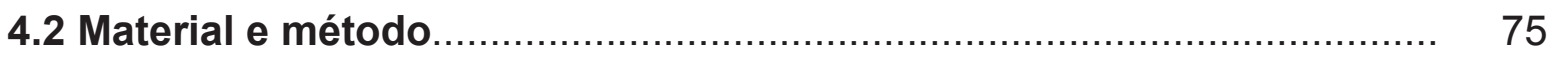

4.2.1 Imunoistoquímica para detecção de células imunorreativas a Ki-67 (IRKi67)

4.2.2 BrdU e NeuN: dupla imunofluorescência para avaliação da colocalização.

4.2.3 Técnicas de análise dos resultados..................................................... 77

4.2.3.1 Proliferação celular na ZSG........................................................... 77

4.2.3.2 Diferenciação neuronal................................................................... 77

4.2.3.3 Volume hipocampal.................................................................... 79

4.2.3.4 Análise estatística.................................................................. 79

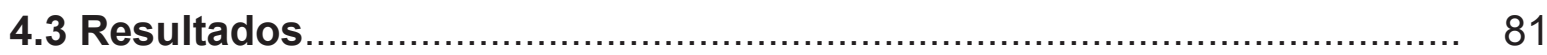

4.3.1 Análise longitudinal da proliferação neural na zona subgranular do giro denteado do hipocampo.............................................................................. 81

4.3.2 Diferenciação neuronal - neurogênese ................................................ 82

4.3.3 Volume hipocampal........................................................................ 85

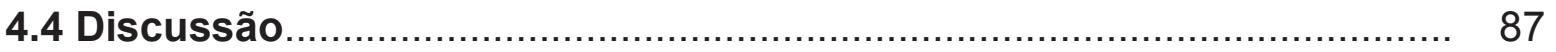

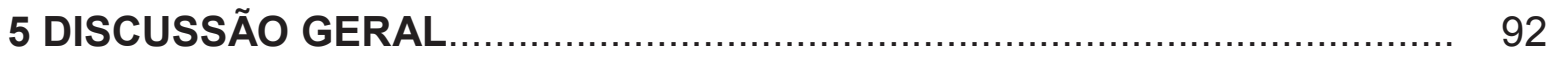

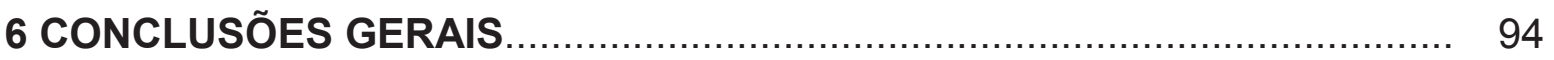

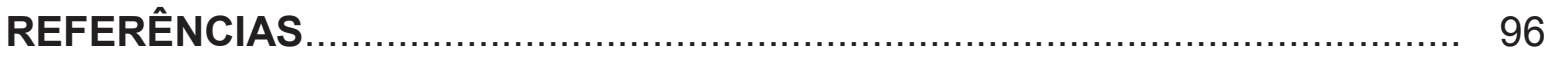

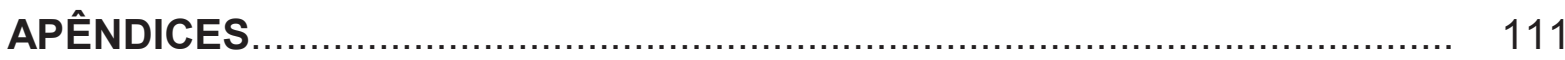

APÊNDICE A - artigo publicado no periódico Journal of Neuroscience

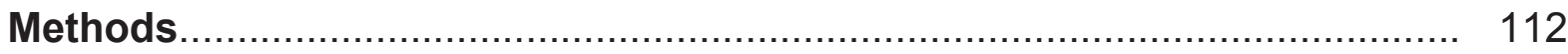

APÊNDICE B - artigo publicado no periódico Stroke................................... 121

APÊNDICE C - artigo publicado no periódico Microscopy (Oxf.)............... 137 
1 INTRODUÇÃO GERAL 


\subsection{Anóxia Neonatal}

O termo "anóxia neonatal" é utilizado, na prática clínica, para definir a condição de diminuição da oxigenação fetal ao nascimento. Historicamente, de acordo com Courville (1950), outros termos foram utilizados para descrever a mesma condição, como "sufocação do recém-nascido", descrito por Roederer em 1760, "asfixia neofitorum", por Erhart em 1785 e "asfixia neonatorum", em 1789, por Regnier.

Contudo, a definição de asfixia ao nascimento é imprecisa. O processo ocorre durante o primeiro e segundo estágios do trabalho de parto, geralmente secundária à interrupção de fluxo sanguíneo placentário. Uma descrição bastante consistente é aquela de uma condição de troca gasosa prejudicada que leva, se persistente, à hipoxemia e hipercapnia (Low et al., 1995).

A anóxia neonatal, considerada problema clínico mundial (Majeed et al., 2007), é uma das mais importantes causas de lesão encefálica em neonatos que pode apresentar consequências graves e permanentes na vida adulta, como déficits cognitivos e comportamentais, paralisia cerebral, epilepsia, deficiências auditivas e visuais (Cannon et al., 2002; Caputa et al., 2005; Casolini et al., 2005; Dell'anna et al., 1995a; Dell'anna et al., 1997; Hedner, Lundborg, 1980; Rogalska et al., 2006; Vannucci et al., 1999; Volpe, 1992; Wainwright et al., 2004).

Estatísticas sugerem incidência de anóxia neonatal em 1-3/1000 crianças nascidas a termo (Graham et al, 2008; Kurinczuk et al., 2010), porém nível de incidência bastante alto, aproximadamente $60 \%$, em neonatos prematuros com baixo peso, constituindo grande preocupação para a saúde pública (Laviola et al., 2004; Vannucci, 2000). Atualmente, devido aos avanços tecnológicos e novos conhecimentos e estratégias terapêuticas, as taxas de sobrevivência de prematuros de 24 a 26 semanas tem aumentado em comparação com períodos anteriores (Suguihara et al., 2005), sendo que a taxa de sequelas associadas à prematuridade, dentre elas a da anóxia neonatal, também tornou-se crescente.

O nascimento prematuro é definido pela Organização Mundial da Saúde (OMS) como partos que ocorrem anteriormente às 37 semanas completas de gestação ou menos que 259 dias desde o primeiro dia do último período menstrual da mulher (OMS, 1977). Pode ser subdividido de acordo com a idade gestacional 
em: prematuro extremo ( $<28$ semanas), muito prematuro (28-<32 semanas) e prematuro moderado (32-<37 semanas).

Segundo Lawn e colaboradores (2005), as principais causas de mortalidade infantil mundial (em crianças menores de 5 anos) estão relacionadas à prematuridade, asfixia perinatal e infecções. Em 1996, as causas perinatais eram responsáveis por $49,7 \%$ dos óbitos infantis no Brasil, tendo aumentado para $53,6 \%$ e $55,4 \%$ nos anos de 2002 e 2003, respectivamente.

Entre as causas perinatais de mortalidade infantil, 61,4\% estão associadas com a prematuridade (Victora, 2001). Mais de 1 em cada 10 bebês nascidos no mundo em 2010 eram prematuros, sendo que mais de 1 milhão não sobreviveu em decorrência à prematuridade (Blencowe et al., 2012). Atualmente, a prematuridade é a segunda causa de morte em crianças abaixo de 5 anos de idade e a principal causa de morte no primeiro mês de vida (Liu et al., 2012). Segundo projeto da Organização Mundial da Saúde, "Born too soon", publicado em 2012, o Brasil era, em 2010, um dos 10 países que mais apresentavam nascimentos prematuros no mundo.

Brenelli-Vitali e colaboradores, em 2005, atribuíram à asfixia perinatal a causa da maioria das mortes nesse período. Especificamente no estado de São Paulo, em estudo recente realizado por Daripa e colaboradores (2013), a asfixia perinatal contribuiu para a morte de 1,71 recém-nascidos a cada 1000 nascidos vivos e $22 \%$ dos óbitos neonatais precoces no estado de São Paulo no período de 2001 a 2003.

Trabalhos da literatura evidenciam que apesar do sistema nervoso central imaturo apresentar maior tolerância a eventos hipóxicos (Dell'anna et al., 1993;Nakajima et al., 1996; Nakajima, 1999; Volpe, 1992), há períodos críticos, onde o encéfalo está mais vulnerável e os neurônios em desenvolvimento são particularmente mais susceptíveis ao insulto hipóxico ou a outros fatores ambientais nocivos, influenciando negativamente sua maturação (Nyakas et al., 1996).

Segundo a teoria de Dobbing (1968), o encéfalo está mais vulnerável a insultos nas fases de grande e rápida proliferação e maturação celular. O primeiro período crítico ocorre durante a multiplicação e organização iniciais de neuroblastos que, nos mamíferos, acontece no período pré-natal (Morgane et al., 1993). O segundo período crítico ocorre na fase de aleitamento do rato (Winick, Noble, 1966), quando há rápido crescimento do encéfalo, com migração e diferenciação neuronais, 
sinaptogênese, multiplicação glial e mielinização evidentes (Dobbing, 1970; Manhães de Castro et al., 2001; Morgane et al., 1993).

A vulnerabilidade do encéfalo em desenvolvimento é dependente do agente agressor, do tempo de exposição a este agente e da capacidade dos metabólitos originados por esta agressão de atingirem o sistema nervoso em desenvolvimento. Exposição a agentes agressores no período de ontogenia de qualquer sistema orgânico pode levar a efeitos adversos mais graves que ao término deste período, quando o órgão ou sistema já estiver completamente desenvolvido. O desenvolvimento do sistema nervoso central em mamíferos compreende fases, a partir da indução da placa neural, proliferação neural, migração, diferenciação, crescimento axonal, sinaptogênese, gliogênese, apoptose e mielinização (Rice, Barone Jr., 2000); uma agressão como o insulto anóxico, incidindo em qualquer uma destas fases, pode acarretar prejuízos com sequelas permanentes.

O encéfalo é extremamente sensível a reduções no suprimento de oxigênio; esta vulnerabilidade decorre do seu alto consumo energético que, quando comprometido, dispara cascata de eventos bioquímicos que simultaneamente induzem lesão ou morte das células mais vulneráveis do sistema nervoso central, primariamente localizadas no hipocampo, uma das regiões cerebrais mais sensíveis à anóxia (Buwalda, 1995; Lutz e Prentice, 002 Vexler, Ferriero, 2001), no córtex cerebral e núcleos basais, estes últimos mais susceptíveis a lesões no último trimestre de gestação em humanos (Cirulli, 2003; Loidl et al., 2000).

O hipocampo possui elevada capacidade plástica e alta demanda metabólica. A plasticidade da circuitaria hipocampal, essencial para sua função na aprendizagem e memória, pode aumentar sua vulnerabilidade a insultos (Shors et al., 1989), em especial a privação de oxigênio, como descrito em trabalhos com o modelo de hipóxia-isquemia e outros modelos de privação de oxigênio (Daval et al., 2004; Johnston, 2001; Liu et al., 2008; Peterson et al., 2012; Yang et al., 2011;).

O modelo de privação de oxigênioutilizado neste trabalho, denominado modelo de anóxia neonatal, foi adaptado e validado em nosso laboratório (Takada et al., 2011), evidenciando, além de alterações neuronais (Takada, 2009) e gliais (Allemandi, 2012) agudas, déficits na memória espacial e aprendizagem em ratos adultos submetidos ao estímulo anóxico neonatal (Ito, 2010). Tais resultados, aliados ao fato de que estudos em animais mostraram que a neurogênese hipocampal é crítica para alguns aspectos importantes da aprendizagem e memória 
(Leuner et al., 2006; Shors et al., 2001; Winocur et al., 2006; Zhang et al., 2008), constituíram as bases para o desenvolvimento do presente trabalho.

Assim, as implicações da anóxia neonatal na morte e na proliferação e diferenciação neurais e no volume do hipocampo em diferentes períodos pós-natais correspondentes ao segundo período crítico citado ( 3 a 21 dias) e na vida adulta (60 dias) foram abordados.

\subsection{Hipocampo}

O hipocampo, ou hippocampus, em grego, significa cavalo marinho, justamente devido ao seu formato encurvado. Corresponde a estrutura bilateral no córtex cerebral, com características morfológicas peculiares, além de apresentar alto grau de plasticidades sináptica e fenotípica ede ter a capacidade de gerar novos neurônios até na vida adulta (neurogênese). Está envolvido em processos fisio e patológicos, como o aprendizado e a memória, doença de Alzheimer e epilepsia (Taupin, 2007).

\subsubsection{Características morfológicas do hipocampo}

A formação hipocampal engloba os seguintes componentes: córtex entorrinal, subículo, pré-subículo e parassubículo e hipocampo propriamente dito, o qual se estende rostralmente entre o corpo caloso e a substância branca profunda do neocórtex (Paxinos, 2004).

O hipocampo (hipocampo propriamente dito), parte da formação hipocampal,é composto de subregiões anatomicamente distintas, com variada morfologia, forma e tamanho celular,conectividade, propriedades eletrofisiológicas e susceptibilidade a insultos (Amaral, Insausti, 1990; Storm-Mathisen et al., 1990): o giro denteado (GD) e o Cornu Ammonis (CA) ou corno de Amon. O GD possui a forma de "V" ou de "U", enquanto o CA é estrutura deformato encurvado que se entrelaça com o GD. A porção interna do GD correspondeàregião hilar ou hilo (Taupin, 2007).

Ambas as regiões são estruturadas em camadas ou strata. De dentro para fora, as camadas do GD são: camada polimórfica, camada granular (stratum granulare) e camada molecular (stratum moleculare); as camadas de CA, também 
de dentro para fora, são: stratum moleculare, stratum lacunosum (or lacunosummoleculare), stratum radiatum, stratum lucidum, camada piramidal (stratum pyramidale), stratum oriens e alveus. As principais camadas de GD e CA são, respectivamente, a camada granular e a camada piramidal, camadas densas que contém corpos de células granulares e piramidais. Outras camadas, como a polimórfica do GD, osstratum oriens e radiatum do CA contêm vários tipos de interneurônios, células musgosas, células em cesto e bipolares (Altman, Bayer, 1973).

Os corpos celulares das células granulares presentes na camada granular do giro denteado tem diâmetro aproximado de $7 \mu \mathrm{m}$. A camada molecular do GD contém os dendritos proximais das células granulares; seus axônios, as fibras musgosas, projetam-se para as células piramidais de CA3 (Claiborne et al., 1986). No rato, o número aproximado de células granulares é de 1 milhão (Amaral et al., 1990; Boss et al., 1985).

A fissura hipocampal separa o giro denteado de CA1, adjacente ao subículo, enquanto CA3 está adjacente à fímbria, fórnix e plexo coróide. A região CA2 situa-se entre CA1 e CA3 e pode ser diferenciada das demais regiões utilzando-se a técnica de Golgi; já CA4 situa-se no hilo do GD (Lorente de No, 1934 ${ }^{1}$, apud Taupin, 2007).

Os corpos celulares das células piramidais possuem formato triangular e diferem em tamanho: em CA2 e CA3 medem 40 a $60 \mu \mathrm{m}$ enquanto que em CA1 medem 20 a $40 \mu \mathrm{m}$. A camada molecular do corno de Amon contém os dendritos apicais das células piramidais, sendo os de CA3 mais espessos e curtos que de CA1.

No stratum lucidum é onde ocorrem os contatos sinápticos estabelecidos pelas fibras musgosas provenientes da camada granular com as células piramidais de CA3. Em ratos, estudos quantitativos estimam que CA3 é composto por cerca de 330.000 células piramidais enquanto CA1 contém 420.000 células piramidais; o número de interneurônios é desconhecido. A subregião CA2 correspondeà região que não elicia o mesmo padrão do stratum lucidum de CA3 com suas saliências espinhosas e, portanto, não recebe as aferências das fibras musgosas. Sua

\footnotetext{
1: Lorente de No, R Studies on the structure of the cerebral cortex. II.Continuation of the study of the ammonic system.J PsycholNeurol (Lpz);1934;46:113-77.
} 
existência é questionada por vários pesquisadores (Amaral et al., 1990; Boss et al., 1985).

\subsubsection{Hipocampo e a privação de oxigênio}

Em modelos de privação de oxigênio, o hipocampo tem sido alvo de muitas pesquisas, tanto por sua susceptibilidade à privação de oxigênio como também devido à sua alta capacidade regenerativa (Bartley et al., 2005; Daval et al., 2004a).

Além disso, alterações no volume de estruturas encefálicas, dentre elas o hipocampo, tem sido descritas em literatura como resultantes da prematuridade em si ou decorrentes de lesões no encéfalo imaturo. Revisão de literatura realizada em 2012 por Keunen e colaboradores, mostrou que prematuros humanos apresentam alterações regionais e globais no tecido encefálico quando comparados aos nascidos a termo e saudáveis, sendo que tais alterações são mais proeminetes quanto menor a idade gestacional. Ainda, mostraram que fatores associados à prematuridade, como lesão da substância branca, hemorragia intraventricular, terapias pós-natais com corticosteróides, atraso do crescimento intra-uterino e doenças pulmonares crônicas são fatores frequentemente associados a alterações volumétricas destas estruturas encefálicas.

Em roedores neonatos, o grau de lesão hipocampal observado em diferentes modelos de privação de oxigênio é variável e depende de muitos fatores, dentre eles a idade em que o animal é submetido ao estímulo (Bartley et al., 2005; Daval et al., 2004a; Pourié et al., 2006; Scheepens et al., 2003).

Para o presente estudo, o rato foi o animal de escolha, uma vez que, quando comparado ao humano, o rato nasce prematuramente, ou seja, o estágio de maturação encefálica do rato neonato é comparável ao final do segundo trimestre em humanos. Assim, a idade em que é realizado o estímulo anóxico nos animais (aproximadamente 30 horas de vida) corresponde aos marcos de desenvolvimento de um bebê prematuro humano entre 23 e 32 semanas de gestação (Semple et al., 2013).

O estudo do hipocampo desperta ainda grande interesse em modelos de privação de oxigênio devido ao fato da memória e aprendizagem, ambas funções relacionadas primordialmente à estrutura hipocampal, frequentemente apresentarem 
déficits em modelos animais e também em humanos que sofreram asfixia perinatal (Semple et al., 2013), com implicações cognitivas.

Desta forma, avaliar como a anóxia neonatal altera a dinâmica entre morte e proliferação neuronais e se promove alterações morfológicas no hipocampode ratos é de suma importância para melhor compreender as causas das sequelas comportamentais relacionadas à memória espacial e aprendizagem observadas no modelo de anóxia neonatal utilizado.

\subsection{Objetivo Geral}

O objetivo do presente trabalho é analisar longitudinalmente a hipótese de que a anóxia neonatal promove alterações na dinâmica do desenvolvimento neural por morte, proliferação e diferenciação neuronais (neurogênese) no hipocampo de ratos, com consequentes alterações morfológicas.

\subsection{Objetivos Específicos}

I - verificar longitudinalmente a morte neural decorrente da anóxia neonatal no hipocampo de ratos Wistar desde 24 horas após o insulto anóxico (P3) até a idade adulta (P60) com técnicas de imunoistoquímica para Caspase-3 ativada, TUNEL e Fluoro-Jade B $®$ e análise estereológica;

II -avaliar, com técnicas de microscopia eletrônica de transmissão, a ocorrência dealterações morfológicas indicativas de diferentes tipos de morte neuronal 24 horas após anóxia neonatal;

III - estudar longitudinalmente os efeitos da anóxia neonatal na dinâmica de proliferação celular da zona subgranular do giro denteado do hipocampo dos ratos (P3, P14, P21 e P60) com técnica de imunoistoquímica para Ki-67; 
IV -analisar, por dupla imunofluorescência, possíveis alterações na quantidade de células neuronais marcadas com BrdU na zona subgranular nos animais adultos (P60) que sofreram anóxia neonatal;

V- verificar, por análise estereológica,se a anóxia neonatal causa alterações no volume hipocampal dos ratos ao longo das idades estudadas (P3, P14, P21 e P60)

Para facilitar o desencadeamento de ideias, a presente tese foi dividida em capítulos: CAPÍTULO 1: ESTUDO DAS IMPLICAÇÕES DA ANÓXIA NEONATAL À MORTE CELULAR NO HIPOCAMPO DE RATOS (Objetivos específicos I e II); CAPÍTULO 2: ESTUDO DA DINÂMICA ESTRUTURAL DO HIPOCAMPO QUANTO AO VOLUME, PROLIFERAÇÃO E DIFERENCIAÇÃO NEURAIS NO GIRO DENTEADO DE RATOS APÓS ANÓXIA NEONATAL (Objetivos específicos III, IV e V). 
2 MATERIAIS E MÉTODOS GERAIS 


\subsection{Animais}

Foram utilizados filhotes de 19 casais de ratos albinos (Rattus novergicus, linhagem Wistar), criados no biotério do Instituto de Ciências Biomédicas, Departamento de Anatomia - USP, com temperatura constante $\left(23^{\circ} \mathrm{C} \pm 1^{\circ} \mathrm{C}\right)$, ciclo claro/escuro de 12:12h, início do claro às 7:00h, e água e comida ad libtum. Os

procedimentos descritos estão de acordo com os Princípios Éticos de Experimentação Animal adotado pelo Colégio Brasileiro de Experimentação Animal (COBEA) e foram aprovados pela Comissão de Ética em Experimentação Animal (CEEA) (Protocolo $\mathrm{n}^{\circ}$ 190, fls. 139 do livro 2 para uso de animais em experimentação).

\subsection{Condições experimentais}

Foram utilizados aproximadamente 90 neonatos machos (Rattus novergicus, linhagem Wistar), com no mínimo 30 horas de vida (P1-P2), pesando entre 6 e 8 g; uma vez que a idade de P1 a P3 corresponde à maturação de um encéfalo humano de 24 a 32 semanas (Semple et al., 2013). Os animais foram divididos em grupos conforme a idade: P3, que corresponde a 24 horas após o insulto anóxico, P14, P21 e P60. Cada grupo foi formado pelos subgrupos anóxia e controle.

Para a exposição dos animais à anóxia, foi utilizado sistema construído e validado em nosso laboratório (Takada, 2009; Takada et al., 2011), constituído por câmara semi-hermética de policarbonato $(31,0 \times 14,0 \times 19,5 \mathrm{~cm})$, com entrada $\mathrm{e}$ saída de gás, acoplada a manômetro, fluxômetro e a cilindro de nitrogênio gasoso. A câmara semi-hermética previne o aumento de pressão no interior da câmara, fazendo com que seja o mais próximo possível da pressão atmosférica. Com o objetivo de evitar hipotermia e potencializar os efeitos da anóxia, a temperatura da câmara foi mantida entre 35 e $37^{\circ} \mathrm{C}$ pela imersão parcial da mesma em água aquecida por resistência elétrica (Figura 1). Esta faixa de temperatura é importante uma vez que a temperatura basal dos neonatos é de $33^{\circ} \mathrm{C}$, constituindo por si só fator de neuroproteção (Caputa et al., 2005; Rogalska et al., 2006; Spasojevic et al., 2013). 
Figura 1 - Sistema utilizado para provocar anóxia em ratos neonatos.

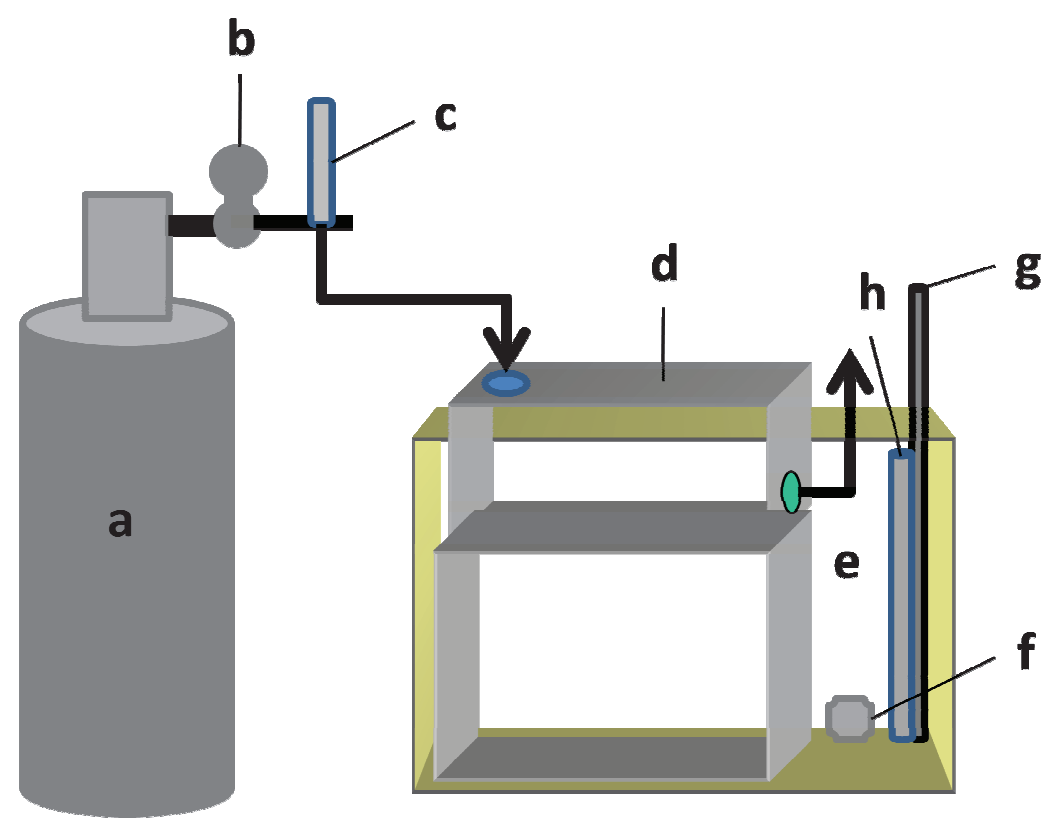

Desenho esquemático mostrando: a - cilindro de nitrogênio gasoso (concentração de 100\%); b - manômetro; c - fluxômetro; d - câmara em policarbonato parcialmente imersa na água; e - cuba em vidro transparente com água aquecida; $f$ - bomba difusora de água (para homogenizar a temperatura da água); $g$ - termômetro; $\mathrm{h}$ - resistência para aquecimento da água.

Fonte: Takada et al., 2011.

Para obtenção das ninhadas, foi realizada a procriação monogâmica (um macho para uma fêmea), de forma ininterrupta, havendo aproveitamento dos neonatos até a sexta ninhada. O desmame ocorreu em 21 dias.

Para a anóxia, primeiramente a câmara foi saturada completamente com nitrogênio $100 \%$ a um fluxo de $3 \mathrm{~L} /$ minuto e pressão próxima à pressão atmosférica (aproximadamente 101,7 kPa) (Takada et al., 2011). Os animais foram então colocados rapidamente na câmara, permanecendo durante 25 minutos nestas condições, considerado o tempo máximo para não ocorrer morte massiva dos neonatos. Testes prévios realizados neste laboratório mostraram que períodos ligeiramente maiores causaram alto índice de mortalidade. Após a recuperação dos animais (recuperação da coloração, da respiração e da movimentação ativa), que ocorreu em média 5 minutos após a retirada da câmara, estes foram devolvidos para a mãe até o momento da perfusão transcardíaca ou até o desmame (21 dias). 
O grupo controle foi exposto às mesmas condições experimentais, sem contudo haver troca do ar dentro da câmara, ou seja, permaneceu ao ar ambiente.

\subsection{Processamento do material biológico}

A perfusão transcardíaca foi realizada de acordo com as idades prédeterminadas; os animais foram profundamente anestesiados com hidrato de cloral $33 \%$ na proporção aproximada de $0,4 \mathrm{ml} / 100 \mathrm{~g}$ (dose letal). Foram perfundidos transcardiacamente com solução salina $(0,9 \%, \mathrm{pH} 7,4)$ e em seguida solução fixadora de formaldeído ( $4 \%$ em tampão fosfato, $\mathrm{pH} 7,4,4{ }^{\circ} \mathrm{C}$ ). Os encéfalos foram dissecados, pós-fixados na mesma solução fixadora overnight e então crioprotegidos em solução tampão fosfato de sódio (PBS, $0,1 \mathrm{M}, \mathrm{pH} 7,4$ ) mais sacarose $20 \%$ até o momento da criosseç̧ão ou microtomia. Os encéfalos dos neonatos de 3 dias de vida (P3) foram cortados em criostato (Leica CM 1850) em cortes frontais de 30 ou $40 \mu \mathrm{m}$ de espessura, coletados em 6 ou 5 séries, respectivamente, montados em lâminas gelatinizadas ou eletrostáticas e armazenados em freezer à $-20^{\circ} \mathrm{C}$ em recipiente protegidos de umidade. Os encéfalos dos animais dos grupos P14, P21 e P60 foram cortados em micrótomo, em cortes frontais de $40 \mu \mathrm{m}$ de espessura, coletados em séries (6 séries em P14 e 12 séries em P21 e P60), armazenadas em solução anti-congelante até o momento de sua utilização.

As técnicas para obtenção dos resultados e métodos de análises serão detalhadas no respectivo capítulo. 
3 CAPÍTULO 1: ESTUDO DAS IMPLICAÇÕES DA ANÓXIA NEONATAL À MORTE CELULAR NO HIPOCAMPO DE RATOS 


\subsection{Introdução}

\subsubsection{Morte neuronal após privação de oxigênio}

A manutenção da função encefálica normal depende de um suprimento contínuo de oxigênio; no sistema nervoso central, os neurônios são extremamente sensíveis à disponibilidade do mesmo. As respostas celulares à privação de oxigênio são bastante complexas e resultam em ativações de mecanismos, a curto e longo prazos, visando a conservação de energia e proteção das células (Corcoran, O'Connor, 2013).

A privação de oxigênio leva naturalmente à privação energética, acometendo o metabolismo celular, podendo ou não induzir à morte por apoptose ou algum outro processo distinto.

Muitos fatores, além da falha energética celular, como a acidose, a liberação de glutamato, o acúmulo de cálcio intracelular, a peroxidação lipídica e neurotoxicidade do óxido nítrico, podem levar à morte neuronal (Zhao et al., 2013).

Pesquisas têm evidenciado maior esclarecimento a respeito dos aspectos celulares e moleculares da neurodegeneração no encéfalo imaturo, especialmente características que o tornam diferente quando comparado a lesões semelhantes no encéfalo adulto. Há hipóteses de que a neurodegeneração se estenda nos dias ou semanas seguintes ao insulto e seja muito influenciada por receptores, enzimas proteolíticas e mecanismos programados de morte celular que são altamente expressos durante o desenvolvimento (Johnston et al., 2002); ainda, estudos clínicos sugerem que insultos hipóxicos no encéfalo durante o período perinatal contribuem para redução, a longo prazo, do crescimento da substância cinzenta (Barret et al., 2007).

Há evidências crescentes que lesões neurais agudas podem desencadear perda celular contínua (Barret et al., 2007; Daval et al., 2004; Liu et al., 2004). Os mecanismos básicos que levam à neurodegeneração, porém, ainda são desconhecidos (Troy, Salvesen, 2002), sendo que a teoria mais descrita ultimamente é aquela relacionada à perda do suporte trófico às células que não sobrevivem.

Durante o período perinatal, neurônios em desenvolvimento são altamente dependentes de suporte trófico para sobrevivência e manutenção das conexões (Li 
et al., 1998); interrupções no desenvolvimento das conexões e a resultante privação de regiões alvo podem causar morte celular no encéfalo imaturo mais rapidamente e com maior frequência que no encéfalo maduro (Miller, Kuhn, 1997).Esta neurodegeneração induzida pela privação das regiões alvo é um dos mecanismos de neurodegeneração que tem sido proposto para a ocorrência de neurodegeneração tardia observada em modelos animais de hipóxia-isquemia (Geddeset al., 2001).

Estudos mostram que a lesão primária após insulto hipóxico-isquêmico em fetos e neonatos ocorre devido à necrose celular, enquanto a lesão secundária, após horas ou dias, é decorrente de apoptose ou morte celular programada (Beilharz et al., 1995; Nakajima et al., 2000; Northington et al., 2001). Ainda, resultados de estudos morfológicos, histoquímicos e moleculares confirmam que os principais tipos de morte neuronal após hipóxia-isquemia são a apoptose e a necrose (Banasiak, Haddad, 1998; Nakajima et al., 2000; Pulera et al., 1998), descritos a seguir.

\subsubsection{Apoptose}

O equilíbrio entre vida e morte a nível celular é crítico para o desenvolvimento (Ribe et al., 2008). A morte celular por apoptose tem importante papel no desenvolvimento encefálico, na lesão neural e em patologias. No sistema nervoso em desenvolvimento, a apoptose ocorre naturalmente, sob controle genético, sendo necessária para determinar o número apropriado de células e para a eliminação de neurônios impropriamente conectados (Liu et al., 2004; Pettman, Henderson, 1998). No sistema nervoso adulto, a indução inapropriada de morte celular apoptótica contribui para patologias associadas a doenças neurodegenerativas (Portera-Cailliau et al., 1995; Smale et al., 1995) e para insultos neurológicos agudos (Nitatori et al., 1995).

A apoptose exerce importante papel em vários estados patológicos, dentre os quais a lesão encefálica ocasionada por hipóxia-isquemia (Banasiak et al., 2000).

Em mamíferos, a apoptose é regulada pela família de proteínas $\mathrm{Bcl}-2$, pela proteína Apaf-1 (apoptotic protease-activatingfactor 1) e pela família de caspases, que são proteases específicas de cisteíno-aspartato (Troy, Salvesen, 2002; Yuan, Yankner, 2000). Há duas vias distintas que iniciam a ativação da apoptose: a via extrínseca ou citoplasmática e a via intrínseca ou mitocondrial (Figura 2). 
A via intrínseca tem início com a ativação da mitocôndria, a qual leva à liberação do citocromo c, sendo que tal liberação é controlada pela ação da família de proteínas Bcl-2, reguladoras da permeabilidade da membrana mitocondrial. Uma vez liberado, o citocromo $c$ se liga ao Apaf-1, e, na presença de dATp ou ATP, recruta e ativa pró-caspase-9 para formar um complexo chamado de apoptossomo. A Caspase-9 ativada, pode ativar assim novas caspases, como a Caspase-3, que finalmente levam ao processo final de apoptose (MacFarlane, Williams, 2004).

A via extrínseca é iniciada quando receptores de morte da família do TNF (tumor necrosisfactor), localizados na superfície da membrana celular, são ativados. Esta ativação resulta em rápida resposta da caspase-8 após seu recrutamento por moléculas adaptadoras ligadas formando o complexo receptor-ligante conhecido como DISC. FADD (Faz-associated death domain protein) é conhecida como adaptador universal utilizado por receptores de morte para recrutar e ativar a Caspase-8. A Caspase-8, considerada iniciadora, ativa a Caspase-3, executora, responsável pela clivagem de importantes substratos celulares resultando em alterações morfológicas e bioquímicas clássicas associadas ao fenótipo de apoptose (MacFarlane, Williams, 2004). 
Figura 2 - Vias de ativação da apoptose.

INTRÍNSECA

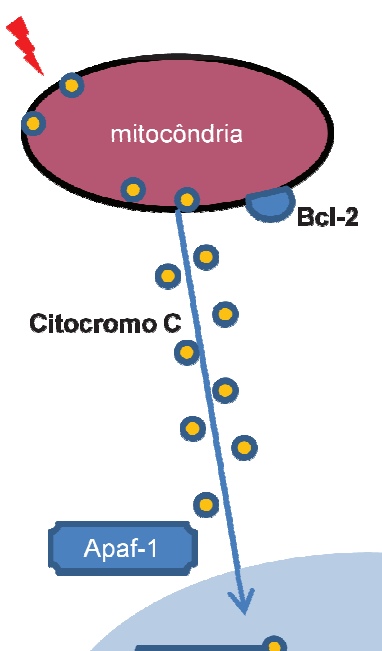

EXTRÍNSECA

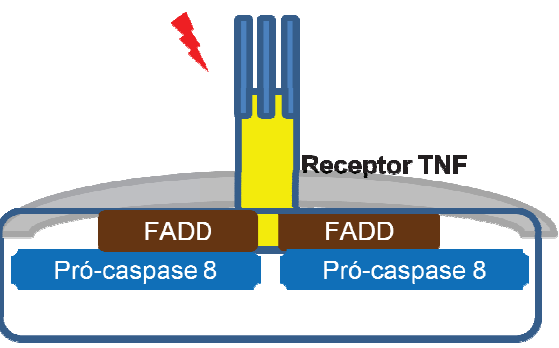

Complexo DISC

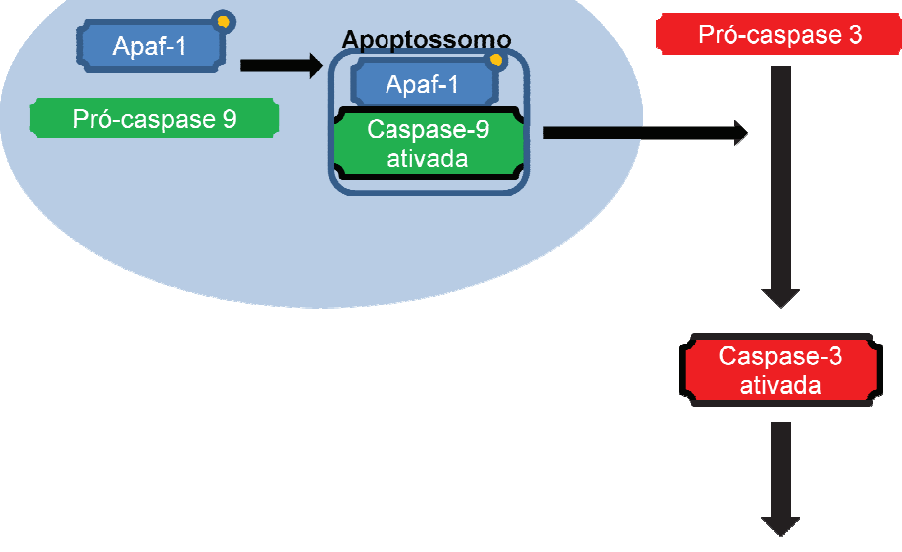

\section{APOPTOSE}

Esquema ilustra as duas vias de ativação da apoptose: via intrínseca ou mitocondrial e via extrínseca ou celular. As duas vias culminam com a ativação da caspase-3, chamada caspase executora, responsável pela clivagem de importantes substratos celulares resultando em alterações morfológicas e bioquímicas clássicas associadas ao fenótipo de apoptose.

Fonte: Adaptado de MacFarlane e Williams, 2004.

Apesar dos neurônios possuírem o mesmo programa de apoptose comum a todas as células do organismo, existem diferentes combinações de membros das famílias do $\mathrm{Bcl}-2$ e das caspases para diferentes tipos de neurônios em diferentes estágios do desenvolvimento (Yuan, Yankner, 2000), tornando o estudo da via intrínseca da apoptose muito mais complexo neste período.

As caspases, pertencentes à superfamília de proteases aspartil-específicas, em especial a Caspase-3, têm papel importante na neurodegeneração após episódio hipóxico-isquêmico (Schulz et al., 1999). 
As principais caspases envolvidas na morte neuronal são as caspases 3 e 9 , sendo que, na cascata da apoptose, a Caspase-9 ativa cliva a Caspase-3 (Yuan, Yankner, 2000). Estudos com camundongos caspase-3-null e caspase-9-null (com ausência destas caspases) mostraram a importância das mesmasdurante 0 desenvolvimento do sistema nervoso, uma vez que sua ausência levou a graves anomalias, como formações de massas ectópicas no córtex cerebral, hipocampo e estriado e ainda expansão da zona periventricular, devido à diminuição da apoptose (Kuida et al.,1996; Kuida et al., 1998).

Para este estudo, foi escolhida a Caspase-3 para detectar e quantificar a morte por apoptose no hipocampo de ratos submetidos à anóxia neonatal a partir de 24 horas após o insulto anóxico, uma vez que estudos com modelos de hipóxiaisquemia neonatal em roedores indicaram que o pico de expressão da Caspase-3 ocorre 24 horas após o estímulo hipóxico (Blomgren et al., 2001; Carloni et al., 2007).

Com o conhecimento a respeito da via intrínseca ou mitocondrial descrita anteriormente, é possível afirmar que a ocorrência da apoptose depende de ATP, a qual está ausente num evento anóxico grave devido à depleção de oxigênio. Desta forma, a via intrínseca fica prejudicada, pois etapas dependentes de ATP, como a produção do apoptossomo, podem não ocorrer, fazendo com que não haja ativação da Caspase-9, o que pode induzir as células a um outro destino, tal como a morte por necrose, descrita a seguir.

\subsubsection{Necrose}

Quando a privação de oxigênio é suficientemente grave a ponto de causar depleção de reservas energéticas teciduais, as células rapidamente respondem ao insulto com acidose, excitotoxicidade por glutamato, geração de espécies reativas ao oxigênio e estresse oxidativo, seguido por períodos prolongados de morte celular tardia ou apoptose e inflamação (Dirnagl et al., 1999; Vannucci, Hagberg, 2004).

A necrose corresponde à forma de morte celular que ocorre rapidamente em resposta a insultos graves, como é o caso da anóxia. Resulta de vias de transdução de sinais específicas (Golstein, Kroemer, 2007) e é caracterizada por falha na regulação osmótica, depleção de ATP e rápida permeabilização da membrana 
plasmática. Este fenômeno está associado a alterações na homeostase dos íons cálcio e sódio (Banasiak et al., 2000).

As características morfológicas da necrose são: aumento do volume celular (oncose), inchaço das organelas, ruptura da membrana plasmática com subsequente perda do conteúdo intracelular (Kroemer et al., 2009). A necrose foi considerada, por muito tempo, uma forma de morte celular acidental e descontrolada; porém, evidências têm mostrado que essa morte celular pode ser controlada por várias vias sinalizadoras e mecanismos catabólicos (Festjens et al., 2006). Em 2008, Hitomi e colaboradores denominaram esta forma de necrose, em especial a mediada pela RIP1, da família de proteínas RIP, sensíveis ao estresse celular, de necroptose.

Como já mencionado, estudos mostram que a lesão primária após insulto hipóxico-isquêmico em fetos e neonatos decorre de necrose celular, enquanto a lesão secundária, após horas ou dias, é ocasionada por apoptose ou morte celular programada (Beilharz et al., 1995; Nakajima et al., 2000; Northington et al., 2001). Porém, a grande maioria dos estudos supracitados foram realizados em modelos de hipóxia-isquemia, causados por cessação permanente do fluxo sanguíneo unilateral e privação parcial do oxigênio em animais com 7 dias de vida.

Clinicamente, o padrão de lesão neural que ocorre devido a insulto hipóxico ou anóxico graves, no prematuro, difere dos padrões vistos na lesão do recémnascido a termo ou que ocorre logo após o nascimento. A leucomalácia periventricular difusa, por exemplo, ocorre mais comumente nos prematuros, assim como lesões talâmicas (Barrett et al., 2007).

Ainda, estudos clínicos sugerem que insultos hipóxicos no encéfalo humano no período perinatal contribuem para redução, a longo prazo, do crescimento da substância cinzenta (Isaacs et al., 2004), sugerindo possível alteração no mecanismo regulatório da neurodegeneração e proliferação neuronais. 


\subsubsection{Objetivos}

I - verificar longitudinalmente a morte celular decorrente da anóxia neonatal no hipocampo de ratos Wistar desde 24 horas após o insulto anóxico (P3) até a idade adulta (P60) com técnicas de imunoistoquímica para Caspase-3 ativada, TUNEL e Fluoro-Jade B $\circledast$ e análise estereológica;

II - avaliar, com técnicas de microscopia eletrônica de transmissão, a ocorrência de alterações morfológicas indicativas de diferentes tipos de morte neuronal 24 horas após anóxia neonatal. 


\subsection{Material e método}

A morte e degeneração neuronais foram analisadas a partir de 24 horas após a anóxia, utilizando as técnicas de histoquímica para detecção de neurodegeneração e fragmentação de DNA (Fluoro-Jade $B$ e e TUNEL, respectivamente), técnica de imunoistoquímica contra a Caspase-3 ativada e técnica de microscopia eletrônica de transmissão para o estudo morfológico dos tipos de morte neuronal presentes.

\subsubsection{Fluoro-Jade $B{ }^{\circledR}$}

Dois diferentes protocolos foram utilizados para detecção dos neurônios positivamente marcados para Fluoro-Jade $B \otimes(F J B+)$, de acordo com a idade do animal e características do tecido encefálico. Para determinação dos protocolos, diferentes testes foram realizados, onde foram observados os seguintes aspectos: aderência do tecido às lâminas, intensidade do background e intensidade da marcação FJB+ (Lee, 2012).

Para animais em P3, secções do tecido $(30 \mu \mathrm{m})$ cortadas em criostato e montadas em lâminas gelatinizadas, foram retiradas do freezer $-20^{\circ} \mathrm{C} 48$ horas antes do processamento, lavadas em PBS $0,1 \mathrm{M}$ e deixadas para secar em temperatura ambiente 24 horas e na estufa a $37^{\circ} \mathrm{C}$ por mais 24 horas. Após este período, foram imersas em solução com $1 \%$ de $\mathrm{NaOH}$ em álcool $80 \%$, seguida por solução de álcool $70 \%$, submetidas a duas lavagens em água destilada (10 minutos cada), imersas em solução de permanganato de potássio $0,06 \%$ por 10 minutos (agitando gentilmente) e lavadas três vezes em água destilada (10 minutos cada). Depois, em ambiente escuro, elas foram colocadas em solução marcadora de Fluoro-Jade $B \circledR$ (Millipore Corporate Headquarters, Billerica, MA, EUA) 0,0004\% por 20 minutos, lavadas três vezes em água destilada ( 2 minutos cada) e colocadas para secar em estufa a $37^{\circ} \mathrm{C}$. Após totalmente secas, elas foram mergulhadas em xilol por pelo menos um minuto e cobertas com lamínulas usando DPX.

Os encéfalos dos demais animais (P14, P21 e P60), cortados na espessura de $40 \mu \mathrm{m}$ em micrótomo, foram montados em lâminas gelatinizadas e deixados para secar em estufa a $37^{\circ} \mathrm{C}$ por 24 horas. A seguir, foram mergulhados em álcool $100 \%$ por 3 minutos e álcool $70 \%$ por 1 minuto; foram então mergulhados em água 
destilada por 1 minuto e permaneceram por 15 minutos em solução de permanganato de potássio 0,06\% em mesa agitadora. Após este procedimento, foram lavados duas vezes com água destilada (1 minuto cada lavagem) e permaneceram 30 minutos em solução de Fluoro-Jade $B$ $0,001 \%$ protegidos da luz, em mesa agitadora. Finalmente, foram lavados 3 vezes com água destilada (1 minuto cada lavagem) e deixados para secar em estufa a a $37^{\circ} \mathrm{C}$. Após secagem, foram mergulhados 3 vezes em xilol (2 minutos cada) e as lâminas foram cobertas com DPX. Outra série de lâminas de cada encéfalo foi submetida a uma coloração em Nissl, para auxiliar na identificação das regiões dos cortes encefálicos onde houve marcação.

\subsubsection{TUNEL}

A técnica histológica de marcação por TUNEL (Terminal Deoxynucleotidyl Transferase (TdT)-mediated dUTP Nick End Labeling) consiste na incorporação da fluoresceína 12-deoxiuridina trifosfato (12-d-UTP) nas terminações 3'-OH do DNA, cujo sinal é amplificado por reação envolvendo a enzima Terminal Deoxynucleotidyl Transferase (rTdT). O DNA fragmentado marcado pela fluoresceína 12-dUTP pode ser visualizado diretamente em microscópio de fluorescência.

Para esta técnica histológica, foi utilizado o "Dead End" ${ }^{T M}$ Fluorometric TUNEL System" (Promega, Madison, WI, EUA), com pequenas modificações em seu

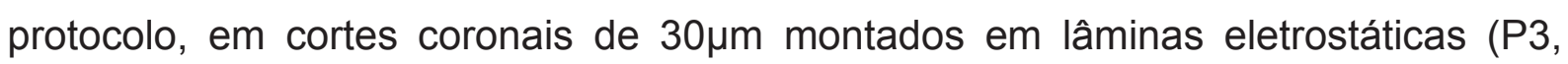
$\mathrm{n}=4$ /grupo) e 40 $\mathrm{m}$ ( $\mathrm{P} 14, \mathrm{P} 21$ e $\mathrm{P} 60, \mathrm{n}=3$ /grupo) de espessura. As lâminas com os cortes foram lavadas em PBS 0,1 M (2 x 5 minutos), permeabilizadas em solução de Proteinase K (1:500) em PBS 0,1 M por 5 minutos, lavadas novamente em PBS (2 x 5 minutos) e incubadas com 100 $\mu$ de Equilibration Buffer a temperatura ambiente,

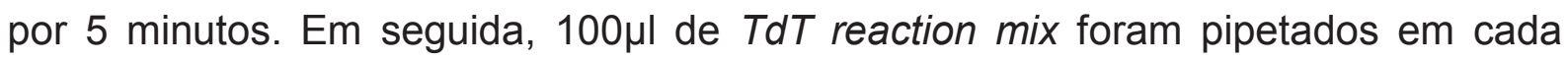
lâmina, sendo cobertas com lamínulas de plástico e levadas à estufa a $37^{\circ} \mathrm{C}$ por 1 hora em câmara úmida protegida da luz. Após este período, as lâminas foram imersas em solução 2X SSC por 15 minutos após a remoção das lamínulas, em seguida foram lavadas em PBS por 5 minutos e cobertas com DAPI/Antifade Solution (Millipore Corporate Headquarters, Billerica, MA, EUA) como meio de montagem. 


\subsubsection{Imunoistoquímica - Caspase-3 ativada}

Secções frontais montadas em lâminas eletrostáticas, foram lavadas em PBS e mergulhadas em solução fervente de ácido cítrico $0,01 \mathrm{M}(\mathrm{pH}$ 6) durante 7 minutos para recuperação antigênica e então deixadas na mesma solução resfriando por 20 minutos. Após novas lavagens em PBS, os cortes foram incubados em solução composta por PBS e soro normal de cabra (NGS) (Vector Laboratories, Burlingame, CA, EUA) por 40 minutos para bloqueio de sítios inespecíficos; a seguir, foram incubadas em mesma solução com anticorpo monoclonal feito em coelho contra Caspase-3 ativada (1:100, ABCAM, Cambridge, MA, EUA) por 48 horas a $8^{\circ} \mathrm{C}$. Após este período, as lâminas foram lavadas em PBS e incubadas por 90 minutos em anticorpo secundário biotinilado contra coelho (1:1000). A este procedimento seguiram-se novas lavagens e incubação por 90 minutos em complexo avidinabiotina (1:500, Vector Laboratories, Burlingame, CA, EUA), novas lavagens em PBS e reação com 3,3'-diaminobenzidina (DAB) como cromógeno. As secções foram então contrastadas com tionina, desidratadas, diafanizadas e cobertas com DPX.

\subsubsection{Microscopia Eletrônica de Transmissão (MET)}

Para identificação morfológica da morte neuronal decorrente da anóxia neonatal, os hipocampos de quatro animais (grupo anóxia, $n=2$; grupo controle, $n=2$ ) foram processados para análise por microscopia eletrônica de transmissão (MET), 24 horas após o estímulo anóxico.

A MET utiliza um feixe de elétrons para atravessar um espécime no interior de uma câmera de vácuo, necessitando que o material biológico a ser analisado tenha sido submetido a processamento peculiar para que se torne estável neste ambiente (Horta Júnior, Garcia, 2007).

Os animais foram anestesiados com solução de hidrato de cloral a $35 \%$ injetado via intraperitonial, na dose de $0,4 \mathrm{ml} / 100 \mathrm{~g}$ e então perfundidos transcardiacamente com solução fixadora Karnovsky modificada (Watanabe, Yamada, 1983), composta por formaldeído a $2 \%$ (preparado previamente a partir da dissolução de paraformaldeído em água destilada, aquecida a $60-65^{\circ} \mathrm{C}$ ) e glutaraldeído a 2,5\%, em tampão cacodilato de sódio a 0,1 M e pH 7,4. 
Os encéfalos foram então dissecados e os hemisférios cerebrais contendo os hipocampos foram emblocados. A seguir, as amostras permaneceram 3 horas, em temperatura ambiente, imersas em solução fixadora. Após este período, os tecidos foram lavados em tampão cacodilato de sódio $0,1 \mathrm{M}, \mathrm{pH}$ 7,4 e seccionados no plano frontal em espessura de $50 \mu \mathrm{m}$, por meio de vibrátomo (Vibratome 3000 sectioning system, Vibratome Company Incorporation - USA) equipado com sistema de refrigeração a banho VB 900r (Vibratome Company Incorporation - USA). Os cortes foram pós-fixados em solução de $\mathrm{OsO}_{4}$ a $1 \%$, tamponada em cacodilato de sódio 0,1 $\mathrm{M}, \mathrm{pH} 7,4$, por $2 \mathrm{~h}$, a $4^{\circ} \mathrm{C}$. Os tecidos foram lavados em solução salina a $0,9 \%$ e imersos em solução aquosa de uranila a $0,5 \%$, por $8 \mathrm{~h}$, a temperatura ambiente.

Em seguida, as amostras foram desidratadas em concentrações crescentes de álcoois $(70 \%, 80 \%, 90 \%, 95 \%$ e $4 x$ 100\%) e óxido de propileno (2x), 3 minutos em cada solução.

Após a desidratação, foi iniciada inclusão em resina, preparada sob a proporção de 1:1 entre óxido de propileno e resina Spurr (Electron Microscopy Sciences, USA), e disposta em misturador rotatório por $4 \mathrm{~h}$. A mistura foi substituída por resina pura e disposta no misturador por um período de 16h. Em seguida, foi novamente substituída por resina pura, deixando-a em estufa a $37^{\circ} \mathrm{C}$, por $1 \mathrm{~h}$. Então, as amostras foram embebidas em nova resina pura e interpostas a duas superfícies plásticas maleáveis e lisas; tal meio as acondicionou entre uma fina película de resina, onde permaneceram por $96 \mathrm{~h}$ em estufa a $60^{\circ} \mathrm{C}$.

Passado esse período, as amostras infiltradas por resina foram reduzidas à região hipocampal e fixadas em blocos de resina. Obtida a região de interesse, foram realizados cortes semi-finos em espessura de $2 \mu \mathrm{m}$, com faca de vidro, em ultra-micrótomo (Leica Ultracut UCT, Leica Microscopes - Áustria). Os cortes foram montados em lâminas histológicas e corados com solução de azul de toluidina 1\%, para visualização em microscópio de luz.

Após confirmado o local de interesse, foi realizada nova trimagem, com maior restrição à área de interesse, para obtenção de cortes ultrafinos em espessura de 90 $\eta \mathrm{m}$, por meio de faca de diamante. Os cortes foram coletados em telas de cobre, com 200 "mesh", contrastados com as soluções de acetato de uranila e citrato de chumbo (Reynolds, 1963; Watanabe, Yamada, 1983; Watson, 1958). As telas foram examinadas em microscópio eletrônico de transmissão JEOL 1010, em 80 kV. 


\subsubsection{Técnicas de análise dos resultados}

\subsubsection{Fluoro-Jade B $®$ e TUNEL}

A morte neuronalidentificada com a Fluoro-Jade B e com o TUNEL foi analisada em microscopia de epifluorescência (filtro FITC, comprimentos de onda de excitação/emissão $=495 \mathrm{~nm} / 521 \mathrm{~nm}$ ) por análise quantitativa na região hipocampal, utilizando como material de apoio o Atlas of the Developing Rat Nervous System (Paxinos et al., 1994). Delimitações anatômicas aproximadas entre as subregiões hipocampais foram realizadas com auxílio de uma série corada com DAPI (Figura 3), em que foi possível visualizar diferenças morfológicas entre as células piramidais de CA1 (camada mais fina e densa, células menores) e CA3 (camada mais espessa e menos densa).

Figura 3-Subregiões do hipocampo de rato em P3.

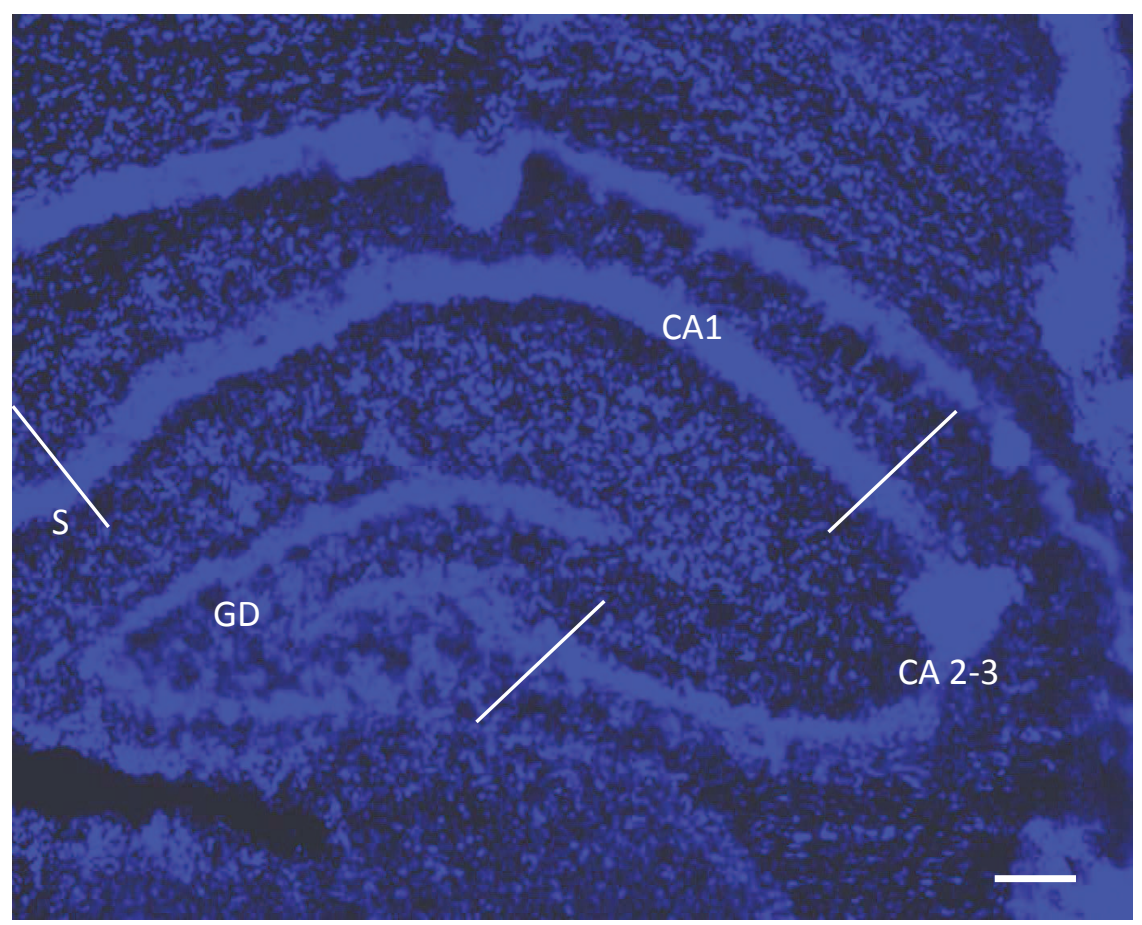

Fotomicrografia de corte coronal de rato em P3, região hipocampal, em microscopia de epifluorescência. Observa-se a divisão anatômica aproximada, com base em características morfológicas das células piramidais em CA1 e CA2-3. Legenda: GD: giro denteado; S: subículo. Escala: $100 \mu \mathrm{m}$.

Para ambas as quantificações, 6 cortes hipocampais foram selecionados, sendo dois da porção rostral, dois da porção média e dois da porção caudal; o 
hipocampo de um dos hemisférios foi analisado e a média da quantificação por subregião e por grupo foi submetida à análise estatística.

\subsubsection{Caspase-3 ativada e volume hipocampal}

A quantificação estereológica das células hipocampais imunorreativas à Caspase-3 ativada (IR-Casp3) e a mensuração do volume hipocampal (descrito no próximo capítulo) ao longo das idades foram realizadas com o software Stereo Investigator versão 10 (MBF Biosciences), sendo o treinamento e análise piloto realizados na UNESP - campus Araçatuba, em colaboração com o Professor Doutor Roelf Cruz Rizzolo e na NorthShore University Healthsystem (Chicago, EUA), sob supervisão do Professor Doutor Sidhartha Tan; a análise quantitativa estereológica foi realizada nas dependências do Departamento de Anatomia no ICB-USP em colaboração com o Professor Doutor Jackson Cioni Bittencourt.

Foram utilizadas de 4 (P21 e P60) a 6 secções (P3 e P14) por animal, $n=5 / g r u p o / i d a d e$, totalizando 40 animais. As secções reagidas para Caspase 3 ativada foram contra-coradas com tionina, permitindo a delimitação das estruturas em microscópio óptico acoplado a sistema de estereologia constituído por uma platina motorizada (Ludl Electronic Products, Hawthorne, NY), câmera para captura (Nikon Instruments Inc., Melville, NY) e o software Stereo Investigator (MBF Biosciences, Williston, VT). Para a delimitação das estruturas foi utilizada a objetiva de 4x. A delimitação das regiões CA1, CA2-3 e giro denteado (GD) foi realizada de forma a padronizar as regiões nos diferentes níveis ao longo do eixo rostro-caudal. Desta forma, a região delimitada como CA3 englobou também CA2, quando presente; a região de GD englobou também a porção que alguns autores denominam CA4 (figura 4).

\subsubsection{Análise estatística}

Para a comparação entre os grupos controle e anóxia em relação à quantidade de células FJB+e TUNEL+, foi empregado o teste T de Student; para a análise dos resultados da quantificação de células IR-Casp3 ao longo das idades, foi utilizado o Two-Way ANOVA. 
Figura 4 - Delimitação das áreas de interesse para análise estereológica do hipocampo de ratos submetidos à anóxia neonatal.

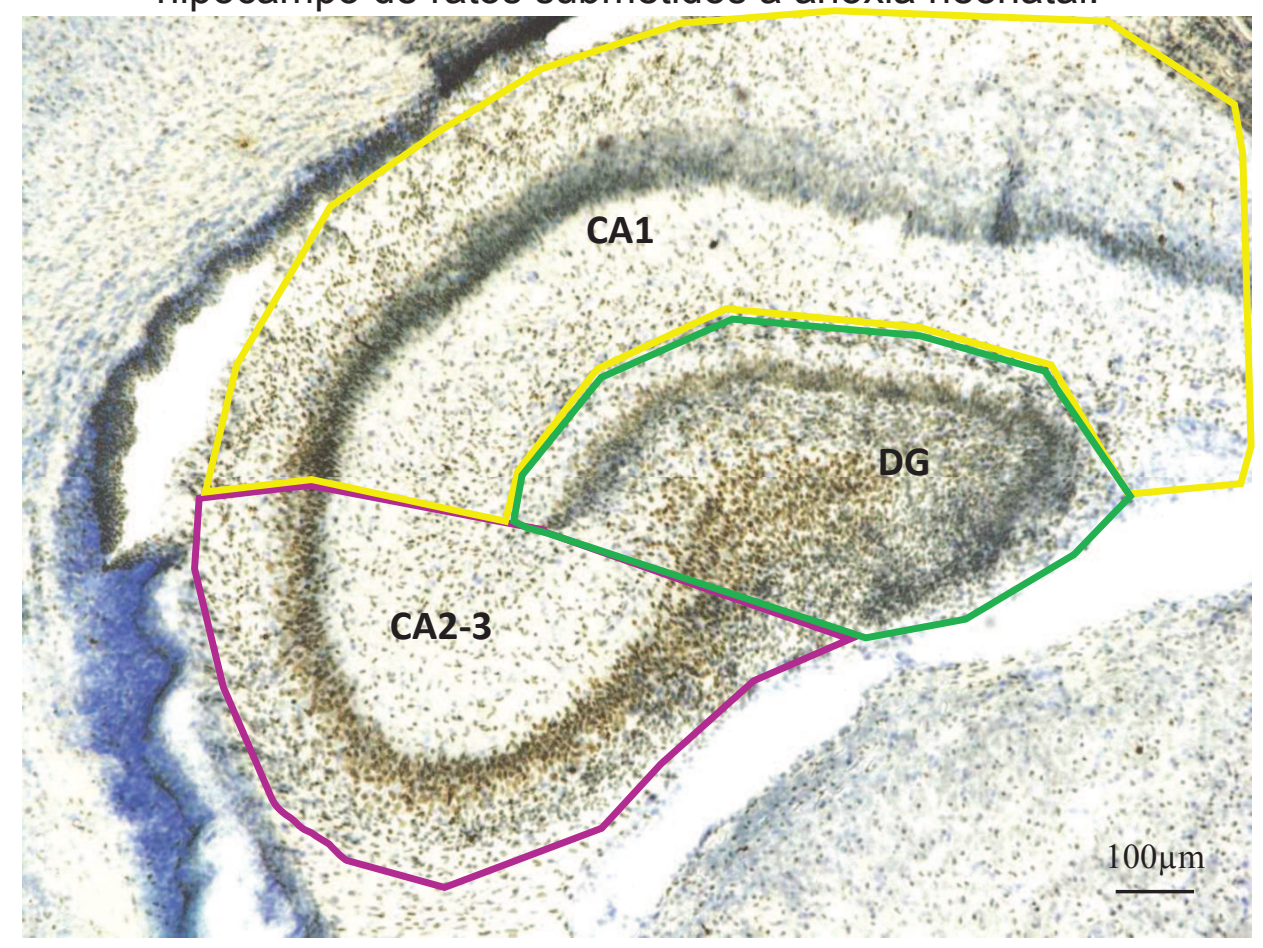

Fotomicrografia em campo claro de corte coronal de encéfalo de rato em P3 mostrando a delimitação da área de interesse e divisão do hipocampo em regiões CA1, CA2-3 e GD em corte reagido por técnica de imunoistoquímica contra Caspase-3 ativada e contra-corado com tionina.

Após definida a área de interesse, foram realizados estudos-piloto para determinação do tamanho do "grid size", quantidade e tamanho do "counting frame" de acordo com a idade do animal e tamanho da estrutura e com o valor do coeficiente de erro de Gundersen $(m=1)$, menor que 0,10. Os mesmos parâmetros foram mantidos em uma determinada idade em todas as regiões e ao longo das secções no eixo rostro-caudal (Tabela 1). A contagem e mensuração do volume foram realizadas com o recurso "Optical Fractionator" do software. 
Tabela 1 - Parâmetros utilizados para análise por estereologia das células IR-Casp3 e volume no hipocampo de ratos submetidos à anóxia neonatal.

\begin{tabular}{c|llll}
\hline Parâmetros/ldade & P3 & P14 & P21 & P60 \\
\hline Counting Frame Area $(\boldsymbol{X Y})\left(\boldsymbol{\mu m ^ { 2 } )}\right.$ & 1,6 & 1,6 & 1,6 & 1,6 \\
Disector Height $(\mathbf{Z})(\boldsymbol{\mu m})$ & 10 & 10 & 10 & 10 \\
Guard Zone Distance $(\boldsymbol{\mu m})$ & 01 & 01 & 01 & 01 \\
Counting Frame Width $(\boldsymbol{X})(\boldsymbol{\mu m})$ & 40 & 40 & 40 & 40 \\
Counting Frame Height $(\boldsymbol{Y})(\boldsymbol{\mu m})$ & 40 & 40 & 40 & 40 \\
Sampling Grid $(\boldsymbol{X})(\boldsymbol{\mu m})$ & 271 & 271 & 353 & 396 \\
Sampling Grid $(\boldsymbol{Y})(\boldsymbol{\mu m})$ & 114 & 114 & 240 & 233 \\
Section Evaluation Interval & 10 & 12 & 24 & 24 \\
\hline
\end{tabular}

Parâmetros utilizados para contagem na estereologia com o recurso "Optical Fractionator" do software Stereo Investigator, versão 10. Estes parâmetros foram definidos conforme o valor do coeficiente de erro de Gundersen $(m=1)$, menor que 0,10.

Devido à característica da marcação para Caspase-3 em diferentes tonalidades, foi padronizada a faixa de intensidade mínima de coloração a ser considerada na contagem (Figura 5).

Figura 5 - Células IR-Casp3 no hipocampo de rato neonato submetido à anóxia neonatal.

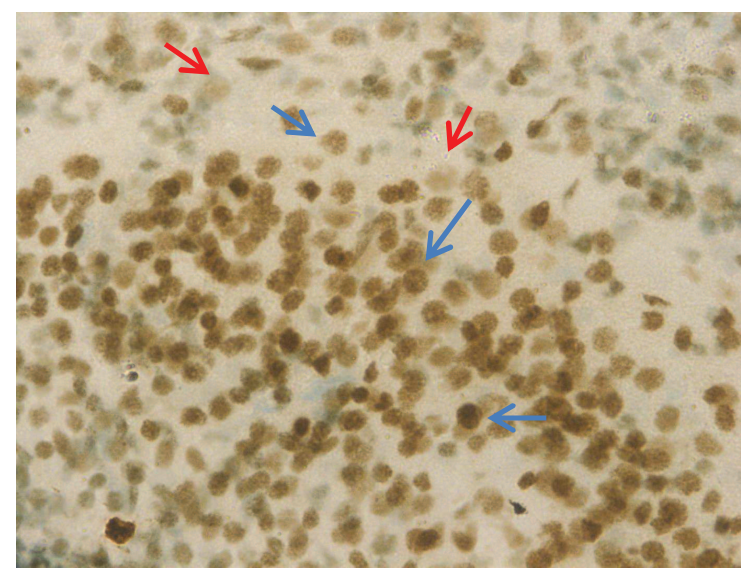

Fotomicrografia em campo claro de corte coronal de encéfalo de rato P3 do grupo anóxia na região de DG evidenciando as células IR-Casp3 de diferentes intensidades de coloração, sendo identificadas exemplos daquelas consideradas na contagem (setas azuis) e aquelas não consideradas na contagem devido à fraca intensidade de marcação (setas vermelhas). 


\subsection{Resultados}

\subsubsection{Fluoro-Jade $B \circledR$ e TUNEL}

A análise das células marcadas positivamente para Fluoro-Jade $B \circledast(F J B+)$ envolveu o estudo quantitativo da neurodegeneração no hipocampo de ratos $(n=12)$ 24 horas após a anóxia neonatal (Lee, 2012), sendo que nas demais idades a marcação era escassa em ambos os grupos. Os resultados revelaram maior quantidade de células $\mathrm{FJB}+$ na região $\mathrm{CA} 2-3$ do hipocampo de ratos do grupo anóxia (18,6 $6 \pm 2,21)$ em comparação ao grupo controle $(11 \pm 1,5), p=0,013$, diferença não observada em CA1 (grupo anóxia: 35,69 \$ 5,67; grupo controle: 41,9 9 5) e giro denteado (grupo anóxia: 7,6 \pm 1,6; grupo controle: 7,9 \pm 0,7) (Tabela 2, Figuras 6 e 7 ).

A quantificação das células TUNEL+ 24 horas após o estímulo anóxico (grupo controle, $n=4$; grupo anóxia, $n=4$ ) evidenciou maior marcação nas subregiões CA1 (grupo anóxia: 90,5 \pm 0,5; grupo controle: $26,3 \pm 3,8$, p $\leq 0,001$ ) e CA3 (grupo anóxia: $34,3 \pm 3,1$; grupo controle: 13,8 $\pm 2,6, p \leq 0,001)$ em animais do grupo anóxia 24 horas após o estímulo anóxico, sendo que no GD (grupo anóxia: $24,5 \pm 6,3$; grupo controle: $14,8 \pm 4,2$ ) não foram observadas diferenças entre os grupos (Tabela 3, Figuras 8, 9 e 10). Nas demais idades a marcação foi escassa em ambos os grupos.

Tabela 2 - Quantidade de células FJB+ no hipocampo de ratos submetidos à anóxia neonatal.

\begin{tabular}{c|cc}
\hline Grupo & Região & P3 (24 horas após o estímulo anóxico) \\
\hline \multirow{3}{*}{ Controle } & CA1 & $41,9 \pm 5,0$ \\
& CA2-3 & $11 \pm 1,5$ \\
& GD & $7,9 \pm 0,7$ \\
\hline \multirow{3}{*}{ Anóxia } & CA1 & $35,7 \pm 5,7$ \\
& ${ }^{*}$ CA2-3 & $18,7 \pm 2,2$ \\
& GD & $7,6 \pm 1,6$ \\
\hline
\end{tabular}

Resultados expressos em Média \pm Erro Padrão. A contagem de neurônios FJB+ revelou maior quantidade na subregião CA3 do hipocampo de ratos do grupo anóxia $(n=6 ; 18,7 \pm$ $2,2)$ em comparação ao grupo controle $(n=6 ; 11 \pm 1,5),{ }^{*} p=0,013$, diferença não observada nas demais regiões. 
Tabela 3 - Quantidade de células TUNEL+ no hipocampo de ratos submetidos à anóxia neonatal.

\begin{tabular}{c|cc}
\hline Grupo & Região & P3 (24 horas após o estímulo anóxico) \\
\hline \multirow{3}{*}{ Controle } & CA1 & $26,3 \pm 3,8$ \\
& CA2-3 & $13,8 \pm 2,6$ \\
& GD & $14,8 \pm 4,2$ \\
\hline \multirow{2}{*}{ Anóxia } & ${ }^{*}$ CA1 & $90,5 \pm 0,5$ \\
& ${ }^{*}$ CA2-3 & $34,3 \pm 3,1$ \\
& GD & $24,5 \pm 6,3$ \\
\hline
\end{tabular}

Resultados expressos em Média \pm Erro Padrão. A contagem de células TUNEL+ revelou maior quantidade nas subregiões CA1 e CA2-3 do hipocampo de ratos do grupo anóxia $(n=4)$ em comparação ao grupo controle $(n=4) .{ }^{*} p \leq 0,001$, diferença não observada no GD.

Figura 6 - Degeneração neuronal no hipocampo de ratos 24 horas após anóxia neonatal.

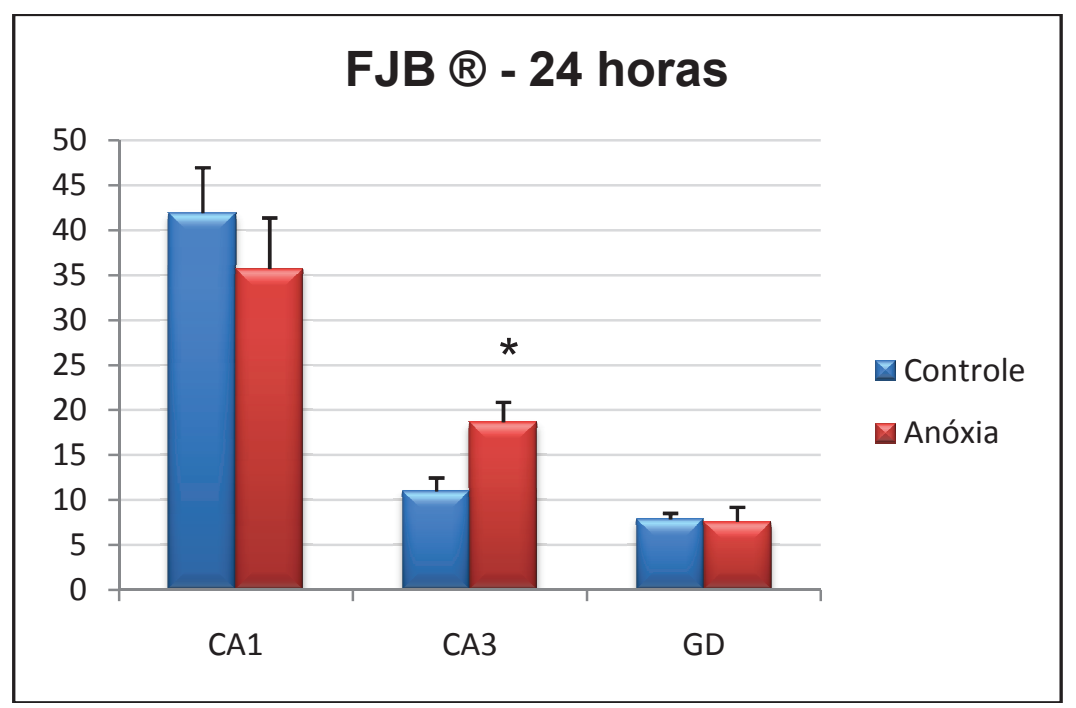

Neurônios FJB+ em maior quantidade em CA2-3 (representado como CA3) do grupo anóxia. Nas demais regiões, não houve diferença entre os grupos. * : $p=0,013$. 
Figura 7 - Células FJB+ no hipocampo de rato 24 horas após anóxia neonatal.
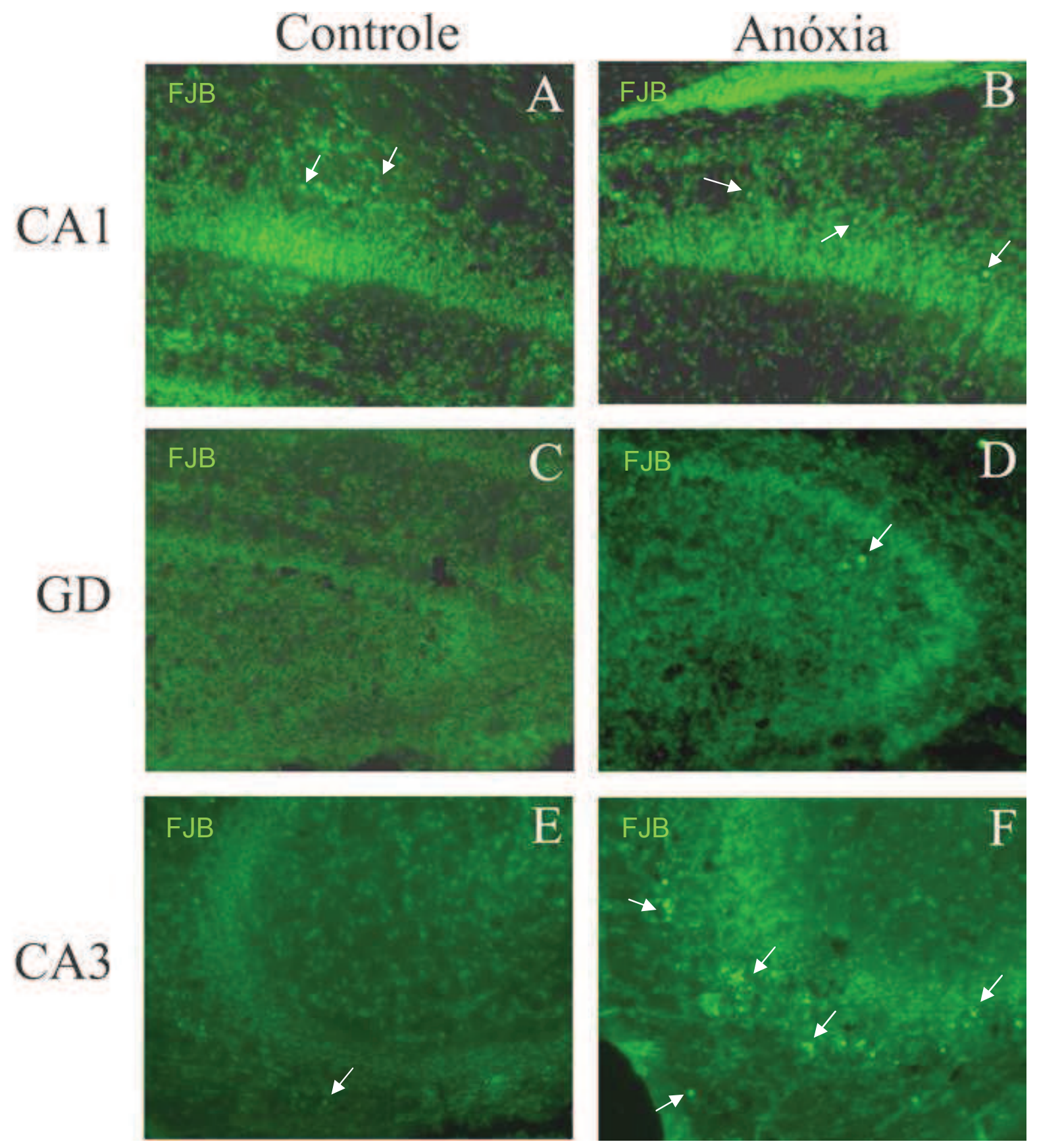

Fotomicrografias de cortes coronais das regiões CA1, GD e CA2-3 (representado como CA3) do hipocampo de ratos dos grupos controle e anóxia 24 horas após insulto anóxico, evidenciando células $\mathrm{FJB}+$ (setas) que indicam neurodegeneração, maior em CA3 no grupo

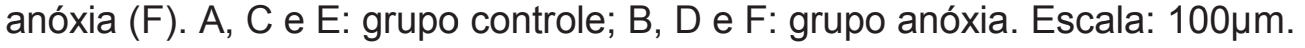


Figura 8 - Células TUNEL+ no hipocampo de ratos 24 horas após anóxia neonatal.
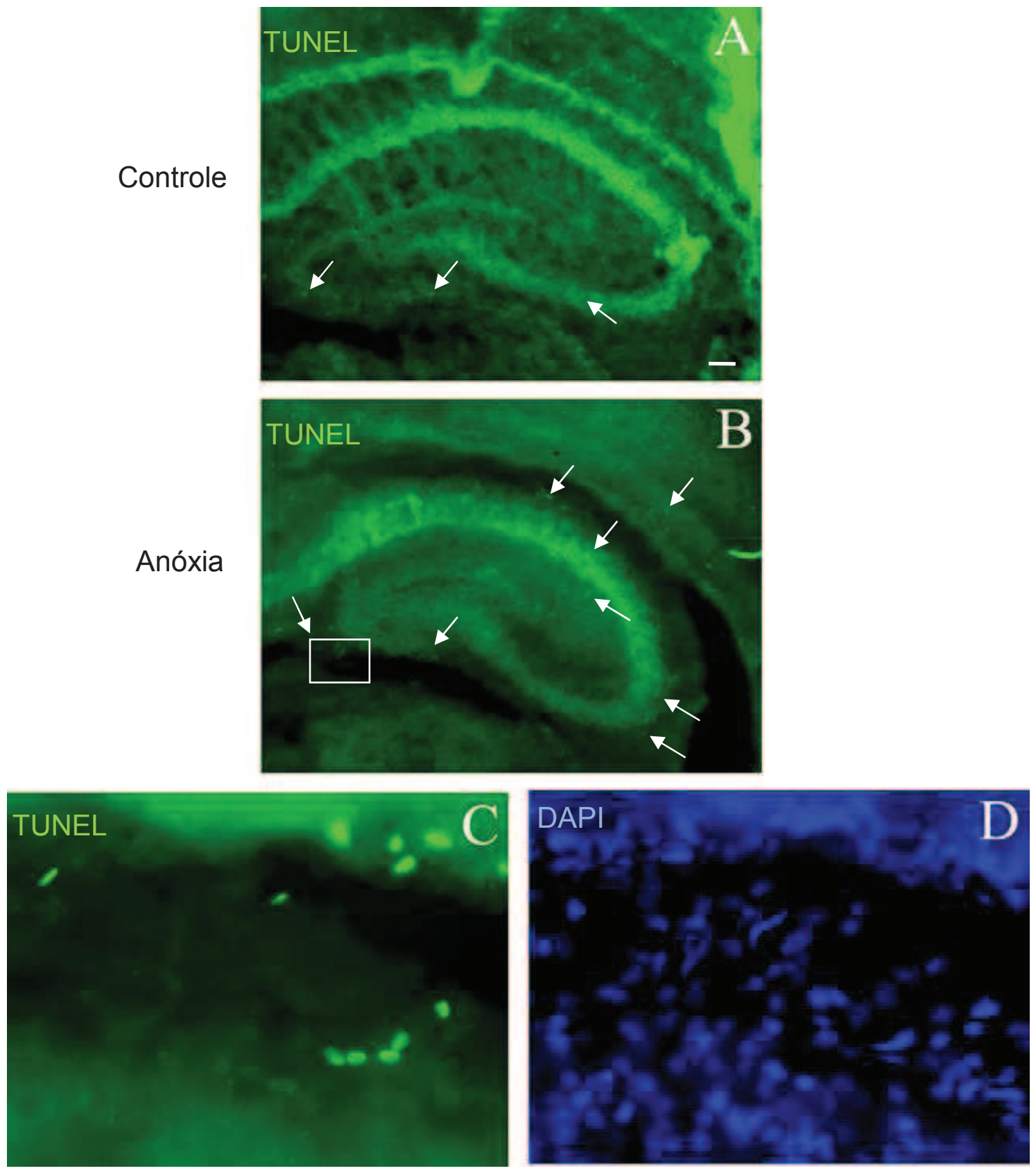

Fotomicrografias de cortes coronais do hipocampo de ratos dos grupos controle (A) e anóxia (B) 24 horas após insulto anóxico, evidenciando células TUNEL+ (setas) que indicam fragmentação do DNA, indicativo de morte celular. O retângulo em $B$ indica região ampliada em C (TUNEL) e D (DAPI), mostrando padrão de marcação das células TUNEL+. Escala: $100 \mu \mathrm{m}$. 
Figura 9 - Células TUNEL+ na região CA1 do hipocampo de ratos 24 horas após anóxia neonatal.

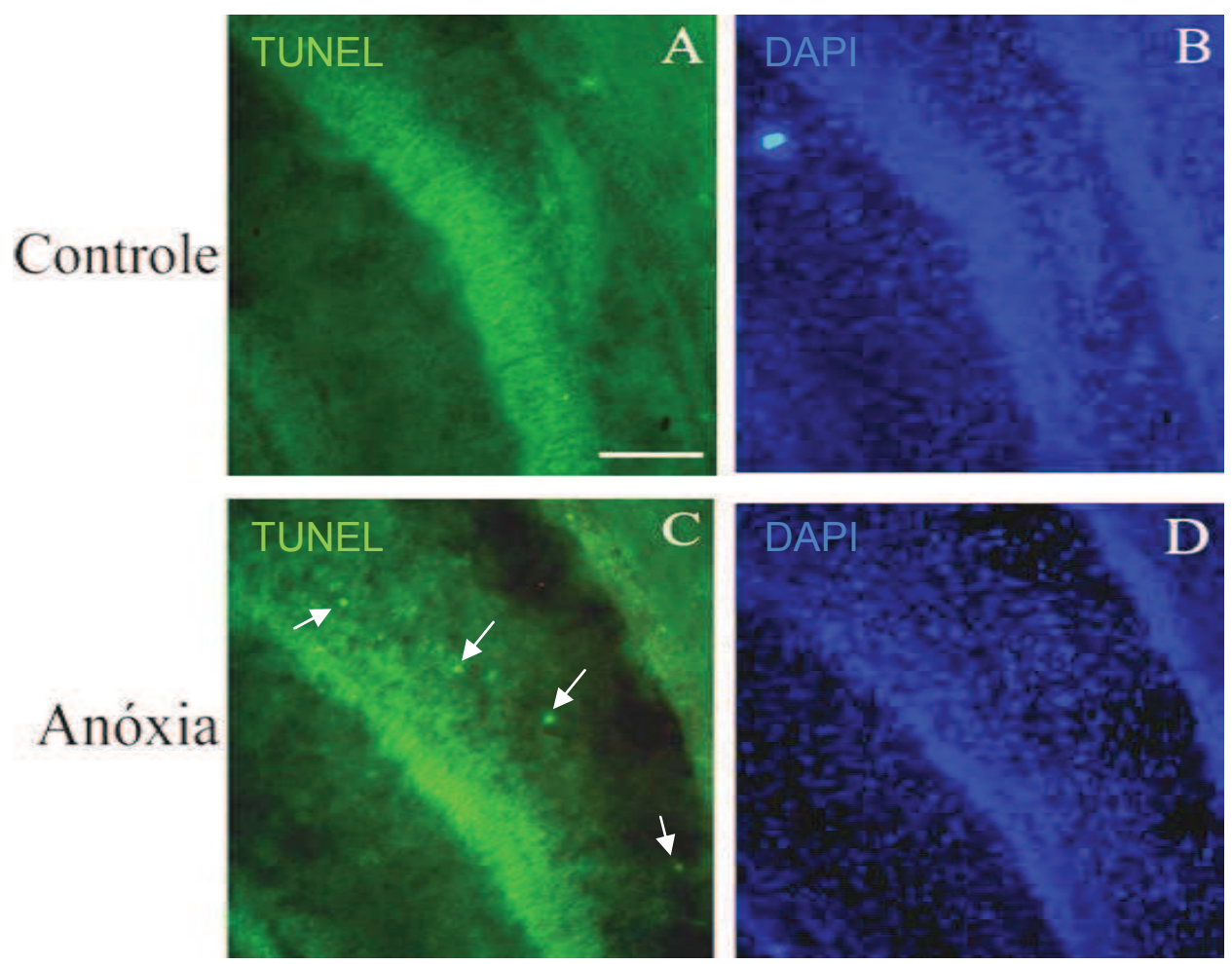

Fotomicrografias de cortes coronais do hipocampo de ratos, região de CA1, dos grupos Controle (A e B) e Anóxia (C e D) 24 horas após insulto anóxico, evidenciando células TUNEL+ (setas) que indicam morte por apoptose. À esquerda, cortes reagidos para TUNEL; à direita, DAPI. Escala: $100 \mu \mathrm{m}$.

Figura 10 - Células TUNEL+ no hipocampo de ratos 24 horas após anóxia neonatal

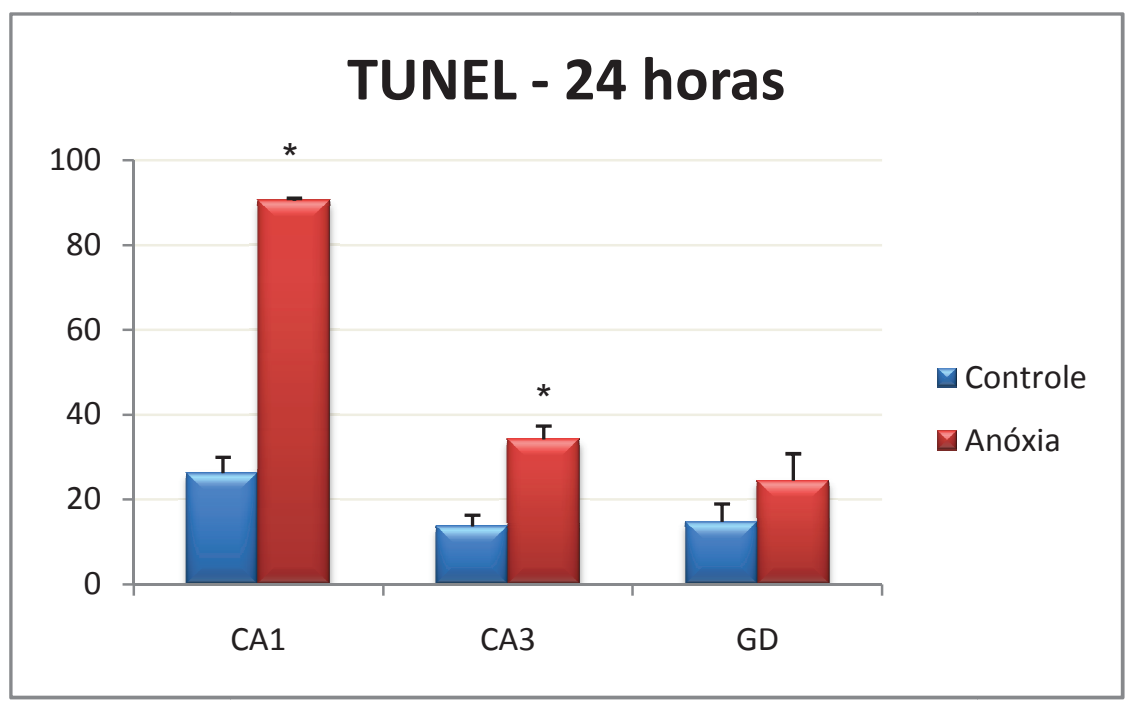

Houve maior quantidade de células TUNEL+ em CA1 e CA3 em animais do grupo anóxia $(n=4)$ em relação ao grupo controle $(n=4) .\left({ }^{*} p \leq 0,05\right)$. 


\subsubsection{Caspase-3 ativada}

A análise estereológica da quantidade absoluta estimada de células IR-Casp3 nas diferentes idades ( $\mathrm{P} 3, \mathrm{P} 14, \mathrm{P} 21$ e P60) mostrou que, em P14, há maior quantidade de células IR-Casp3 na região CA1 do grupo anóxia $(n=5)$ em relação ao controle $(n=5)$, diferença esta não observada nas demais idades e regiões hipocampais analisadas (Tabela 4).

O cálculo da densidade por volume, dividindo-se o total de células IR-Casp3 pelo volume em $\mathrm{mm}^{3}$, não evidenciou diferença entre os grupos anóxia e controle (Tabela 5).

Em ambas as análises, porém, foram observadas diferenças em relação às idades estudadas, tanto no grupo anóxia como controle (Tabelas 4 e 5, Figuras 10 a 14). Assim, a quantidade absoluta de células IR-Casp3 em CA1 aumentou de P3 para P14 e de P14 para P21 no grupo controle, permanecendo estável em P60. Já no grupo anóxia, em CA1, houve aumento de P3 para P14 e nesta idade alcançou a estabilidade, não aumentando nas demais.

A densidade por volume, em CA1, revelou decréscimos de P3 para P14 e de $\mathrm{P} 14$ para $\mathrm{P} 21$, em ambos os grupos.

Em CA3, a quantidade absoluta de células IR-Casp3 aumentou de P3 para P14 e de P14 para P21 nos dois grupos; a densidade por volume mostrou diminuição de $\mathrm{P} 3$ para $\mathrm{P} 14$ e de $\mathrm{P} 14$ para $\mathrm{P} 60$, indicando que, entre $\mathrm{P} 14$ e P21 não houve alterações, em ambos os grupos.

A quantidade absoluta de células IR-Casp3 em GD aumentou progressivamente de $\mathrm{P} 3$ a $\mathrm{P} 21$ nos dois grupos para então decair em $\mathrm{P} 60$, enquanto a densidade por volume diminuiu em P14, ficou estável em P21 e então diminuiu novamente em P60 (Figuras 11 a 13). 
Tabela 4 - Quantidade de células IR-Casp3 após anóxia neonatal.

\begin{tabular}{c|ccccc}
\hline Grupo & Região & P3 & P14 & P21 & P60 \\
\hline & CA1 & $145,2 \pm 31,9$ & $264 \pm 20,2^{\mathrm{a}}$ & $413,3 \pm 33,7^{\mathrm{ab}}$ & $317,6 \pm 40^{\mathrm{a}}$ \\
Controle & CA3 & $108,3 \pm 9,4$ & $196,2 \pm 31,8^{\mathrm{a}}$ & $290 \pm 48,2^{\mathrm{ab}}$ & $337,3 \pm 34^{\mathrm{a}}$ \\
$\left(\mathbf{x} \mathbf{1 0}^{3}\right)$ & GD & $73,6 \pm 8,3$ & $187,1 \pm 19,5^{\mathrm{a}}$ & $466,1 \pm 86,5^{\mathrm{ab}}$ & $301 \pm 15,8^{\mathrm{ac}}$ \\
\hline & CA1 & $160,3 \pm 14,9$ & $425,5 \pm 20,7^{\mathrm{a}}$ & $399,4 \pm 25,1^{\mathrm{a}}$ & $297,3 \pm 24,9^{\mathrm{a}}$ \\
Anóxia & CA3 & $127,7 \pm 7,9$ & $208,2 \pm 20,3^{\mathrm{a}}$ & $389,1 \pm 64,1^{\mathrm{ab}}$ & $264 \pm 65,1^{\mathrm{a}}$ \\
$\left.\mathbf{( x ~ 1 0 ~}^{3}\right)$ & GD & $101,2 \pm 14,3$ & $247,8 \pm 18,3^{\mathrm{a}}$ & $357 \pm 45^{\mathrm{ab}}$ & $283,5 \pm 31,4^{\mathrm{ac}}$ \\
\hline
\end{tabular}

Resultados expressos em Média \pm Erro Padrão. A quantificação estereológica das células neurais IR-Casp3 (Two-Way ANOVA) revelou aumento em P14, região CA1, no grupo anóxia ( $n=5 /$ idade) em relação ao controle ( $n=5 /$ idade), $p \leq 0,05$. Legenda: ${ }^{a}: \neq P 3 ;{ }^{b}: \neq P 14 ;{ }^{c}$ : fP21.

Tabela 5 -Densidade de células IR-Casp3 por volume $\left(\mathrm{mm}^{3}\right)$ após anóxia neonatal.

\begin{tabular}{|c|c|c|c|c|c|}
\hline Grupo & Região & P3 & P14 & P21 & $\mathrm{P} 60$ \\
\hline & CA1 & $90,8 \pm 14,9$ & $53 \pm 2,5^{\mathrm{a}}$ & $38,2 \pm 3,1^{\text {ab }}$ & $30,9 \pm 2,8^{\mathrm{ab}}$ \\
\hline Controle & CA3 & $120 \pm 16,9$ & $54,2 \pm 2,8^{a}$ & $39,5 \pm 6,2^{\mathrm{a}}$ & $35,6 \pm 3,4^{a b}$ \\
\hline \multirow[t]{2}{*}{$\left(\times 10^{3}\right)$} & GD & $156,3 \pm 13,4$ & $77,2 \pm 8^{a}$ & $73,5 \pm 6,8^{a}$ & $53,9 \pm 4,2^{\mathrm{ab}}$ \\
\hline & CA1 & $98,2 \pm 13,2$ & $63,6 \pm 3,1^{a}$ & $40 \pm 5,3^{\mathrm{ab}}$ & $29,1 \pm 2,4^{\text {ab }}$ \\
\hline Anóxia & CA3 & $142 \pm 15,9$ & $56 \pm 4,1^{a}$ & $49,8 \pm 5,5^{\mathrm{a}}$ & $32,5 \pm 2,9^{a b}$ \\
\hline$\left(x 10^{3}\right)$ & GD & $204,5 \pm 35$ & $98 \pm 6,2^{\mathrm{a}}$ & $75,3 \pm 14,8^{a}$ & $55,7 \pm 6,2^{\mathrm{ab}}$ \\
\hline
\end{tabular}

Resultados expressos em Média \pm Erro Padrão. A densidade por volume das células neurais IR-Casp3(Two-Way ANOVA) não mostrou diferenças entre os grupos anóxia ( $n=5 /$ idade) e controle ( $\mathrm{n}=5 /$ idade). Legenda: ${ }^{\mathrm{a}}$ : $\neq \mathrm{P} 3 ;^{\text {b. }}$ : $\neq \mathrm{P} 14$; $^{\mathrm{c}}$ : $\neq \mathrm{P} 21$. 
Figura 11 -Análise estereológica da quantidade absoluta e relativa (células $/ \mathrm{mm}^{3}$ )de células IR-Casp3 no hipocampo de ratos após anóxia neonatal.

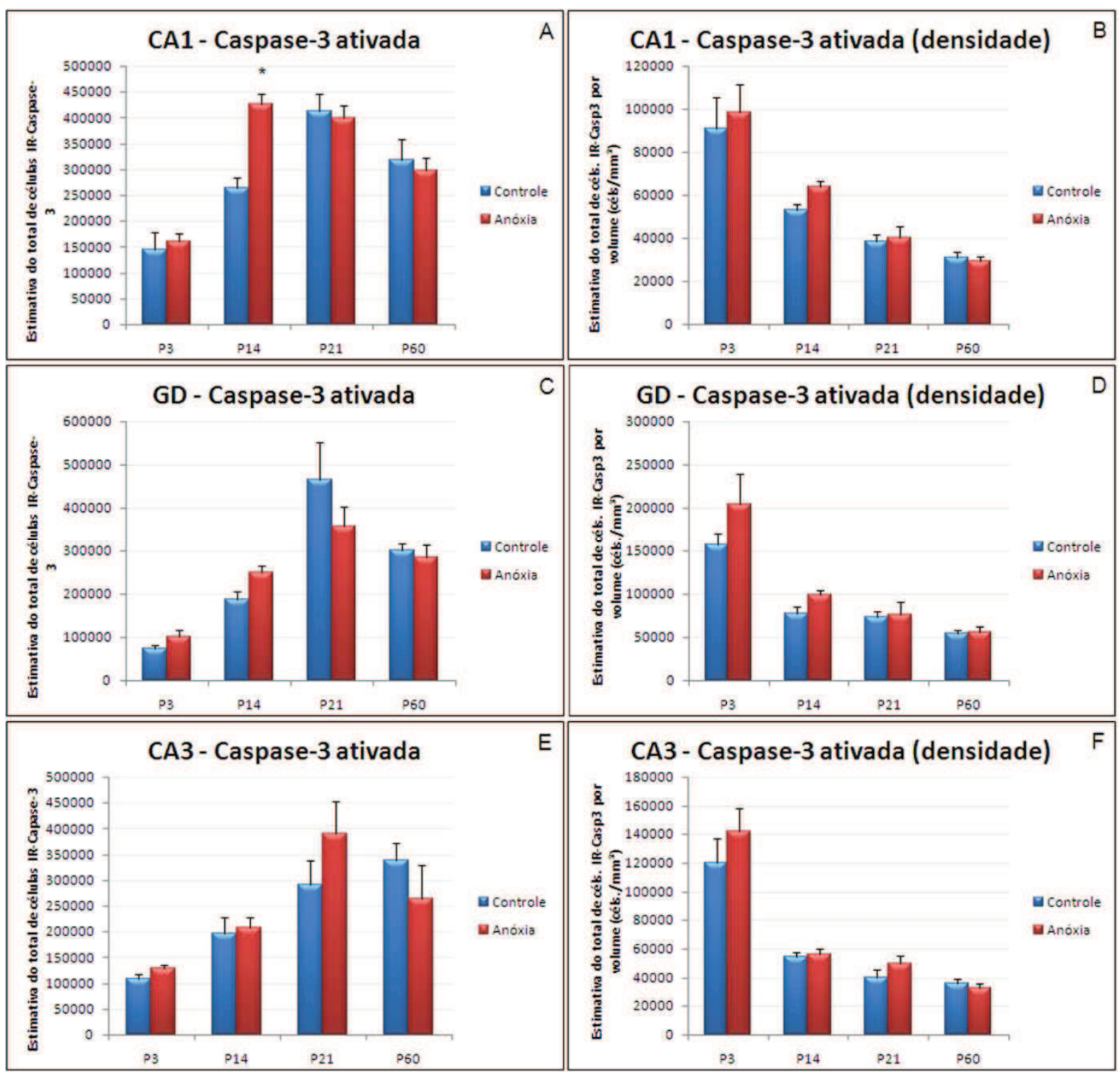

Os gráficos mostram a quantificação estereológica de células IR-Casp3 nas regiões CA1, GD e CA3 do hipocampo de ratos submetidos à anóxia neonatal ( $n=5$ por idade) e não submetidos ao insulto anóxico (grupo controle, $\mathrm{n}=5$ por idade). A, C e E representam a estimativa do total de células IR-Casp3 e B, D e $F$ representam a densidade por volume (Céls. $/ \mathrm{mm}^{3}$ ). A maior quantidade absoluta de células IR-Casp3 aparece em CA1 em P14 no grupo anóxia. Two-Way ANOVA. * : $p \leq 0,05$ (A). 
Figura 12 - Padrão de marcação de células IR-Casp3 no hipocampo de ratos submetidos à anóxia neonatal.
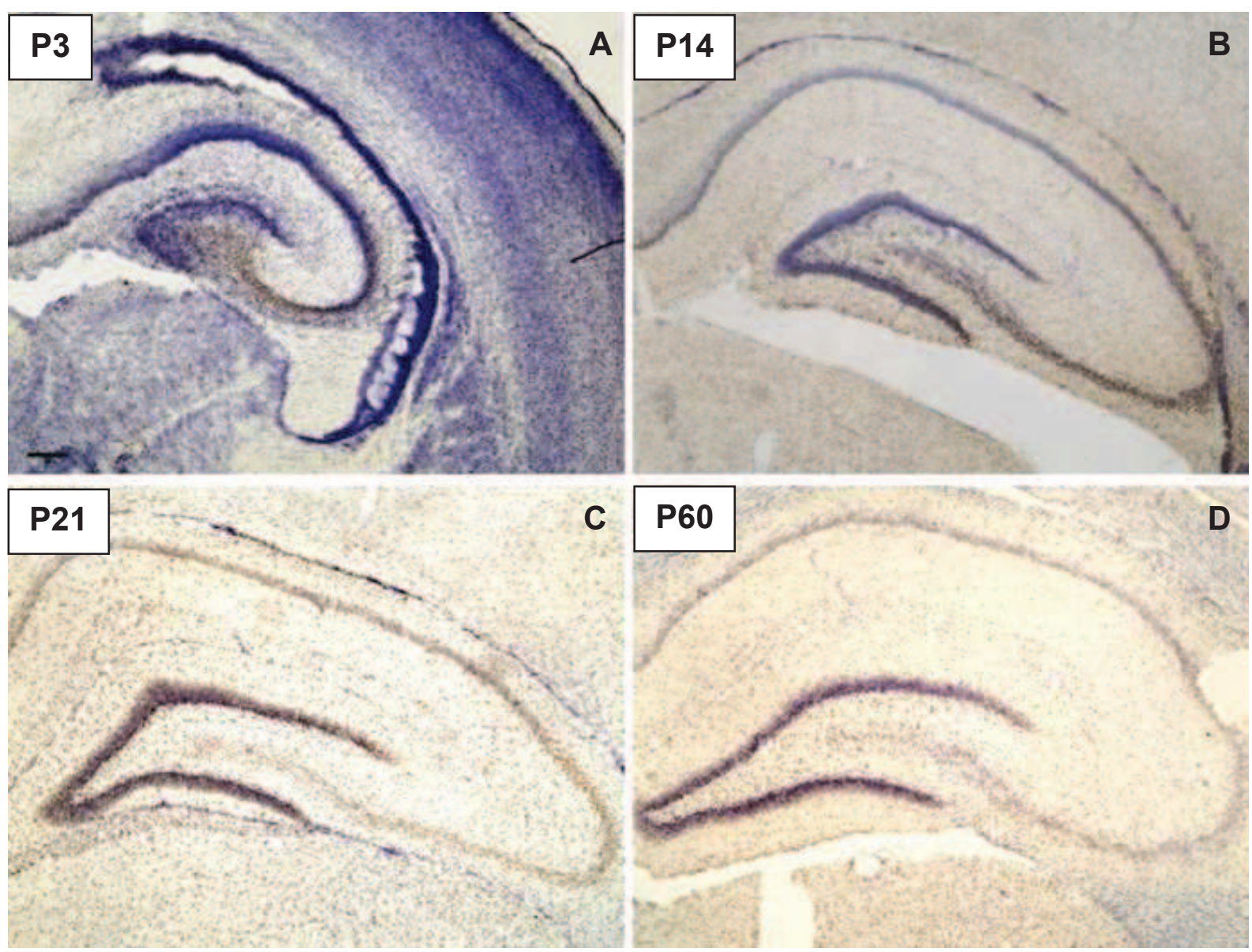

Fotomicrografias em campo claro evidenciam a variação na quantidade de células IR-Casp3 ativada no hipocampo de ratos após anóxia neonatal ao longo das idades: P3 (A), P14 (B), P21 (C) e P60 (D). A marcação em marrom corresponde à imunoistoquímica para Caspase3 ativada, contra-corada com tionina em azul. Escala: $200 \mu \mathrm{m}$. 
Figura 13 - Padrão de marcação de células IR-Casp3 nas subregiões CA1, CA2-3 e GD do hipocampo de ratos após anóxia neonatal, ao longo das idades.

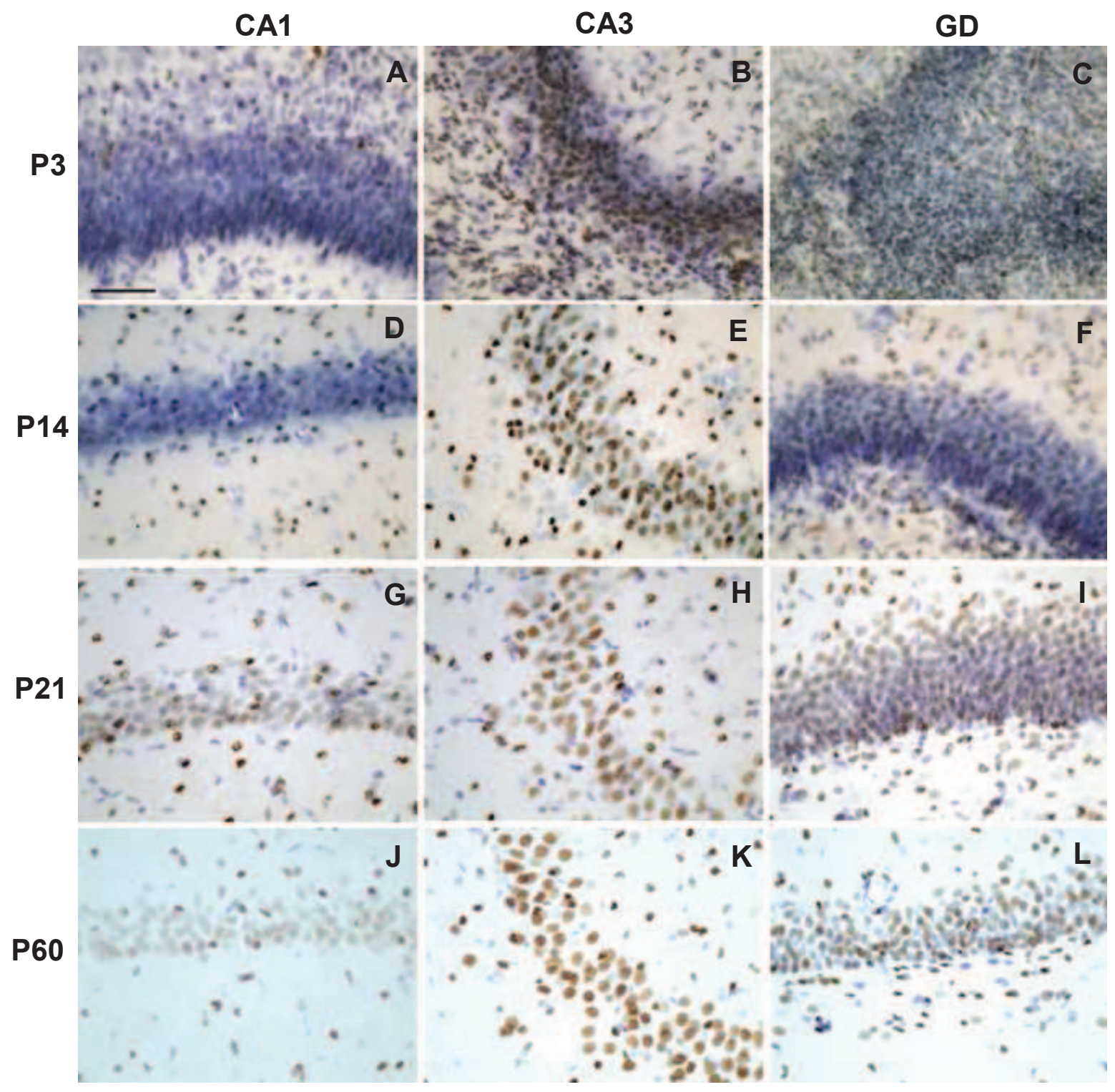

Fotomicrografias em campo claro evidenciando a variação na quantidade de células IRCasp3 ativa na ssubregiões CA1, CA2-3 e GD do hipocampo de ratos após anóxia neonatal ao longo das idades: P3 (A, B e C), P14 (D, E e F), P21 (G, H e I) e P60 (J, K e L). Houve maior quantidade absoluta, mas não relativa, de células IR-Casp3 no grupo anóxia em relação ao controle em $\mathrm{P} 14, \mathrm{p} \leq 0,05$. Nas demais idades, na região $\mathrm{CA} 1$, não houve diferença entre os grupos anóxia e controle. A marcação em marrom corresponde à imunoistoquímica para Caspase-3 ativada, contra-corada com tionina em azul. Escala: $100 \mu \mathrm{m}$. 


\subsubsection{Microscopia eletrônica}

A análise das características morfológicas por microscopia eletrônica foi realizada em colaboração com o Professor Doutor li-Sei Watanabe, do Departamento de Anatomia do Instituto de Ciências Biomédicas da Universidade de São Paulo.

As imagens da região CA1 e GD do hipocampo foram obtidas de amostras com 24 horas após o estímulo anóxico (grupo controle, $\mathrm{n}=2$; grupo anóxia, $\mathrm{n}=2$ ). Estas revelaram que ambos os grupos, controle e anóxia, apresentam grande quantidade de células com características apoptóticas, como condensação e polarização da cromatina, formação de corpos apoptóticos e encolhimento celular (Figuras 14 e 15A).

Neurônios com características de necrose clássica, como inchaço e vacuolização de organelas, perda da integridade da membrana celular e digestão aleatória da cromatina (Northington et al., 2011) foram observados na região CA1 do hipocampo de animais somente do grupo anóxia (Figura 15B).

Foi observada ainda, a presença de um tipo misto de morte neuronal no grupo anóxia, onde são observadas características de apoptose e necrose simultâneas, denominada continuum (Figura 15A). Morfologicamente, o continuum é caracterizado por organização crescente da cromatina em agregados regulares, dissolução parcial da membrana nuclear e preservação da membrana citoplasmática com ou sem inchaço de organelas citoplasmáticas e citoplasma condensado (Northington et al., 2011).

Tipos morfológicos neuronais em acordo com a descrição de necrose programada, a necroptose, foram observados nestas preparações. Segundo Northington e colaboradores (2011), o neurônio em necroptose apresenta dissolução aleatória da cromatina, inchaço e vacuolização de organelas citoplasmáticas incluindo retículo endoplasmático e mitocôndria (Figura 16A).

Ainda nos animais do grupo anóxia, surgiu um tipo morfológico peculiar, em que há encolhimento da célula e condensação da cromatina de forma diferenciada, a qual pode ser característica de excitoxicidade (Figura 16B). Na literatura, a excitotoxicidade é descrita por padrões irregulares de condensação da cromatina como se fosse um mostrador de relógio, com membrana nuclear intacta e com ou 
sem preservação da membrana citoplasmática e suas organelas (Northingtonet al., 2011).

Tanto os animais do grupo controle como os animais do grupo anóxia apresentaram, ainda, outros tipos de células com características morfológicas em comum: presença de vacúolos citoplasmáticos com características prováveis de autofagossomos nos aumentos observados, cromatina nuclear parcialmente condensada e preservação da integridade celular, indicando possível morte por autofagia (Figura 17). 
Figura 14 - Apoptose em micrografias eletrônicas de neurônios do hipocampo de ratos neonatos submetidos à anóxia neonatal 24 horas antes.
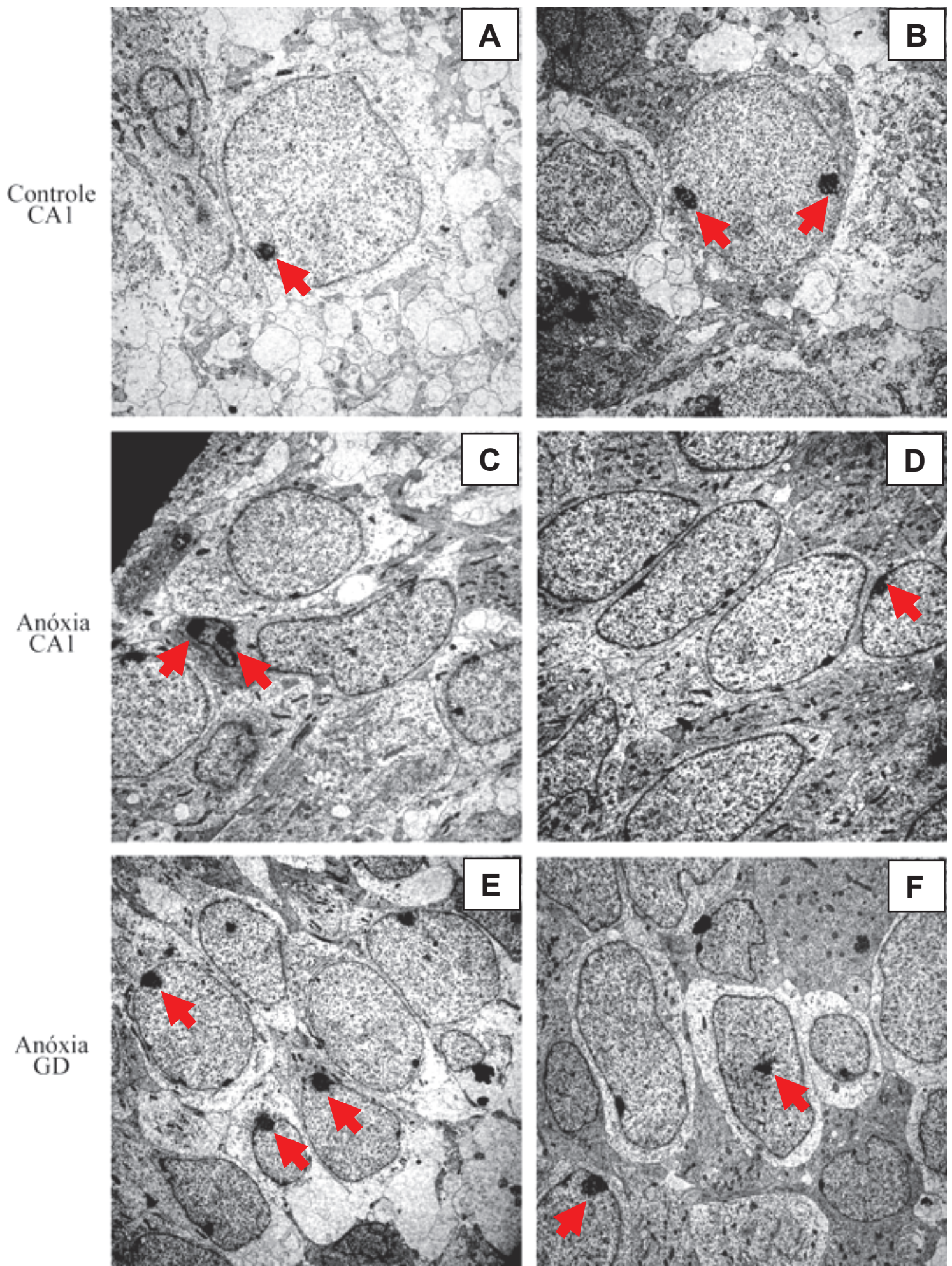

Animais em P3. Neurônios em apoptose, com início de condensação da cromatina indicadas com setas vermelhas. Aumentos: Fig. $A=5.000 X$; Figs. $B, C, D=4.000 X$; Fig. $E=5.000 X$; Fig. $\mathrm{F}=4.000 \mathrm{X}$. 
Figura 15 - Micrografias eletrônicas de neurônios em CA1 do hipocampo de ratos 24 horas após a anóxia neonatal em diferentes processos de morte.
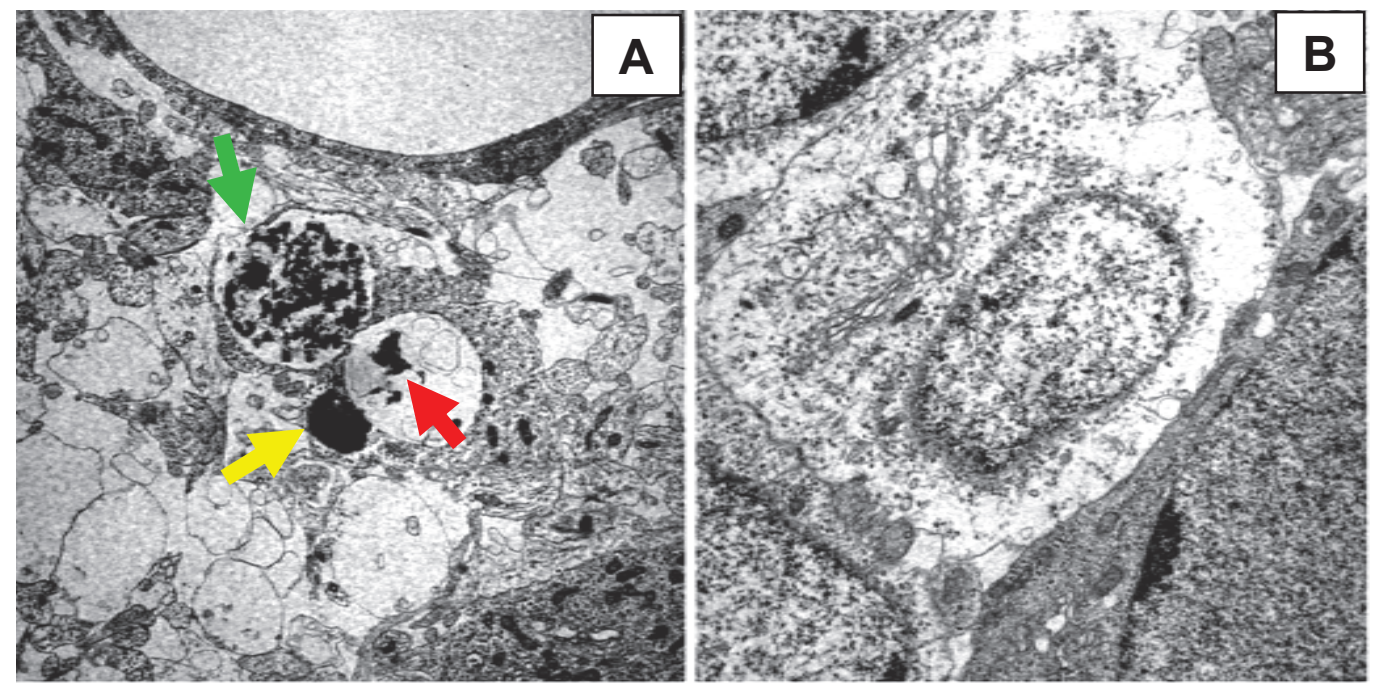

Animais em P3. Micrografias de cortes coronais da região CA1 do hipocampo de rato do grupo anóxia. Na figura A observa-se 3 padrões distintos de condensação da cromatina: intensa, com tamanho celular reduzido (seta amarela), condizente como padrão descrito para o final da apoptose; em processo de condensação, portanto, em outra etapa da apoptose (seta vermelha) e com características morfológicas de continuum: organização crescente da cromatina em agregados regulares, dissolução parcial da membrana nuclear e preservação da membrana citoplasmática e citoplasma condensado (seta verde).Em B: célula com características de necrose, tais como inchaço e vacuolização de organelas, perda da integridade da membrana celular e digestão aleatória da cromatina. Aumentos: Fig. $A=6.000 X$; Fig. $B=10.000 X$. 
Figura 16- Micrografias eletrônicas de neurônios do hipocampo de ratos 24 horas após a anóxia neonatal possivelmente em necroptose e excitotoxicidade.
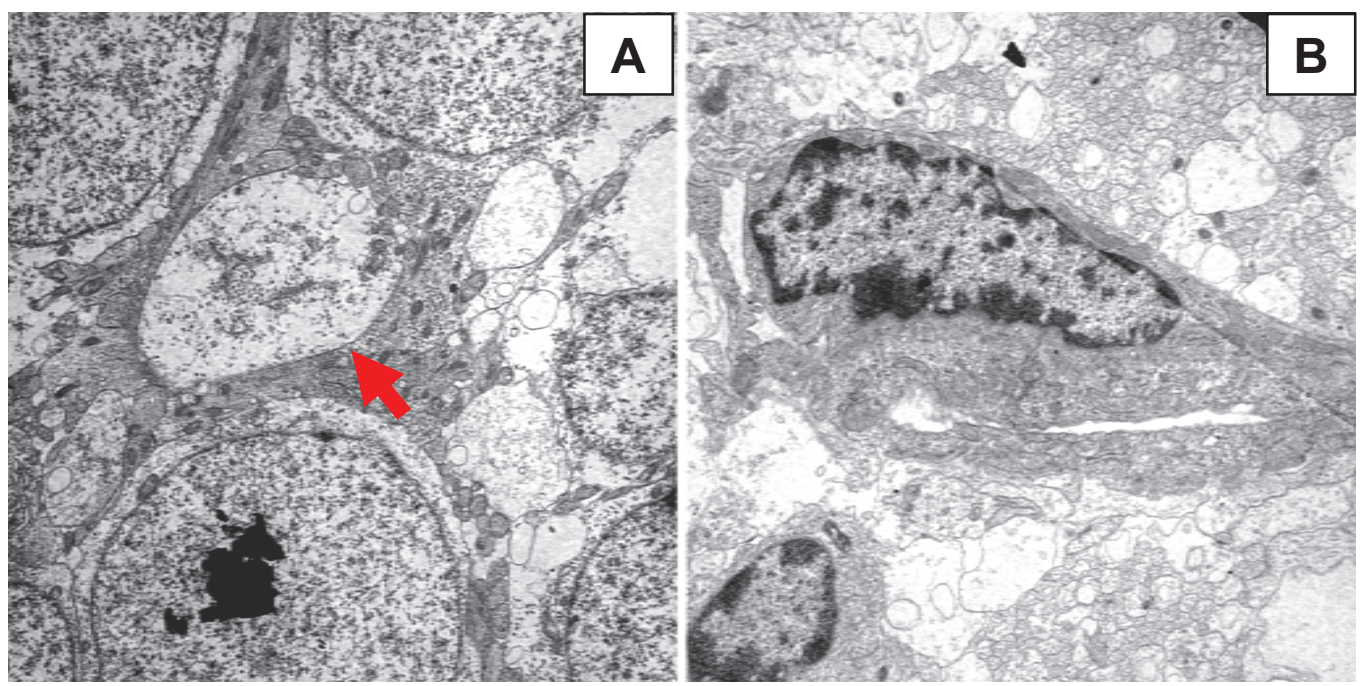

Em A: célula com digestão aleatória quase total da cromatina, intensa vacuolização e condensação citoplasmática (seta vermelha), porém difere da célula em necrose clássica mostrada em 15B e apresenta aparente integridade das membranas nuclear e citoplasmática, indicando possível morte por necroptose. Em B: célula neuronal com características morfológicas de morte por excitotoxicidade: padrões irregulares de condensação da cromatina como se fosse um mostrador de relógio, com membrana nuclear intacta e com ou sem preservação da membrana citoplasmática e suas organelas. Aumentos: Fig. $A=5.000 X$; Fig. $B=7.500 X$. 
Figura 17 - Micrografias eletrônicas de neurônios das subregiões CA1 e GD do hipocampo de ratos neonatos submetidos à anóxia neonatal 24 horas antes em possível autofagia.
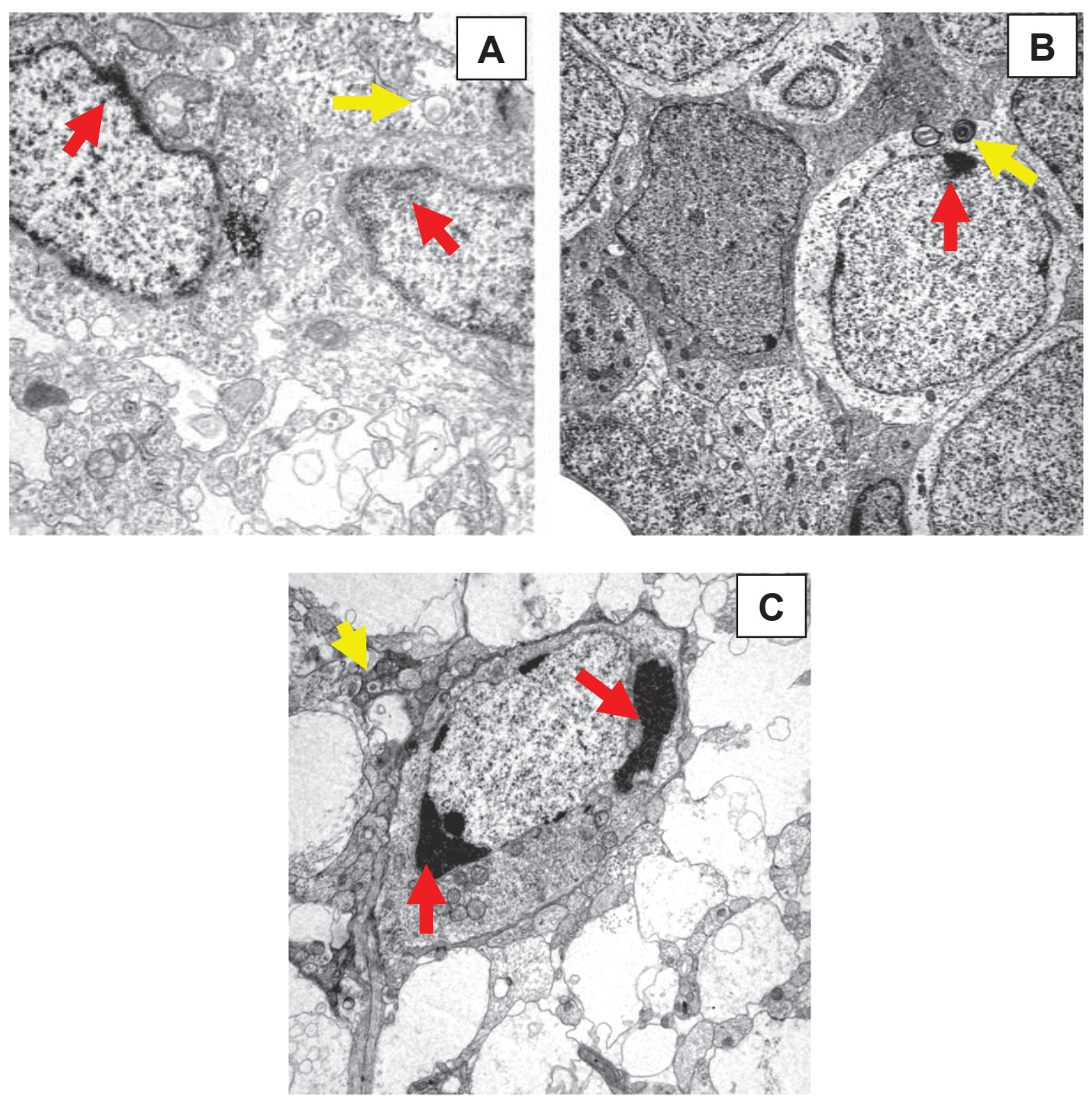

As micrografias mostram cortes coronais das subregiões CA1 (A e C) e GD (B) do hipocampo de rato do grupo anóxia, evidenciando neurônios com características morfológicas em comum, tais como: presença de vacúolos citoplasmáticos (setas amarelas), cromatina nuclear parcialmente condensada (setas vermelhas) e preservação da integridade celular (observar membranas nucleares e citoplasmáticas sem rupturas). Caso estes vacúolos, em maior aumento e melhor resolução, representem autofagossomos, possivelmente a célula estaria em processo de autofagia. Aumento: Fig. $A=5.000 X$; Fig. $B=6.000 X$; Fig. $C=7.500 X$. 


\subsection{Discussão}

Em primeira análise, o estudo da neurodegeneração que ocorre após a privação de oxigênio em modelo animal desenvolvido em nosso laboratório mostrou, 24 horas após o estímulo anóxico, marcação positiva para Fluoro-Jade $B\left({ }^{\circ}(F J B+)\right.$ em CA3 do hipocampo de ratos. A FJB, fluorocromo descrito pela primeira vez em 2000 por Schmuede e Hopkins, é utilizado como marcador de degeneração neuronal, como demonstrado em estudo com ácido caínico no hipocampo de ratos. Segundo o mesmo estudo, a FJB não colocaliza com marcadores gliais como o GFAP, sendo portanto específico para marcação neuronal. O tipo de morte que a FJB marca, porém, é ainda desconhecido.

O hipocampo é reconhecidamente região vulnerável à privação de oxigênio (Johnston et al., 1997; Kirino et al., 2000; Pimentel et al., 2011; Zhao et al., 2013) e seria esperado que maior quantidade de células em morte neuronal ocorresse na região CA1 após a anóxia, por ser descrita, na literatura, como mais susceptível a lesões (Daval et al., 2004; Johansen et al., 1992; Zhao et al., 2013). Corroborando com estes dados, a análise quantitativa da marcação TUNEL+ revelou maior densidade de marcação nesta região nos animais submetidos à anóxia, apesar de diferente resultado ter sido encontrado com a FJB, provavelmente por evidenciarem tipos distintos de morte neuronal.

Os resultados do TUNEL mostraram maior presença de células marcadas 24 horas após a anóxia em CA1 e CA2-3 do hipocampo de ratos do grupo anóxia. Curiosamente, a subregião CA2-3 do hipocampo é descrita por alguns autores como resistente a eventos isquêmicos, como após infarto do miocárdio em humanos (Petitoet al., 1987), ou utilizando modelo de isquemia em outras espécies de roedores (Kirino, 1982). Papadakis e colaboradores, em 2013, analisaram a proteômica das regiões CA1 e CA3 em ratos adultos submetidos à isquemia, para tentar melhor compreender as causas que poderiam levar à maior susceptibilidade de uma região em relação à outra. Eles encontraram uma substância chamada hamartina, produto do gene do complexo 1 da esclerose tuberosa (TSC1), seletivamente induzida pela isquemia em neurônios de CA3, supondo que a hamartina pudesse ter ação neuroprotetora endógena. De fato, seu estudo comprovou o potecial neuroprotetor da hamartina em CA3. Portanto, isso poderia 
explicar o porquê da maior susceptibilidade da subregião CA1, em que há ausência desta substância neuroprotetora, à privação de oxigênio

Neste caso, em particular, é importante lembrar que o TUNEL não marca obrigatoriamente células em apoptose (Galluzzi et al., 2009), inespecificidade esta apresentada também pela FJB. Ambas as histoquímicas podem ter marcado células em processo natural de seu desenvolvimento, em que a apoptose tem grande participação, como também as células necróticas devido ao insulto anóxico neonatal.

Nakajima e cols., em 2000, realizaram estudo sobre a variação temporal e regional do padrão de morte neuronal por apoptose e necrose utilizando modelo de hipóxia-isquemia $(\mathrm{H}-\mathrm{I})$ em ratos de 7 dias. Foi encontrado pico de densidade de células imunorreativas a Caspase-3 no GD e em CA3, de 24 a 72 horas após a H-I, a qual decresce a partir de então. Em CA1, foi encontrado pico de densidade de células imunorreativas a Caspase-3, 6 horas após a $\mathrm{H}-\mathrm{I}$, permanecendo elevada até 7 dias após a mesma, decaindo a partir deste período. Um detalhe bastante importante é que utilizaram anticorpo contra a Caspase-3 não clivada, o que não indica, necessariamente, processo apoptótico. Observaram ainda escassas células necróticas eosinófilas no hipocampo, apesar de outros autores terem observado morte por necrose em outras regiões, como córtex ipsilateral à isquemia e núcleos da base (Northington et al., 2001; Rice et al., 1981; Towfighi et al., 1995).

Com relação aos resultados da análise estereológica da Caspase-3 ativada, apesar de ter sido observado aumento na quantidade absoluta de células IR-Casp3 em CA1 do grupo anóxia em P14, não foram observadas diferenças na densidade (células $/ \mathrm{mm}^{3}$ ) de células IR-Casp3 entre os grupos anóxia e controle nas idades estudadas.

Daval e colaboradores, em 2004, utilizando modelo bastante similar ao do presente estudo, encontraram pico de morte neuronal por apoptose 7 dias após insulto hipóxico em CA1. Talvez, por conta disso, não observamos maior quantidade de células IR-Casp3 nesta região 24 horas após a anóxia.

A primeira hipótese a levantar, portanto, é a de que seria possível observar alguma diferença em CA1 ao analisarmos a idade de P8/9 (7 dias após o insulto anóxico), conforme descrito na literatura (Daval et al., 2004; Larsson et al., 2001; Nakajima et al., 2000).

Uma outra hipótese que poderia explicar os resultados da análise estereológica de Caspase-3 ativada é em relação à técnica utilizada, a 
imunoistoquímica, uma vez que, mesmo tendo realizado a análise estereológica, método comprovadamente confiável para quantificação de células (Larsson et al., 2001), pode não ser sensível para mensurar a quantidade de Caspase-3 ativada nas células, indicando apenas sua presença ou ausência nas mesmas. Apesar disso, alguns estudos (Liu et al., 2004; Papadaki et al., 2013) observaram em modelos de $\mathrm{H}$-I ou isquemia, por técnicas de imunofluorescência, aumento das células IR-Casp3 em ratos submetidos ao insulto, bem como por outras técnicas, como o Western Blotting.

Ao mesmo tempo, o resultado obtido em CA1 e CA3 não foi o mesmo que com a FJB e TUNEL, provavelmente porque são técnicas distintas que podem indicar diferentes tipos de morte celular, em diferentes estágios.

Vários estudos mostraram que o modelo de H-I provoca ativação da Caspase3 (Blomgren et al., 2001;Delivoria-Papadopoulos et al., 2008; Gill et al., 2002; Northington et al., 2011; Pulera et al., 1998; Wang et al., 2001), seja por via intrínseca ou mitocondrial, mediada pela Caspase- 9 , ou extrínseca, mediada pela Caspase-8; em nosso modelo de anóxia, seria bastante interessante estudar, concomitante à Caspase-3 ativada, as Caspases iniciadoras -8 e -9.

As variações na densidade de células IR-Casp3 de acordo com a idade já eram esperadas, diminuindo nas 3 regiões progressivamente, de acordo com o que é descrito em literatura (Hu et al., 2000; Liu et al., 2004; Liu et al., 2008).

Liu e colaboradores, em 2008, estudaram as diferentes expressões de Caspase-3 em subregiões hipocampais de ratos durante o desenvolvimento pósnatal. As células IR-Casp3 ativadas foram quantificadas através da intensidade de fluorescência dividido por 1000 células.

Como resultados, encontraram que o pico de expressão de Caspase-3 ativada ocorreu em P7 em CA1, em P2 em CA3 e então decaiu com a idade. Particularmente em GD, a expressão de Caspase-3 ativada aumentou discretamente após P7, permanecendo em níveis elevados até a vida adulta. Em suma, puderam concluir que há padrões específicos espaço-temporais para a expressão de Caspase-3 ativada nas subregiões hipocampais durante o desenvolvimento pósnatal do rato, sugerindo que as células progenitoras neuronais de GD e os neurônios pós-mitóticos da CA1 e CA3 podem desempenhar diferentes papéis e mecanismos durante o desenvolvimento pós-natal. 
Diferentemente dos achados de Liu e colaboradores (2008), estes resultados indicaram decréscimo na densidade de células IR-Casp3 em GD de P3 para P14, mantendo-se estável em P21 e decaindo novamente em P60.Diferenças estas que poderiam decorrer: primeiro, pelo tipo de metodologia empregada para a análise quantitativa, sendo a intensidade de fluorescência, utilizada pelos referidos autores, menos acurada que a análise estereológica; em segundo lugar, não foi descrito no artigo como foi realizada a delimitação das subregiões para a quantificação. Talvez pelo fato de ter sido incluída a subregião CA4 em nossa análise do GD que a densidade de células IR-Casp3 possa ter sido diferente.

Em relação à quantidade absoluta das células IR-Casp3, que aumentou conforme a idade nas 3 regiões estudadas, pode ser sugerido que a caspase-3, mesmo ativada, possa exercer outras funções e não, obrigatoriamente, resultar em apoptose, como a sobrevivência, proliferação, diferenciação e na inflamação celulares (Lamkanfi et al., 2007).

A caspase-3, em especial, pode exercer funções como a inibição da proliferação de células B (Woo et al., 2003), inibição da expressão de MHCIl e maturação dendrítica celular (Santambrogio et al., 2005), proliferação de células prosencefálicas e queratinócitos (Okuyama et al., 2004; Yan et al., 2001), além de ter papel na diferenciação de algumas células, como eritroblastos, plaquetas, mioblastos, osteoblastos e células tronco neurais (De Botton et al., 2002; Fernando et al., 2002; Fernando et al., 2005; Zermatti et al., 2001).

Vale ressaltar que a apoptose é apenas uma das formas de morte celular programada (PCD, em inglês - Programmed Cell Death); há formas independentes de caspases, como aquela mediada pela AIF (Apoptosis Inducible Factor), liberada pela mitocôndria após permeabilização de sua membrana externa, e pelo recrutamento de nucleases como a ciclofilina $A$, ocasionando a fragmentação do DNA. Esta é a chamada Apoptosis-like PCD, caracterizada morfologicamente por condensação parcial e periférica da cromatina (Kranticbet al., 2005; Northington et al., 2011).

Além desta forma de PCD, há outro tipo, também independente de caspase, denominado Necrosis-like PCD, que pode ocorrer por morte autofágica ou por paraptose. Interessante é que, neste tipo, não há condensação primária da cromatina (Krantic et al., 2005). 
Resultados instigantes foram obtidos com a análise por microscopia eletrônica de transmissão. Segundo Liu e colaboradores (2004), o estudo morfológico da morte neuronal durante o desenvolvimento pode apresentar 3 tipos distintos: apoptótico, autofágico e vesiculado não lisossomal, que seriam, portanto, os 3 tipos de PCD descritos.

Características típicas de apoptose foram encontradas em ambos os grupos estudados, anóxia e controle, como já era esperado, assim como características clássicas de necrose foram encontradas em células de CA1 dos animais do grupo anóxia e não foram visualizadas no grupo controle, dado este bastante interessante e que pode corroborarcom os achados da FJB e até mesmo do TUNEL.

A necrose é o principal fenótipo de morte celular neuronal encontrado após lesão por H-I em ratos (Carloni et al., 2007; Towfighi et al., 1995). Na análise por microscopia eletrônica deste estudo, células com características de necrose foram achados frequentes em ratos do grupo anóxia, sugerindo que o modelo utilizado de anóxia neonatal tende a apresentar características em comum em relação ao tipo de morte provocado nos modelos de $\mathrm{H}-\mathrm{I}$.

Quanto às características de autofagia, foram observados vacúolos provavelmente autolisossômicos e autofagossômicos em ambos os grupos, controle e anóxia, com aspecto do núcleo que se assemelha à descrição da literatura sobre as características da célula autofágica, como a cromatina nuclear parcialmente condensada e preservação da integridade celular (Northington et al., 2011).

A autofagia é um importante mecanismo no controle do crescimento normal e durante a falta de nutrientes, além de representar uma estratégia adaptativa para as células sobreviverem a estresse bioenergético (Carloni et al., 2008). Autores têm descrito a ativação da autofagia em neurônios expostos à hipóxia (Zhu et al., 2005), isquemia focal (Rami et al., 2008) e estímulos excitotóxicos (Wang et al., 2008), sendo que, em modelos de $\mathrm{H}-\mathrm{I}$, alguns sugerem o papel neuroprotetor da autofagia na fase aguda (Carloni et al., 2008; Uchiyama et al., 2008).

A microscopia eletrônica é considerada o método de ouro para detecção da autofagia (Mizushima et al, 2004), porém é necessária extrema cautela em afirmar se o que está sendo visualizado realmente é caracteristica morfológica da autofagia. Além disso, a quantificação por microscopia eletrônica é dificultada uma vez que grande aumentos são utilizados.Portanto, no presente estudo, seria interessante utilizar marcadores, como o GFP-LC3 (Kroemer et al., 2009) para detecção e 
quantificação das células em autofagia visando a comparação entre os dois grupos, anóxia e controle.

Um outro tipo de morte neuronal bastante encontrado em modelos de $\mathrm{H}-\mathrm{I}$ com roedores é o continuum (Blomgren et al., 2007; Carloni et al., 2007; Northington et al., 2007), que mescla características de apoptose com necrose, descrito primeiramente por Portera-Caillau e colaboradores em 1997.

A análise por microscopia eletrônica de transmissão mostrou células com estas características, no hipocampo de animais que sofreram anóxia, sugerindo que, da mesma forma que descrito em modelos de $\mathrm{H}-\mathrm{I}$ em roedores, o modelo de anóxia utilizado também pode ocasionar morte neuronal por continuum.

Há alguns anos, a existência ou não de tipos de morte neuronal intermediários exibindo características de necrose e apoptose simultâneas era controverso (Roy, Sapolsky, 1999). Porém, com os avanços nas técnicas utilizadas para o estudo de morte e a possibilidade da análise detalhada das diferentes cascatas que levam a diferentes tipo de morte, não somente a existência deste tipo intermediário de morte neuronal, como outros tipos, puderam ser sugeridos. Atualmente, do ponto de vista morfológico, sabe-se da existência da apoptose e da necrose clássicas e das formas híbridas, em que se enquadram o continuum, a excitotoxicidade, a necroptose e a autofagia (Northington et al., 2011).

A excitotoxicidade, mediada pela ativação excessiva de canais de receptores glutamatérgicas iônicos e canais iônicos voltagem-dependentes, provavelmente é induzida pela privação de oxigênio. O cálcio livre no citoplasma em quantidade aumentada causa a ativação de cascatas sinalizadoras letais (Northington et al., 2011; Orrenius et al., 2003). Devido às suas características que facilmente se sobrepõem a outros tipos de morte, como necrose e apoptose, dependendo da intensidade do estímulo, não pode ser classificada separadamente como um tipo de morte (Kroemer et al., 2009).

Nesta análise por microscopia eletrônica, foram encontrados alguns tipos celulares com fenótipo similar ao descrito por Northington e colaboradores (2011) como pertencentes ao processo de excitotoxicidade, somente nos animais submetidos à anóxia neonatal: inchaço somato-dendrítico, lesão mitocondrial e condensação da cromatina em agrupamentos irregulares. 
Foram observadas ainda células neuronais com características morfológicas não descritas em literatura e que parecem mesclar, assim como no continuum, os fenótipos de necrose com apoptose, apenas no grupo anóxia.

Interessantemente, grande parte dos estudos citados em microscopia eletrônica utilizaram o modelo de $\mathrm{H}-\mathrm{I}$ com ratos de 7 dias, quando ocorre, segundo Liu e colaboradores (2008), o pico natural de Caspase-3 ativada, e foram encontradas células apoptóticas em abundância; neste estudo, o insulto anóxico ocorreu quando o animal tinha aproximadamente 30 horas de vida, ou seja, em P1P2, sendo perfundido e processado para análise 24 horas depois, em P2-P3. Os estudos em que nos baseamos para a escolha deste período de 24 horas após a privação de oxigênio (Blomgren et al., 2001; Carloni et al., 2007), como sendo o pico da apoptose, utilizaram modelos de $\mathrm{H}$-I em ratos de 7 dias de vida. Desta forma, poderia ser sugerido que tais estudos pudessem ter tido como resultado uma maior expressão de caspase-3 ativada em ratos de 8 dias (24 horas após o estímulo) justamente por ser este período o período de máxima perda celular por apoptose. Isso poderia explicar porque seria bastante interessante escolher outras idades, em nosso modelo de anóxia, para o estudo da morte neuronal, seja por apoptose como outros tipos de morte. Mesmo Daval e colaboradores (2004), em modelo de hipóxia, encontraram pico de ativação de caspase-3 em CA1 em ratos de 7 dias, 6 após o insulto hipóxico.

Além disso, devido às diferenças de maturação e mesmo das características morfológicas celulares de ratos neonatos de diferentes idades, alguns fenótipos celulares encontrados em nossos animais do grupo anóxia na microscopia eletrônica não puderam ser encontrados na literatura, baseada totalmente em modelos de $\mathrm{H}-\mathrm{I}$ em ratos de 7 dias.

Enfim, com base nos instigantes resultados obtidos com as diferentes técnicas para o estudo de morte neuronal, foi possível encontrar dados que podem nortear estratégias de investigação para posterior aplicação terapêutica de agentes neuroprotetores, como $o$ estudo de receptores e potenciais inibidores glutamatégicos, a investigação da necroptose com posterior utilização da necrostatina, dentre outros. 
4 CAPÍTULO 2: ESTUDO DA DINÂMICA ESTRUTURAL DO HIPOCAMPO QUANTO AO VOLUME, PROLIFERAÇÃO E DIFERENCIAÇÃO NEURAIS NO GIRO DENTEADO DE RATOS APÓS ANÓXIA NEONATAL 


\subsection{Introdução}

Neste capítulo serão abordados os efeitos da anóxia neonatal na proliferação neural na zona subgranular do giro denteado e na neurogênese nesta região, além de possíveis alterações na volumetria do hipocampo.

\subsubsection{Proliferação}

A neurogênese é determinada pela proliferação celular e o processo central da proliferação é o ciclo celular, que é iniciado quando uma nova célula é formada a partir de divisão mitótica. Inicialmente, se na fase $\mathrm{G} 1$ a célula diplóide $(2 \mathrm{~N})$ entra na fase $\mathrm{S}$ de síntese de DNA e torna-se tetraploide $(4 \mathrm{~N})$, após curta pausa, denominada fase G2, essa célula entra em mitose (fase $M$ ) produzindo duas novas células diplóides (2N) (Nowakovski, Hayes, 2008).

Os processos de entrada e saída do ciclo celular e a extensão do ciclo celular estão correlacionadas e atuam em conjunto para produzir células neurais complementares em qualquer região do SNC. Existe grande variação do tempo para a célula completar seu ciclo, de acordo com o tecido e a idade do animal; ainda, o tempo que a célula permanece em cada fase do ciclo celular também é variável. No encéfalo em desenvolvimento, a capacidade de gerar novas células varia também de acordo com a região e o tipo celular, sendo que os processos proliferativos de humanos e roedores ocorrem paralelamente (Bayer et al., 1993; Nowakovski e Hayes, 2008; Semple et al., 2013;).

Durante o período embrionário, as células neurais se formam a partir de uma matriz germinativa proliferativa denominada neuroepitélio, localizada na parede do tubo neural (Bayer, 1989, Paxinos, 2004). Em humanos, as células neurais originamse da zona periventricular localizada próximo ao lúmen dos ventrículos cerebrais, de onde migram para outras regiões (Zecevicet al., 2005). Aproximadamente na sétima semana após a concepção, é formada a zona subventricular (ZSV) a partir de células em proliferação (Zecevicet al., 2005). Durante o terceiro trimestre, a ZSV, frequentemente considerada como matriz germinativa, contém células-tronco neurais e células progenitoras; a proliferação a partir da ZSV resulta no desenvolvimento do córtex cerebral, que ocorre na segunda metade da gestação em primatas (Romanko et al., 2004). 
As células que deixam o neuroepitélio podem se tornar pós-mitóticas e se diferenciarem em neurônios, assim como podem se tornar células gliais ou precursoras gliais, ou ainda podem reter sua capacidade proliferativa e formar a matriz germinativa secundária. A matriz germinativa forma três fluxos migratórios no telencéfalo do embrião: nas direções lateral, rostral e do denteado. No hipocampo em desenvolvimento, a corrente migratória para o denteado (Altman, Bayer, 1990) contém os progenitores das células granulares do giro denteado.

Em humanos, a neurogênese cortical ocorre predominantemente durante a gestação mas continua após os 2 anos e meio de idade (Herschkowitz et al., 1997; Prins, Hovda, 2003). A migração neuronal tem início algumas semanas após a concepção e está quase completa ao nascimento. Após o nascimento, a sinaptogênese, a mielinização e o refinamento das sinapses aquisições evidentes do sistema nervoso (Barret et al., 2007; Semple et al., 2013; Stahl, 2002).

No rato, modelo animal escolhido para este estudo, áreas específicas começam a se formar com a neurogênese e migração de células no prosencéfalo, mesencéfalo e rombencéfalo na segunda semana de gestação, aproximadamente no nono dia da gestação. O desenvolvimento regional, no geral, é bastante similar ao dos humanos, seguindo a mesma sequência de desenvolvimento e maturação (Rice, Barone Jr., 2000).

\subsubsection{Ontogênese e neurogênese hipocampal pós-natal}

Durante o desenvolvimento, a neurogênese é um processo que compreende várias etapas: proliferação celular, saída do ciclo celular, sobrevivência ou morte, migração celular, diferenciação celular e decisões a respeito do destino celular, ou seja, que fenótipo assumirá a nova célula: glia ou qual o tipo de neurônio irá se tornar (Nowakowski, Hayes, 2008).

As primeiras células neuronais a se formar no hipocampo são as células piramidais de CA3, seguida pelas células piramidais de CA1 e então de CA4 (no hilo). Já as células granulares do giro denteado se formam tardiamente, sendo que aproximadamente $85 \%$ destes neurônios são gerados no período pós-natal e estão maduros somente no desmame (21 dias). Além disso, a camada subgranular do giro denteado é um conhecido nicho neurogênico em ratos jovens e adultos (Paxinos, 2004). 
Podemos dividir a formação da camada granular do GD em dois estágios distintos: no primeiro estágio, células progenitoras se proliferam na zona periventricular da parte medial do córtex cerebral embrionário e então essas progenitoras neurais e neuroblastos migram para a região do GD durante os períodos perinatais (Altman, Bayer, 1990b; Nakahira, Yuasa, 2005). Em ratos, as células migratórias formam a concha externa da camada de células granulares (CG) em P5, assim como a zona proliferativa do hilo. No segundo estágio, as células recém geradas no hilo e zona subgranular (ZSG) formam a concha interna da CG (Altman, Bayer, 1990a).

Namba e colaboradores, em 2005, mostraram que, no período pós-natal de ratos, o hilo é temporariamente preenchido com células proliferativas que expressam marcadores astrocitários e da glia radial e neurônios imaturos, sugerindo que uma população substancial destas células proliferativas geram precursores celulares neuronais proliferativos e neurônios imaturos no hilo, que então migram para a camada granular e se diferenciam em células granulares.

O estudo da neurogênese pós-natal, estado de transição entre a neurogênese embrionária e a adulta é de grande importância, pois propicia informações importantes sobre a continuidade deste evento até o estágio adulto, quando passa a ser restrita a algumas regiões encefálicas apenas (Namba et al., 2005). Há pouquíssimos relatos sobre a neurogênese pós-natal, especialmente do giro denteado hipocampal, subregião em que células neuronais continuam a ser geradas desde a fase embrionária até a vida adulta.

Estudar a proliferação celular neural que ocorre no período pós-natal no hipocampo, mais especificamente na subregião do giro denteado e compreender como esta proliferação é alterada com a idade e sob influência ou não da anóxia neonatal constitui objeto relevante para melhor compreender os mecanismos iniciais do ciclo celular e a diferenciação neural que ocorrerá na fase adulta, assim como obter subsídios que possam orientar ações preventivas ou minimizadoras de danos neurais a esta região tão suscetível à privação de oxigênio nos períodos críticos do desenvolvimento. 


\subsubsection{Neurogênese hipocampal adulta}

Assim como na neurogênese pós-natal, durante a neurogênese adulta também ocorrem vários processos, emboracom menor intensidade proliferação e diferenciação neuronal (Nowarovski, Hayes, 2008).

Durante muitos anos, a neurogênese no sistema nervoso de mamíferos foi vista como fenômeno restrito ao início do desenvolvimento encefálico (Bear et al., 2002; Christie, Cameron, 2006). Entretanto, novas evidências mostraram que este processo persiste em algumas regiões específicas do encéfalo adulto de aves e mamíferos, incluindo o homem (Eriksson et al., 1998; Garcia-Verdugo et al., 2002; Gould et al., 1999; Lledo et al., 2006; Spalding et al., 2013; Van Der Kooy, Weiss, 2000).

Este processo resulta do balanço entre proliferação, morte e diferenciação de precursores comprometidos com o fenótipo neuronal e/ou da morte ou sobrevivência de neurônios já estabelecidos na circuitaria cerebral (Ramirez-Amaya et al., 2006). Há evidências de que, no encéfalo adulto, a neurogênese continua em duas regiões: a zona subventricular, que delineia os ventrículos laterais e forma conexões com novos interneurônios que alcançam o bulbo olfatório, e a camada subgranular do giro denteado, que origina novas células granulares (Taupin, Gage, 2002).

Estudos demonstraram que a neurogênese hipocampal é modulada tanto por estímulos fisiológicos (Kempermann et al., 1997; Gould et al., 1999) e condições patofisiológicas (Parent, 2002; Kokaia, Lindvall, 2003).

No encéfalo maduro normal, vários fatores podem alterar a neurogênese hipocampal, tais como exercícios físicos (van Praaget al., 1999), ambiente enriquecido (Kempermann et al., 1997), envelhecimento (Kuhn et al., 1996), esteroides (Cameron, Gould, 1994) e neurotransmissores (Berg et al., 2013).

Animais sob privação de oxigênio por hipóxia-isquemia no período neonatal apresentaram alterações no padrão de neurogênese, tanto no período de desenvolvimento encefálico quanto no encéfalo maduro (Barret et al., 2007; Blaise et al., 2009; Daval et al., 2004; Jin et al., 2001; Kokaia, Lindvall, 2003; Ong et al., 2005).

Fagel e colaboradores (2006), utilizando modelo de hipóxia perinatal crônica, observaram aumento da neurogênese cortical em camundongos. Em 2008, Kadam e 
colaboradores estudaram os efeitos da isquemia neonatal, também em camundongos, avaliando proliferação, migração e diferenciação neurais; eles encontraram alterações a longo prazo nestes eventos. Aumento na proliferação neural em regiões específicas do encéfalo de camundongos após hipóxia-isquemia foi encontrado também por Zhu e colaboradores (2009).

No entanto, não são conhecidos os mecanismos que causam alterações na proliferação após privação de oxigênio e é importante ressaltar que não há relatos em literatura dos efeitos da anóxia neonatal na proliferação e neurogênese utilizando o presente modelo de insulto anóxico em ratos neonatos.

Desta forma, somando-se ao fato de que alterações de memória espacial e aprendizagem já foram observados em ratos adultos submetidos à anóxia neonatal em trabalhos prévios em nosso laboratório (Ito, 2010), acreditamos que a investigação da neurogênese hipocampal deve adicionar dados importantes para melhor compreensão dos efeitos da privação de oxigênio neonatal a médio e longo prazo.

\subsubsection{Objetivos}

I - Estudar longitudinalmente os efeitos da anóxia neonatal na dinâmica de proliferação celular da zona subgranular do giro denteado do hipocampo dos ratos (P3, P14, P21 e P60) com técnica de imunoistoquímica para Ki-67;

II - Analisar, por dupla imunofluorescência, possíveis alterações na quantidade de células neuronais marcadas com BrdU na zona subgranular nos animais adultos (P60) que sofreram anóxia neonatal;

III - Verificar, por análise estereológica, se a anóxia neonatal causa alterações no volume hipocampal dos ratos ao longo das idades estudadas (P3, P14, P21 e P60) 


\subsection{Material e método}

Para análise da proliferação celular neural, foi analisada uma proteína endógena que somente é expressa em células mitóticas em atividade (Ki-67). Para a análise da diferenciação neuronal e neurogênese, foram utilizados animais tratados com marcador de células na fase $S$ da mitose, a 5-bromo-2'-deoxiuridina (BrdU) e o anticorpo contra NeuN em dupla imunofluorescência. Os animais receberam injeção única por via intraperitonial de BrdU (200 mg/kg, Christie, Cameron, 2006) 28 dias antes da perfusão transcardíaca para estudo do fenótipo neural. O BrdU (SigmaAldrich Company, St. Louis, MO) foi dissolvido em salina estéril (contendo $0.007 \mathrm{~N}$ $\mathrm{NaOH}$ ) e aplicado um volume de $10 \mathrm{ml} / \mathrm{kg}$ do peso corporal.

A sequência de experimentos está esquematizada na Figura 18.

Figura 18 - Estudo longitudinal dos efeitos da anóxia neonatal na proliferação neural, neurogênese e morte neuronal no hipocampo de ratos.

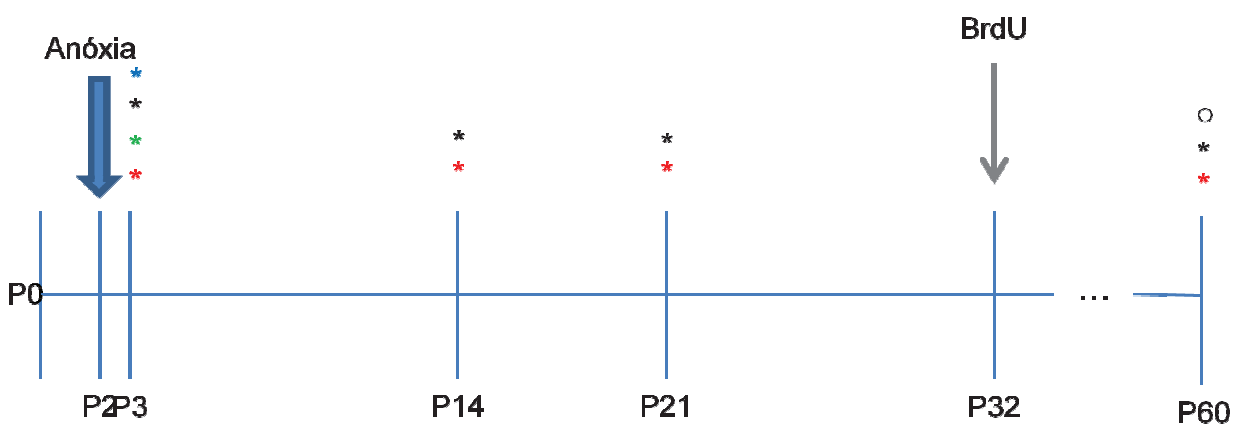

\footnotetext{
${ }^{*} \mathrm{FJB}$

* Ki-67

* Caspase 3 ativada

* Microscopia Eletrônica de Transmissão

$\circ \mathrm{BrdU}+\mathrm{NeuN}$
}

Desenho esquemático representando os procedimentos experimentais nas diferentes idades estudadas, sendo P0 correspondente ao dia do nascimento, P2 ao dia do insulto anóxico, P32 idade em que há injeção de BrdU e P3, P14, P21 e P60 correspondem às idades em que foram realizadas as análises histológicas. 
4.2.1 Imunoistoquímica para detecção de células imunorreativas a Ki-67 (IR-Ki67)

Os animais com 6 a $8 \mathrm{~g}$ foram submetidos à anóxia neonatal conforme descrito na primeira parte deste trabalho (MATERIAS E MÉTODOS GERAIS), perfundidos nas idades de 3, 14, 21 e 60 dias e seus encéfalos foram processados para estudo histológico.

Para a detecção de células neurais IR-Ki67, as secções de 30 (em P3) ou 40 $\mu \mathrm{m}$ (em P14, P21 e P60) montadas em lâminas eletrostáticas foram fervidas em ácido cítrico $0,01 \mathrm{M}$ por 7 minutos ( $\mathrm{pH}=6$ ), lavadas em PBS 0,1 M (5 lavagens de 6 minutos cada) e incubadas com anticorpo monoclonal feito em camundongo contra Ki-67, concentração de 1:200 (para P21 e P60) ou 1:300 (para P3 e P14) (Vector Laboratories, Burlingame, CA, EUA), por $48 \mathrm{~h}$ a $4^{\circ} \mathrm{C}$. Seguinte à incubação com o anticorpo primário, as secções foram lavadas em PBS $0,1 \mathrm{M}$ (5 lavagens de 6 minutos cada) e incubadas com o biotinilado IgG feito em cavalo contra camundongo durante 90 minutos a temperatura ambiente, lavadas novamente em PBS 0,1M (5 lavagens de 6 minutos cada) e então incubadas no complexo avidina-biotina (Vector Laboratories, Burlingame, CA, EUA) por mais 90minutos, para então serem reagidas com solução contendo 3,3'-diaminobenzidina (DAB) como cromógeno para visualização das células marcadas. Após lavagens em PBS 0,1M (3 lavagens de 10 minutos cada), as lâminas contendo os cortes foram deixadas para secar overnight. No dia seguinte, as secções foram então contrastadas com tionina, desidratadas, diafanizadas e cobertas com DPX (distrene, plasticiser e xilene).

\subsubsection{BrdU e NeuN: dupla imunofluorescência para avaliação da co-localização}

Inicialmente, para a detecção de células imunorreativas a BrdU (IR-BrdU), as lâminas contendo os cortesde animais P60 foram fervidas em ácido cítrico $0,01 \mathrm{M}$ $(\mathrm{pH}=6)$ por 7 minutos, esfriaram em temperatura ambiente por 20 minutos e foram lavadas em PBS 0,1 M (5 lavagens de 6 minutos cada), desnaturadas por 30 minutos com ácido clorídrico $2,4 \mathrm{~N}$ em estufa a $37^{\circ} \mathrm{C}$, lavadas novamente com PBS 0,1 M (5 lavagens de 6 minutos cada) e incubadas com anticorpo monoclonal feito em camundongo contra BrdU (Vector Laboratories, Burlingame, CA, EUA), na concentração de 1:100, por $48 \mathrm{~h}$ a $4^{\circ} \mathrm{C}$. Em sequência, as lâminas foram lavadas em 
PBS 0,1M (5 lavagens de 6 minutos cada) e incubadas em solução contendo o anticorpo secundário conjugado ao fluoróforo Cy3 (Jackson Immuno Research Laboratories Inc., West Grove, PA, EUA), sendo utilizada a concentração de 1:1000, por 3 horas em temperatura ambiente. Após este período, as lâminas foram lavadas em PBS 0,1 M (5 lavagens de 6 minutos cada ) e, para a marcação de neurônios maduros, foi usado NeuN feito em camundongo acoplado ao fluoróforo AlexaFluor 488 (Millipore Corporate Headquarters, Billerica, MA, EUA) na concentração de 1:100 e tempo de incubação de 24 horas em temperatura ambiente. As lâminas foram então lavadas em PBS 0,1 M (5 lavagens de 6 minutos cada) e deixadas para secar por duas horas, sendo então cobertas com lamínulas utilizando glicerol 50\% como meio de montagem.

\subsubsection{Técnicas de análise dos resultados}

\subsubsection{Proliferação celular na ZSG}

A análise histológica da proliferação neural (IR-Ki67) foi realizada em microscopia de campo claro (E-1000, Nikon Corporation). As células localizadas até o limite de dois corpos celulares a partir da camada granular em direção ao hilo foram consideradas pertencentes à zona subgranular; células localizadas mais distalmente foram consideradas parte do hilo (Figura 19).

\subsubsection{Diferenciação neuronal}

As análises do fenótipo neural foram realizadas em microscopia de fluorescência (E-1000, Nikon Corporation, Japão), sendo contabilizadas as células duplamente marcadas para BrdU e NeuN localizadas na camada granular do giro denteado do hipocampo, bilateralmente (Figura 20). A co-localização celular foi confirmada com utilização de microscopia confocal de varredura a Laser (LSM 510, Zeiss, Alemanha) (Figura 21). 
Figura 19 - Proliferação celular no giro denteado de rato adulto (IR-Ki-67).

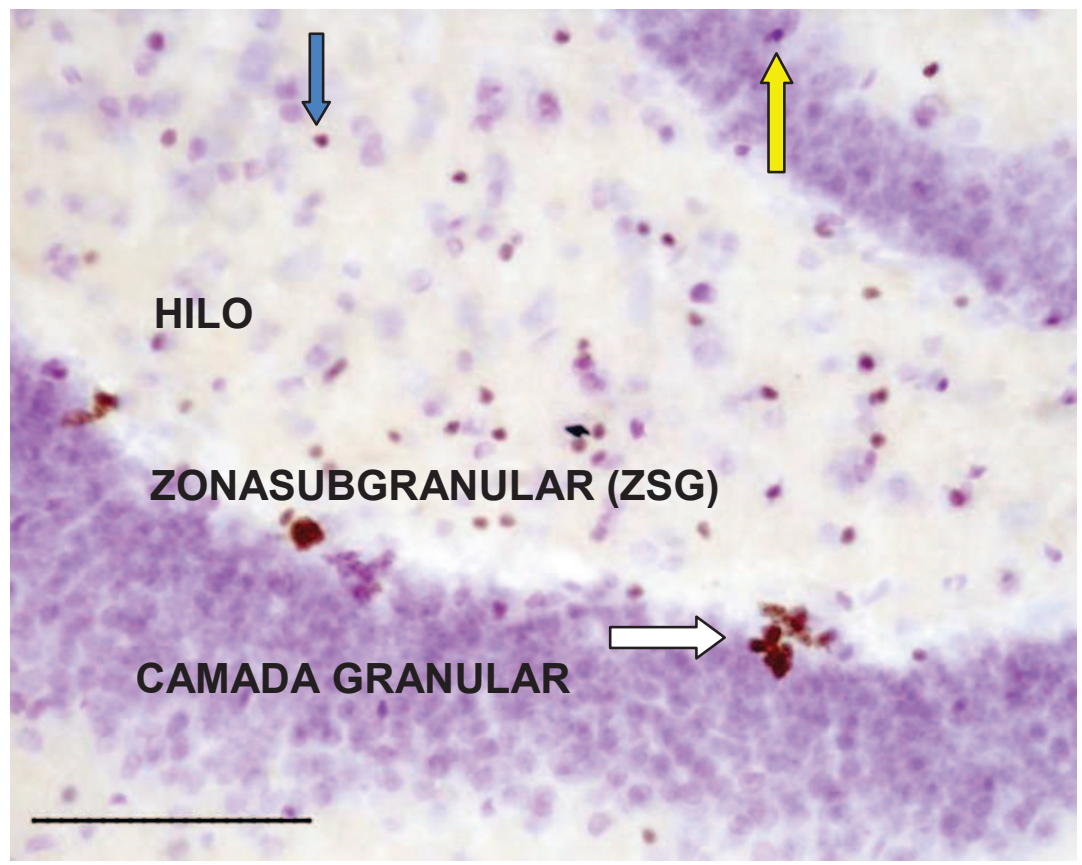

Fotomicrografia do giro denteado do hipocampo em campo claro, corte coronal. Rato do grupo P60 reagido para Ki-67, contrastado pela coloração de Nissl. Seta branca: agrupamento celular ("cluster") imunorreativo a Ki-67 considerado pertencente à Zona Subgranular; seta azul: célula imunorreativa a Ki-67 pertencente ao hilo; seta amarela: célula imunorreativa a Ki-67 pertencente à camada granular do giro denteado do hipocampo. Escala: $200 \mu \mathrm{m}$. 


\subsubsection{Volume hipocampal}

O volume do hipocampo ao longo das idades (P3, P14, P21 e P60) foi mensurado por estereologia com a técnica de análise do fracionador óptico, conforme descrito no CAPÍTULO 1.

\subsubsection{Análise estatística}

A análise estatística empregada para a quantificação decélulas IR-Ki67 e para o estudo do volume hipocampal foi o Two-Way ANOVA; para o estudo da diferenciação neuronal, foi utilizado o teste $\mathrm{T}$ de Student, sendo considerado como significante o $p \leq 0,05$.

Figura 20 -Dupla marcação BrdU-NeuN no hipocampo de ratos de 60 dias.
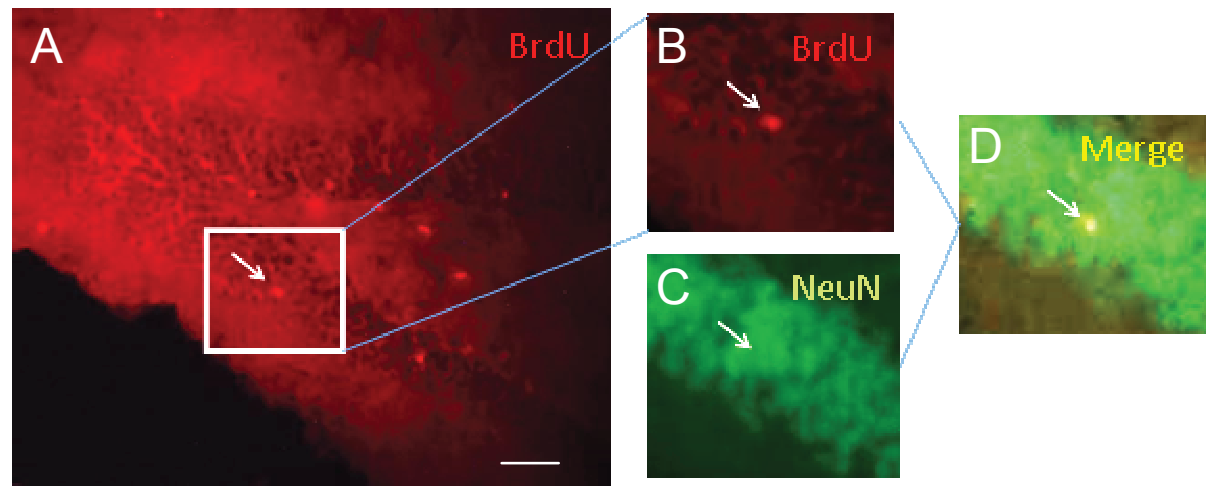

Fotomicrografias do giro denteado do hipocampo em microscopia de fluorescência, corte coronal. Rato do grupo P60 reagido para BrdU e NeuN para análise do fenótipo neuronal. $\mathrm{O}$ esquema representa, em $\mathrm{A}$, a célula marcada positivamente para BrdU (seta), pertencente à camada granular; em $\mathrm{B}$, a área foi ampliada para mostrar a marcação positiva para BrdU (seta); em C, mesma célula marcada positivamente para NeuN (seta) e, em D, a sobreposição das imagens, mostrando a célula duplamente marcada para BrdU e NeuN (seta) considerada na contagem. Escala: $100 \mu \mathrm{m}$. 
Figura 21 -Confirmação da co-localização da dupla marcação BrdU-NeuN na camada granular do giro denteado do hipocampo de ratos.

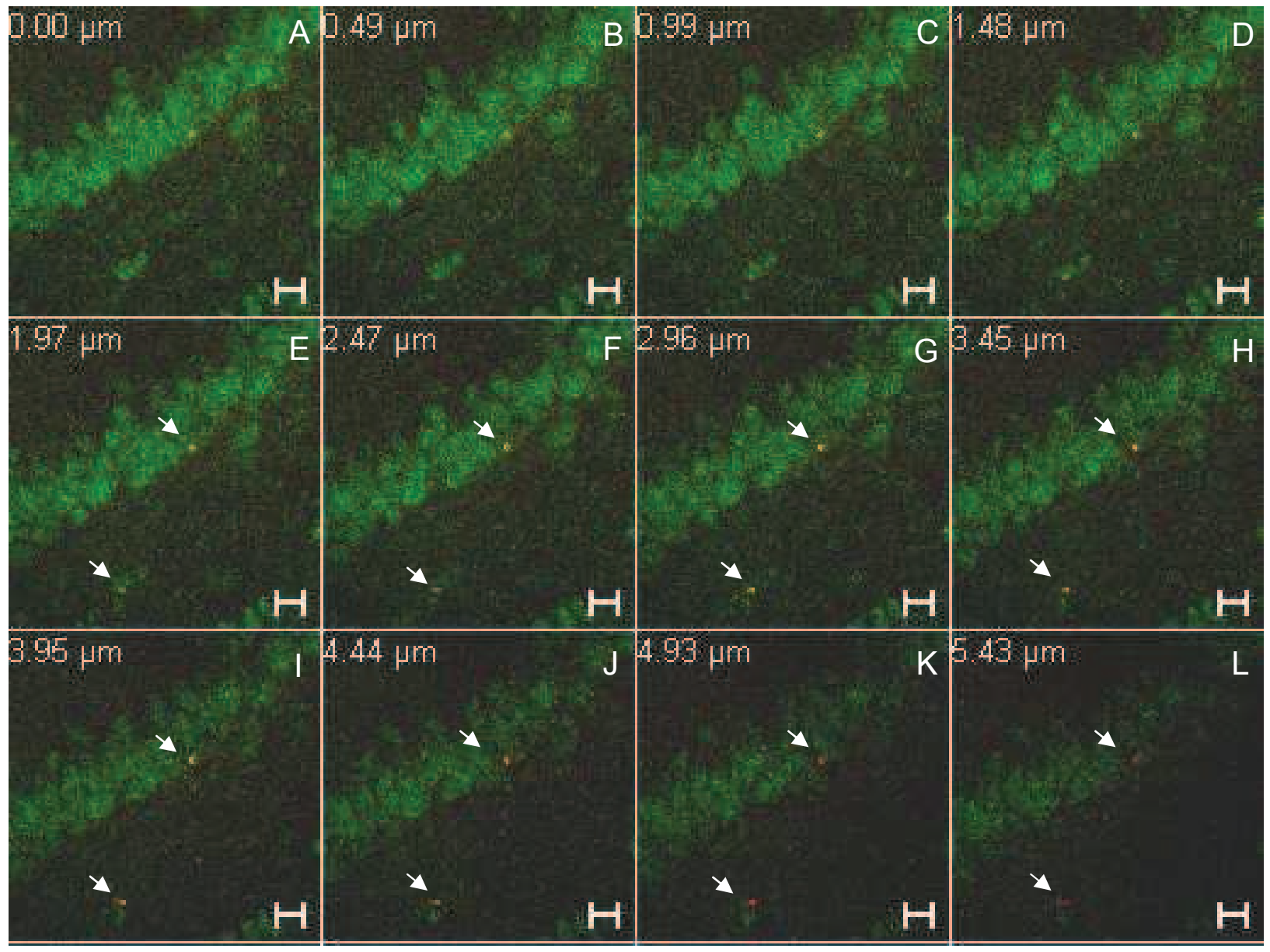

Fotomicrografias em microscópio de fluorescência confocal de varredura à laser, mostrando sequência de imagens de corte coronal, região da camada granular do giro denteado do hipocampo de rato adulto submetido à anóxia neonatal, reagido por técnicas de dupla imunofluorescência para BrdU (vermelho) e NeuN (verde). Observa-se os núcleos das duas células duplamente marcadas para BrdU e NeuN (setas). Escala: $20 \mu \mathrm{m}$. 


\subsection{Resultados}

4.3.1 Análise longitudinal da proliferação neural na zona subgranular do giro denteado do hipocampo

Com a técnica de imunoistoquímica para o marcador endógeno de proliferação Ki-67, foram quantificadas as células da camada subgranular do giro denteado em ambos os grupos, controle e anóxia. Não foram observadas diferenças entre eles em nenhuma das idades estudadas. Porém, a comparação das quantidades de células IR-Ki-67 nas diversas idades evidenciou que a proliferação é elevada nas duas primeiras semanas de vida e que decai em P21 e se mantém estável em P60 (Figura 22, Tabela 6).

Figura 22 -Análise longitudinal da influência da anóxia neonatal na proliferação celular da zona subgranular do giro denteado de ratos.

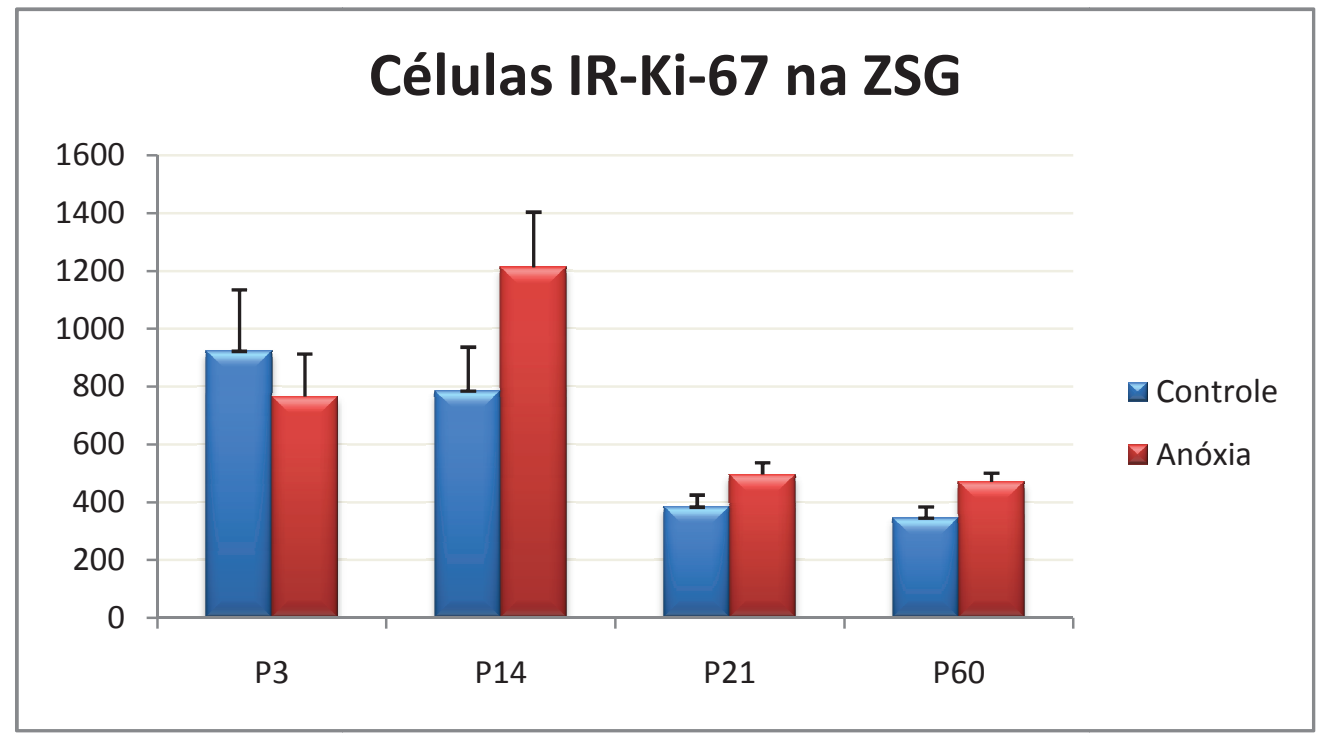

O gráfico ilustra a variação da quantidade de células IR-Ki-67 na ZSG do giro denteado do hipocampo de ratosP3 (controle, $n=5$; anóxia, $n=9$ ), P14 (controle, $n=7$; anóxia, $n=7$ ), P21 (controle, $n=5$; anóxia, $n=5$ ) e P60 (controle, $n=10$; anóxia, $n=10$ )expressa em Média \pm Erro padrão. A análise de variância (ANOVA) não mostrou diferenças significantes $(p \leq 0,05)$ entre os grupos controle e anóxia, porém houve diferença entre as idades: entre P3 e P60, entre P3 e P21, entre P14 e P21 e entre P14 e P60, mostrando que a proliferação é elevada no início da vida até P14, decaindo em P21 e permanecendo baixa em P60, em ambos os grupos $(p \leq 0,05)$. 
Tabela 6 - Quantificação de células imunorreativas e Ki-67 na zona subgranular do giro denteado do hipocampo de ratos em diferentes idades.

\begin{tabular}{ccrcc}
\hline Grupo/Idade & P3 & P14 & P21 & P60 \\
\hline Controle & $923,4 \pm 211,47$ & $785,43 \pm 151,1$ & $384,2 \pm 40,71^{\mathrm{ab}}$ & $346,5 \pm 37,13^{\mathrm{ab}}$ \\
Anóxia & $765,89 \pm 147,14$ & $1213,14 \pm 190,24$ & $495,8 \pm 40,54^{\mathrm{ab}}$ & $470,8 \pm 29,94^{\mathrm{ab}}$ \\
\hline
\end{tabular}

Valores expressos em Média \pm Erro padrão. Médias da contagem de células IR-KI-67 na ZSG do hipocampo de ratos em diferentes idades: P3 (controle, $n=5$; anóxia, $n=9$ ), P14 (controle, $n=7$; anóxia, $n=7$ ), P21 (controle, $n=5$; anóxia, $n=5$ ) e P60 (controle, $n=10$; anóxia, $\mathrm{n}=10$ ). Legenda: ${ }^{\mathrm{a}}$ : diferente de P3; ${ }^{\mathrm{b}}$ : diferente de $\mathrm{P} 14, \mathrm{p} \leq 0,05$.

\subsubsection{Diferenciação neuronal - neurogênese}

A quantificação das células neurais marcadas por dupla imunofluorescência para BrdU e NeuN no giro denteado do hipocampo, indicativa de diferenciação neuronal, foi realizada em ratos adultos (P60).

Houve diminuição da quantidade de células duplamente marcadas no grupo anóxia (grupo controle, $n=5: 84,8 \pm 11,9$; grupo anóxia, $n=5: 37,6 \pm 5,3$ ). $O$ gráfico, o padrão de neurogênese em ambos os grupos e a co-localização BrdU-NeuN estão representados nas figuras 23,24 e 25 .

Figura 23 -Diminuição da neurogênese no giro denteado do hipocampo de ratos adultos submetidos à anóxia neonatal.

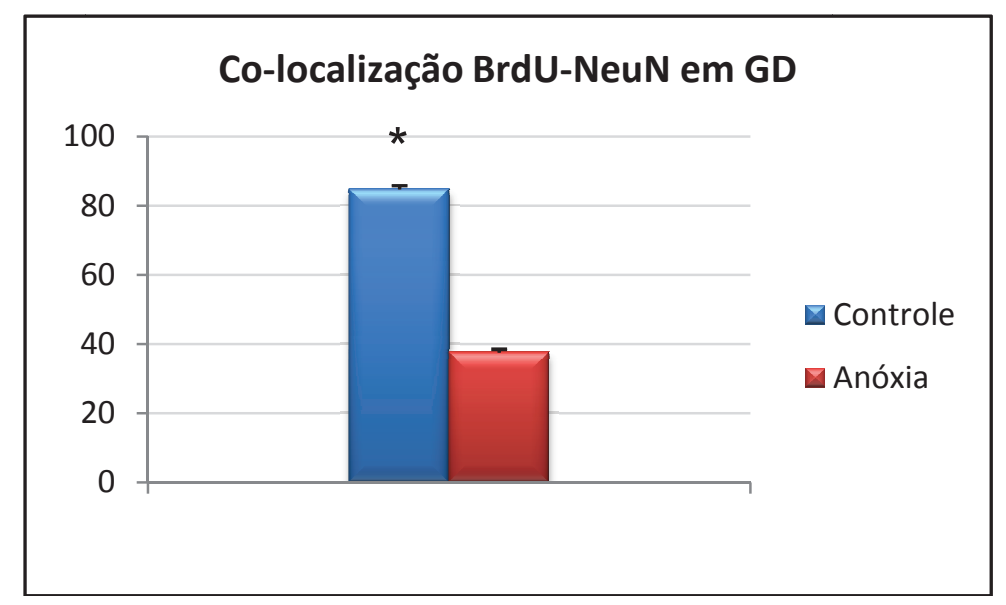

Redução na quantidade de células marcadas duplamente por imunofluorescência para BrdU e NeuN no giro denteado do hipocampo de ratos em P60 submetidos à anóxia neonatal. *: $p<0,05$. 
Figura 24 -Padrão de neurogênese no GD do hipocampo de ratos de 60 dias de vida após anóxia neonatal.

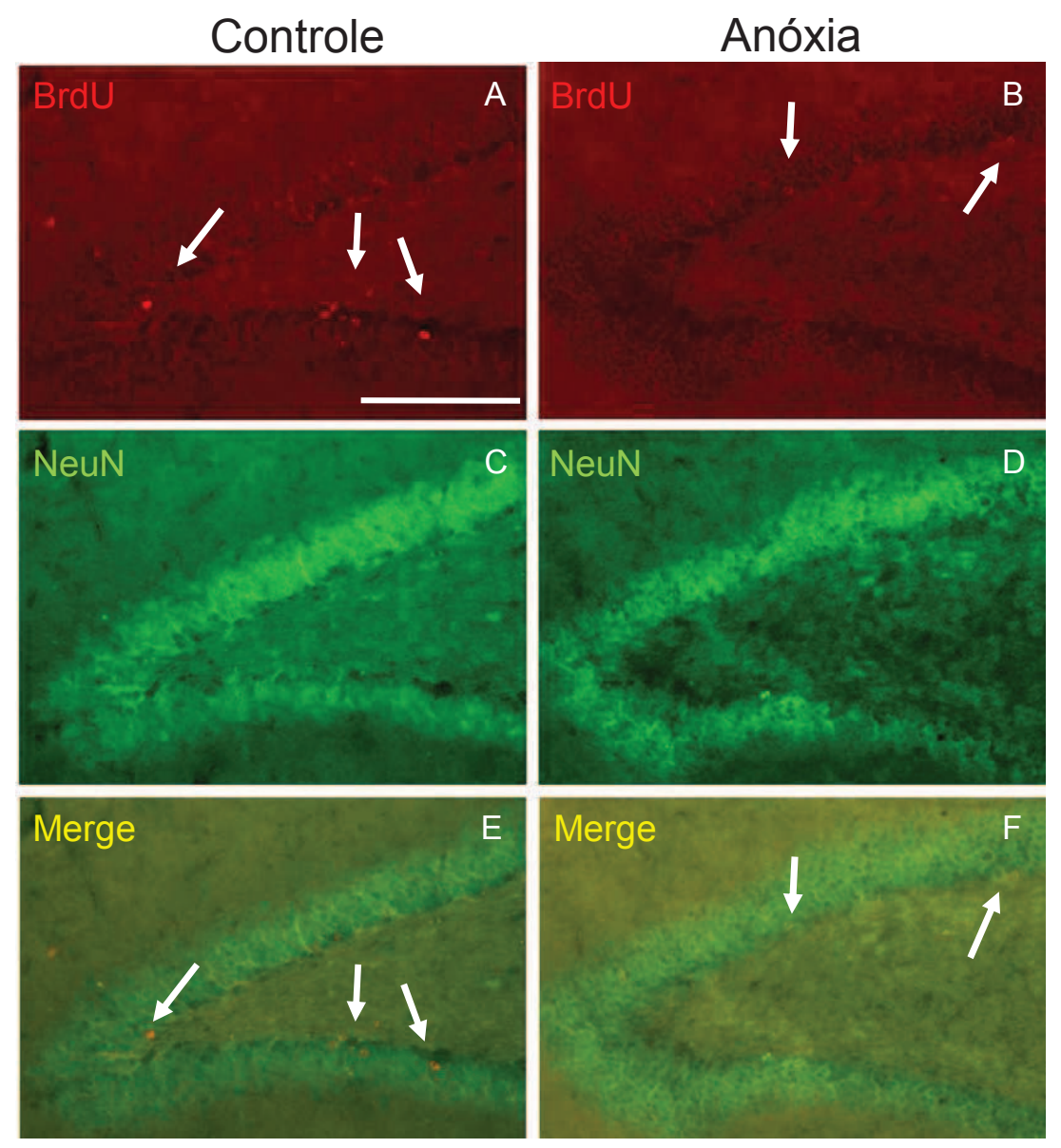

Fotomicrografias de cortes coronais de encéfalos de ratos de 60 dias submetidos à anóxia neonatal $(B, D$ e $F)$ e grupo controle $(A, C$ e $E)$, evidenciando a imunofluorescência para NeuN (A e B), BrdU (C e D) e a dupla marcação NeuN + BrdU (E e F). Observa-se maior quantidade de células duplamente marcadas no animal do grupo controle, que evidencia maior neurogênese nestes animais em relação ao grupo anóxia. Escala:100 $\mu \mathrm{m}$. 
Figura 25 -Co-localização da dupla marcação BrdU-NeuN na camada granular e hilo do giro denteado do hipocampo de ratos adultos.
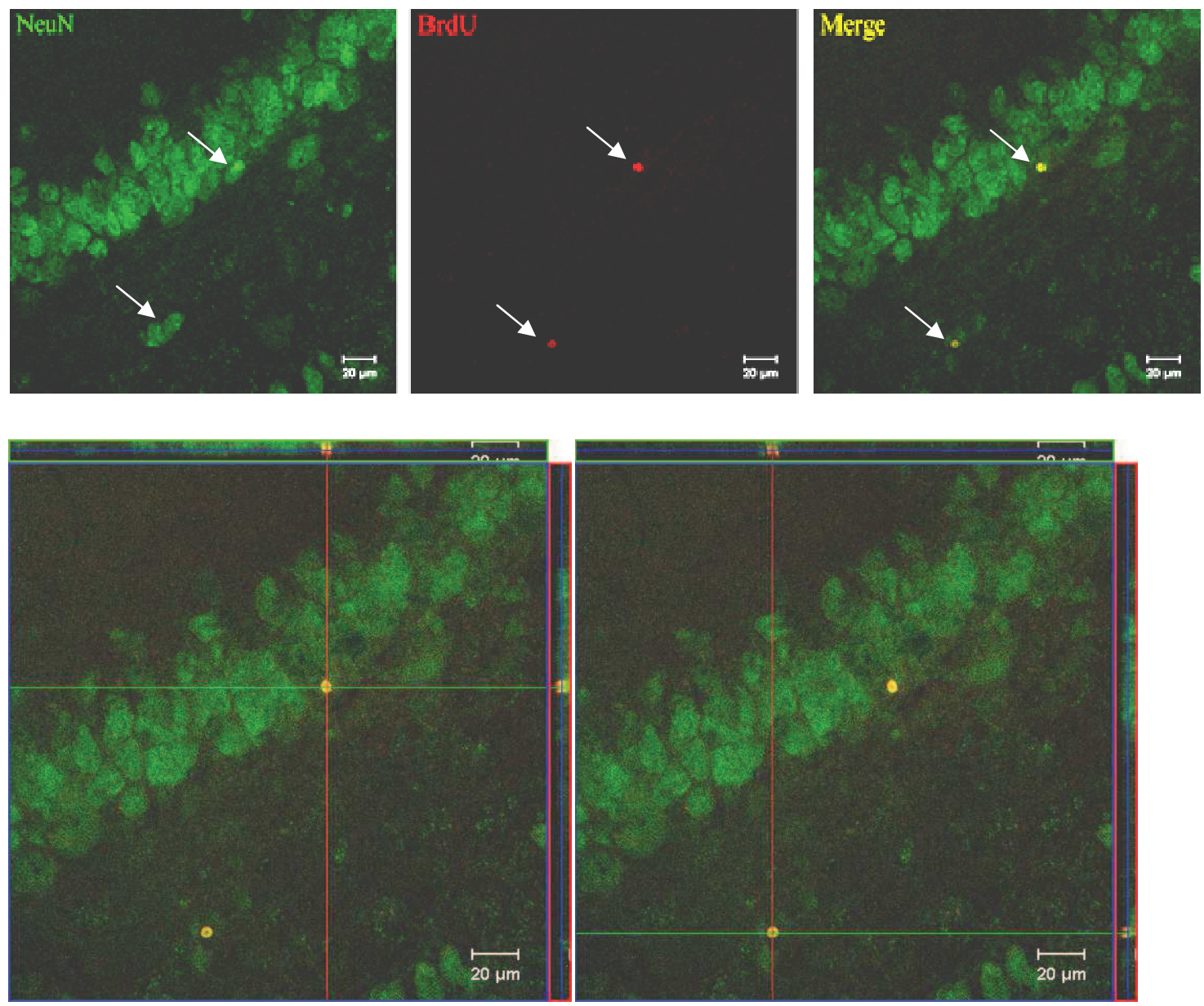

Fotomicrografias em microscópio de fluorescência confocal de varredura à laser, mostrando corte coronal, região do giro denteado do hipocampo de rato P90, reagido por técnicas de dupla imunofluorescência para BrdU (vermelho) e NeuN (verde). Observa-se as duas células duplamente marcadas para BrdU e NeuN (setas), na camada granular e no hilo, sendo que somente a presente na camada granular foi considerada na contagem. Escala: $20 \mu \mathrm{m}$.

Foram encontradas células duplamente marcadas para BrdU e NeuN principalmente na camada granular do giro denteado, tanto no grupo controle como no anóxia. 


\subsubsection{Volume hipocampal}

A análise por estereologia do volume hipocampal indicou aumento de volume na região CA1, em P14, no grupo anóxia (Tabela 7 e Figura 26).

Entre as idades, foi observado aumento progressivo nos volumes de CA3 e GD a partir de P3 até P21 e não foi encontrada diferença de volume entre P21 e P60.

Tabela 7 - Volume do hipocampo de ratos submetidos à anóxia neonatal, mensurado por estereologia (em $\mathrm{mm}^{3}$ ).

\begin{tabular}{l|lllll}
\hline Grupo & Região & P3 & P14 & P21 & P60 \\
\hline \multirow{3}{*}{ Controle } & CA1 & $1,57 \pm 0,12$ & $5,00 \pm 0,38^{*}$ & $10,87 \pm 0,46$ & $10,14 \pm 0,47$ \\
& CA3 & $0,95 \pm 0,10$ & $3,66 \pm 0,59^{\mathrm{a}}$ & $7,40 \pm 0,79^{\mathrm{ab}}$ & $9,51 \pm 0,51^{\mathrm{ab}}$ \\
& GD & $0,47 \pm 0,04$ & $2,44 \pm 0,16^{\mathrm{a}}$ & $6,19 \pm 0,63^{\mathrm{ab}}$ & $5,63 \pm 0,20^{\mathrm{ab}}$ \\
\hline \multirow{3}{*}{ Anóxia } & CA1 & $1,67 \pm 0,08$ & $6,70 \pm 0,09^{*}$ & $10,35 \pm 0,79$ & $10,21 \pm 0,11$ \\
& CA3 & $0,94 \pm 0,11$ & $3,71 \pm 0,24^{\mathrm{a}}$ & $7,73 \pm 0,79^{\mathrm{ab}}$ & $8,08 \pm 1,68^{\mathrm{ab}}$ \\
& GD & $0,51 \pm 0,04$ & $2,56 \pm 0,22^{\mathrm{a}}$ & $5,02 \pm 0,49^{\mathrm{ab}}$ & $5,09 \pm 0,04^{\mathrm{ab}}$ \\
\hline
\end{tabular}

Resultados expressos em Média \pm Erro Padrão. A quantificação estereológica das células neurais IR-Casp3 revelou aumento em P14, região CA1, no grupo anóxia ( $n=5 /$ idade) em relação ao controle ( $n=5 /$ idade) Two-Way ANOVA *: $p \leq 0,05$. 
Figura 26 -Variação dos volumes das subregiões hipocampais após anóxia neonatal.

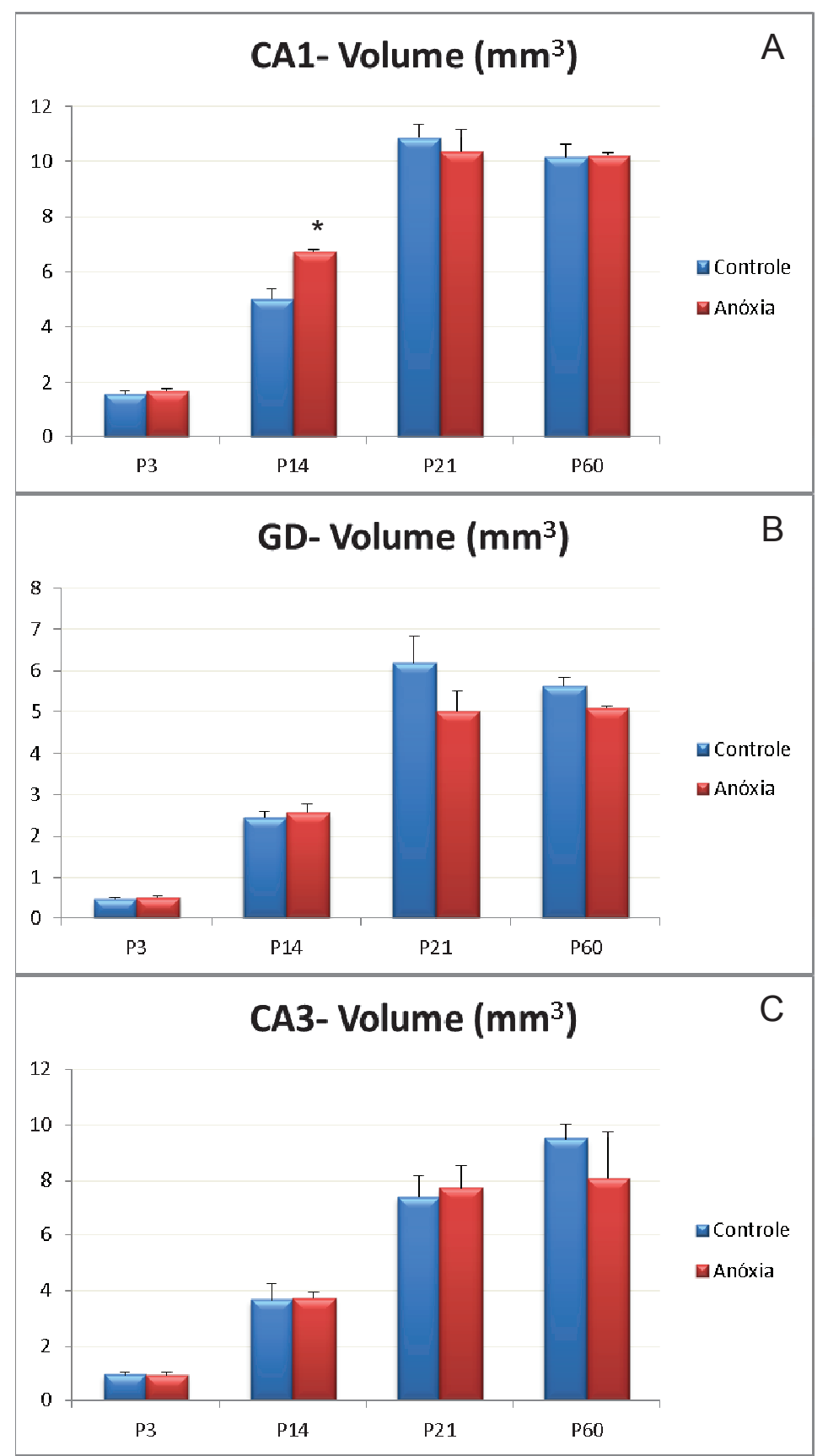

Variação dos volumes das sub-regiões hipocampais ao longo das idades nos grupos controle (azul) e anóxia (vermelho). Há aumento de volume em CA1 de P14 nos animais submetidos à anóxia neonatal $(A)$. * $p \leq 0,05$. 


\subsection{Discussão}

O estudo do volume, da proliferação neural e da neurogênese no hipocampo de ratos revelou que a anóxia neonatal acarreta aumentos no volume de CA1 em P14, não altera a proliferação neural na camada subgranular do giro denteado em P3, P14, P21 e P60, porém provoca diminuição da neurogênese hipocampal em ratos adultos $(\mathrm{P} 60)$.

O sistema nervoso em desenvolvimento apresenta particular susceptibilidade a variações no suprimento de oxigênio, porém sua capacidade plástica e de remodelamento é elevada, sobretudo no hipocampo (Daval et al., 2004).

Agentes estressores e lesões encefálicas que ocorrem durante 0 desenvolvimento podem resultar em significativos e persistentes decréscimos nos volumes corticais e hipocampais (Semple et al., 2013). Vasileiadis e colaboradores, em 2004, constataram reduzidos desenvolvimento e crescimento corticais em crianças prematuras em comparação a crianças a termo. Herpfer e colaboradores (2012) observaram, após separação materna, diminuição do volume hipocampal até a idade de P30 em camundongos, seguida pelo restabelecimento ao volume normal na vida adulta.

Em 2013, Malik e colaboradores constataram, em coelhos, que o parto prematuro suprimia a neurogênese correspondente ao terceiro trimestre da gestação, contribuindo para a redução de volume de determinadas estruturas encefálicas em prematuros.

Em modelos de hipóxia-isquemia neonatal, atrofia das substâncias branca e cinzenta são achados frequentes (Semple et al., 2013).

Entretanto, neste estudo não foi verificado redução de volume em nenhuma das idades estudadas. Pelo contrário, foi encontrado aumento do volume na região CA1 do hipocampo de ratos submetidos à anóxia neonatal em P14. Este achado é bastante interessante porque pode estar correlacionado com outros resultados obtidos: nesta subregião, ocorre marcação TUNEL+ mais evidente em P3 no grupo anóxia, portanto, é provável que a lesão observada em P3 tenha ocasionado resposta a médio prazo em $\mathrm{P} 14$, aumentando o volume de CA1 por possível processo inflamatório, por exemplo. Porém, o mesmo não ocorreu na subregião CA3, em que também houve maior quantidade de marcação TUNEL+ em P3 nos animais do grupo anóxia. 
Por outro lado, Nakatomi e colaboradores (2002) e Daval e colaboradores (2004) sugerem que a privação de oxigênio neonatal pode levar à neurogênese aumentada em CA1 como mecanismo auto-reparador da lesão, apesar desta região ser reconhecidamente pós-mitótica ao nascimento (Liu et al., 2008). Em seu estudo, Daval et al.(2004), encontraram progressiva diminuição na densidade de células da camada piramidal de CA1 até 6 dias após o estímulo hipóxico, havendo recuperação gradual a partir de então; não mencionaram e não mensuraram o volume de CA1, o qual poderia estar alterado independente da quantidade de células.

No presente estudo, análise concomitante de CA1 em P60 não revelou marcação positiva para BrdU e NeuN, indicando que, em ratos adultos, estes neurônios são provavelmente pós-mitóticos.

Durante as primeiras semanas de vida pós-natal, ocorre aproximadamente 50 vezes mais neurogênese que no sistema nervoso adulto, mas pouco é conhecido a respeito do efeito da lesão encefálica neonatal na proliferação durante o desenvolvimento (Scheepens et al., 2002).

No presente estudo, a análise da prolilferação neural na zona subgranular do giro denteado não indicou diferença entre os grupos controle e anóxia em nenhuma das idades avaliadas. Contudo, houve diferenças significantes na proliferação celular do grupo anóxia que permaneceu elevada até P14, decaiu a partir de então e permaneceu baixa em P60.

Scheepens e colaboradores, em 2003, utilizando modelo de asfixia perinatal em ratos, observaram resultado similar em animais do grupo controle. Em animais asfixiados, porém, observaram expressivo aumento da proliferação hipocampal somente em P5, ou seja, 5 dias após a asfixia. Apesar do modelo utilizado também causar asfixia global ao nascimento, da mesma forma que o desta pesquisa, algumas diferenças observadas em seus resultados podem advir deles terem utilizado ${ }^{3} \mathrm{H}$-Timidina como técnica. Entretanto, neste estudo não foi avaliado o efeito da anóxia em idades compreendidas entre P3 e P14. Realmente, este estudo evidenciou tendência a aumento da proliferação em P14, o que talvez seja reflexo deaumento significativo ocorrido anteriormente, após P3. Seria interessante, portanto, ampliar esta análise para as demais idades, comopor exemplo P6 ou P7.

Em outro estudo, realizado por Bartley e colaboradores em 2005, não somente a proliferação neural foi estudada, mas também a diferenciação neuronal, utilizando modelo de $\mathrm{H}-\mathrm{I}$ em camundongos. Comparando os hemisférios cerebrais, 
estes pesquisadores encontraram aumento de regeneração neuronal e de outras células no GD do hemisfério ipsilateral à isquemia em relação ao hemisfério que sofreu somente a hipóxia.

Outros diversos estudos têm associado o aumento de neurogênese em diferentes modelos que combinam a hipóxia com isquemia em neonatos e adultos, de forma isolada e combinada, em várias espécies.

Zhu e colaboradores, em 2009, estudaram os efeitos da hipóxia-isquemia na neurogênese do córtex cerebral e do estriado em camundongos de 9 e 21 dias, onde observaram que células recém-geradas no encéfalo imaturo, seja em condições normais ou patológicas, sobrevivem por período mais prolongado que as células recém-geradas no animal jovem. Entretanto, o estriado do animal jovem não segue a esta regra, pois observaram aí aumento de neurogênese induzida pela hipóxiaisquemia em P9 (analisados 28 dias após o estímulo).

Em modelos de acidente vascular encefálico em roedores adultos, a lesão isquêmica aguda mostrou estimular a neurogênese na zona subventricular (ZSV) adjacente a região de infarto (Arvidsson et al., 2002; Parent et al., 2002; Zhang et al., 2001) e na zona subgranular do giro denteado do hipocampo (Geibig et al., 2012).

Em contraste, modelos de $\mathrm{H}-\mathrm{I}$ em neonatos mostraram diferentes resultados, dependendo da intensidade do estímulo: Levison e colaboradores, em 2001, mostraram que a $\mathrm{H}-\mathrm{I}$ em ratos de 7 dias causava a depleção de precursores neurais na ZSV; Plane e colaboradores, em 2004, utilizando modelo de $\mathrm{H}$-I moderado em camundongos, observaram aumento de neurogênese de 1 a 3 semanas após o estímulo; ainda, em ratos, o mesmo grupo de pesquisadores (Ong et al., 2005) observou que o este tipo de estímulo causava aumento de proliferação e neurogênese na ZSV de 1 a 3 semanas após o estímulo; porém, após esse período, observaram que os novos neurônios não sobreviviam, tanto em ratos como em camundongos.

Em 2006, Pourié e colaboradores utilizaram modelo de hipóxia neonatal breve (100\% $\mathrm{N}_{2}$ por 5 minutos) em ratos e observaramaumento de proliferação e da densidade de células em CA1 e GD 20 dias após o estímulo, assim como a neurogênese aumentada na ZSV e no GD.

O paradigma de hipóxia intermitente também mostrou aumentar a neurogênese hipocampal em ratos adultos (Zhu et al., 2010). 
Neste estudo da neurogênese hipocampal após anóxia neonatal, apesar de não terem sido observadas alterações na proliferação neural na ZSG decorrentes da anóxia nas idades estudadas, foi encontrada menor quantidade de células BrdU/NeuN+ em ratos adultos do grupo anóxia. Tal resultado é bastante intrigante, uma vez que não há, na literatura, modelo animal de anóxia neonatal com exatamente as mesmas características que as que utilizamos.

Diferenças aparentemente mínimas nos modelos utilizados podem acarretar resultados completamente distintos. Enquanto Daval e cols. utilizaram ratos neonatos com 10 a 24 horas de vida, expostos a 20 minutos de $\mathrm{N}_{2} 100 \%$, em nosso modelo de anóxia utilizamos ratos mais velhos com cerca de 30 horas de vida (e provavelmente mais sensíveis a privação de oxigênio - Zhu et al., 2009), expostos ao mesmo gás por 25 minutos. A diferença de 5 minutos é bastante importante, uma vez que, no modelo descrito por Bjelke e colaboradores (1991), o tempo de 19 minutos deve ser seguido para evitar grande taxa de mortalidade; em nosso modelo, o tempo de 30 minutos, por exemplo, levou a uma porcentagem de morte de $50 \%$ (Takada, 2009).

De acordo com o que foi observado na literatura, o tempo menor de exposição à hipóxia gera efeito regenerador aumentando a neurogênese, ao contrário do que Bartley e colaboradores (2005) sugeriram em seu trabalho, no qual atribuíram a robustez de seus resultados ao estímulo pouco intenso.

A temperatura também é um parâmetro fundamental, principalmente quando o estímulo hipóxico é aplicado a neonatos, uma vez que a hipotermia fisiológica que apresentam constitui fator neuroprotetor e, até mesmo, influenciam positivamente a neurogênese (Silasi, Coulbourne, 2011).

Dos trabalhos citados, a maioria detectou aumento de neurogênese a curto e médio prazo após a privação de oxigênio, sendo sugerido por Plane e colaboradores (2004) e Ong e colaboradores (2005) que os novos neurônios não conseguissem sobreviver.

Seguindo o mesmo raciocínio, é possível sugerir que isto também possa ter ocorrido em nosso estudo, sendo interessante a inclusão de grupo intermediário para que a neurogênese seja estudada a curto e médio prazos.

Um outro fato que merece destaque na comparação entre resultados dos diversos modelos de privação de oxigênio é a utilização da hipóxia isolada, combinada à isquemia, ou então a isquemia isolada. Zhu e colaboradores (2009), 
utilizando modelo de hipóxia-isquemia em que a isquemia é feita unilateralmente e a hipóxia é global, teve o cuidado de comparar o hemisfério ipsilateral à isquemia (que sofreu hipóxia-isquemia combinadas) com o contralateral (que sofreu somente hipóxia) e acrescentou um grupo controle que não foi submetido à hipóxia-isquemia. Pelo que pôde ser observado em seus resultados, os valores referentes à neurogênese no hemisfério hipóxico contralateral à isquemia são praticamente iguais aos animais controle, sugerindo portanto que a hipóxia global, neste modelo, não causou aumento de neurogênese.

Enfim, estes resultados permitem concluir que o presente modelo de anóxia neonatal, apesar de provocar aumento de volume de CA1 em P14, não acarreta alterações na proliferação celular da ZSG do GD; porém, na idade adulta, causa decréscimo na neurogênese hipocampal. 
5 DISCUSSÃO GERAL 
A anóxia neonatal é um grave problema de saúde pública que tem estreita relação com a prematuridade, sendo ambos problemas comuns em países em desenvolvimento, como o Brasil. Propor estratégias para recuperação ou neuroproteção das estruturas encefálicas acometidas requer estudos aprofundados dos mecanismos de resposta ao insulto anóxico que o encéfalo em desenvolvimento possui. Desta forma, faz-se necessário o desenvolvimento de modelos animais que se aproximem ao máximo do insulto anóxico que ocorre em humanos em seus diversos aspectos e peculiaridades, sendo este um grande desafio.

Dentro de diversos modelos descritos em literatura, adaptamos e validamos um modelo de anóxia neonatal (Takada et al., 2011) que visa atender ao nosso principal objetivo que é estudar o evento primário da asfixia, ou anóxia, ao nascimento, etapa comum a diversas condições clínicas que podem acometer o prematuro humano.

Analisando o histórico dos estudos realizados na temática da anóxia neonatal, podemos perceber que a grande maioria dos estudos iniciais focavam na morte neuronal aguda sendo que, aos poucos, os pesquisadores observaram que a morte neuronal poderia continuar a ocorrer, havendo perda contínua de células neuronais. Ao mesmo tempo, notaram também que o encéfalo responde naturalmente à neurodegeneração, tentando reestabelecer o equilíbrio entre a ativação de componentes neurodestrutivos e os mecanismos protetores endógenos (Bossenmeyer-Pourié et al., 2002), como a neurogênese.

Assim, o objetivo geral deste trabalho foi analisar como a dinâmica entre morte neural e neurogênese no hipocampo de ratos foi alterada, ao longo das idades, pela anóxia neonatal. 
6 CONCLUSÕES GERAIS 
Os resultados obtidos permitem concluir que:

a) a anóxia neonatal promove morte neural nas subregiões CA1 e CA3 do hipocampo de ratos 24 horas após o insulto anóxico, sendo que, nas demais idades, as técnicas metodológicas empregadas não evidenciaram alterações quanto à morte neural;

b) diferentes tipos de morte neuronal podem ser observados 24 horas após anóxia neonatal, dentre eles apoptose, necrose e caracteristicas morfológicas atípicas sugestivas de continuum, necroptose e autofagia;

c) a anóxia neonatal não altera a proliferação neural na zona subgranular do giro denteado do hipocampo de ratos em P3, P14, P21 e P60;

d) animais adultos submetidos à anóxia neonatal têm diminuição da neurogênese no giro denteado do hipocampo;

e) a dinâmica de desenvolvimento do hipocampo de ratos submetidos à anóxia neonatal ao longo das idades estudadas altera o volume da subregião CA1 em P14, levando a seu aumento.

Portanto, é possível afirmar que a anóxia neonatal promove alterações morfológicas e estruturais agudamente ao estímulo anóxico que podem refletir em alterações na dinâmica do desenvolvimento neural a longo prazo, promovendo diminuição da neurogênese hipocampal, o que poderia explicar os déficits cognitivocomportamentais apresentados por estes animais na vida adulta, conforme visto em outros trabalhos utilizando modelo de anóxia semelhante.

Desta forma, por mais que possa ter havido a tentativa de regeneração, esta não ocorreu satisfatoriamente, levando-nos a pensar que, talvez, medidas neuroprotetoras no sentido de se adequar o ambiente celular para uma maior sobrevivência neuronal, por exemplo, seriam interessantes, tanto em relação aos precursores neurais, como em relação aos novos neurônios formados. 


\section{REFERÊNCIAS}




\section{REFERÊNCIAS*}

Aisa B, Elizalde N, Tordera R, Lasheras B, Del Río J, Ramírez MJ. Effects of neonatal stress on markers of synaptic plasticity in the hippocampus: implications for spatial memory. Hippocampus. 2009;19(12):1222-31.

Allemandi W.Estudo da imunorreatividade da proteína $S 100 \beta$ no sistema nervoso central de ratos neonatos submetidos à anóxia.[tese (Doutorado em Ciências Morfofuncionais)] - Instituto de Ciências Biomédicas, Universidade de São Paulo, São Paulo, 2012.

Altman J, Bayer SA. Migration and distribution of two populations of hippocampal granule cell precursors during the perinatal and postnatal periods. J Comp Neurol. 1990a;301(3):365-81.

Altman J, Bayer SA.Prolonged sojourn of developing pyramidal cells in the intermediate zone of the hippocampus and their settling in the stratum pyramidale. JComp Neurol. 1990b;301(3):343-64.

Amaral DG, Dent JA. Development of the mossy fibers of the dentate gyrus: I. A light and electron microscopic study of the mossy fibers and their expansions. J Comp Neurol. 1981;195(1):51-86.

Amaral DG, Ishizuka N, Claiborne B. Neurons, numbers and the hippocampal network. Prog Brain Res. 1990;83:1-11. Review.

Banasiak KJ, Haddad GG. Hypoxia-induced apoptosis: effect of hypoxic severity and role of p53 in neuronal cell death. Brain Res. 1998;797:295-304.

Banasiak KJ, Xia Y, Haddad GG. Mechanisms underlying hypoxia-induced neuronal apoptosis. Progress in Neurobiology. 2000;62(3):215-49. Review.

Barrett RD, Bennet L, Davidson J, Dean JM, George S, Emerald BS, Gunn AJ. Destruction and reconstruction: hypoxia and the developing brain. Birth Defects Res (Part C). 2007;81:163-76.

Bartley J, Soltau T, Wimborne H, Kim S, Martin-Studdard A, Hess D, Hill W, Waller J, Carroll J. BrdU-positive cells in the neonatal mouse hippocampus following hypoxicischemic brain injury.BMC Neurosci. 2005;6:15.

Bayer AS.Cellular aspects of brain development.Neurotoxicology.1989;10(3):307320.

\footnotetext{
"De acordo com:

International Committee of Medical Journal Editors. Uniform requirements for manuscripts submitted to Biomedical Journal: sample references. [2011July15]. Available from:http//www.icmje.org.
} 
Bear MF, Connors BW, Paradiso MA. Neurociências: desvendando o sistema nervoso. 2. ed. São Paulo: Artmed; 2006. 855 p.

Beilharz EJ, Williams CE, Dragunow M, Sirimanne ES, Gluckman PD. Mechanisms of delayed cell death following hypoxic-ischemic injury in the immature rat: evidence for apoptosis during selective neuronal loss. Mol Brain Res. 1995;29(1):1-14.

Berg DA, Belnoue L, Song $H$, Simon A. Neurotransmitter-mediated control of neurogenesis in the adult vertebrate brain.Development. 2013;140(12):2548-61.

Bjelke B, Andersson K, Ogren SO, Bolme P. Asphyctic lesion: proliferation of tyrosine hydroxylase-immunoreactive nerve cell bodies in the rat substantianigra and functional changes in dopamine neurotransmission.Brain Res. 1991;543(1):1-9.

Blaise SA, Nédélec E, Alberto JM, Schroeder H, Audonnet S, Bossenmeyer-Pourié C, Guéant JL, Daval JL. Short hypoxia could attenuate the adverse effects of hyperhomocysteinemia on the developing rat brain by inducing neurogenesis. Exp Neurol. 2009;216:231-238.

Blencowe H, Cousens S, Oestergaard MZ, Chou D, Moller AB, Narwal R, Adler A, Vera Garcia C, Rohde S, Say L, Lawn JE. National, regional, and worldwide estimates of preterm birth rates in the year 2010 with time trends since 1990 for selected countries: a systematic analysis and implications.Lancet. 2012;379(9832):2162-72.

Blomgren K, Zhu C, Wang X, Karlson JO, Leverin AL, Bahr BA, Mallard C, Hagberg $\mathrm{H}$. Synergistic activation of caspase-3 by m-Calpain after neonatal hypoxia-ischemia: a mechanism of "pathological apoptosis"? J Biol Chem. 2001;276(13):10191-8.

Boss BD, Peterson GM, Cowan WM.On the number of neurons in the dentate gyrus of the rat. Brain Res. 1985;338(1):144-50.

Bossenmeyer-Pourié C, Lièvre V, Grojean S, Koziel V, Pillot T, DavalJL.Sequential expression patterns of apoptosis- and cell cycle-related proteins in neuronal response to severe or mild transient hypoxia. Neuroscience. 2002;114(4):869-82.

Buwalda B, Nyakas C, Vosselman HJ, Luiten PGM. Effects of early postnatal anoxia on adult learning and emotion in rats.Behav Brain Res. 1995;67:85-90.

Cameron HA, Gould E. Adult neurogenesis is regulated by adrenal steroids in the dentate gyrus. Neuroscience.1994;61:203-9.

Cannon M, Jones PB, Murray RM. Obstetric complications and schizophrenia: historical and meta-analyric review. Am J Psych. 2002;159:1080-92.

Caputa M, Rogalska J, Wentowska K, Nowakowska A. Perinatal asphyxia, hyperthermia and hyperferremia as factors inducing behavioural disturbances in adulthood: a rat model. Behav Brain Res. 2005;163:246-256. 
Carloni S, Carnevali A, Cimino M, Balduini W. Extended role of necrotic cell death after hypoxia-ischemia-induced neurodegeneration in the neonatal rat. Neurobiol Dis. 2007;27(3):354-61.

Carloni S, Buonocore G, BalduiniW.Protective role of autophagy in neonatal hypoxiaischemia induced brain injury.Neurobiol Dis. 2008;32(3):329-39.

Casolini P, Zuena AR, Cinque C, Matteucci P, Alemà GS, Adriani W, Carpinelli G, Santoro F, Alleva E, Bosco P, Nicoletti F, Laviola G, Catalani A. Sub-neurotoxic neonatal anoxia induces subtle behavioural changes and specific abnormalities in brain group-i metabotropic glutamate receptors in rats. J Neurochem. 2005;95:13745.

Chen WF, Chang H, Wong CS, Huang LT, Yang CH, Yang SN. Impaired expression of postsynaptic density proteins in the hippocampal CA1 region of rats following perinatal hypoxia. Exp Neurol. 2007;204:400-10.

Chiang MC, Ashraf QM, Ara J, Mishra OP, Delivoria-Papadopoulos M. Mechanism of caspase-3 activation during hypoxia in the cerebral cortex of newborn piglets.Neurosci Lett. 2007;421:67-71.

Christie BR, Cameron HA.Neurogenesis in the adult hippocampus. Hippocampus. 2006;16:199-207.

Cirulli F, Bonsignore LT, Venerosi A, Valanzano A, Chiarotti F, Alleva E. Neurotoxicol Teratol. 2003;25(5):571-8.

Claiborne BJ, Amaral DG, Cowan WM.A light and electron microscopic analysis of the mossy fibers of the rat dentate gyrus. J Comp Neurol. 1986;246(4):435-58.

Coq JQ, Strata F, Russier M, Safadi FF, Maerzenich MM, Byl NN, Barbe MF. Impact of neonatal asphyxia and hind limb immobilization on musculoskeletal tissues and s1 map organization: implications for cerebral palsy. Exp Neurol. 2008;210:95-108.

Corcoran A, O'Connor JJ. Hypoxia inducible factor signalling mechanisms in the central nervous system.Acta Physiol (Oxf). 2013 May 21.

Courville, CB. Anoxemia and brain disease.Calif Med. 1953;79(3):214-7.

Daripa M, Caldas HM, Flores LP, Waldvogel BC, Guinsburg R, Almeida MF.Perinatal asphyxia associated with early neonatal mortality: populational study of avoidable deaths. Rev Paul Ped. 2013;(1):37-45.

Daval JL, Pourié G, Grojean S, Lièvre V, Strazielle C, Blaise S, Vert P. Neonatal hypoxia triggers transient apoptosis followed by neurogenesis in the rat CA1 hippocampus. Ped Res. 2004a;55:561-7.

Daval JL, VertP.Apoptosis and neurogenesis after transient hypoxia in the developing rat brain.Semin Perinatol. 2004b;(4):257-63. 
Dell'anna ME, Calzolari S, Molinari M, luvone L, Calimici R. Neonatal anoxia induces transitory hyperactivity, permanent spatial memory deficits and CA1 cell density reduction in developing rats. Behav Brain Res. 1991;45:125-34.

Dell'anna ME, Luthman J, Lindqvist E, Olson L. Development of monoamine systems after neonatal anoxia in rats. Brain Res Bull. 1993;32:159-70.

Dell'anna ME, Geloso MC, Draisci G, Luthman J. Transient changes in Fos and GFAP immunoreactivity precede neuronal loss in the rat hippocampus following neonatal anoxia. Exp Neurol. 1995a;131:144-56.

Dell'anna E, Chen Y, Loidl F, Andersson K, Luthman J, Goiny M, Rawal R, Lindgren $T$, Herrera-Marschitz M. Short-term effects of perinatal asphyxia studied with fosimmunocytochemistry and in vivo microdialysis in the rat. Exp Neurol. 1995b;131:279-87.

Dell'anna E, luvone L, Calzolari S, Geloso, MC. Effect of acetyl-L-carnitine on hyperactivity and spatial memory deficits of rats exposed to neonatal anoxia. Neurosci Lett. 1997;223:201-5.

Delivoria-Papadopoulos M, Ashraf QM, Ara J, Mishra OP.Nuclear mechanisms of hypoxic cerebral injury in the newborn: the role of caspases.Semin Perinatol. 2008;32(5):334-43.

Dirnagl U, ladecola C, MoskowitzMA. Pathobiology of ischaemic stroke: an integrated view. Trends Neurosci. 1999;22:391-7.

Dobbing J. The development of the blood-brain barrier.Prog Brain Res. 1968;29:41727.

Dobbing J. The effects of early growth retardation on the human brain: the usefulness of animal experiments. J Pathol. 1970;101:13.

Eriksson PS, Perfilieva E, Bjork-Eriksson T, Alborn AM, Nordborg C. Neurogenesis in the adult human hippocampus. Nat Med. 1998;4:1313-7.

Fagel DM, Ganat Y, Silbereis J, Ebbit T, Stewart W, Zhang H, Ment LR, Vaccarino FM. Cortical neurogenesis enhanced by chronic perinatal hypoxia. Exp Neurol. 2006;99:77-91.

Fernando P, Kelly JF, Balazsi K, Slack RS, Megeney LA.Caspase 3 activity is required for skeletal muscle differentiation. P Natl Acad Sci USA. 2002;99(17):1102530.

Fernando P, Brunette S, MegeneyLA.Neural stem cell differentiation is dependent upon endogenous caspase 3 activity.FASEB J. 2005;19(12):1671-3.

Festjens N, VandenBerghe T, Vandenabeele P. Necrosis, a well-orchestrated form of cell-demise: signaling cascades, important mediators and concomitant immune response. Biochim Byophis Acta. 2006;1757:1371-87. 
Fornal CA, Stevens J, Barson JR, Blakley GG, Patterson-Buckendahl P, Jacobs BL. Delayed suppression of hippocampal cell proliferation in rats following inescapable shocks. Brain Res. 2007;1130:48-53.

Fuchs E, Gould E. Mini-review: in vivo neurogenesis in the adult brain: regulation and functional implications. Eur J Neurosci. 2000;12:2211-4.

Gage FH, Kempermann G, Palmer TD, Peterson DA, Ray J. Multipotent progenitor cells in the adult dentate gyrus. J Neurobiol. 1998;36:249-66.

Galluzzi L, Blomgren K, KroemerG.Mitochondrial membrane permeabilization in neuronal injury.Nature Reviews. Neuroscience. 2009;10(7):481-94.

García-Verdugo JM, Ferrón S, Flames N, Collado L, Desfilis E, Font E. The proliferative ventricular zone in adult vertebrates: a comparative study using reptiles, birds, and mammals. Brain Res Bull. 2002;57:765-75.

Geddes R, Vannucci RC, Vannucci SJ. Delayed cerebral atrophy following moderate hypoxia-ischemia in the immature rat.Dev Neurosci. 2001;23(3):180-5.

Geibig CS, Keiner S, Redecker C.Functional recruitment of newborn hippocampal neurons after experimental stroke. Neurobiol Dis. 2012;46(2):431-9.

Gill R, Soriano M, Blomgren K, Hagberg H, Wybrecht R, Miss MT, Hoefer S, Adam $\mathrm{G}$, Niederhauser $\mathrm{O}$, Kemp JA, Loetscher $\mathrm{H}$. Role of caspase-3 activation in cerebral ischemia-induced neurodegeneration in adult and neonate brain. $\mathrm{J}$ Cerebr Blood $\mathrm{F}$ Met. 2002;22:420-30.

Golstein P, Kroemer G.A multiplicity of cell death pathways. Symposium on apoptotic and non-apoptotic cell death pathways.EMBO Reports. 2007;8(9):829-33.

Gould E, Mcewens BS, Tanapat P, Galea LA, Fuchs E. Neurogenesis in the dentate gyrus of the adult tree shrew is regulated by psychosocial stress and NMDA receptor activation. J Neurosci. 1997;17:2492-8.

Gould E, Reeves AJ, Fallah M, Tanapat P, Gross CG. Hippocampal neurogenesis in adult Old World primates. P Natl Acad Sci. 1999;96:5263-7.

Graham EM, Ruis KA, Hartman AL, Northington FJ, Fox HE. A systematic review of the role of intrapartum hypoxia-ischemia in the causation of neonatal encephalopathy.American J Obstet Gynaecol. 2008;199(6):587-95.

Hedner $\mathrm{T}$, Lundborg $\mathrm{P}$. Serotonin metabolism in neonatal rat brain during asphyxia and recovery. Acta Physiol Scand. 1980;109:163-8.

Herpfer I, Hezel H, Reichardt W, Clark K, Geiger J, Gross CM, Heyer A, Neagu V, Bhatia H, Atas HC, Fiebich BL, Bischofberger J, Haas CA, Lieb K, NormannC.Early life stress differentially modulates distinct forms of brain plasticity in young and adult mice.PLoS One. 2012;7(10):e46004. 
Hitomi J, Christofferson DE, Ng A, Yao J, Degterev A, Xavier RJ, Yuan J.Identification of a molecular signaling network that regulates a cellular necrotic cell death pathway. Cell. 2008;135(7):1311-23.

Hu BR, Liu CL, Ouyang Y, Blomgren K, SiesjöBK.Involvement of caspase-3 in cell death after hypoxia-ischemia declines during brain maturation. J Cerebr Blood $F$ Metab. 2000;20(9):1294-300.

Huffman SL, Zehner ER, VictoraC.Can improvements in breast-feeding practices reduce neonatal mortality in developing countries?Midwifery. 2001;17(2):80-92.

Isaacs EB, Edmonds CJ, Chong WK, Lucas A, Morley R, Gadian DG.Brain morphometry and IQ measurements in preterm children.Brain. 2004;127:2595-607.

Ito $\mathrm{PH}$. Avaliação comportamental de ratos submetidos à anóxia neonatal. [dissertação (Mestrado)]. São Paulo: Instituto de Psicologia, Universidade de São Paulo; 2010.

luvone L, Geloso MC, Dell'anna E. Changes in open fieldbehavior, spatialmemory, andhippocampalparvalbuminimmunoreactivity following enrichment in rats exposed to neonatal anoxia. Exp Neurol. 1996;139:25-33.

Jin K, Minami M, Lan JQ, Mao XO, Batteur S, Simon RP, Greenberg DA. Neurogenesis in dentate subgranular zone and rostral subventricular zone after focal cerebral ischemia in the rat. P Natl Acad Sci. 2001;98:4710-5.

Johansen FF, Sørensen T, Tønder N, Zimmer J, Diemer NH.Ultrastructure of neurons containing somatostatin in the dentate hilus of the rat hippocampus after cerebral ischaemia, and a note on their commissural connections.Neuropath Appl Neuro. 1992;18(2):145-57.

Johnston MV, Trescher WH, Ishida A, Nakajima W. Neurobiology of HypoxicIschemic Injury in the Dev Brain.Ped Res. 2001;49(6):735-41.

Kadam SD, Mulholland JD, McDonald JW, Comi AM. Neurogenesis and neuronal commitment following ischemia in a new mouse model for neonatal stroke. Brain Res. 2008;1208:35-45.

Kee NJ, Preston E, Wojtowicz JM.Enhanced neurogenesis after transient global ischemia in the dentate gyrus of the rat. Exp Brain Res. 2001;136:313-20.

Kempermann G, Kuhn HG, Gage FH. More hippocampal neurons in adult mice living in an enriched environment.Nature. 1997;386:493-95.

Kirino T. Delayed neuronal death in the gerbil hippocampus following ischemia.Brain Res. 1982 ;239(1):57-69.

Kirino T. Delayed neuronal death.Neuropathology. 2000 Sep;20 Suppl:S95-7. Review. 
Kokaia Z, Lindvall O. Neurogenesis after ischaemic brain insults. Curr Opin Neurobiol. 2003;13:127-32.

Kroemer G, Galluzzi L, Vandenabeele P, Abrams J, Alnemri ES, Baehrecke EH, Blagosklonny MV, El-Deiry WS, Golstein P, Green DR, Hengartner M, Knight RA, Kumar S, Lipton SA, Malorni W, Nuñez G, Peter ME, Tschopp J, Yuan J, Piacentini M, Zhivotovsky B, Melino G; Classification of cell death: recommendations of the Nomenclature Committee on Cell Death 2009. Cell Death Differ. 2009;16(1):3-11.

Kuida K, Zheng TS, Na S, Kuan C, Yang D, Karasuyama H, Rakic P, Flavell RA. Decreased apoptosis in the brain and premature lethality in CPP32-deficient mice.Nature. 1996;384:368-72.

Kuida K, Haydar TF, Kuan CY, Gu Y, Taya C, Karasuyama H, Su MS, Rakic P, Flavell R A. Reduced apoptosis and cytochrome c-mediated caspase activation in mice lacking Caspase-9 . Cell. 1998;94:325-37.

Kuhn HG, Dickinson-Anson H, Gage FH. Neurogenesis in the dentate gyrus of the adult rat: age-related decrease of neuronal progenitor proliferation. $J$ Neurosci.1996;16:2027-33.

Kurinczuk JJ, White-Koning M, BadawiN.Epidemiology of neonatal encephalopathy and hypoxic-ischaemic encephalopathy.Early Hum Dev. 2010;86(6):329-38.

Lamkanfi M, Festjens N, Declercq W, VandenBerghe T, VandenabeeleP.Caspases in cell survival, proliferation and differentiation.Cell Death Differ. 2007;14(1):44-55.

Larsson E, Lindvall O, KokaiaZ.Stereological assessment of vulnerability of immunocytochemically identified striatal and hippocampal neurons after global cerebral ischemia in rats. Brain Res. 2001;913(2):117-32.

Laviola G, Adriani W, Rea M, Aloe L, Alleva E. Social withdrawal, neophobia, and stereotyped behavior in developing rats exposed to neonatal asphyxia. Psychopharmacology. 2004;175:196-205.

Lee, VY. Identificação da degeneração neuronal no encéfalo de ratos após anóxia neonatal.Trabalho de Iniciação Científica. São Paulo: Instituto de Ciências Biomédicas, Universidade de São Paulo; 2012.

Leuner B, Gould E, Shors TJ. Is there a link between adult neurogenesis and learning? Hippocampus. 2006;16(3):216-24.

Levison SW, Rothstein RP, Romanko MJ, Snyder MJ, Meyers RL, VannucciSJ.Hypoxia/ischemia depletes the rat perinatal subventricular zone of oligodendrocyte progenitors and neural stem cells.Dev Neurosci. 2001;23(3):234-47.

Liu CL, Siësjo BK, Hu BR. Pathogenesis oh hippocampal neuronal death after hypoxia-ischemia changes during brain development. Neuroscience. 2004;127:11323. 
Liu JP, Chang LR, Gao XL, Wu Y.Different expression of caspase-3 in rat hippocampal subregions during postnatal development. Microsc Res Techniq. 2008;71(9):633-8.

Liu J, Solway K, Messing RO, and Sharp FR. Increased neuro- genesis in the dentate gyrus after transient global ischemia in gerbils.J Neurosci. 1998;18:7768-78.

Liu L, Johnson HL, Cousens S, Perin J, Scott S, Lawn JE, Rudan I, Campbell H, Cibulskis R, Li M, Mathers C, Black RE; Child Health Epidemiology Reference Group of WHO and UNICEF.Global, regional, and national causes of child mortality: an updated systematic analysis for 2010 with time trends since 2000.Lancet. 2012;379(9832):2151-61.

Lledo PM, Alonso M, Grubb MS. Adult neurogenesis and functional plasticity in neuronal circuits. Nat Rev Neurosci. 2006;7:179-93.

Lloidl CF, Gavilanes AW, Van Dijk EH, Vreuls W, Blokland A, Vles JS, Steinbusch HW, Blanco CE.Physiol Behav. 2000;68(3):263-9.

Lutz PL, Prentice HM. Sensing and responding to hypoxia, molecular and physiological mechanisms. Integr Comp Biol. 2002;42:463-8.

MacFarlane M, Williams AC. Apoptosis and disease: a life or death decision. EMBO reports. 2004;5(7):674-8.

Majeed R, Memon Y, Majeed F, Shaikh NP, Rajar UD. Risk factors of birth asphyxia.Journal of Ayub Medical College, Abbottabad. 2007;19:67-71.

Malik S, Vinukonda G, Vose LR, Diamond D, Bhimavarapu BB, Hu F, Zia MT, Hevner $\mathrm{R}$, Zecevic N, BallabhP.Neurogenesis continues in the third trimester of pregnancy and is suppressed by premature birth. J Neurosci. 2013;33(2):411-23.

Manhães De Castro R, Barreto Medeiros JM, Mendes Da Silva C, Ferreira LM, Guedes RC, Cabral Filho JE, Costa JA. Reduction of intraspecific agression in adult rats by neonatal treatment with a selective serotonin reuptake inhibitor.Braz $\mathrm{J}$ Med Biol Res. 2001;34:121-124.

McCabe BK, Silveira DC, Cilio MR, Cha BH, Liu X, Sogawa Y, Holmes GL. Reduced neurogenesis after neonatal seizures.J Neurosci. 2001;21:2094-103.

Miller MW, Kuhn PE.Neonatal transection of the infraorbital nerve increases the expression of proteins related to neuronal death in the principal sensory nucleus of the trigeminal nerve. Brain Res. 1997;769(2):233-44.

Mizushima N.Methods for monitoring autophagy. Intl J Biochem. 2004;36(12):2491502. Review. 
Morgane PJ, Austin-Lafrance R, Bronzino J, Tonkiss J, Díaz-Cintra S, Cintra L, Kemper T, Galler JR. Prenatal malnutrition and development of the brain. Neurosci Biobehav Rev. 1993;17:91-128.

Nakajima W, Ishida A, Takada G. Effect of anoxia on striatal monoamine metabolism in immature rat brain compared with that of hypoxia: an in vivo microdialysis study. Brain Res. 1996;740:316-22.

Nakajima W, Ishida A, Takada G. Anoxic and hypoxic immature rat model for measurement of monoamine using in vivo microdialysis. Brain Res Protoc. 1999;3: 252-56.

Nakajima W, Ishida A, Lange MS, Gabrielson KL, Wilson MA, Martin LJ, Blue ME, Johnston MV. Apoptosis has a prolonged role in the neurodegeneration after hypoxic ischemia in the newborn rat. J Neurosci. 2000;20(21):7994-8004.

Namba T, Mochizuki H, Onodera M, Mizuno Y, Namiki H, Seki T. The fate of neural progenitor cells expressing astrocytic and radial glial markers in the postnatal rat dentate gyrus. Eur J Neurosci. 2005;22:1928-41.

Nitatori T, Sat N, Waguri S, Karasawa Y, Araki H, Shibanai K, Kominami E, Uchiyama Y. Delayed neuronal death in the CA1 pyramidal cell layer of the gerbil hippocampus following transient ischemia is apoptosis. J Neurosci. 1995;15:100111.

Northinghton F, Ferriero D, Graham E, Traystman RJ, Martin LJ. Early neurodegeneration after hypoxia-ischemia in neonatal rat is necrosis while delayed neuronal death is apoptosis. Neurobiol Dis. 2001;8:207-19.

Northinghton FJ, Chavez-Valdez R, Martin LJ. Neuronal Cell Death in Neonatal Hypoxia-Ischemia. Ann Neurol. 2011;69(5):743-58.

Nyakas C, Buwalda B, Luiten PGM. Hypoxia and Brain Development.Prog Neurobiol. 1996;49:1-51.

Nowarovski RS, Hayes, NL. Numerology of Neurogenesis: Characterizing the Cell Cycle of Neurostem Cells. In: Gage FH, Kempermann G, Song H. Adult Neurogenesis.NY.Cold Spring Harbor Laboratory Press;2008,673p.

Okuyama R, Nguyen BC, Talora C, Ogawa E, Tommasi di Vignano A, Lioumi M, Chiorino G, Tagami $H$, Woo M, DottoGP.High commitment of embryonic keratinocytes to terminal differentiation through a Notch1-caspase 3 regulatory mechanism. Dev Cell. 2004;6(4):551-62.

Ong J, Plane JM, Parent JM, Silverstein FS. Hypoxic-ischemic injury stimulates subventricular zone proliferation and neurogenesis in the neonatal rat. Ped Res. 2005;58:600-606.

Orrenius S, Kaminskyy VO, Zhivotovsky B Autophagy in toxicology: cause or consequence? Ann Rev Pharmacol Toxicol. 2013;53:275-97. 
Papadakis M, Hadley G, Xilouri M, Hoyte LC, Nagel S, McMenamin MM, Tsaknakis G, Watt SM, Drakesmith CW, Chen R, Wood MJ, Zhao Z, Kessler B, Vekrellis K, Buchan AM. Tsc1 (hamartin) confers neuroprotection against ischemia by inducing autophagy. Nature Med. 2013;19(3):351-7.

Parent JM. The role of seizure-induced neurogenesis in epileptogenesis and brain repair. Epilepsy Res. 2002;50:179-89..

Peterson BL, Larson J, Buffenstein R, Park TJ, Fall CP.Blunted neuronal calcium response to hypoxia in naked mole-rat hippocampus.PLoS One. 2012;7(2).

Petito CK, Feldmann E, Pulsinelli WA, Plum F.Delayed hippocampal damage in humans following cardiorespiratory arrest.Neurology. 1987;37(8):1281-6.

Pettmann B, Henderson CE. Neuronal cell death. Neuron. 1998;20:633-47.

Pimentel VC, Pinheiro FV, De Bona KS, Maldonado PA, da Silva CR, de Oliveira SM, Ferreira J, Bertoncheli CM, Schetinger MR, Da Luz SC, Moretto MB.Hypoxicischemic brain injury stimulates inflammatory response and enzymatic activities in the hippocampus of neonatal rats.Brain Res. 2011 4;1388:134-40.

Plane JM, Liu R, Wang TW, Silverstein FS, Parent JM. Neonatal hypoxic-ischemic injury increases forebrain subventricular zone neurogenesis in the mouse. Neurobiol Dis. 2004;16:585-95.

Paxinos G. The rat nervous system. $3^{\text {rd }}$ ed. London: Elsevier Academic Press; 2004. $1280 \mathrm{p}$.

Portera-Cailliau C, Hedreen JC, Price DL, KoliatsosVE.Evidence for apoptotic cell death in Huntington disease and excitotoxic animal models.J Neurosci.1995; 15:3775-87.

Rami A, Langhagen A, SteigerS.Focal cerebral ischemia induces upregulation of Beclin 1 and autophagy-like cell death.Neurobiol Dis. 2008;29(1):132-41.

Ramirez-Amaya V, Marrone DF, Gage FH, Worley PF, Barnes CA. Integration of new neurons into functional neural networks. J Neurosci. 2006;26:12237-41.

Reynolds ES.The use of lead citrate at high $\mathrm{pH}$ as an electron-opaque stain in electron microscopy.J Cell Biol.1963;17:208-12.

Ribe EM, Serrano-Saiz E, Akpan N, Troy CM. Mechanisms of neuronal death in disease: defining the models and the players. Biochem J. 2008;415(2):165-82.

Rice JED, Vannucci RC, Brierley JB. The influence of immaturity on hypoxic-ischemic brain damage in the rat. Ann Neurol. 1981;9:131-41. 
Rice D, BaroneJr S. Critical periods of vulnerability for the developing nervous system: evidence from humans and animal models. Environl Health Persp. 2000; 108Suppl 3:511-33.

Rogalska J, Caputa M, Wentowska K, Nowakowska A. Stress-induced behaviour in adult and old rats: effects of neonatal asphyxia, body temperature and chelation of iron.J Physiol Pharmacol. 2006;57:17-34.

Romanko MJ, Rothstein RP, Levison SW. Neural stem cells in the subventricular zone are resilient to hypoxia/ischemia whereas progenitors are vulnerable. J Cerebr Blood F Met.2004; 24:814-25.

Roy M, Sapolsky R.Neuronal apoptosis in acute necrotic insults: why is this subject such a mess? Trends Neurosci. 1999;22(10):419-22.

Santambrogio L, Potolicchio I, Fessler SP, Wong SH, Raposo G, StromingerJL.Involvement of caspase-cleaved and intact adaptor protein 1 complex in endosomal remodeling in maturing dendritic cells. Nature Immunol.2005 ;6(10):1020-8.

Schulz J, Weller M, MoskowitzMA. Caspases as treatment targets in stroke and neurodegenerative diseases. Ann Neurol. 1999;45:421-9.

Scheepens A, Wassink G, Piersma MJ, Van de Berg WD, Blanco CE.A delayed increase in hippocampal proliferation following global asphyxia in the neonatal rat.Brain Research Developmental Brain Res. 2003;142(1):67-76.

Schmued LC, Hopkins KJ.Fluoro-Jade B: a high affinity fluorescent marker for the localization of neuronal degeneration.Brain Res. 2000;874(2):123-30.

Schulz JB, Weller M, Matthews RT, Heneka MT, Groscurth P, Martinou JC, Lommatzsch J, von Coelln R, Wüllner U, Löschmann PA, Beal MF, Dichgans J, KlockgetherT.Extended therapeutic window for caspase inhibition and synergy with MK-801 in the treatment of cerebral histotoxic hypoxia.Cell Death Differ. 1998;5(10):847-57.

Semple BD, Blomgren K, Gimlin K, Ferriero DM, Noble-Haeusslein LJ. Brain development in rodents and humans: Identifying benchmarks ofmaturation and vulnerability to injury across species.Prog Neurobiol.2013;106-107:1-16.

Shors TJ, Miesegaes G, Bevllin A, Zhao M, Rydel T, Gould E. Neurogenesis in the adult is involved in the formation of trace memories. Nature. 2001;410(6826):372-6.

Silasi G, ColbourneF.Therapeutic hypothermia influences cell genesis and survival in the rat hippocampus following global ischemia. JCerebr Blood FMet. 2011;31(8):1725-35.

Smale G, Nichols NR, Brady DR, Finch CE, Horton Jr WE.Evidence for apoptotic cell death in Alzheimer's disease. Exp Neurol. 1995;133:225-30. 
Spalding KL, Bergmann O, Alkass K, Bernard S, Salehpour M, Huttner HB, Boström E, Westerlund I, Vial C, Buchholz BA, Possnert G, Mash DC, Druid H, Frisén J. Dynamics of Hippocampal Neurogenesis in Adult Humans. Cell.2013;153(6):121927.

Spasojevic SD, Stojanovic VD, Barisic NA, Doronjski AR, Zikic DR, Babovic SM.Neuroprotective effects of hypothermia and erythropoietin after perinatal asphyxia in newborn rats. J Matern Fetal Neon Med. 2013.[Epub ahead of print].

Stahl SM. Psicofarmacologia: base neurocientífica e aplicações práticas. 2. ed. Rio de Janeiro: Medsi; 2002. 617 p.

Storm-Mathisen J, Ottersen OP.Immunocytochemistry of glutamate at the synaptic level.J Histochem Cytochem. 1990;38(12):1733-43.

Suguihara C, Lessa AC. Strategies to minimize lung injury in extremely low birth weight infants. J Ped. 2005;81:69-78.

Takada SH. Efeitos da anóxia neonatal no encéfalo de ratos: estudo da distribuição de neurônios imunorreativos a Fos. [dissertação (Mestrado). São Paulo: Instituto de Ciências Biomédicas, Universidade de São Paulo; 2009.

Takada SH, Sampaio CA, Allemandi W, Ito PH, Takase LF, Nogueira MI. A modifiedratmodelof neonatal anoxia: development and evaluation by pulse oximetry, arterial gasometry and Fos immunoreactivity. J Neurosci Meth. 2011;198(1):62-9.

Tang AC, Nakazawa M. Neonatal novelty exposure ameliorates anoxia-induced hyperactivity in the open field. Behav Brain Res. 2005;163:1-9.

Taupin P, Gage FH. Adult neurogenesis and neural stem cells of the central nervous system in mammals. J Neurosci Res. 2002;69:745-9.

Towfighi J, Zec N, Yager J, Housman C, VannucciRC.Temporal evolution of neuropathologic changes in an immature rat model of cerebral hypoxia: a light microscopic study. Acta Neuropathol. 1995;90(4):375-86.

Troy CM, Salvesen GS.Caspases on the brain.JNeurosci Res. 2002; 69: 145-150.

Uchiyama $Y$, Koike M, Shibata M.Autophagic neuron death in neonatal brain ischemia/hypoxia. Autophagy. 2008;4(4):404-8. Review.

Van Der Kooy D, Weiss S. Why stem cells? Science. 2000;287:1439-41.

vanPraag $\mathrm{H}$, Kempermann G, Gage $\mathrm{FH}$ : Running increases cell proliferation and neurogenesisin the adult mouse dentate gyrus. Nat Neurosci. 1999;2:266-70.

Vannucci RC. Hypoxia-ischemia: Clinical aspects. In: Fanaroff AA, Martin RJ, editors. Neonatal perinatal medicine. $4^{\text {th }}$ ed. Philadelphia: Mosby-Yearbook; 1997. p. 877-91. 
Vannucci RC, Connor JR, Mauger DT, Palmer C, Smith MB, Towfighi J, Vannucci SJ. Rat model of perinatal hypoxic-ischemic brain damage. J Neurosci Res. 1999;55: $155-63$.

Vannucci SJ, Hagberg H. Hypoxia-ischemia in the immature brain.J Exp Biol. 2004; 207:3149-54.

Vasileiadis GT, Gelman N, Han VK, Williams LA, Mann R, Bureau Y, Thompson RT. Uncomplicated intraventricular hemorrhage is followed by reduced cortical volume at near-term age. Pediatrics. 2004;114(3):e367-72.

Vexler Z, Ferriero D. Molecular and biochemical mechanisms of perinatal brain injury.SemNeonatol. 2001;6:99-108.

Volpe JJ. Perinatal hypoxic-ischemic brain injury: overview. In: Fukuyama Y, Suzuki $\mathrm{Y}$, Kamoshita S, Casaer P, editors.Fetal and perinatal neurology. Tokyo: Joint Convention of the 5th International Child Neurology and the 3rd Asian and Oceanian Congress of Child Neurology, 1992. p. 232-52.

Wainwright MS, Craft JM, Griffin ST, Marks A, Pineda J, Padgett KR, Eldik V. Increased susceptibility of S100B transgenic mice to perinatal hypoxia-ischemia. Ann Neurol. 2004;56:61-7.

Wang X, Karlsson JO, Zhu C, Bahr BA, Hagberg H, Blomgren K.Caspase-3 activation after neonatal rat cerebral hypoxia-ischemia.Biol Neonate. 2001;79(34):172-9.

Wang Y, Han R, Liang ZQ, Wu JC, Zhang XD, Gu ZL, Qin ZH.Anautophagic mechanism is involved in apoptotic death of rat striatal neurons induced by the non$\mathrm{N}$-methyl-D-aspartate receptor agonist kainic acid. Autophagy. 2008;4(2):214-26.

Watanabe I, Yamada E. The fine structure of lamellated nerve endings found in the rat gingival. ArchHistol Jap. 1983; 46(2):173-82.

Watson $\mathrm{JH}$. Electron microscopy, iron crystals and medicine. Henry Ford Hosp Med Bull. 1958;6(1):111-9.

Winick M, Noble A. Cellular response in rats during malnutrition at various ages. $\mathrm{J}$ Nutrition. 1996;89:300-306.

Winocur G, Wojtowicz JM, Sekeres M, Snyder JS, Wang S. Inhibition of neurogenesis interferes with hippocampus-dependent memory function. Hippocampus. 2006;16(3):296-304.

Woo M, Hakem R, Furlonger C, Hakem A, Duncan GS, Sasaki T, Bouchard D, Lu L, Wu GE, Paige CJ,Mak TW Caspase-3 regulates cell cycle in B cells: a consequence of substrate specificity.Nat Immunol. 2003;4(10):1016-22. 
Yan XX, Najbauer J, Woo CC, Dashtipour K, Ribak CE, Leon M.Expression of active caspase-3 in mitotic and postmitotic cells of the rat forebrain. J Comp Neurol. $2001 ; 433(1): 4-22$.

Yang T, Zhuang L, Terrando N, Wu X, Jonhson MR, Maze M, Ma D.A clinically relevant model of perinatal global ischemic brain damage in rats. Brain Res. 2011;1383:317-23.

Yuan J, Yankner BA.Apoptosis in the nervous system.Nature. 2000;407:802-9.

Zecevic N, Chen Y, Filipovic R. Contributions of cortical subventricular zone to the development of the human cerebral cortex. J Comp Neurol. 2005;491:109-22.

Zermati Y, Garrido C, Amsellem S, Fishelson S, Bouscary D, Valensi F, Varet B, Solary E, Hermine O.Caspase activation is required for terminal erythroid differentiation. J Exp Med. 2001;193(2):247-54.

Zhang RL, Zhang ZG, ChoppM.Neurogenesis in the adult ischemic brain: generation, migration, survival, and restorative therapy.Neuroscientist. 2005;11(5):408-16. Review.

Zhang CL, Zou Y, He W, Gage FH, Evans RM.A role for adult TLX-positive neural stem cells in learning and behaviour.Nature. 2008;451(7181):1004-7.

Zhao YD, Ou S, Cheng SY, Xiao Z, He WJ, Zhang JH, RuanHZ.Dendritic development of hippocampal CA1 pyramidal cells in a neonatal hypoxia-ischemia injury model.J Neurosci Res. 2013. [Epub ahead of print]

Zhu L, Wu L, Yel D, Fan M. Effects of hypoxia on the proliferation and differentiation of NSCs. Mol Neurobiol. 2005;31(1-3):231-42.

Zhu C, Qiu L, Wang X, Xu F, Nilsson M, Cooper-Kuhn C, Kuhn HG, Blomgren K. Age-dependent regenerative responses in the striatum and cortex after hypoxiaischemia. J Cerebr Blood F Met. 2009;29(2):342-54. 
APÊNDICES - Artigos de Periódicos 
APÊNDICE A -Takada SH, Sampaio CA, Allemandi W, Ito PH, Takase LF, Nogueira MI. A modified rat model of neonatal anoxia: Development and evaluation by pulse oximetry, arterial gasometry and Fos immunoreactivity.J Neurosci

Methods.2011;198(1):62-9. 


\title{
A modified rat model of neonatal anoxia: Development and evaluation by pulseoximetry, arterial gasometry and Fos immunoreactivity
}

\author{
S.H. Takada ${ }^{\mathrm{a}, *}$, C.A.G. Sampaio ${ }^{\mathrm{a}}$, W. Allemandi ${ }^{\mathrm{a}}$, P.H. Ito ${ }^{\mathrm{a}}$, L.F. Takase ${ }^{\mathrm{b}}$, M.I. Nogueira ${ }^{\mathrm{a}, *}$ \\ a Laboratory of Neuroscience, Institute of Biomedical Sciences, Universidade de São Paulo, São Paulo, SP, Brazil \\ ${ }^{\mathrm{b}}$ Department of Morphology and Pathology, Center of Biological and Health Sciences, Universidade Federal de São Carlos, São Carlos, SP, Brazil
}

\section{A R T I C L E I N F O}

\section{Article history:}

Received 7 January 2011

Received in revised form 8 March 2011

Accepted 9 March 2011

\section{Keywords:}

Neonatal anoxia

Anoxia animal model

Fos immunoreactivity

Oximetry

Peripheral arterial oxygen saturation

Rats

\begin{abstract}
A B S T R A C T
Neonatal anoxia is a worldwide clinical problem that has serious and lasting consequences. The diversity of models does not allow complete reproducibility, so a standardized model is needed. In this study, we developed a rat model of neonatal anoxia that utilizes a semi-hermetic system suitable for oxygen deprivation. The validity of this model was confirmed using pulse oximetry, arterial gasometry, observation of skin color and behavior and analysis of Fos immunoreactivity in brain regions that function in respiratory control. For these experiments, 87 male albino neonate rats (Rattus norvegicus, lineage Wistar) aged approximate 30 postnatal hours were divided into anoxia and control groups. The pups were kept in an euthanasia polycarbonate chamber at $36 \pm 1{ }^{\circ} \mathrm{C}$, with continuous $100 \%$ nitrogen gas flow at $3 \mathrm{~L} / \mathrm{min}$ and $101.7 \mathrm{kPa}$ for $25 \mathrm{~min}$. The peripheral arterial oxygen saturation of the anoxia group decreased $75 \%$ from its initial value. Decreased $\mathrm{pH}$ and partial pressure of oxygen and increased partial pressure of carbon dioxide were observed in this group, indicating metabolic acidosis, hypoxia and hypercapnia, respectively. Analysis of neuronal activation showed Fos immunoreactivity in the solitary tract nucleus, the lateral reticular nucleus and the area postrema, confirming that those conditions activated areas related to respiratory control in the nervous system. Therefore, the proposed model of neonatal anoxia allows standardization and precise control of the anoxic condition, which should be of great value in indentifying both the mechanisms underlying neonatal anoxia and novel therapeutic strategies to combat or prevent this widespread public health problem.
\end{abstract}

(c) 2011 Elsevier B.V. All rights reserved.

\section{Introduction}

Neonatal anoxia, which is considered a worldwide clinical problem, is one of the most important causes of encephalic lesions in human newborns. Such lesions can have serious and lasting consequences, including mental retardation, cerebral palsy, epilepsy, hearing and visual deficiencies, as well as motor and behavioral deficits (Hedner and Lundborg, 1980; Volpe, 1992; Dell'anna et al., 1993; Dell'anna et al., 1995; Dell'Anna et al., 1997; Faraone and Biederman, 1998; Vannucci et al., 1999; Cannon et al., 2002; Wainwright et al., 2004; Caputa et al., 2005; Casolini et al., 2005; Mikati et al., 2005; Rogalska et al., 2006; Majeed et al., 2007; Chen et al., 2007). The incidence of neonatal anoxic insults appears to be $2-4 / 1000$ full-term infants, but this rate is much higher (approximately $60 \%$ ) in low-weight premature newborns, corresponding to

\footnotetext{
* Corresponding authors at: Institute of Biomedical Sciences, Universidade de São Paulo, Departamento de Anatomia, Laboratório de Neurociências, Av. Prof. Lineu Prestes, 2415 Cidade Universitária, São Paulo, SP CEP: 05508-900, Brazil. Tel.: +55 1130917401

E-mail address: minog@usp.br (M.I. Nogueira).
}

a significant public health concern (Vannucci, 1997; Laviola et al., 2004).

The diversity of models described in the literature does not allow complete reproducibility due to a large variety of different parameters, so a standardized model is needed. Controlled experiments could reveal links between particularities of the sequelae and morpho-functional changes that follow anoxic insult. Therefore, developing an animal model of anoxia is an important contribution to this field.

In this study, based on the literature reports regarding neonatal anoxia we developed a non-invasive model of anoxia in neonate rats. This method, actually, mostly an optimization of those in use, consists of some adjustments in the apparatus added to the standardization of various parameters of anoxic stimulation, which were tested and evaluated. In this condition, it allows precise and reproducible control of the duration and extent of anoxia. It may also simulate the physiological consequences of human neonatal anoxia. The effectiveness of this method was assessed monitoring arterial peripheric oxygen saturation, arterial gasometry, motor and respiratory behavior and also by the skin color of neonate rats during the oxygen deprivation period. In addition, the effects of anoxia on the central nervous system were analyzed with a 

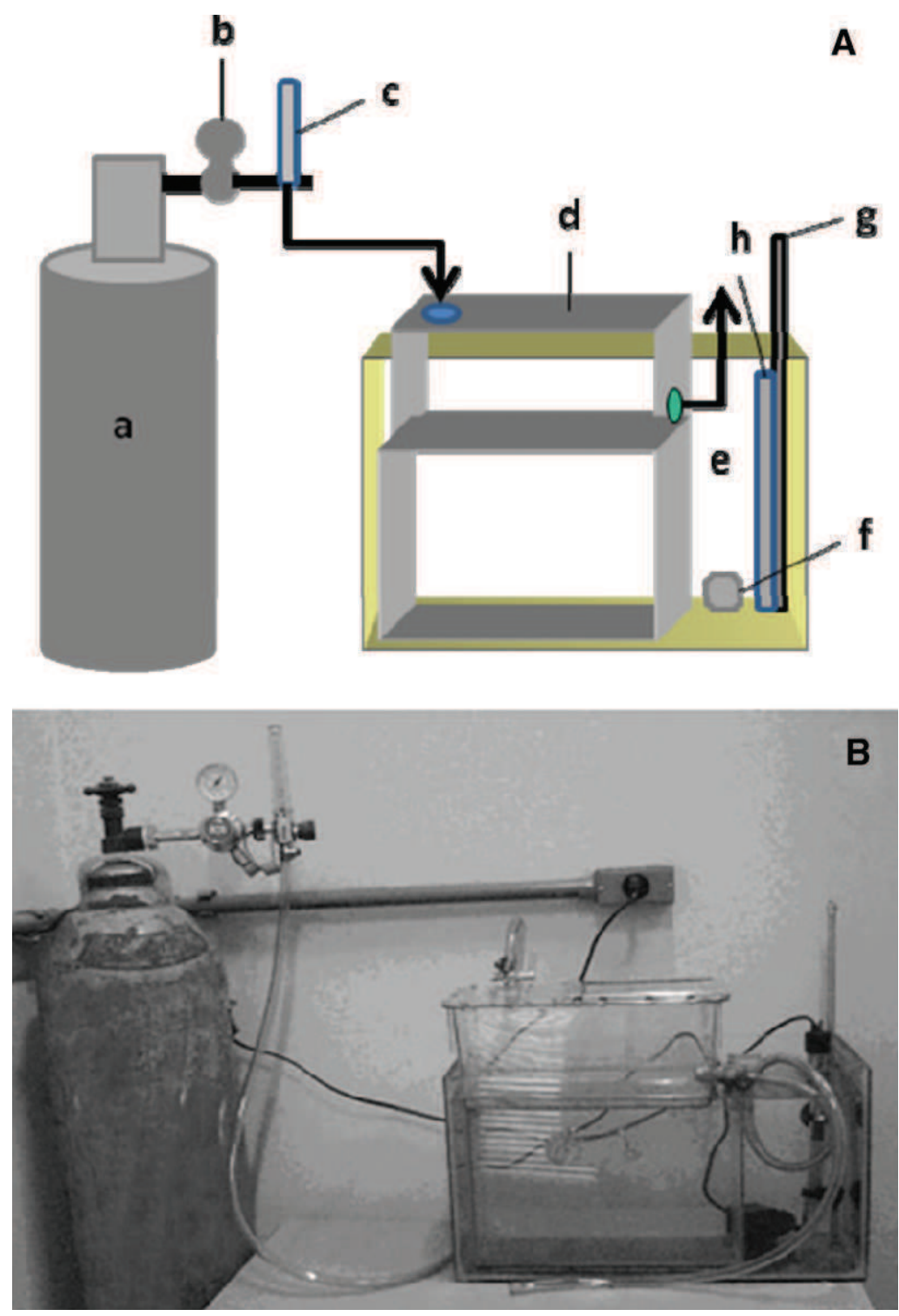

Fig. 1. The system used to induce anoxia in neonate rats. (A) Schematic drawing showing: (a) nitrogen gas cylinder (100\%), (b) manometer, (c) flowmeter, (d) semi-hermetic polycarbonate chamber, (e) glass box with heated water, (f) diffusion water pump (to maintain homogeneous water temperature), (g) thermometer and (h) electrical resistance water heater; black arrows indicates inflow and outflow of gas. (B) Semi-hermetic chamber connected to the cylinder of nitrogen gas and partially immersed in heated water.

Fos immunoreactivity (Fos-IR) assay for neuronal activation in the nuclei of the nervous system that are related to respiratory control.

\section{Materials and methods}

\subsection{Animals}

Eighty-seven male albino neonate rats (Rattus norvegicus, Wistar), approximately $30 \mathrm{~h}$ old and weighing $6-8 \mathrm{~g}$, were used. The pups were housed with the dam in the home cage at the vivarium of the Institute of Biomedical Sciences, Universidade de São Paulo, under a $12: 12 \mathrm{~h}$ light/dark cycle and at a constant temperature $\left(23 \pm 1^{\circ} \mathrm{C}\right)$, with water and food provided ad libitum. The procedures were approved by the University Ethics Committee and conformed to the guide for the Care and Use of Laboratory Animals (COBEA Protocol no. 134, fls. 38 of book 2).

\subsection{Development of the anoxia system}

The exposure of animals to anoxia was performed in a semihermetic polycarbonate chamber $(31.0 \times 14.0 \times 19.5 \mathrm{~cm})$, which is commonly used for euthanization of mice. The term semi-hermetic means that the chamber has a sliding polycarbonate door with no sealant around the door, leading to a minimum increase of pressure inside the chamber due to a gap of $2 \mathrm{~mm}$. The chamber was equipped with a gas inlet and outlet as well as connected to a manometer, flowmeter and a $100 \%$ nitrogen gas cylinder. The chamber was partially immersed in warm water (between 35 and $37^{\circ} \mathrm{C}$ ) to avoid hypothermia and thus potentiate anoxic lesions. The water was heated by a water resistance heater supported by a water pump to homogenize the temperature, which was measured by a mercury thermometer (Fig. 1).

To induce anoxia, the lid was rapidly closed after individually placing neonates in the chamber, and this chamber was completely saturated with $100 \%$ nitrogen at a flow of $3 \mathrm{~L} / \mathrm{min}$ at a pressure of approximately $101.7 \mathrm{kPa}$ (Tang and Nakazawa, 2005; Rogalska 


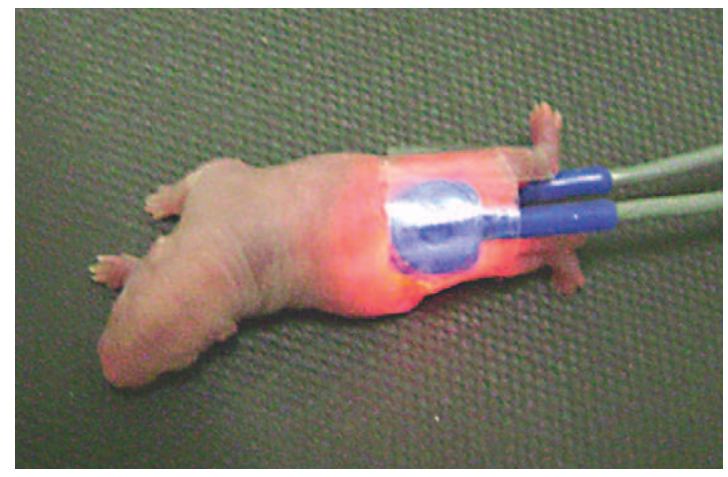

Fig. 2. Photograph of a neonate rat with a Y sensor attached to the proximal region of the animal's tail.

et al., 2006; Coq et al., 2008) for 25 min (Dell'anna et al., 1995b). After recovery, as monitored by skin color, respiration and locomotor behavior, which occurred in an average of 5 min after removal from the chamber, the animals were returned to the dams.

The control group was exposed to the same experimental conditions, but the chamber contained air instead of nitrogen.

\subsection{Measurement of peripheral oxygen saturation}

Ten pups (anoxia, $n=5$; control, $n=5$ ) were used for the measurement of peripheral oxygen saturation.

A pulse oximeter (Philips Respironics/Novametrix, model 513, Murrysville, Pennsylvania) with a pediatric Y sensor was coupled with colorless tape near the proximal region of the animals' tail at the dorsal and ventral faces of the abdomen (Decker et al., 1989) (Fig. 2). After positioning the sensor, the apparatus was turned on and a value between $97 \%$ and $99 \%$ of oxygen saturation was observed when the sensor was correctly positioned. Pups were placed into the chamber with the connected oximetry apparatus and the values of oxygen saturation were collected by an observer every minute during the anoxia or control procedures.

This pulse oximeter model is appropriate for veterinary utilization and has superior performance under conditions in which motion artifacts may occur and under conditions of low blood perfusion, as found in our experiment. The pediatric Y sensor was used in our animals because it is indicated for small areas.

\subsection{Analyses of respiration, locomotor behavior and skin color change}

Analyses of motor and respiratory behaviors as well as skin color changes were used as additional parameters to evaluate oxygen saturation in the pups (Strata et al., 2004). Ten pups, divided into two groups (control, $n=5$; anoxia, $n=5$ ), were individually placed in the chamber and submitted to control or anoxia procedure. Any changes in skin color or locomotor behavior were recorded every minute by an observer. Respiration was observed based on inspiration movements in chest wall and number and frequency of gasping movements. This experiment was not performed on the same pups used for oximetry because $\mathrm{Y}$ sensor functioned as a restriction device for active movements and covered part of skin leading to difficulties to observe color changes.

\subsection{Blood sample collection and analysis of $\mathrm{pH}$, partial pressure} of oxygen $\left(\mathrm{pO}_{2}\right)$ and partial pressure of carbon dioxide $\left(\mathrm{pCO}_{2}\right)$

For analysis of arterial blood, another ten pups (anoxia, $n=5$; control, $n=5$ ) were deeply anesthetized and arterial blood was collected immediately after anoxic or control procedure by heart puncture. The recovery period of $5 \mathrm{~min}$ was not included in this procedure. For the heart puncture, heparinized syringes (BD Preset, $\mathrm{Ca}^{2+}$ LH 30 I.U. 1ML) that allowed blood collection without air contact were introduced into the intercostals space between the third and fourth ribs in the latero-ventral region of the pup. When the needle entered the left ventricle, blood flow started to raise the syringe plunger and $100 \mu \mathrm{l}$ of arterial blood was collected.

The samples were stored in a cold water bath $\left(0^{\circ} \mathrm{C}\right)$, and $\mathrm{pH}$, $\mathrm{pO}_{2}$ and $\mathrm{pCO}_{2}$ were analyzed within 45 min using an ABL5 blood gas analyzer (Radiometer, Denmark).

\subsection{Fos immunohistochemistry}

Two hours after the stimulus, which is considered long enough to reach the maximum level of Fos expression (Hoffman and Lyo, 2002), the pups were deeply anesthetized with 35\% chloral hydrate and perfused through the left ventricle with $30 \mathrm{ml}$ of $0.9 \%$ saline solution at room temperature, followed by $50 \mathrm{ml}$ of $4 \%$ paraformaldehyde solution plus borax, $\mathrm{pH} 9.5$ at $4{ }^{\circ} \mathrm{C}$ (Nogueira et al., 1997). The brains were removed from the crania and cryoprotected in $0.1 \mathrm{M}$ phosphate buffered saline (PBS), $\mathrm{pH} 7.5$ plus $20 \%$ sucrose overnight; the preserved brain tissue was sectioned into $30-\mu \mathrm{m}$ thick coronal sections using a cryostate (Leica Microsystems Nussloch GmbH, CM1850, Germany). All sections were collected in three series, mounted on slides and stored at $4{ }^{\circ} \mathrm{C}$. These series contained similar caudo-rostral sequences of the brain from each animal.

The second tissue series from each animal was processed for Fos immunohistochemistry using an avidin-biotin complex with 3,3'diaminobenzidine tetrahydrochloride (the $\mathrm{ABC}-\mathrm{DAB}$ technique).

Briefly, the slides were incubated for 5 min in $0.1 \%$ hydrogen peroxide to inhibit endogenous peroxidase activity. The slides were immediately incubated for $48 \mathrm{~h}$ in primary polyclonal rabbit anti-Fos serum (Oncogene Research Products, San Diego, CA) in blocking solution $(1: 10,000 ; 2 \%$ normal goat serum and $0.3 \%$ Triton X-100 in PBS) at room temperature. The slides were rinsed in PBS and incubated for a further $90 \mathrm{~min}$ in biotinylated goat antirabbit secondary antiserum (Vector Laboratories, Burlingame, CA) in blocking solution (1:200). The slides were then incubated with an avidin-biotin complex (Vectastain Elite ABC Kit, Vector Laboratories, Burlingame, CA) in PBS (1:500) for $90 \mathrm{~min}$. After three rinses in PBS, the slides were reacted with 3,3'-diaminobenzidine tetrahydrochloride (DAB) as a chromogen and nickel ammonium sulfate was used to intensify the reaction product. When Fos staining was sufficient, as established by microscopic examination, the reaction was stopped by rinsing the slides in PBS. The slides were dried overnight and the labeling was intensified with osmium tetroxide. Finally, the slides were dehydrated and coverslipped under DPX.

\subsection{Fos-IR data analysis}

The slides were examined with a Nikon E-1000 microscope (Nikon Corporation, Tokyo, Japan) using the bright field to quantify the number of Fos-immunoreactive (Fos-IR) neurons; only those nuclei that were clearly and intensely stained were counted. The boundaries of each nucleus were established according to the Atlas of Developing Rat Nervous System by Paxinos et al. (1994) using an adjacent Nissl-stained series as a reference.

\subsection{Statistical analysis}

The data were expressed as means \pm SEM.

For the statistical analysis of the Fos-IR data in the solitary tract nuclei, two-way ANOVA (treatment $\times$ region) followed by Tukey's test was used. For the statistical analysis of the area postrema and 


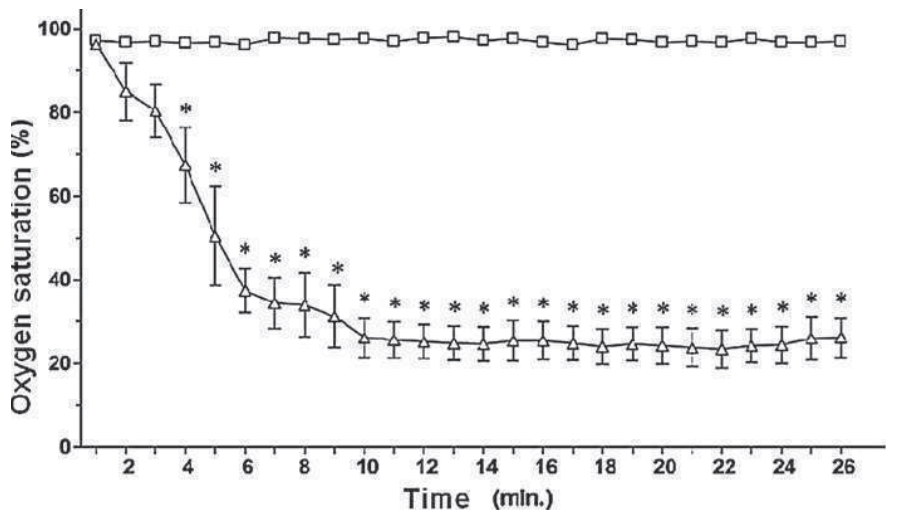

Fig. 3. Evaluation of peripheral arterial oxygen saturation by pulse oximetry over time. Legend: $(\square)$ control group, $(\triangle)$ anoxia group; $\left({ }^{*}\right)$ statistically significant values.

lateral reticular nuclei, Student's $t$-test was employed. Probability values $<0.05$ were considered to be statistically significant.

For the statistical analysis of the gasometry data $\left(\mathrm{pH}, \mathrm{pO}_{2}\right.$ and $\mathrm{pCO}_{2}$ ) Student's $t$-test was used and the repeated measures ANOVA was employed for the statistical analysis of the oximetry.

\section{Results}

\subsection{Peripheral arterial oxygen saturation}

A comparison of the peripheral arterial oxygen saturation values of the anoxia $(n=5)$ and control $(n=5)$ groups is shown in Fig. 3. This parameter was evaluated in the neonates of the anoxia group by pulse oximetry, which showed an average 30\% drop in arterial peripheral oxygen saturation by the fourth minute of nitrogen exposure. This value progressively decreased until the tenth minute and then remained stable until the end of the anoxic period $(25 \pm 0.8 \%)$. Therefore, between 1 st minute and 26 th minutes from the beginning of the procedure, there was a $75 \%$ drop in peripheral arterial oxygen saturation in the anoxia group. The control group showed no changes in this parameter over time, exhibiting a constant value of $97 \pm 0.5 \%$.

\subsection{Skin color and behavior}

Hyperactivity was observed after $1 \mathrm{~min}$ of exposure to anoxia and lasted up to $2 \mathrm{~min}$, followed by a change in the color of the animal's skin, from pink to blue. This change was followed by the loss of movement, onset of sporadic gasping, which became less frequent, and, finally, total immobility in the last 5-8 min. In contrast, the control group animals had normal activity levels during the procedure, and their skin color remained pink until the end of the experiment.

\subsection{Analysis of $\mathrm{pH}, \mathrm{pO}_{2}$ and $p \mathrm{CO}_{2}$}

The $\mathrm{pH}, \mathrm{pO}_{2}$ and $\mathrm{pCO}_{2}$ levels in the anoxia and control groups are shown in Fig. 4. The $\mathrm{pH}$ in the anoxia group $(6.7 \pm 0.4)$ was lower than that in the control group $(7.0 \pm 0.08)(p=0.008)$. The $\mathrm{pO}_{2}$ levels were lower in the anoxia group $(47.8 \pm 4.48)$ than in the control group $(108.6 \pm 10.69)$, and the $\mathrm{pCO}_{2}$ levels were significantly elevated in the anoxia group $(117.4 \pm 12.66)$ compared with the control group $(38.2 \pm 4.76)(p<0.001)$. These results are characteristic of hypoxia and hypercapnia, respectively (Levitzky, 2009).
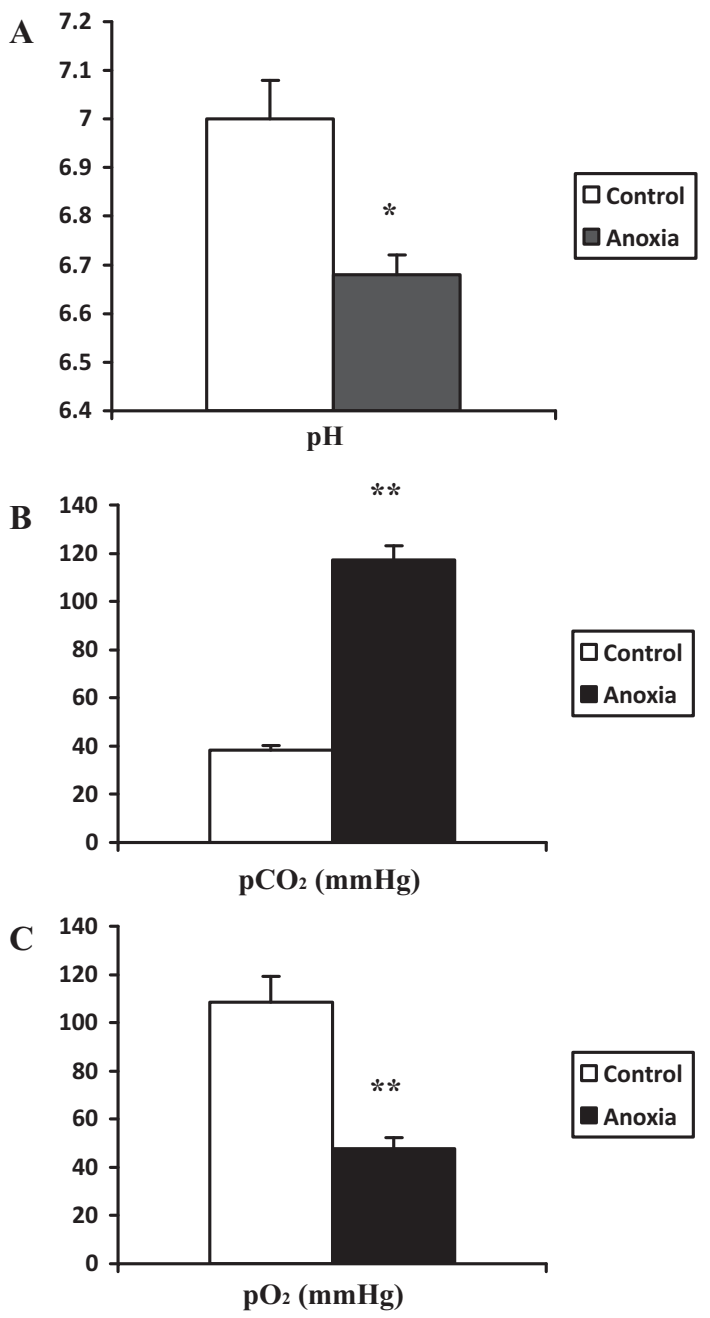

Fig. 4. Parameter levels evaluated by gasometry analysis in anoxia and controls groups: (A) $\mathrm{pH},(\mathrm{B}) \mathrm{pCO}_{2}$ and $(\mathrm{C}) \mathrm{pO}_{2} \cdot{ }^{*} p=0.008,{ }^{* *} p<0.001$.

\subsection{Fos immunoreactivity (Fos-IR)}

There was a visible difference in the Fos-IR labeling of neurons between the anoxia and control groups in areas of the brain related to respiratory control such as the area postrema, the nuclei of the solitary tract and the lateral reticular nuclei of the medulla. In the area postrema, the mean number of Fos-IR neurons was $34 \pm 5.7$ in the anoxia group and $3 \pm 1.0$ in the control group $(p<0.001)$ (Fig. 5 ). There was also a difference between the anoxia and control groups in the lateral reticular nuclei ( $32 \pm 4.9$ vs. $11 \pm 3.9 ; p<0.05$ ) (Fig. 6).

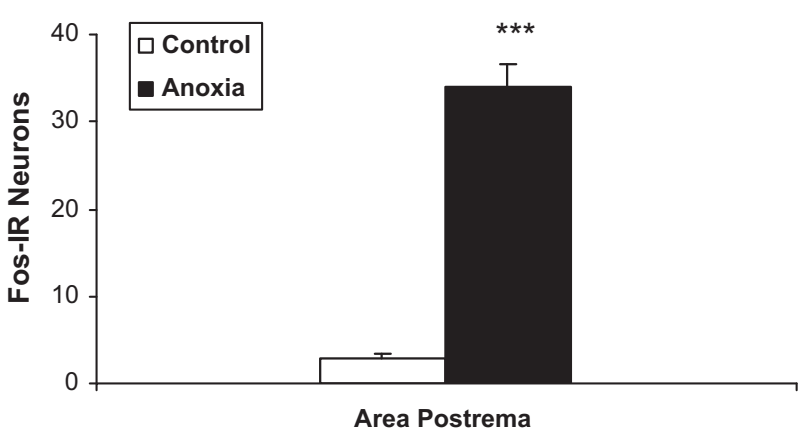

Fig. 5. Evaluation of Fos protein immunoreactivity in the area postrema. Control $(3 \pm 1.0)$ and anoxia $(34 \pm 5.7)$ groups. ${ }^{* * *} p<0.001$. 


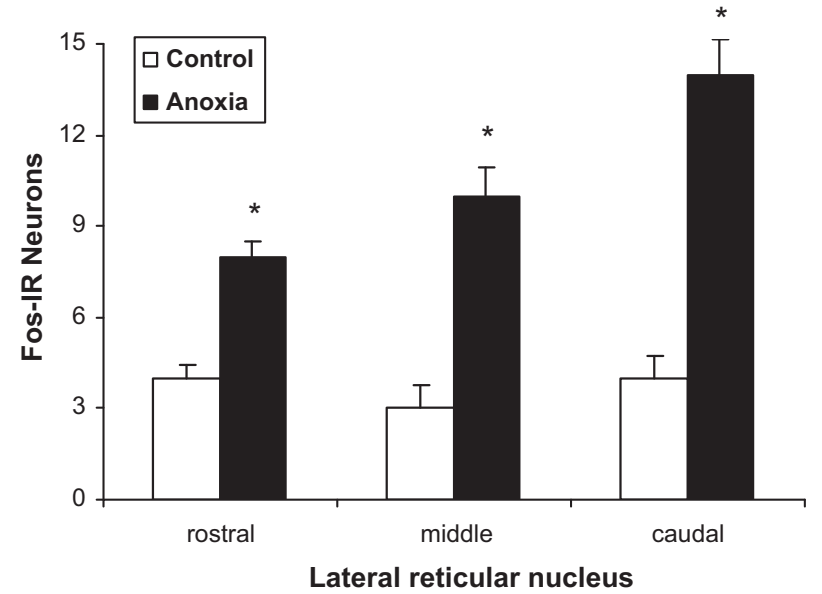

Fig. 6. Evaluation of Fos protein immunoreactivity in the lateral reticular nucleus of the medulla. Control $(11 \pm 3.9)$ and anoxia $(32 \pm 4.9)$ groups. ${ }^{*} p<0.05$.

For analytical purposes, the solitary tract nuclei were anatomically divided into 3 regions: rostral, middle and caudal. The mean numbers of Fos-IR neurons in the anoxia group were $3 \pm 1.3$ (rostral); $4 \pm 1.6$ (middle) and $15 \pm 1.7$ (caudal). In the control group, these numbers were $2 \pm 2.1$ (rostral); $3 \pm 2.1$ (middle) and $3 \pm 1.5$ (caudal). In the anoxia group, Fos-IR in the caudal region was significantly higher than in any region of the control group $(p<0.05)$ and was also higher than in the other regions of the anoxia group $(p<0.05)$ (Fig. 7).

Photographs of Fos-immunoreactivity in brain regions correlated to respiratory control are shown in Fig. 8.

\subsection{Mortality rates}

Preliminary experiments performed in this laboratory showed that periods of anoxia longer than 25 min caused high mortality rates ( $\geq 50 \%$ ), whereas the period of 25 min presented mortality rate of $9.43 \%$ (with death having occurred during the anoxia procedure in the semi-hermetic chamber). For this mortality rate study, we used six litters (53 pups). Studies using a similar procedure reported mortality rate of approximately 10\% (Dell'anna et al., 1991; Iuvone et al., 1996).

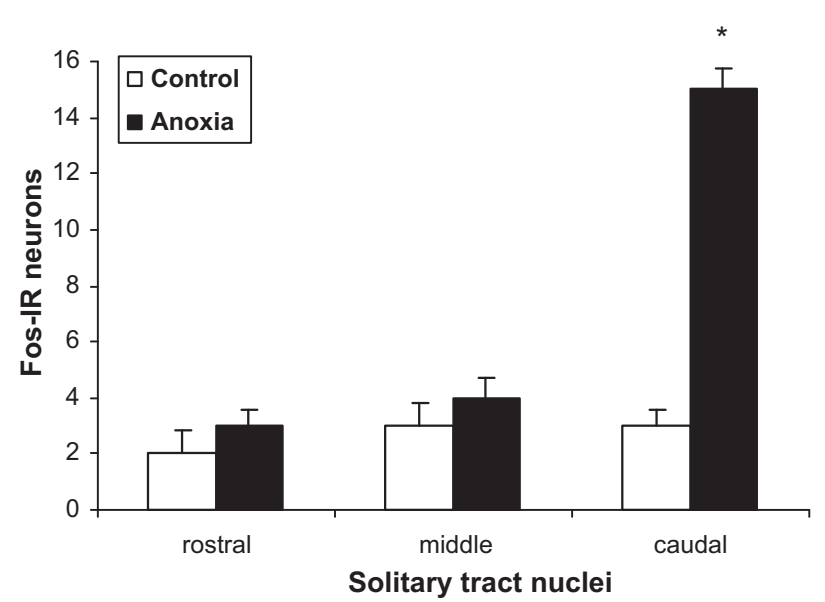

Fig. 7. Evaluation of Fos immunoreactivity in the solitary tract nuclei. Control (rostral: $2 \pm 2.1$; middle: $3 \pm 2.1$ and caudal: $3 \pm 1.5$ ) and anoxia (rostral: $3 \pm 1.3$; middle: $4 \pm 1.6$ and caudal: $15 \pm 1.7$ ) groups. ${ }^{*} p<0.05$.

\section{Discussion}

In this research a model of neonatal anoxia in rats, was developed with low cost materials, which is non-invasive and easily reproducible. In addition, testing and evaluations standardized various parameters of the anoxic stimulus. It was demonstrated that the described model elicits the main metabolic and physiological changes that occur in human neonates, when exposed to oxygen deprivation, such as arterial gasometry and oximetry alterations.

The rat is the most widely used animal in experimental studies, which is the reason they were selected for this study. The maturity of a newborn rat brain is comparable to that of a 24 -week-old human fetus and the brain of a ten-day-old rat is comparable to the brain of a newborn human (Nyakas et al., 1996). Therefore, taking into account the developmental periods under analysis is important when establishing research correlations between these animals and human neonates.

A literature review showed that three different methodologies and periods of development have been primarily used to cause oxygen deprivation in neonate rats. The first model is hypoxia-ischemia (initially proposed by Levine, 1960), in which seven-day-old rats undergo occlusion of one of the common carotid arteries and are placed in a chamber containing $8 \%$ oxygen and $92 \%$ nitrogen for periods ranging from $30 \mathrm{~min}$ to $3 \mathrm{~h}$ (Rice et al., 2004; Gunn et al., 1990; Åden et al., 1994; Vannucci et al., 1999; Oorschot et al., 2000; Ten et al., 2003). The second model is perinatal asphyxia, in which a female about to give birth is decapitated or anesthetized, and its uterus (containing the pups) is removed and immersed in saline solution for 16-25 min (Dell'anna et al., 1995a; Flores et al., 2002; El-Khodor and Boksa, 2003; Cirulli et al., 2003; Juarez et al., 2003; Venerosi et al., 2004). In the third model of neonatal anoxia, newborns (at approximately $30 \mathrm{~h}$ of age) are placed in a hermetic chamber containing $100 \%$ nitrogen for 20-30 min (Dell'anna et al., 1995b; Buwalda et al., 1995; Iuvone et al., 1996; Nakajima et al., 1996, 1999; Tang and Nakazawa, 2005; Rogalska et al., 2006; Coq et al., 2008) and many different parameters of temperature, pressure and flow are used.

The third model (neonatal anoxia) is the model of choice for researchers interested in the behavioral sequelae resulting from oxygen deprivation, which include attention deficit hyperactivity disorder (ADHD), spatial memory learning deficits, and abnormal responses to stress. This method has fewer stress-related variables because it is not invasive and does not require the euthanization of the mother or subsequent use of a surrogate mother, as required in the second model (perinatal asphyxia). The first model (hypoxia-ischemia) allows visualization of the unilateral effects of the stimulus and is valuable because it allows histological comparison between brain hemispheres. The major disadvantage of the hypoxia-ischemia model is that it does not enable behavioral tests. Therefore, considering our research goals to simulate anoxic insults in premature humans at about 24 weeks of age, the neonatal anoxia model was the suitable choice. Interestingly, this model produces changes in adult behavior, based on studies that are ongoing in our laboratory (unpublished data).

Contrary to Hicks et al. (1962), who stated that anoxia alone could not produce any harm in neonate rats, we observed that simple modifications in this model can produce important alterations in neonate brain, most of them similar to human alterations due to neonatal anoxia. For example, the model proposed by Coq et al. (2008) is very interesting because it tries to mimic the condition called cerebral palsy, a very common sequel of neonatal anoxia, but presents some differences from the model we present. The authors separated the anoxic insult in two episodes of 12 min each, at $\mathrm{P} 0$ and P1, while we used a single episode of $25 \mathrm{~min}$ of nitrogen exposure at P2. 

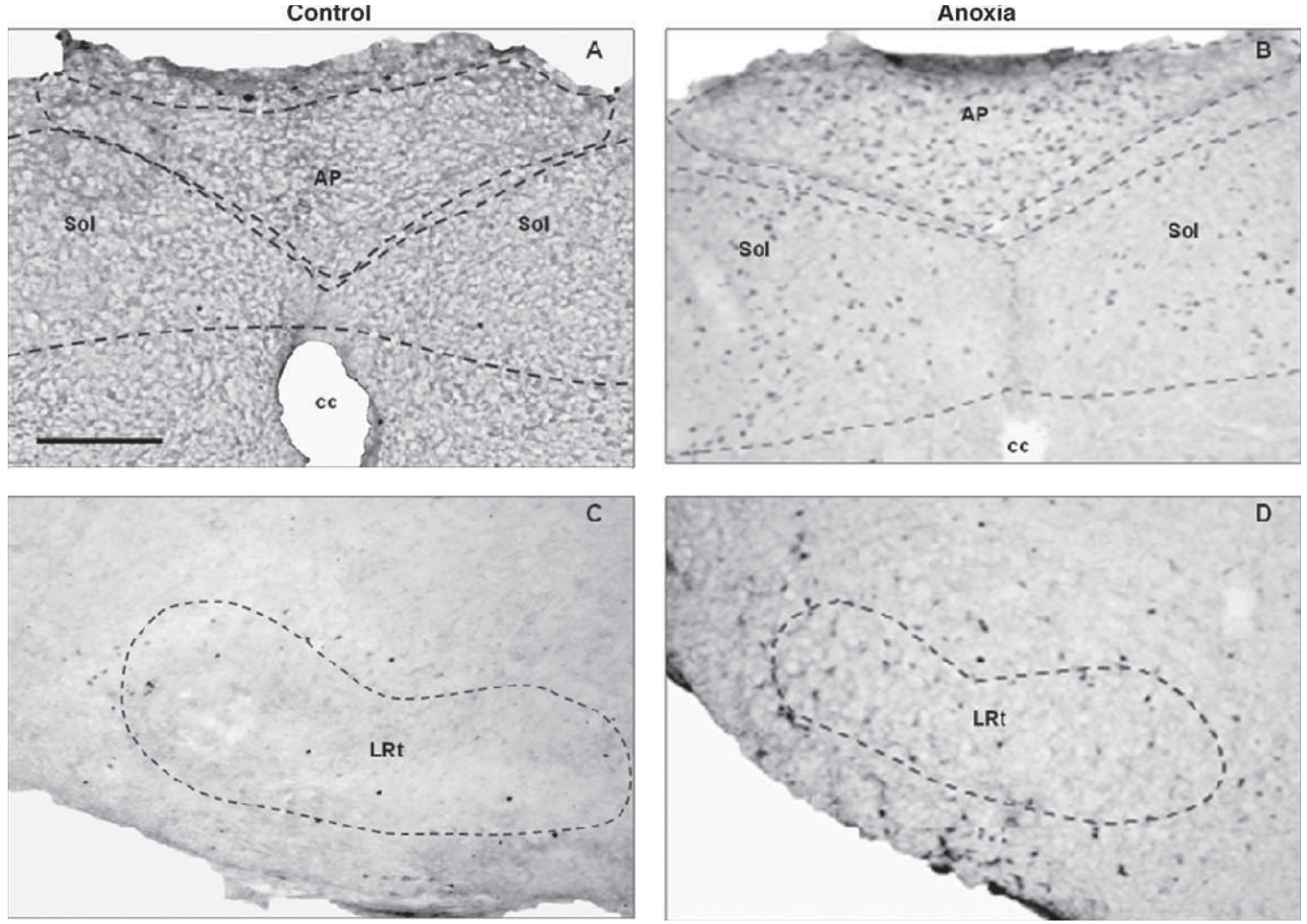

Fig. 8. Photomicrographs of brainstem coronal sections, depicting Fos protein immunoreactivity in the solitary tract nuclei (Sol) and area postrema (AP) (A, B) and in the lateral reticular nucleus (C, D) of a control animal (left) and an anoxic animal (right). CC: central canal. Scale bar: $500 \mu \mathrm{m}$.

The other difference between the two models is the use of a semi-hermetic chamber instead of a hermetic one to minimize the condition of increased pressure inside the chamber, as already discussed.

Nakajima et al. $(1996,1999)$ demonstrated that exposure to anoxia had significant influence on striatal monoamine metabolism in immature brain using in vivo microdialysis and subsequent HPLC. In their study the pups were exposed to warmed and humidified $100 \%$ nitrogen delivered at $0.5 \mathrm{~L} / \mathrm{min}$ in a hermetic chamber for 16 non-continuous minutes. During this period nitrogen income is briefly cut when the pups presented incontinence of urine or feces. After confirming their recovery, anoxic exposure is resumed. This process is repeated several times until the scheduled time is reached. If one of the pups dies, the exposure is stopped immediately, leaving the residual time. The main difference between Nakajima's model $(1996,1999)$ and the model used in the present study is the nitrogen flow regimen. The model using continuous $25 \mathrm{~min}$ of anoxia, without recovery time for the pups, mimics better the conditions of anoxia usually found in newborn humans.

The other parameters used in this study were adopted from the literature and are detailed below. The water temperature (between 35 and $37^{\circ} \mathrm{C}$ ) was selected to increase the normally low temperature of the newborns (around $33^{\circ} \mathrm{C}$ ), which is a temperature that exerts neuroprotective action against anoxia (Caputa et al., 2005; Rogalska et al., 2006). The flow rate $(3 \mathrm{~L} / \mathrm{min})$ was scaled to the dimensions of the chamber so that it would be completely saturated with the gas in less than $3 \mathrm{~min}$. The chamber pressure $(101.7 \mathrm{kPa})$ roughly corresponds to atmospheric pressure, which is generally adopted to avoid conditions of hypobaric or hyperbaric anoxia, and the introduction of the semi-hermetic feature in the chamber assures the maintenance of this pressure.
The pulse oximetry technique employed to measure the degree of hypoxia or anoxia has become a vital tool in pediatrics and neonatology (Bakr and Habib, 2005) because it is one of the most reliable ways to monitor the blood circulation of a patient, and it has the advantage of being a non-invasive procedure (Shimada et al., 1984). These characteristics also made pulse oximatry useful in this study. Hypoxemia is a condition where the concentrations of peripheral arterial oxygen are at or below $85 \%$ of normal (Hay et al., 2002; Petrova and Mehta, 2006). Studies in human fetuses have shown that when the peripheral oxygen saturation drops below $30 \%$ of normal and remains there for more than $10 \mathrm{~min}$, fetal blood pH drops below the critical value of 7.2 (a condition known as metabolic acidosis), which is characteristic of anoxia (Swedlow, 1997; Bloom et al., 1999; Gorenberg et al., 2003). In this study, the neonatal anoxia group presented values of peripheral oxygen saturation below $30 \%$ of normal by the tenth minute, and this value remained practically unchanged until the end of the experiment (15 min later). This result is evidence that the animal suffered an anoxic insult severe enough to generate metabolic changes and acidosis. The observed skin color and behavioral changes of the anoxia group animals further confirmed this condition, as pointed in previous researches (Nakajima et al., 1999; Strata et al., 2004).

The anoxia group presented lower $\mathrm{pH}$ values than the control group, as shown by gasometry analysis, revealing the presence of metabolic acidosis similar to that seen in most asphyxiated human neonates. The $\mathrm{pO}_{2}$ and $\mathrm{pCO}_{2}$ values in the anoxia group indicated that these pups were experiencing hypoxia and hypercapnia. These conditions occur in human neonates who suffered from neonatal anoxia or asphyxia, and the resulting hypoxia and hypercapnia likely represent attempts to protect the nervous system from injuries since studies have shown that hypercapnia may have a neuroprotective effect (Vannucci et al., 1995) and that hypocapnia 
$\left(\mathrm{pCO}_{2}\right.$ between 25 and $30 \mathrm{mmHg}$ ) can lead to an increased incidence of cystic periventricular leucomalacia and cerebral palsy in preterm infants (Ambalavanan and Carlo, 2001).

Because the brain activity could not be directly measured, we monitored the level of Fos expression, which is a physiological marker of neuronal changes after the anoxic insult, to verify whether the central respiratory control areas of the brain were involved under these conditions (Dell'anna et al., 1995a; Gunn et al., 1990). Research reports have shown that moderate systemic hypoxia in conscious rabbits or rats resulted in high levels of expression of c-fos in various regions of the lower brain stem, including the solitary tract nuclei and the lateral reticular nuclei (Erickson and Millhorn, 1994; Smith et al., 1995; Breen et al., 1997; Hirooka et al., 1997; Buller et al., 1999; Berquin et al., 2000).

Fos-IR experiments revealed labeled neurons in the solitary tract nuclei of both the anoxia and control groups but labeled neurons were more numerous in the anoxia group, especially in its caudal portion near the obex, where ventilatory responses to hypoxia are mediated (Finley and Katz, 1992). In addition, there was a higher density of labeling in the area postrema of the anoxia group relative to the control group. This circumventricular organ is considered to be the chemosensitive portion of the dorsal vagal complex (Saper, 1995) and its connections in rats (Shapiro and Miselis, 1985; Larsen et al., 1991) are evidence of its involvement in the regulation of cardiovascular functions (Ling and Wong, 1987). Our data are consistent with previous studies that detected increased expression of c-fos in this region after exposure to hypobaric hypoxia (Kaur et al., 2001).

The Fos-IR observed in the lateral reticular nucleus of the neonates in the anoxia group is consistent with its role in motor activity and its coordination via connections with cerebellar areas (Rajakumar et al., 1992; Ruigrok et al., 1995). This observation is also consistent with a neural cardiovascular regulation (Rajakumar et al., 1992).

The absence of Fos-IR neurons in both of the groups in regions such as the Bötzinger complex, pre-Bötzinger complex or the Kölliker-Fuse nucleus may be intriguing. Almost all previous studies used the hypoxia or hypoxia-ischemia models (Erickson and Millhorn, 1994; Smith et al., 1995; Breen et al., 1997; Hirooka et al., 1997; Buller et al., 1999; Berquin et al., 2000), which cause different physiological and molecular responses from the model used here. Hypoxia does not cause total deprivation of oxygen, as occurs with anoxia, but when combined with ischemia, hypoxia is much more traumatic because the oxygenation of the capillary network ceases. Moreover, newborn rats used in models of hypoxia and hypoxia-ischemia were older (seven days old) than those used in this study (two days old) and thus possess a different degree of somatic maturation and different neural and physiological characteristics.

Berquin et al. (2000), demonstrated that the activation of Fos by hypoxia in respiratory control neurons in the medulla increases during the first two weeks of life. In the solitary tract nuclei, Ohtake et al. (2000) showed that the density of neurons doubly labeled for c-fos and NR-1 increases with age. Thus, neuronal activation in this region after oxygen deprivation might differ between newborn rats of two and seven days of age.

In summary, the experimental model of neonatal anoxia, presented here, which comprises mostly innovations with low cost materials in the former used apparatus and the standardization of the anoxia evaluation parameters, is effective for producing temporary oxygen deprivation in the brains of neonate rats, leading to metabolic and physiological responses consistent with anoxia. This conclusion was validated by oximetry, gasometry, behavior, and by Fos immunoreactivity in neural regions related to respiratory and cardiovascular control. The possibility to precisely control the anoxic conditions provided by this model should lead to rele- vant advances in the field of oxygen deprivation and the sequelae it causes.

\section{Acknowledgements}

We acknowledge the financial support from FAPESP (processes 2001-13873-5, 2007-52445-5 and 2010-01488-9) and S.H.T. was a recipient of a doctoral fellowship (process 2009-51557-0). We gratefully thank Professor Gerhard Malnic and his Ph.D student Thaissa Pessoa from Department of Physiology and Biophysics, for all the facilities with gasometry analysis. We thank Fabio Prosdocimi and Milton Kanashiro for their help in collecting blood samples of the rats. We also thank Cleyton Roberto Sobrinho for the help with the figures edition and Rosana C. Prisco for statistic analysis. This paper was revised by American Journal Experts.

\section{References}

Åden U, Bona E, Hagberg H, Fredholm BB. Changes in c-fos mRNA in the neonatal rat brain following hypoxic ischemia. Neurosci Lett 1994;180:91-5.

Ambalavanan N, Carlo WA. Hypocapnia and hypercapnia in respiratory management of newborn infants. Clin Perinatol 2001;28:517-31.

Bakr AF, Habib HS. Normal values of pulse oximetry in newborns at high altitude. J Trop Med 2005;51:170-3.

Berquin P, Cayetanot F, Gros F, Larnicol N. Postnatal changes in Fos-like immunoreactivity evoked by hypoxia in the rat brainstem and hypothalamus. Brain Res 2000;877:149-59.

Bloom SL, Swindle RG, McIntire DD, Leveno KJ. Fetal pulse oximetry: duration of desaturation and intrapartum outcome. Obstet Gynecol 1999;93:1036-40.

Breen S, Ress S, Walker D. Identification of brainstem neurons responding to hypoxia in fetal and newborn sheep. Brain Res 1997;748:107-21.

Buller KM, Smith DW, Day TA. NTS catecholamine cell recruitment by hemorrhage and hypoxia. Neuroreport 1999;10:3853-6.

Buwalda B, Nyakas C, Vosselman HJ, Luiten PGM. Effects of early postnatal anoxia on adult learning and emotion in rats. Behav Brain Res 1995;67:85-90.

Cannon M, Jones PB, Murray RM. Obstetric complications and schizophrenia: historical and meta-analytic review. Am J Psych 2002;159:1080-92.

Caputa M, Rogalska J, Wentowska K, Nowakowska A. Perinatal asphyxia, hyperthermia and hyperferremia as factors inducing behavioural disturbances in adulthood: a rat model. Behav Brain Res 2005:163:246-56.

Casolini P, Zuena AR, Cinque C, Matteucci P, Alemà GS, Adriani W, Carpinelli G Santoro F, Alleva E, Bosco P, Nicoletti F, Laviola G, Catalani A. Sub-neurotoxic neonatal anoxia induces subtle behavioural changes and specific abnormalities in brain group-I metabotropic glutamate receptors in rats. J Neurochem 2005; 95:137-45.

Chen WF, Chang H, Wong CS, Huang LT, Yang CH, Yang SN. Impaired expression of postsynaptic density proteins in the hippocampal CA1 region of rats following perinatal hypoxia. Exp Neurol 2007;204:400-10.

Cirulli F, Bonsignore LT, Venerosi A, Valanszano A, Chiarotti F, Alleva E. Long-term effects of acute perinatal asphyxia on rat maternal behavior. Neurotoxicol Teratol 2003;25:571-8.

Coq JQ, Strata F, Russier M, Safadi FF, Maerzenich MM, Byl NN, Barbe MF. Impact of neonatal asphyxia and hind limb immobilization on musculoskeletal tissues and S1 map organization: implications for cerebral palsy. Exp Neurol 2008;210:95-108.

Decker MJ, Conrad KP, Strohl KP. Noninvasive oximetry in the rat. Biomed Instrum Technol 1989;23:222-8.

Dell'anna ME, Calzolari S, Molinari M, Iuvone L, Calmici R. Neonatal anoxia induces transitory hyperactivity, permanent spatial memory deficits and CA1 cell density reduction in developing rats. Behav Brain Res 1991;45:125-34.

Dell'anna ME, Luthman J, Lindqvist E, Olson L. Development of monoamine systems after neonatal anoxia in rats. Brain Res Bull 1993;32:159-70.

Dell'anna E, Chen Y, Loidl F, Andersson K, Luthman J, Goiny M, Rawal R, Lindgren T, Herrera-Marchitz M. Short-term effects of perinatal asphyxia studied with Fos-immunocytochemistry and in vivo microdialysis in the rat. Exp Neurol 1995a;131:279-87.

Dell'anna ME, Geloso MC, Draisci G, Luthman J. Transient changes in Fos and GFAP immunoreactivity precede neuronal loss in the rat hippocampus following neonatal anoxia. Exp Neurol 1995b;131:144-56.

Dell'Anna E, Chen Y, Engidawork E, Andersson K, Lubec G, Luthman J, HerreraMarschitz M. Delayed neuronal death following perinatal asphyxia in rat. Exp Brain Res 1997;115:105-15.

El-Khodor B, Boksa P. Differential vulnerability of male versus female rats to long-term effects of birth insult on brain catecholamine levels. Exp Neurol 2003; 182:208-19.

Erickson JT, Millhorn DE. Hypoxia and electrical stimulation of the carotid sinus nerve induce Fos-like immunoreactivity within catecholaminergic and serotoninergic neurons of the rat brainstem. J Comp Neurol 1994;348:161-82.

Faraone SV, Biederman J. Neurobiology of attention-deficit hyperactivity disorder. Biol Psychiatry 1998;44:951-8. 
Finley JC, Katz DM. The central organization of carotid body afferent projections to the brainstem of the rat. Brain Res 1992;572:108-16.

Flores C, Stewart J, Salmaso N, Zhang Y, Boksa P. Astrocytic basic fibroblast growth factor expression in dopaminergic regions after perinatal anoxia. Biol Psychiatry 2002:52:362-70

Gorenberg DM, Pattillo C, Hendi P, Rumney PJ, Garite TJ. Fetal pulse oximetry: correlation between oxygen desaturation, duration, and frequency and neonatal outcomes. Am J Obst Gynecol 2003;189:136-8.

Gunn AJ, Dragunow M, Faull RL, Gluckman PD. Effects of hypoxia-ischemia and seizures on neuronal and glial-like c-fos protein levels in the infant rat. Brain Res 1990;531:105-16.

Hay Jr WW, Rodden DJ, Collins SM, Melara DL, Hale KA, Fashaw LM. Reliability of conventional and new pulse oximetry in neonatal patients. J Perinatol 2002;22:360-6.

Hedner T, Lundborg P. Serotonin metabolism in neonatal rat brain during asphyxia and recovery. Acta Physiol Scand 1980;109:163-8.

Hicks SP, Cavanaugh MC, OǐBrien ED. Effect of anoxia on the developing cerebral cortex in the rat. Am J Pathol 1962;40:615-35.

Hirooka Y, Polson JW, Potts PD, Dampney RA. Hypoxia-induced Fos expression in neurons projecting to the pressor region in the rostral ventrolateral medulla. Neuroscience 1997;80:1209-24

Hoffman GE, Lyo D. Anatomical markers of activity in neuroendocrine systems: are we all'fos-ed out'? J Neuroendocrinol 2002;14:259-68.

Iuvone L, Geloso MC, Dell'anna E. Changes in open field behavior, spatial memory, and hippocampal parvalbumin immunoreactivity following enrichment in rats exposed to neonatal anoxia. Exp Neurol 1996;139:25-33.

Juarez I, Silva-Gomez AB, Peralta F, Flores G. Anoxia at birth induced hyperresponsiveness to amphetamine and stress in postpubertal rats. Brain Res 2003;992:281-7.

Kaur C, You Y, Singh J, Peng CM, Ling EA. Expression of Fos immunoreactivity in some catecholaminergic brainstem neurons in rats following high-altitude exposure. J Neurosci Res 2001;63:54-63.

Larsen PJ, Meller M, Mikkelsen JD. Efferent projections from the periventricular and medial parvicellular subnuclei of the hypothalamic paraventricular nucleus to circumventricular organs of the rat: a Phaseolus vulgaris-leucoagglutinin(PHA-L) tracing study. J Comp Neurol 1991;306:462-79.

Laviola G, Adriani W, Rea M, Aloe L, Alleva E. Social withdrawal, neophobia, and stereotyped behavior in developing rats exposed to neonatal asphyxia. Psychopharmacology 2004;175:196-205.

Levine S. Anoxic-ischemic encephalopathy in rats. Am J Pathol 1960;36: $1-37$.

Levitzky MG. Fisiologia Pulmonar. seventh ed. McGraw Hill: Rio de Janeiro; 2009.

Ling EA, Wong WC. Ultrastructure of the area postrema of the monkey Macaca fascicularis. Histol Histopathol 1987;2:39-48.

Majeed R, Memon Y, Majeed F, Shaikh NP, Rajar UD. Risk factors of birth asphyxia. J Ayub Med Coll Abbottabad 2007; 19:67-71.

Mikati MA, Zeinieh MP, Kurdi RM, Harb SA, El Hokayem JA, Shamseddine A, Obeid M, Bitar FF, El Sabban M. Long-term effects of acute and of chronic hypoxia on behavior and on hippocampal histology in the developing brain. Develop Brain Res 2005;157:98-102.

Nakajima W, Ishida A, Takada G. Effect of anoxia on striatal monoamine metabolism in immature rat brain compared with that of hypoxia: an in vivo microdialysis study. Brain Res 1996;740:316-22.

Nakajima W, Ishida A, Takada G. Anoxic and hypoxic immature rat model for measurement of monoamine using in vivo microdialysis. Brain Res Protocols 1999;3:252-6.

Nogueira MI, Barbieri C, Vieira R, Marques ER, Moreno JE. A practical device for histological fixative procedures that limits formaldehyde deleterious effects in laboratory environments. J Neurosci Methods 1997;72:65-70.

Nyakas C, Buwalda B, Luiten PGM. Hypoxia and brain development. Prog Neurobiol 1996;49:1-51.
Ohtake PJ, Simakajornboon N, Fehniger MD, Xue YD, Gozal D. N-Methyl-D-aspartate receptor expression in the nucleus tractus solitarii and maturation of hypoxic ventilatory response in the rat. Am J Respir Crit Care Med 2000;162:1140-7.

Oorschot DE, Black MJ, Rangi F, Scarr E. Is Fos protein expressed by dying striatal neurons after immature hypoxic-ischemic brain injury? Exp Neurol 2000;161:227-33.

Paxinos G, Ashwell KWS, Tork I. Atlas of the developing rat nervous system. second ed. San Diego: Academic Press; 1994.

Petrova A, Mehta R. Near-infrared spectroscopy in the detection of regional tissue oxygenation during hypoxic events in preterm infants undergoing critical care. Pediat Crit Care Med 2006; 7:449-54.

Rajakumar N, Hrycyshyn AW, Flumerfelt BA. Afferent organization of the lateral reticular nucleus in the rat: an anterograde tracing study. Anat Embryol 1992; 185:25-37.

Rice 3rd JE, Vannucci RC, Brierley JB. The influence of immaturity on hypoxic-ischemic brain damage in the rat. Ann Neurol 2004;9:321-9.

Rogalska J, Caputa M, Wentowska K, Nowakowska A. Stress-induced behaviour in adult and old rats: effects of neonatal asphyxia, body temperature and chelation of iron. J Physiol Pharmacol 2006;57:17-34.

Ruigrok TJ, Cella F, Voogd J. Connections of the lateral reticular nucleus to the lateral vestibular nucleus in the rat $A$ anterograde tracing study with Phaseolus vulgaris leucoagglutinin. Eur J Neurosci 1995;7:1410-3.

Saper CB.Paxinos G, editor. The rat nervous system. San Diego: Academic Press; 1995. p. 107-28.

Shapiro RE, Miselis RR. The central neural connections of the area postrema of the rat. J Comp Neurol 1985;234:344-64.

Shimada Y, Yoshioka I, Oka N, Hamaguri K. Effects of multiple scattering and peripheral circulation on arterial oxygen saturation measured with a pulse-type oximeter. Med Biol Eng Comput 1984;22:475-8.

Smith DW, Buller KM, Day TA. Role of ventrolateral medulla catecholamine cells in hypothalamic neuroendocrine cell responses to systemic hypoxia. J Neurosci 1995;15:7979-88.

Strata F, Coq JO, Byn N, Merzenich MM. Effects of sensorimotor restriction and anoxia on gait and motor cortex organization: implications for a rodent model of cerebral palsy. Neuroscience 2004;129:141-56.

Swedlow DB. Review of evidence for a fetal $\mathrm{SpO}_{2}$ critical threshold of $30 \%$. Nell Pur Benn Perin Note 1997;2:1-9.

Tang AC, Nakazawa M. Neonatal novelty exposure ameliorates anoxia-induced hyperactivity in the open field. Behav Brain Res 2005;163:1-9.

Ten VS, Bradley-Moore M, Gingrich J, Stark J, Pinsky DJ. Brain injury and neurofunctional deficit in neonatal mice with hypoxic-ischemic encephalopathy. Behav Brain Res 2003;145:209-19.

Vannucci RC, Towfighi J, Heitjan DF, Brucklacher RM. Carbon dioxide protects the perinatal brain from hypoxic-ischemic damage: an experimental study in the immature rat. Pediatrics 1995;95:868-74.

Vannucci RC. Hypoxia-ischemia clinical aspects. In: Fanaroff AA, Martin RJ, editors. Neonatal perinatal medicine. Philadelphia: Mosby-Yearbook; 1997. p. 87791.

Vannucci, Connor RC, Mauger JR, Palmer DT, Smith C, Towfighi MB, Vannucci JSJ. Rat model of perinatal hypoxic-ischemic brain damage. J Neurosci Res 1999;55:155-63.

Venerosi A, Valanzano A Cirulli F, Alleva E, Calamandrei G. Acute global anoxia during C-section birth affects dopamine-mediated behavioural responses and reactivity to stress. Behav Brain Res 2004;154:155-64.

Volpe JJ. Perinatal hypoxic-ischemic brain injury: overview. In: Fukuyama Y, Suzuki Y, Kamoshita S, Casaer P, editors. Fetal and perinatal neurology. joint convention of the 5th international child neurology and the 3rd Asian and Oceanian congress of child neurology; 1992. p. 232-52.

Wainwright MS, Craft JM, Griffin ST, Marks A, Pineda J, Padgett KR, Eldik V. Increased susceptibility of S100B transgenic mice to perinatal hypoxia-ischemia. Ann Neurol 2004;56:61-7. 
APÊNDICE B -Drobyshevsky A, Derrick M, Luo K, Zhang LQ, Wu YN, TakadaSH, Yu

L, Tan S. Near-term fetal hypoxia-ischemia in rabbits: MRI can predict muscle tone abnormalities and deep brain injury. Stroke. 2012;43(10):2757-63. 


\section{Stroke}

Journal of the American Heartassociation

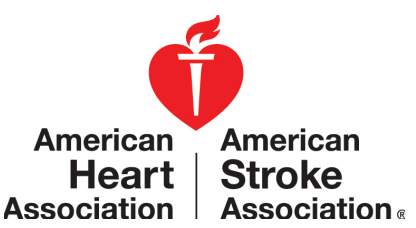

Near-Term Fetal Hypoxia-Ischemia in Rabbits: MRI Can Predict Muscle Tone Abnormalities and Deep Brain Injury

Alexander Drobyshevsky, Matthew Derrick, Kehuan Luo, Li-Qun Zhang, Yi-Ning Wu, Silvia Honda Takada, Lei Yu and Sidhartha Tan

Stroke. 2012;43:2757-2763; originally published online July 24, 2012; doi: 10.1161/STROKEAHA.112.653857

Stroke is published by the American Heart Association, 7272 Greenville Avenue, Dallas, TX 75231 Copyright $\mathbb{C} 2012$ American Heart Association, Inc. All rights reserved. Print ISSN: 0039-2499. Online ISSN: 1524-4628

The online version of this article, along with updated information and services, is located on the World Wide Web at:

http://stroke.ahajournals.org/content/43/10/2757

Data Supplement (unedited) at:

http://stroke.ahajournals.org/content/suppl/2012/07/24/STROKEAHA.112.653857.DC1.html

Permissions: Requests for permissions to reproduce figures, tables, or portions of articles originally published in Stroke can be obtained via RightsLink, a service of the Copyright Clearance Center, not the Editorial Office. Once the online version of the published article for which permission is being requested is located, click Request Permissions in the middle column of the Web page under Services. Further information about this process is available in the Permissions and Rights Question and Answer document.

Reprints: Information about reprints can be found online at:

http://www.lww.com/reprints

Subscriptions: Information about subscribing to Stroke is online at: http://stroke.ahajournals.org//subscriptions/ 


\title{
Near-Term Fetal Hypoxia-Ischemia in Rabbits MRI Can Predict Muscle Tone Abnormalities and Deep Brain Injury
}

\author{
Alexander Drobyshevsky, PhD; Matthew Derrick, MD; Kehuan Luo, MD; Li-Qun Zhang, PhD; \\ Yi-Ning Wu, PhD; Silvia Honda Takada; Lei Yu, MD; Sidhartha Tan, MD
}

Background and Purpose-The pattern of antenatal brain injury varies with gestational age at the time of insult. Deep brain nuclei are often injured at older gestational ages. Having previously shown postnatal hypertonia after preterm fetal rabbit hypoxia-ischemia, the objective of this study was to investigate the causal relationship between the dynamic regional pattern of brain injury on MRI and the evolution of muscle tone in the near-term rabbit fetus.

Methods-Serial MRI was performed on New Zealand white rabbit fetuses to determine equipotency of fetal hypoxia-ischemia during uterine ischemia comparing 29 days gestation (E29, 92\% gestation) with E22 and E25. E29 postnatal kits at 4, 24, and 72 hours after hypoxia-ischemia underwent T2- and diffusion-weighted imaging. Quantitative assessments of tone were made serially using a torque apparatus in addition to clinical assessments.

Results-Based on the brain apparent diffusion coefficient, 32 minutes of uterine ischemia was selected for E29 fetuses. At E30, 58\% of the survivors manifested hind limb hypotonia. By E32, 71\% of the hypotonic kits developed dystonic hypertonia. Marked and persistent apparent diffusion coefficient reduction in the basal ganglia, thalamus, and brain stem was predictive of these motor deficits.

Conclusions-MRI observation of deep brain injury 6 to 24 hours after near-term hypoxia-ischemia predicts dystonic hypertonia postnatally. Torque-displacement measurements indicate that motor deficits in rabbits progressed from initial hypotonia to hypertonia, similar to human cerebral palsy, but in a compressed timeframe. The presence of deep brain injury and quantitative shift from hypo- to hypertonia may identify patients at risk for developing cerebral palsy. (Stroke. 2012;43:2757-2763.)

Key Words: diffusion-weighted imaging $\mathbf{n}$ hypertonia $\mathbf{a}$ hypoxic-ischemic encephalopathy

$\mathrm{C}$ erebral palsy (CP) is a clinical syndrome commonly designating a group of conditions characterized by chronic motor impairment due to early occurrence of a nonprogressive lesion to the developing brain..$^{1,2}$ The type and site of lesions depend on the stage of brain maturation during which pathogenic events occurred. ${ }^{3-5}$

Newborns with hypoxic-ischemic encephalopathy are initially hypotonic and subsequently develop hypertonia after some months. ${ }^{6}$ The pathophysiology and evolution of dysfunctional motor control in patients with $\mathrm{CP}$ are largely unknown.

In a clinically relevant animal model after fetal hypoxiaischemia (H-I) at $70 \%$ to $79 \%$ (E22 and E25) gestation in rabbits, newborn kits at E32 manifest hypertonia, resembling motor deficits of human CP. ${ }^{7-10}$ MRI markers on diffusionweighting imaging during the insult in utero at E25 are predictive of hypertonia. ${ }^{11}$ Compared with humans, rabbit motor development is compressed in time. Given the 7- to 10-day period in utero after H-I in the rabbit model, it was possible that the hypotonic period occurred in utero and evolved into hypertonia before birth.

Muscle tone is typically assessed clinically by ordinal measures with distinction into spasticity, rigidity, or dystonia for hypertonia. ${ }^{12}$ Laboratory measurements objectively quantify the different types of hypertonia by determining contributions of velocity dependent (viscous) and independent (elastic) components in human ${ }^{13,14}$ and animal studies. ${ }^{15,16}$

The hypothesis of this study was that muscle tone in the rabbit would evolve from hypotonia to hypertonia after an H-I insult and that apparent diffusion coefficient (ADC) changes on MRI could be used to predict the eventual motor phenotype. We could not test this hypothesis previously because the preterm fetuses could not be observed ex utero. Sufficient near-term rabbit fetuses survived delivery immediately after H-I to allow immediate neurological examination. The secondary hypothesis was that the pattern of injury

Received February 13, 2012; final revision received May 21, 2012; accepted June 4, 2012.

From the Department of Pediatrics, NorthShore University Health Systems, Evanston, IL (A.D., M.D., K.L., L.Y., S.T.); Rehabilitation Institute of Chicago and Northwestern University, Chicago, IL (L.-Q.Z., Y.-N.W.); and the Laboratory of Neurosciences, Institute of Biomedical Sciences, University of São Paulo, São Paulo, Brazil (S.H.T.).

The online-only Data Supplement is available with this article at http://stroke.ahajournals.org/lookup/suppl/doi:10.1161/STROKEAHA.112.653857/-/DC1. Correspondence to Alexander Drobyshevsky, PhD, NorthShore University Health Systems Research Institute, 2650 Ridge Avenue, Evanston Hospital, Department of Pediatrics, Evanston, IL 60202. E-mail oldrobys@gmail.com

(C) 2012 American Heart Association, Inc.

Stroke is available at http://stroke.ahajournals.org 
in near-term H-I would differ from preterm H-I (E22 and E25) with greater involvement of deep brain structures. We used dynamic MRI for evaluation of regional brain injury and torque apparatus measurement of passive joint resistance to stretch for longitudinal and quantitative evaluation of muscle tone changes. The study was designed to investigate shortterm outcomes at E32 for comparison with previous studies of earlier gestational ages.

\section{Methods}

The Institutional Animal Care and Use Committee of NorthShore University HealthSystem approved all animal experiments.

\section{Prenatal H-I Model and \\ Neurobehavioral Assessment}

New Zealand white pregnant rabbits (Myrtle's Rabbits, Thompson Station, TN) at 29 days of gestation (90\% term) underwent uterine ischemia induced by inflation of an intra-aortic balloon catheter, which caused in vivo global fetal H-I. ${ }^{10}$ Newborn kits were delivered 4 hours after $\mathrm{H}-\mathrm{I}$ by hysterotomy. ${ }^{10}$ Neurobehavioral measurements, tone assessment by a torque-displacement apparatus, and serial MRI were performed at $6,18,24$, and 72 hours after H-I.

Muscle tone assessment was based on a modified Ashworth scale, ${ }^{10}$ which takes into account hypotonia and hypertonia as well as differences in forelimb and hind limb tone. Final assessment of motor deficits was at 72 hours after H-I. Kits were labeled as with or without motor deficits. The former category included kits having abnormal muscle tone (hypertonia or hypotonia), abnormal posture, or locomotion.

\section{Objective Measurements of Muscle Tone}

We built a torque-displacement apparatus that measured passive resistance and stretch angle during sinusoidal joint stretch (onlineonly Data Supplement Methods and Figure I). Joint stiffness (slope of torque-displacement curve), derived from the laboratory muscle tone, was assessed and correlated with manual muscle tone assessment (online-only Data Supplement ID).

\section{Fetal MRI}

A subset of dams was studied in a clinical 3-T magnet. T2-weighted and diffusion-weighted imaging of fetal brains $\left(b=0,0.8 \mathrm{~ms} / \mu \mathrm{m}^{2}\right)$ were acquired as previously described. ${ }^{11}$ Uterine position of each fetus was first identified and ADC of fetal brain was measured. ${ }^{11}$ Whole brain ADC could be obtained reliably but regional changes could not be consistently quantified because of fetal motion.

\section{Postnatal MRI}

Newborn kits after delivery were studied in an animal 4.7-T magnet and T2-weighted and diffusion tensor images (6 diffusion directions, $\mathrm{b}=0,0.8 \mathrm{~ms} / \mu \mathrm{m}^{2}$ ) were acquired as previously described. ${ }^{8}$ Injury in the region of interest was determined by quantifying the volume of voxels on ADC maps below a predefined threshold value of $0.7 \mu \mathrm{m}^{2} / \mathrm{ms}$.

\section{Statistical Analysis}

Data were analyzed using SPSS 14.0 software and expressed as means \pm SEM. Differences between groups were tested using oneway analysis of variance with Tukey post hoc group comparisons. Longitudinal data series were tested with repeated-measures analysis of variance. The cutoff threshold of fetal brain ADC nadir during H-I was determined by linear discriminant analysis, separating hypertonia from nonhypertonia outcomes.

\section{Results}

\section{Perinatal Death Increases With Gestation Age for} the Same Duration of H-I

We first compared the severity of 40-minute fetal H-I in near-term E29 fetuses with preterm E22 and E25 in terms of
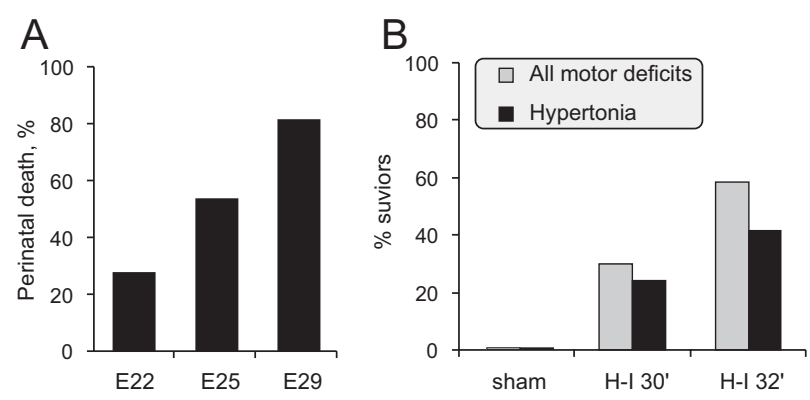

Figure 1. A, Perinatal death increased with age after 40 minutes global fetal $\mathrm{H}-\mathrm{I}$ at E22 ( $\mathrm{n}=369$ fetuses), E25 (186 fetuses), and E29 (89 fetuses; $\left.P<0.001, \chi^{2}\right)$. B, Increase of postnatal neurobehavioral deficits with increasing durations of $\mathrm{H}-\mathrm{I}$ at E29 $(P<0.05$, $\chi^{2}$ for both motor deficits and hypertonia). Sham controls had no deficits. $n=10,67,60$ for sham; 30 minutes $\mathrm{H}-\mathrm{I}$; and 32 minutes $\mathrm{H}$-I correspondingly. $\mathrm{H}-\mathrm{I}$ indicates hypoxia-ischemia.

mortality and morbidity (E22/E25 data are partly from previously published $\mathrm{data}^{7}$ ). The term (E32) death rate increased with increasing age, suggesting that fetal vulnerability to $\mathrm{H}-\mathrm{I}$ increases with age (Figure 1A).

\section{Establishing Equipotent Insult}

Previously, we showed that 30 minutes H-I at E22 resulted in all normal-appearing kits. ${ }^{10}$ The E29 H-I duration was decreased from 40 minutes to 30 or 32 minutes (Figure 1B) resulting in a similar proportion of live-born kits at 72 hours (40.0\% and 55.2\%, respectively) compared with 59\% live kits after 40 minutes $\mathrm{H}-\mathrm{I}$ at E22. ${ }^{7}$ Thirty minutes H-I at E29 resulted in a lower incidence of hypertonia than after 40 minutes $\mathrm{H}-\mathrm{I}$ at E22, ${ }^{7}$ whereas 32 minutes $\mathrm{H}-\mathrm{I}$ had a similar incidence and was chosen for subsequent studies.

\section{ADC Decline Occurs Faster and Is More Pronounced During H-I at E29 Fetuses}

Another parameter to compare brain vulnerability with H-I insult between preterm and near-term fetuses was ADC time course during $\mathrm{H}-\mathrm{I}$, because ADC decrease below a threshold level of in E25 fetal brains was predictive of postnatal hypertonia. ${ }^{11}$ The pattern of the ADC response to H-I with increasing fetal age for E22 and E29 fetuses was compared with our previous study of E25 fetuses. ${ }^{11}$ The fall in ADC at E29 started earlier, was deeper, and recovered more slowly (Figures 2A, 2C, and 2D). The ADC took a median of 28.4 minutes (interquartile range, 25.4-31.3) to fall below the threshold of $0.83 \mu \mathrm{m}^{2} / \mathrm{ms}$ for E25 fetuses, which distinguished postnatal hypertonia from nonhypertonia. The time of ADC to reach the corresponding mean value at end of 40 minutes H-I in E25 $\left(0.78 \mu \mathrm{m}^{2} / \mathrm{ms}\right.$ ) was 29.6 minutes (median, 28.4; interquartile range, 27.5-32.9) in E29 fetuses.

For 32 minutes H-I in E29 fetuses, the predictive threshold of whole brain ADC for distinguishing hypertonia from nonhypertonia was $0.75 \mu \mathrm{m}^{2} / \mathrm{ms}$ determined by discriminant analysis. Also, as shown previously, if ADC did not recover in the late reperfusion-reoxygenation period, those fetuses were more likely to die (Figure 2B).

\section{Muscle Tone of After Near-Term Fetal H-I Evolves From Hypotonia to Hypertonia}

The incidence and pattern of motor deficits after 32 minutes $\mathrm{H}-\mathrm{I}$ at E29 were compared with previously published data at 
A

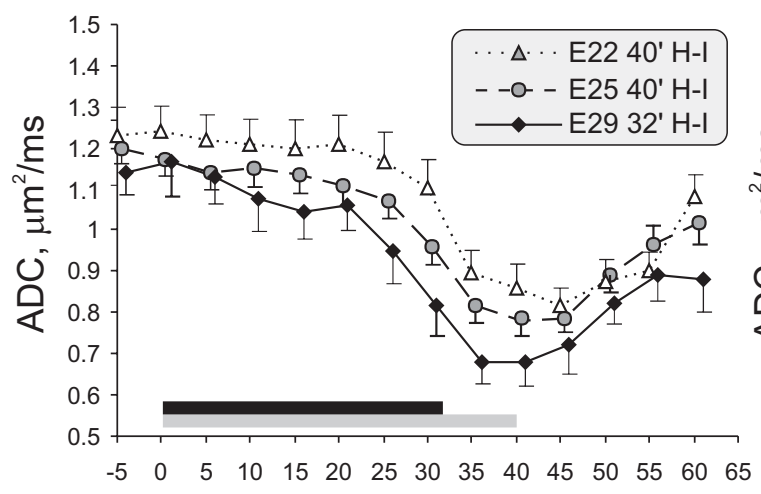

time of $\mathrm{H}-\mathrm{I}, \min$
B

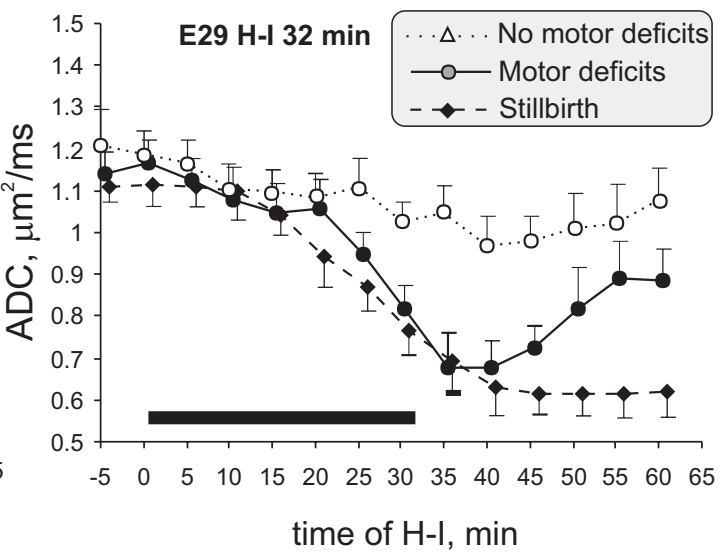

C Time to rapid ADC decline

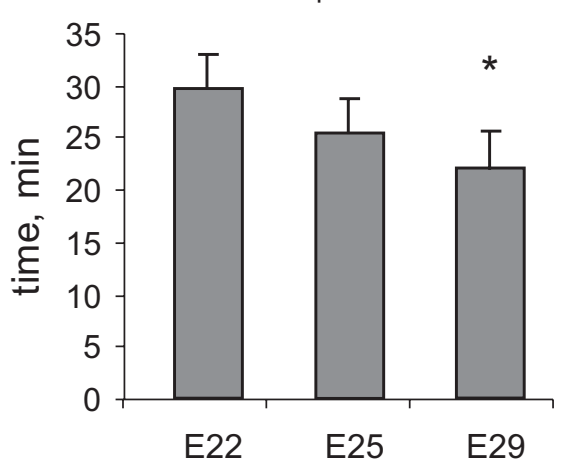

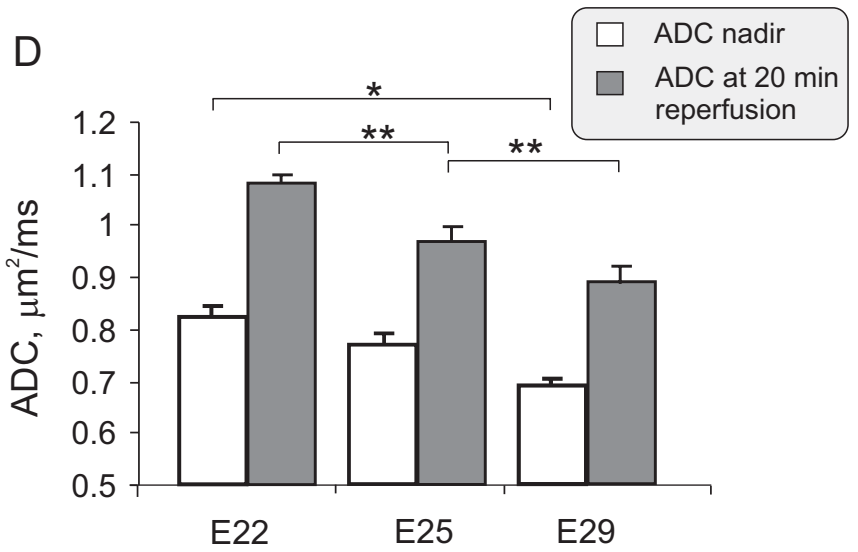

Figure 2. A, Dynamic ADC changes during $\mathrm{H}-\mathrm{I}$ and reperfusion-reoxygenation in E22, E25, and E29 fetuses that were born alive with motor deficits. Duration of $\mathrm{H}-\mathrm{I}$ was 40 minutes for E22 and E25 fetuses (gray bar) and 32 minutes for E29 fetuses (black bar). With increasing age there is an earlier and deeper fall in ADC during $\mathrm{H}-\mathrm{I}$. B. Fetuses that developed motor deficits later showed a pattern of ADC different from sham controls (not shown), nonhypertonic, and stillbirths with 32 minutes $\mathrm{H}-\mathrm{I}$ at E29. C, The onset of rapid phase of ADC decline during $\mathrm{H}-\mathrm{I}$ occurred significantly earlier at E29 than at E22. ${ }^{*} P<0.05$ in E29 group compared with E22. D, The lowest value of ADC during time course (nadir) was lower in E29 compared with E22 $\left({ }^{*} P<0.05\right)$. The ADC value at 20 minutes reperfusion progressively decreased with increasing gestational age. ${ }^{\star *} P<0.05$ in E25 group compared with E22 and E29 groups. Analysis of variance with Tukey post hoc group comparisons. ADC indicates apparent diffusion coefficient; $\mathrm{H}-\mathrm{I}$, hypoxia-ischemia.

E22 and E25. The incidence of hypertonia after H-I at E22 was $75 \%$ using a clinical score based on modification of the Ashworth scale. ${ }^{7}$ In E29 animals, 24 hours after the H-I, 14 of 24 surviving kits $(58 \%)$ had hypotonia of the hind limbs. Of these hypotonic kits, 10 (71\%) subsequently developed hypertonia at 72 hours, 7 in hind limbs (Figure 3A) and 3 in all limbs. The other 4 kits continued to have hind limb hypotonia at 72 hours. In addition to manual evaluation, ${ }^{7}$ the qualitative assessment of tone was validated and subsequently quantified by measures of muscle resistance to passive stretch using the torque-displacement apparatus. Kits that developed hypertonia by 72 hour after H-I had initial resistance to stretch that was lower than corresponding age-matched control kits at 24 hour after H-I (Figure 3B). Limb resistance to passive stretch
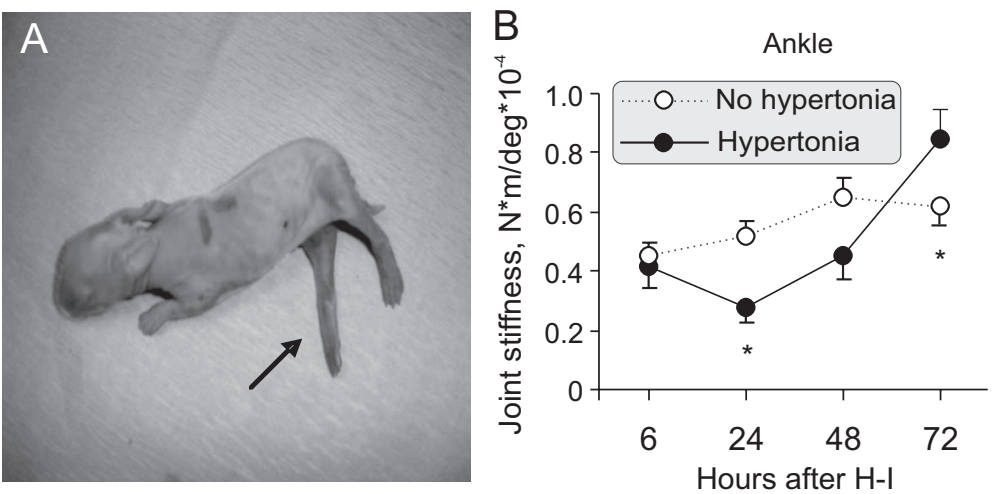

Figure 3. A, Illustrative case of hind limb hypertonia at 72 hours after E29 fetal $\mathrm{H}-\mathrm{I}$. Increased tone in knee and ankle extensors (arrow). B, Biphasic change of muscle tone in surviving kits after E29 fetal $\mathrm{H}-\mathrm{I}$. The tone measure, joint stiffness, was calculated as a slope between joint resistance to passive stretch and joint displacement angle, obtained with a torque-displacement apparatus (online-only Data Supplement Figure I). The hypertonic group (at 72 hours) had initially lower hind limb tone at 24 hours, replaced by elevated tone by 72 hours after $\mathrm{H}-\mathrm{I}$. ${ }^{*} P<0.05$ in tone difference between groups, repeated-measures analysis of variance. $\mathrm{H}-\mathrm{I}$ indicates hypoxia-ischemia. 


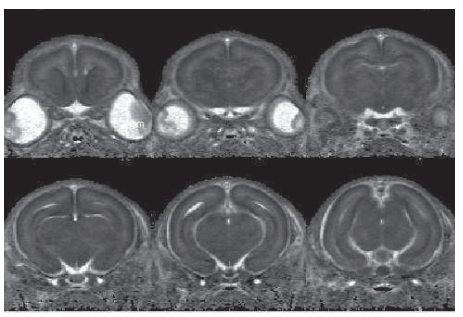

A

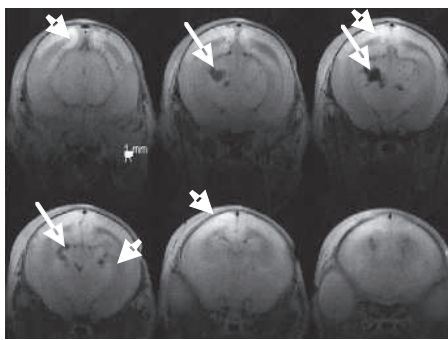

C

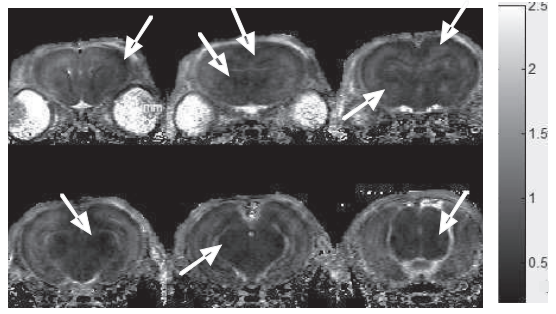

B

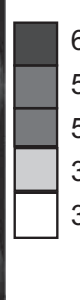

$65(51) \%$ thalamus

$53(42) \%$ basal ganglia

$53(42) \%$ brain stem

$38(30) \%$ midbrain

$31(24) \%$ cortex

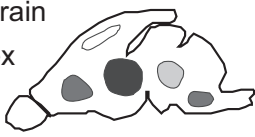

Figure 4. Diffusion weighted images 24 hours after $\mathrm{H}-\mathrm{I}$ in E29 brain on showing no injury in $\mathbf{A}$ and severe injury in $\mathbf{B}$, in areas of cortex, basal ganglia, thalamus, midbrain, brain stem (arrows indicates areas with abnormally low ADC less $0.7 \mu \mathrm{m}^{2} / \mathrm{ms}$ ). Color map bar units are $\mu \mathrm{m}^{2} / \mathrm{ms}$. C, T2-weighted images 72 hours after $\mathrm{H}-\mathrm{I}$ in E29 brain ( $n=19$ kits) show ischemic regions (arrowheads, bright image) and hemorrhagic lesions (long arrows, black image) in thalamus and cortex. D, The frequency of injury is depicted as a proportion of all kits with any injury on MRI and a proportion of all studied kits after $\mathrm{H}-\mathrm{I}$ in parenthesis. did not change with stretch velocity, indicative of dystonic hypertonia and not spastic hypertonia as assessed by human criteria. ${ }^{12}$ The dystonic hypertonia after H-I at E29 kits was similar to that found after H-I at E22. ${ }^{10}$ The quantitative data confirm that hypertonia is preceded by a period of hypotonia in rabbit kits. The short duration of hypotonia also confirms the rapid development of rabbit motor function, similar to other nonhuman mammals and distinct from the slower human development.

\section{Deep Brain Nuclei Pattern of Injury After E29 H-I} Regional injury could be demarcated by abnormally low ADC at 24 hours after H-I (Figure 4A-B). We also found a spectrum of abnormalities on T2-weighted MRI 72 hours after H-I (Figure 4C), including hyperintensive areas (white arrows), indicative of high water content, and also hypointensive lesions (yellow arrows) in some severely affected kits, suggestive of hemorrhages. The prevalence and locations of brain injury are depicted in Figure 4D. Thalamic injury was most common $(65 \%)$ and often seen in combination with other regions. In addition, there was frequent injury to the other deep brain structures such as the basal ganglia and brain stem, including the midbrain, pons, and medulla. Cortical injury, predominantly parasagittal, was observed less frequently and mostly in severe cases with pronounced hypertonia of all limbs. There were also cases with predominantly basal ganglia injury without thalamic involvement $31 \%$ of cases with any injury on MRI and 24\% of all studied E29 kits after H-I).

\section{Persistent Regional Reduction of ADC Within 24 Hours After H-I Is Indicative of Injury}

The regions with abnormally low ADC (Figure 4) corresponded to areas with abundant terminal deoxynucleotidyl transferase-mediated dUTP nick-end labeling, indicative of cell injury (Figure 5A-C). The number of terminal deoxynucleotidyl transferase-mediated dUTP nick-end labeling- positive cells was significantly higher in regions with ADC $<0.7 \mu \mathrm{m}^{2} / \mathrm{ms}$ (Figure 5D).

The kits that developed hypertonia had a marked and persistent reduction of ADC during acute $\mathrm{H}-\mathrm{I}$ in the basal ganglia, thalamus, and midbrain compared with nonhypertonic kits (online-only Data Supplement Figure II) and the decrease persisted for 24 hours. At 72 hours after H-I, abnormally high ADC, tissue loss, or hyperintensities on T2-weighted images were observed in the areas of initially decreased ADC (online-only Data Supplement Figure II), similar to the evolution of perinatal brain H-I injury in other animal models and humans. ${ }^{17}$

\section{Deep Brain Nuclear Injury, Diagnosed by ADC Decrease, Is a Biomarker of Motor Deficits}

In kits that developed motor deficits, ADC in the thalamus declined at the end of $\mathrm{H}-\mathrm{I}$ and remained low at 6,18 , and 24 hours (Figure 6A) and this decline was greater than in those kits without motor deficits. A similar pattern of ADC change was observed in the other deep gray matter regions and parietal cortex. ADC changes in the frontal and motor cortex were not significantly different from sham controls. The decrease of ADC values after H-I at 6 and 18 hours was significantly lower than corresponding values in control kits ( $P<0.05$, repeated-measures analysis of variance), even on the background of significant maturational changes of ADC in the perinatal period. ${ }^{18}$

The severity of H-I injury was delineated by the volume of voxels with an ADC value $<0.7 \mu \mathrm{m}^{2} / \mathrm{ms}$. We chose this empirical threshold because gray and white matter ADC in control animals between E29 and E32 were always above this value and because increased cell injury was observed in regions below this threshold (Figure 5). The volume of voxels with ADC below the cutoff value in injured animals decreased from 6 to 24 hours after H-I (Figure 6B) but was still significantly higher at the latter time point in all examined regions (except the cerebral cortex). The ADC normalized to control values beyond 24 hours after H-I in deep gray matter 

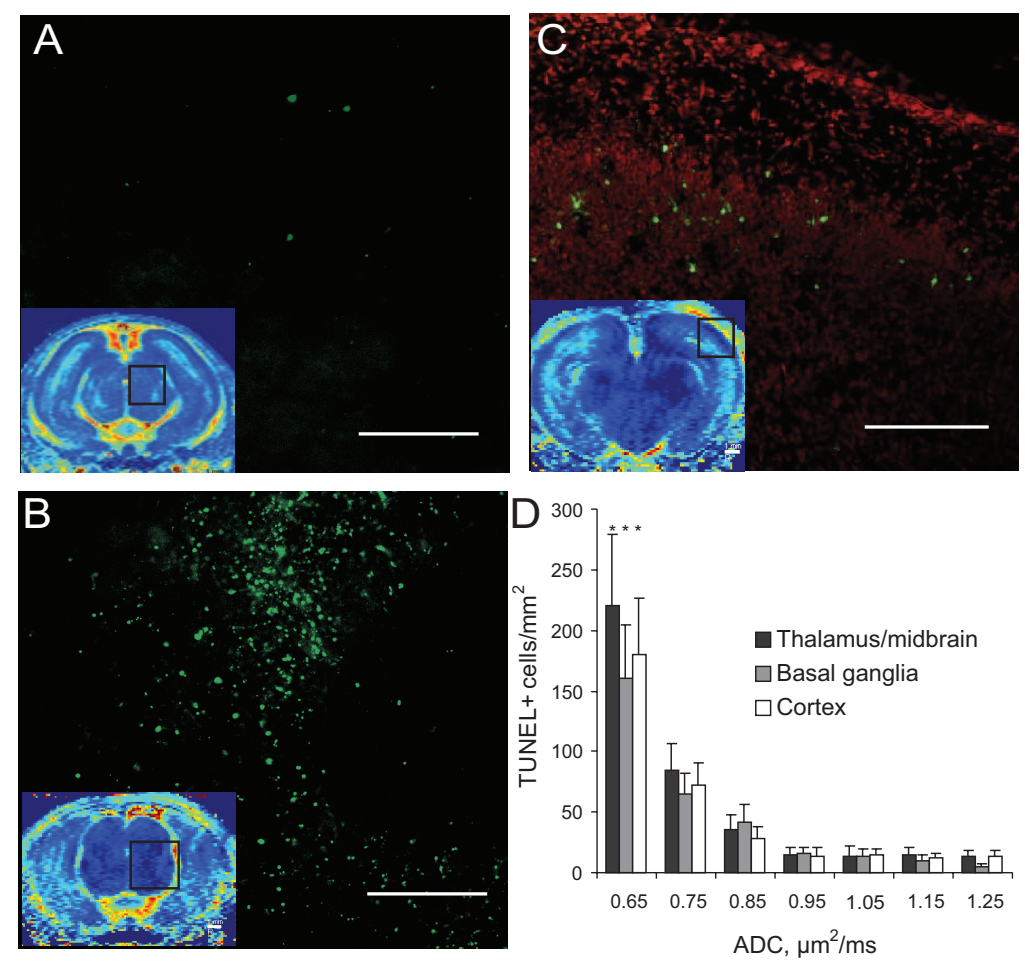

\section{$\begin{array}{lllll}0.5 & 1.0 & 1.5 & 2.0 & 2.5\end{array}$}

Figure 5. Regions of injury defined by ADC decrease below threshold $0.7 \mu \mathrm{m}^{2} / \mathrm{ms}$ shown on ADC maps from the same animals (color inserts) on sections at midbrain (A-B) and thalamus (C) levels in controls (A) and hypertonic (B-C) kits had numerous injured cells with positive TUNEL staining 24 hours after $\mathrm{H}-\mathrm{I}$ injury at E29. Overlay TUNEL (green)+ propidium iodide (red; C) demonstrate that cortical injury was mostly in Layer 4 . The number of TUNEL-positive cells was significantly higher in regions with $A D C<0.7 \mu \mathrm{m}^{2} / \mathrm{ms}$ (D) in all counted gray matter regions $(P<0.05$, analysis of variance). Color map bar units are $\mu \mathrm{m}^{2} / \mathrm{ms}$. Scale bar $500 \mu \mathrm{m}$. Number of samples $\mathrm{n}=4$ /group in $\mathrm{H}-\mathrm{I}$ and control groups. ADC indicates apparent diffusion coefficient; TUNEL, terminal deoxynucleotidyl transferase-mediated dUTP nick-end labeling; $\mathrm{H}-\mathrm{I}$, hypoxia-ischemia. and the cortex (Figure 6A). Therefore, a persistent ADC decrease between 6 and 24 hours in deep gray matter regions can be used as an early marker of acute hypoxic injury in deep gray matter and is predictive of subsequent motor deficits. Interestingly, T2-weighted images at 72 hours, but not at 24 hours, showed changes that suggest possible hemorrhages in thalamus/midbrains of 2 kits $(6 \%)$ in areas that had abnormally low ADC at 24 hours after H-I. However, these T2 changes did not possess an independent predictive value of hypertonia and seems to be secondary to the severe injury observed with ADC. To test the association between pattern of injury observed in kits 24 hours and the presence of neurological abnormalities at 72 hours after H-I, a regression analysis was applied. The best combination of predictors for any motor deficits was injury in basal ganglia and in brain stem and for hypertonia in the thalamus and brain stem (online-only Data Supplement Table III).

\section{Discussion}

\section{Biphasic Muscle Tone Changes After Antenatal H-I}

For the first time in a perinatal H-I model, evolution of motor abnormalities was quantitatively assessed by measuring resistance to passive joint stretch (online-only Data Supplement Figure I). The present study shows the rapid evolution (a few days) from hypotonia to hypertonia in the developing rabbit. Previously only hypertonia was observed after delivery at E32 or P1 after H-I at E22 and E25.7,9,11 This evolution of hypotonia to hypertonia after E29 H-I is similar to that of humans with H-I injury. Patients with neonatal encephalopathy have mostly hypotonia as an initial finding and hypertonia may develop months or years later with the diagnosis of spasticity or dystonia. ${ }^{19}$ This timespan makes causal etiologic linkages difficult in human clinical studies. The rapid transi-
A

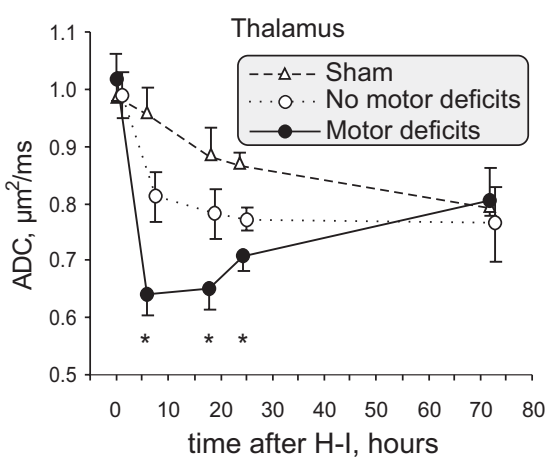

B

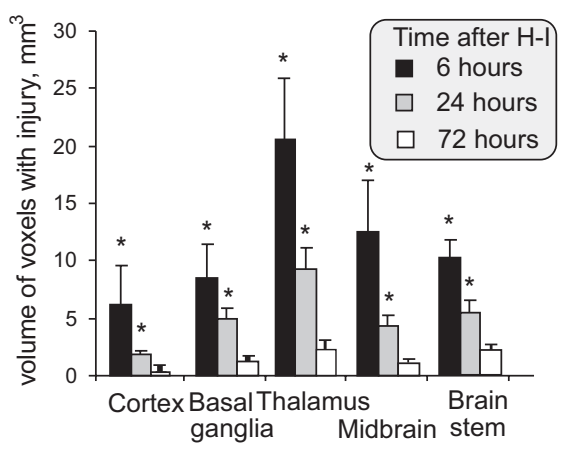

Figure 6. A, Dynamic changes of ADC in the region of thalamus at the level of third ventricle. Significant ADC decrease persisted in the thalamus 6 to 24 hours after $\mathrm{H}-\mathrm{I}$ and is an early marker of acute hypoxic thalamic injury. ${ }^{\star} P<0.05$ comparing motor deficits with group without motor deficits, repeated-measures analysis of variance. $\mathbf{B}$, Volume of voxels with ADC $<0.7 \mu \mathrm{m}^{2} / \mathrm{ms}$ in the brains of kits with motor deficits, as an indicator of injury severity, declined from 6 hours to 24 hours after $\mathrm{H}$-I but remained significant at the 24-hour time point. ${ }^{\star} P<0.05, t$ test and Bonferroni correction. ADC indicates apparent diffusion coefficient; $\mathrm{H}-\mathrm{I}$, hypoxia-ischemia. 
tion in perinatal rabbits makes the model a convenient platform to study the etiology of motor deficits of $\mathrm{CP}$ after H-I. Furthermore, we show structural lesions on MRI are predictive of motor deficits postnatally and there is a regional predilection to brain injury.

\section{Sensitivity of Deep Brain Nuclei to H-I Injury and Importance of the Injury in the Pathogenesis of CP}

Human term newborns often have cerebral cortical-deep nuclear or deep nuclear-brain stem types of brain injury. ${ }^{4-6,19}$ The basal ganglia/thalamus pattern in term and premature infants ${ }^{5}$ is associated with the most impaired motor and cognitive outcome at 30 months. $^{4-5,20}$ Thalamic motor nuclei are especially injured. ${ }^{21}$ Similarly, the near-term rabbit studies at E29 confirm the predictive value of basal ganglia-thalamusbrain stem injury to postnatal motor deficits (online-only Data Supplement Table IV).

The injury also involved cortex and periventricular white matter, albeit to a lesser extent. In human infants after perinatal asphyxia, decreased brain MRI ADC values of the brain stem and basal ganglia correlated with abnormal or adverse outcome. ${ }^{22}$ The implication of neuronal loss and gliosis being more common in the thalamus in human periventricular leukomalacia ${ }^{21,23}$ is either due to a primary injury or a secondary anterograde or retrograde injury. The secondary consequences of a primary neuronal injury could involve white matter axons with subsequent hypomyelination and impaired development of the cerebral cortex and thalamus/basal ganglia. ${ }^{24}$ This study, however, was designed only to study short-term outcome at 72 hours because we wanted to compare with E32 findings of previous studies of earlier gestational ages. Longer-term white matter and cortical/ subcortical abnormalities and involvement in motor and cognitive impairment in rabbits require further investigation.

\section{MRI as a Biomarker}

A decrease of whole brain ADC $<0.83 \mu \mathrm{m}^{2} / \mathrm{ms}$ in E2 $25^{11}$ and $<0.75 \mu \mathrm{m}^{2} / \mathrm{ms}$ in E29 rabbits during and immediately after H-I (Figure 2) was predictive of motor deficits. We have extended the time window to 6 to 24 hours postnatally after H-I and demonstrated a threshold of ADC decrease $<0.7 \mu \mathrm{m}^{2} / \mathrm{ms}$ to be a reliable diagnostic tool for injury to the deep brain nuclei and was predictive of hypertonia and other motor deficits. The implication is also that MRI indicates a level of regional injury that is significant clinically to cause a motor phenotype. The absence of the specific ADC fall also may be useful prognostically.

\section{Comparison of Timing}

Our study underlines the importance of timing in diagnosing perinatal brain injury by diffusion-weighting imaging. In contrast to rodent ${ }^{25}$ and piglet ${ }^{26}$ neonatal stroke models, we did not observe a secondary decline of ADC 24 hours after $\mathrm{H}-\mathrm{I}$. In rabbits, whole brain ADC only partially recovered after 20 minutes of reperfusion-reoxygenation and was consistently low at 6 to 24 hours in deep brain nuclei and cortex. This discrepancy can be attributed to species differences and global nature of H-I and is more analogous to the human situation. In a prospective human longitudinal study with known time of insult, ADC declined and reached a nadir in injured regions of $35 \%$ of the control values between 2 and 3 days. ${ }^{17} \mathrm{ADC}$ returned to normal levels by 7 days. In the present study, the corresponding nadir of ADC occurred around 6 hours and returned to normal levels at approximately 3 days, suggesting the evolution of H-I injury follows the human patterns but occurs 4 to 6 times faster. This may correspond to the relatively short timeframe of neurobehavioral evolution from hypotonia to hypertonia in rabbits.

\section{Summary}

The near-term rabbit model may be a useful platform to test mechanisms for evolution of muscle tone changes. We have shown that quantification of lesions is important both for prediction and studying evolution of muscle tone. Abnormally low ADC values suggestive of deep brain injury 6 to 24 hours after near-term H-I predicts dystonic hypertonia postnatally. The first torque-displacement studies to be done in perinatal models indicate that motor deficits in rabbits progressed from initial hypotonia to hypertonia, similar to human $\mathrm{CP}$ but in a compressed timeframe. The presence of deep brain injury and quantitative shift from hypo- to hypertonia may identify patients at risk for developing $\mathrm{CP}$.

\section{Acknowledgments}

We thank Xinhai Ji and Aiping Liu.

\section{Sources of Funding}

Supported by ENH pilot award, National Institutes of Health (NIH) NS062367, UCP/Hearst foundation (Dr Drobyshevsky), and NIH NS 43285, NS051402 (Dr Tan).

None.

\section{Disclosures}

\section{References}

1. Laura LD, Deborah G-S. Assessment and treatment of movement disorders in children with cerebral palsy. Orthop Clin North Am. 2010;41: 507-517.

2. Rosenbaum P, Paneth N, Leviton A, Goldstein M, Bax M, Damiano D, et al. A report: the definition and classification of cerebral palsy April 2006. Dev Med Child Neurol Suppl. 2007;109:8-14.

3. Volpe JJ. Neurobiology of periventricular leukomalacia in the premature infant. Pediatr Res. 2001;50:553-562.

4. Rutherford M, Biarge M, Allsop J, Counsell S, Cowan F. MRI of perinatal brain injury. Pediatr Radiol. 2010;40:819-833.

5. Miller SP, Ramaswamy V, Michelson D, Barkovich AJ, Holshouser B, Wycliffe N, et al. Patterns of brain injury in term neonatal encephalopathy. J Pediatr. 2005;146:453-460.

6. Volpe JJ. Neurology of the Newborn. Philadelphia, PA: WB Saunders Co; 2001.

7. Tan S, Drobyshevsky A, Jilling T, Ji X, Ullman LM, Englof I, et al. Model of cerebral palsy in the perinatal rabbit. J Child Neurol. 2005;20: 972-979.

8. Drobyshevsky A, Derrick M, Wyrwicz AM, Ji X, Englof I, Ullman LM, et al. White matter injury correlates with hypertonia in an animal model of cerebral palsy. J Cereb Blood Flow Metab. 2007;27:270-281.

9. Derrick M, Drobyshevsky A, Ji X, Tan S. A model of cerebral palsy from fetal hypoxia-ischemia. Stroke. 2007;38:731-735.

10. Derrick M, Luo NL, Bregman JC, Jilling T, Ji X, Fisher K, et al. Preterm fetal hypoxia-ischemia causes hypertonia and motor deficits in the neonatal rabbit: a model for human cerebral palsy? J Neurosci. 2004;24: 24-34. 


\section{Drobyshevsky et al}

11. Drobyshevsky A, Derrick M, Prasad PV, Ji X, Englof I, Tan S. Fetal brain magnetic resonance imaging response acutely to hypoxia-ischemia predicts postnatal outcome. Ann Neurol. 2007;61:307-314.

12. Sanger TD, Delgado MR, Gaebler-Spira D, Hallett M, Mink JW. Classification and definition of disorders causing hypertonia in childhood. Pediatrics. 2003;111:e89-97.

13. Chen JJ, Wu YN, Huang SC, Lee HM, Wang YL. The use of a portable muscle tone measurement device to measure the effects of botulinum toxin type A on elbow flexor spasticity. Arch Phys Med Rehabil. 2005; $86: 1655-1660$.

14. Lee HM, Chen JJ, Ju MS, Lin CC, Poon PP. Validation of portable muscle tone measurement device for quantifying velocity-dependent properties in elbow spasticity. J Electromyogr Kinesiol. 2004;14 577-589.

15. Kakinohana O, Hefferan MP, Nakamura S, Kakinohana M, Galik J, Tomori Z, et al. Development of GABA-sensitive spasticity and rigidity in rats after transient spinal cord ischemia: a qualitative and quantitative electrophysiological and histopathological study. Neuroscience. 2006; 141:1569-1583.

16. Wu YN, Hyland BI, Chen JJ. Biomechanical and electromyogram characterization of neuroleptic-induced rigidity in the rat. Neuroscience. 2007; 147:183-196.

17. McKinstry RC, Miller JH, Snyder AZ, Mathur A, Schefft GL, Almli CR, et al. A prospective, longitudinal diffusion tensor imaging study of brain injury in newborns. Neurology. 2002;59:824-833.

18. Drobyshevsky A, Song SK, Gamkrelidze G, Wyrwicz AM, Derrick M, Meng F, et al. Developmental changes in diffusion anisotropy coincide with immature oligodendrocyte progression and maturation of compound action potential. J Neurosci. 2005;25:5988-5997.

19. Volpe JJ. Neurology of the Newborn. Philadelphia, PA: Saunders/ Elsevier; 2008.

20. Okereafor A, Allsop J, Counsell SJ, Fitzpatrick J, Azzopardi D, Rutherford MA, et al. Patterns of brain injury in neonates exposed to perinatal sentinel events. Pediatrics. 2008;121:906-914.

21. Ligam P, Haynes RL, Folkerth RD, Liu L, Yang M, Volpe JJ, et al. Thalamic damage in periventricular leukomalacia: novel pathologic observations relevant to cognitive deficits in survivors of prematurity. Pediatr Res. 2009;65:524-529.

22. Liauw L, van Wezel-Meijler G, Veen S, van Buchem MA, van der Grond J. Do apparent diffusion coefficient measurements predict outcome in children with neonatal hypoxic-ischemic encephalopathy? AJNR Am J Neuroradiol. 2009;30:264-270.

23. Pierson CR, Folkerth RD, Billiards SS, Trachtenberg FL, Drinkwater ME, Volpe JJ, et al. Gray matter injury associated with periventricular leukomalacia in the premature infant. Acta Neuropathol. 2007;114: 619-631.

24. Volpe JJ. Brain injury in premature infants: a complex amalgam of destructive and developmental disturbances. Lancet Neurol. 2009;8: 110-124.

25. Nedelcu J, Klein MA, Aguzzi A, Boesiger P, Martin E. Biphasic edema after hypoxic-ischemic brain injury in neonatal rats reflects early neuronal and late glial damage. Pediatr Res. 1999;46:297-304.

26. Thornton JS, Ordidge RJ, Penrice J, Cady EB, Amess PN, Punwani S, et al. Temporal and anatomical variations of brain water apparent diffusion coefficient in perinatal cerebral hypoxic-ischemic injury: relationships to cerebral energy metabolism. Magn Reson Med. 1998;39:920-927. 


\section{SUPPLEMENTARY MATERIAL \\ NEAR-TERM FETAL HYPOXIA-ISCHEMIA IN RABBITS: MRI CAN PREDICT MUSCLE TONE ABNORMALITIES AND DEEP BRAIN INJURY}

\section{SUPPLEMENTARY METHODS}

\section{Prenatal hypoxia-ischemia model.}

In vivo global hypoxia-ischemia of fetuses was induced by sustained uterine ischemia at 29 days gestation $(90 \%$ term) in timed pregnant New Zealand white rabbits (Myrtle's Rabbits, Thompson Station, Tennessee) as described previously ${ }^{1}$. This scenario models acute placental insufficiency at near term gestation. Briefly, dams were anesthetized and a balloon catheter was introduced into the left femoral artery and advanced into the descending aorta to above the uterine and below the renal arteries. The balloon was inflated for 30, 32, or 40 minutes causing uterine ischemia and subsequent global fetal H-I. Sham animals underwent the same procedure but without balloon inflation. At the end of H-I, the balloon was deflated, resulting in uterine reperfusion. The catheter was then removed, femoral artery repaired, and the dams were allowed to recover. A subset of dam was imaged during H-I and reperfusion in a GE 3 T clinical magnet as described earlier ${ }^{2}$. Four hours after H-I fetuses were delivered by laparatomy. Fetal positions in uterus were recorded to identify the position corresponding fetuses on MRI scan during H-I. Surviving kits were kept in a temperature controlled incubator and gavage fed up to E32=P1 (72 hours after H-I) with rabbit milk. At 6, 18, 24 and 72 hours after $\mathrm{H}-\mathrm{I}$ newborn kits underwent neurological assessment, clinical measurement of tone and muscle tone measurements using a custom built torque-displacement apparatus and a serial MRI scan.

\section{Neurological assessment.}

At E32 kits underwent a battery of neurobehavioral tests for the presence of sensory and motor deficits as described previously ${ }^{1}$. The assessments include tests for posture, muscle tone, activity, locomotion, orofacial reflexes, and sense of touch and smell. The test was video recorded and results were evaluated by 2 observers masked to the treatment group assignment. Muscle tone assessment was based on a modified Ashworth scale ${ }^{1}$, that takes into account both hypotonia and hypertonia, as well as difference in forelimb and hind limb tone in control newborns. Presence of motor deficits was finally assessed at $72 \mathrm{~h}$ after H-I and kits were labeled as "with no motor deficits" or "with motor deficits". The latter category included kits having abnormal either/or muscle tone (hypertonia or hypotonia), posture or locomotion.

\section{Setup of a portable muscle tone measurement system for small animals.}

Muscle tone is a subjective assessment of resistance to a passive stretch. Muscle tone was assessed in wrist, elbow, shoulder, hip, knee and ankle joints on the left and right sides by both a clinical method of subjective assessment and by quantitative measures of passive resistance to stretch. To quantify muscle tone in small neonatal 
animals a portable system was developed to measure passive resistance and stretch angle during sinusoidal joint stretch. The design of the system and principle of measurements was similar to other laboratory muscle tone measurement devices, used to assess muscle tone components in humans ${ }^{3-4}$ and animal studies ${ }^{5-6}$ and adapted for small animal size and small force measurements. The arrangement of this hand-held device and its recording system can be seen in supplementary figure S1.

An animal was positioned on a platform so that the rotational axis of a measured joint was aligned with the rotational axis of a jig and was held in place manually by experimenter. The distal joint part was placed in a U-shaped plastic restrainer connected to the rotating jig and underwent repetitive flexion and extension cycles. The joint was stretched at 4 velocities, $0.5,1,1.5$ and 2 cycles/sec for $30 \mathrm{sec}$ each, paced with the aid of computer generated cycles. The maximal allowed joint rotation range was \pm 40 degrees. Stretching at each velocity was repeated twice in random order. Angle of the joint rotation and applied force (torque) was measured by sensors and recorded using data acquisition card (National Instruments, TX) connected to laptop running custom build program on LabView (National Instruments, TX). The force transducer was calibrated with a set of known weights. The rabbit kits were first subjected to 15-20 cycles so that the kit got used to the apparatus. Recording was started after the kits stopped their voluntary contractions. Care was taken to measure only passive resistance.

Joint stiffness, as a measure of muscle tone, was derived from a linear regression of the displacement-torque curves and was mostly determined by elastic component of muscle resistance. Joint resistance was also decomposed to viscous and elastic components and a complex modulus of resistance was calculated as a measure of total joint resistance ${ }^{4}$.

\section{MR imaging.}

Survival in utero MR imaging was performed in $3 \mathrm{~T}$ GE clinical magnet as described previously ${ }^{2}$. The anesthetized dam instrumented with an aortic catheter (as described above) was positioned in a quadrature extremity coil. An extended catheter connection allowed initiating and ceasing uterine ischemia by inflating and deflating the balloon remotely without moving the animal. Single shot fast spin echo (SSFSE) T2weighted images were taken for anatomical reference in axial, coronal and sagittal planes, with 25-32 axial slices covering all the fetuses inside dam, slice thickness $4 \mathrm{~mm}$, matrix $256 \times 192$, and field of view $16 \mathrm{~cm}$. Anatomical scans were followed by continuous series of diffusion weighted echo-planar images (DWI) with $b=0$, and $0.8 \mathrm{~ms} / \mu \mathrm{m}^{2}, \mathrm{TR} / \mathrm{TE}=$ $7400 / 70 \mathrm{~ms}, \mathrm{NEX}=1$, and the same slice geometry as in the reference anatomical images during the $5 \mathrm{~min}$ before $\mathrm{H}-\mathrm{I}$, during $\mathrm{H}-\mathrm{I}$ and $20 \mathrm{~min}$ of reperfusion. Apparent diffusion coefficient (ADC) maps were calculated from DWI series using in-house software, written on Matlab (Natick, MA) and mean ADC values was obtained for each fetal brain for each time point by placing a region of interest on whole fetal brain. ADC nadir was defined as the lowest ADC value during $\mathrm{H}-\mathrm{I}$ and $20 \mathrm{~min}$ of reperfusion. Time to rapid ADC decline was calculated as an intersection of baseline ADC and a regression line with the fastest slope of ADC decline, determined form ADC curve between 15 and 40 
min of $\mathrm{H}-\mathrm{I}$ phase using sliding 5 min time window.

Uterine position of each fetus was identified, to serially follow ADC time course of fetal brains during H-I in utero and postnatally after delivery by hysterotomy. For comparison of $\mathrm{H}-\mathrm{I}$ between different gestation ages, 4 E29 dams (27 fetuses) were imaged during 32 min H-I, 2 E22 dams (12 fetuses) during 40 min H-I and compared to published data ${ }^{2}$ from 8 E25 dams (56 fetuses) during 40 min H-I.

Postnatal MR imaging and data analysis. MR imaging was performed using 4.7T Bruker magnet and $30 \mathrm{~mm}$ circular surface coil and multi-slice T2-wheighted RARE sequence (TE/TR 80/4000 ms) to determine presence of gross anatomical abnormalities. Diffusion tensor images were acquired with parameters: field of view $2 \mathrm{~cm}$, matrix 128x64, 12 axial slices $1 \mathrm{~mm}$ thick, 6 diffusion directions, 6 averages, TR/TE 2000/21 ms, b= 0, 0.8 $\mathrm{ms} / \mu \mathrm{m}^{2}$. ADC and FA maps were calculated ${ }^{7}$. Spatial distribution of ADC changes was assessed by the region of interest analysis. The studied regions included cerebral cortex, basal ganglia, thalamus, midbrain and pons, based on anatomical landmarks. Severity of injury was quantified by counting volume of voxels on ADC maps with the value below predefine threshold lower than $0.7 \mu \mathrm{m}^{2} / \mathrm{ms}$ in all slices where the studied regions were present. Volume of injury was quantified as a product of number of voxels below threshold by voxel size. The empirical threshold $0.7 \mu \mathrm{m}^{2} / \mathrm{ms}$ was chosen since the voxels with ADC, lower than this cut-off ADC value, are not normally present in control animal gray and white matter at the studied perinatal period. 


\section{SUPPLEMENTARY FIGURES AND FIGURE LEGENDS}

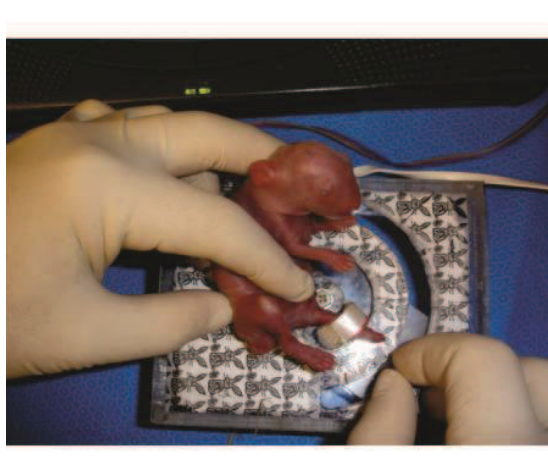

A

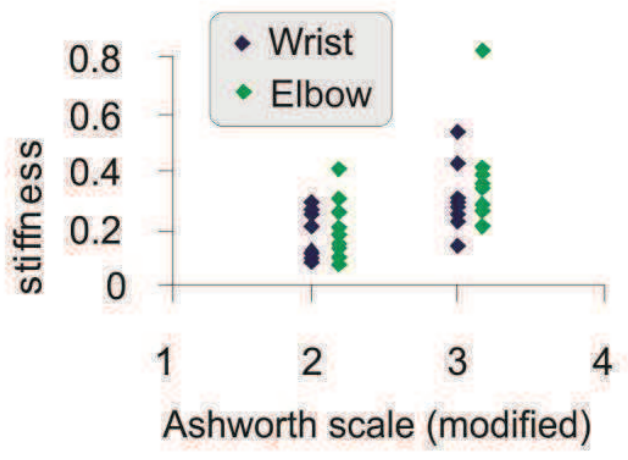

D

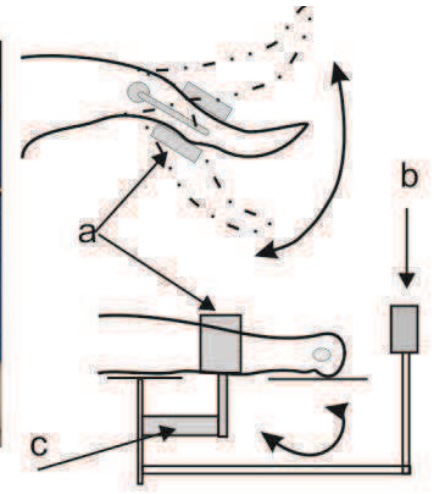

B

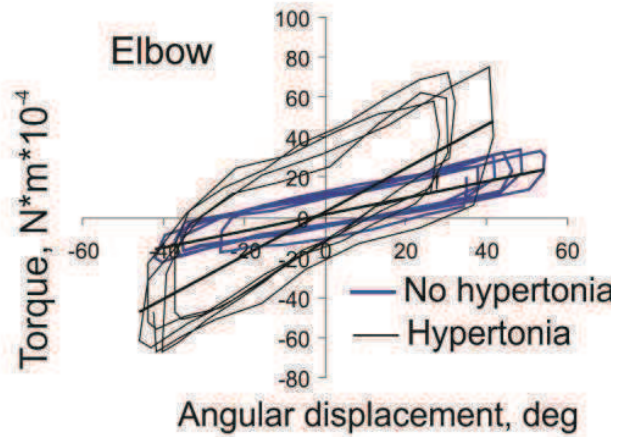

C

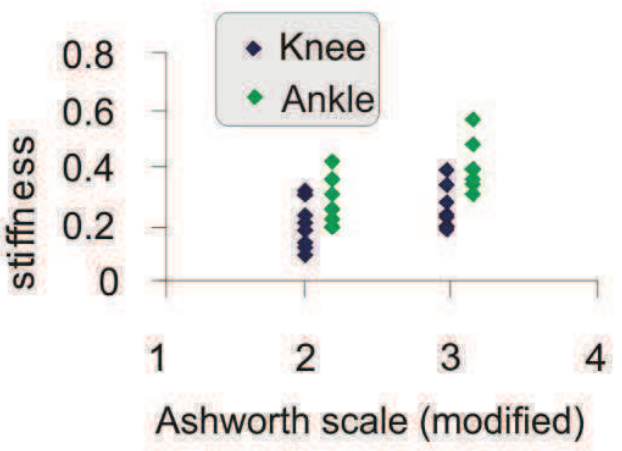

E

Figure S1. Laboratory testing of muscle tone in P1 rabbit kit.

A. General view of the torque-displacement apparatus.

B. The limb was placed in a U-shaped restrainer (a) connected to a pivoting rig. The joint was rotated at several predefined velocities manually by investigator using handle (b) attached to the rotation axes. Applied force (torque) was measured with a force sensor (c). Joint angular position and applied force (torque) was recorded on computer and analyzed by software written on LabView and Matlab. Care was taken to measure only passive resistance.

C. Typical torque - angular displacement curve on P1 rabbit kit. Joint stiffness was estimated from the slope of torque-displacement curve. Hysteresis due to phase shift can between reactive resistance and angular displacement be observed on the plot, which shows the viscous property of the targeted muscle.

D-E. Joint stiffness correlated with manual muscle tone assessment according to modified Ashworth scale ${ }^{1}$ in forelimbs ( $\mathrm{R}=0.58$ for wrist and $\mathrm{R}=0.48$ for elbow) and hind limbs $(\mathrm{R}=0.36$ for knee and $\mathrm{R}=0.63$ for ankle $)$. 


\section{Hypertonia}

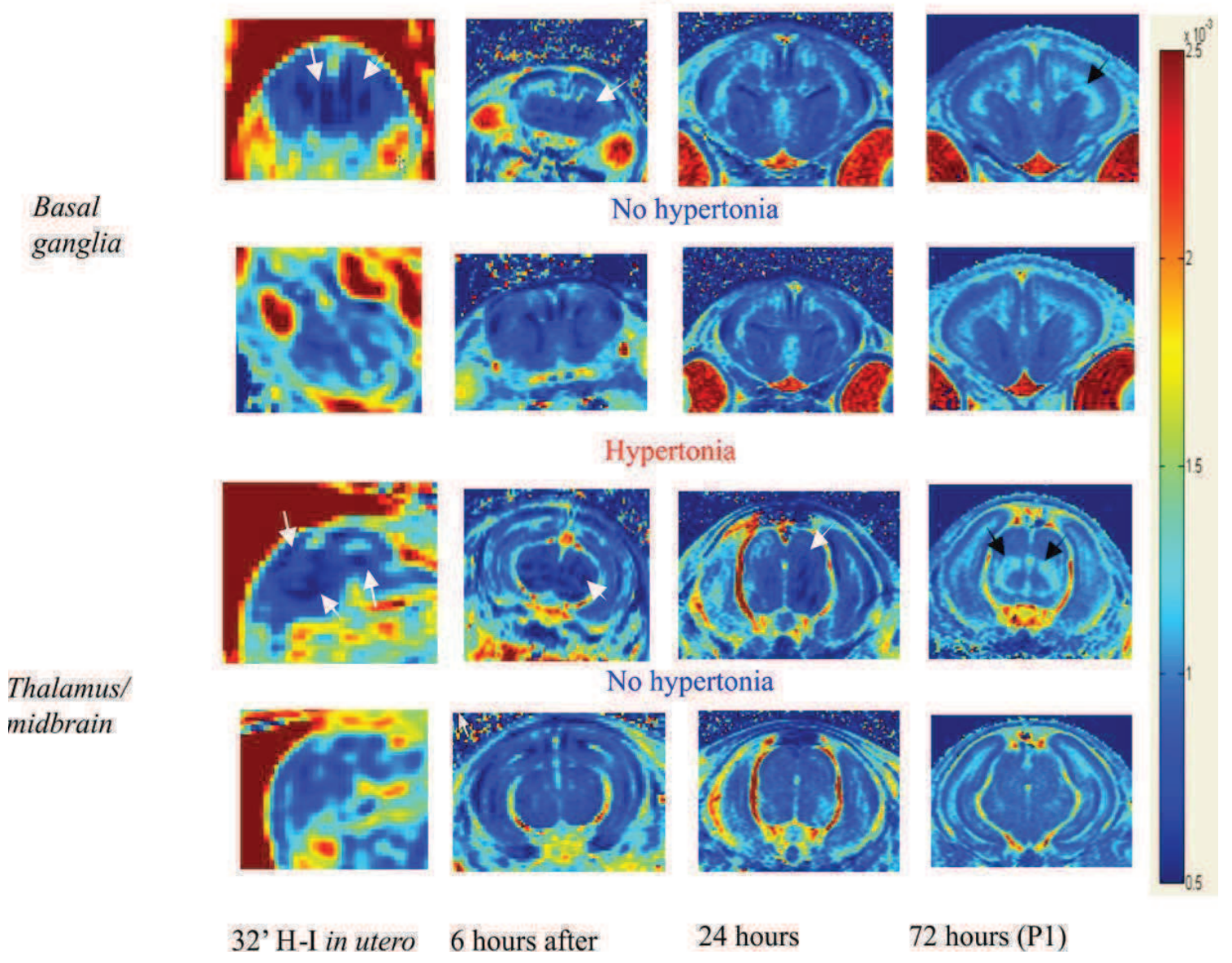

Figure S2. ADC time course was obtained in serial imaging on E29 fetuses, starting from in utero imaging at $32 \mathrm{~min}$ of $\mathrm{H}-\mathrm{I}$ (first column) and postnatal imaging in kits after Csection delivery 4 hours after H-I. Representative images are shown for kits with and without muscle hypertonia, assessed at 72 hours after H-I (at E32, corresponding to P1 in naïve controls). After E29 H-I, ADC was lower (deep blue) in basal ganglia and midbrain in hypertonic kit at 6 and 24 hours (white arrows). At 72 hours after H-I, ADC in thalamus/midbrain/basal ganglia increased relative to non-hypertonic kits (black arrow). Cortex was relatively spared in both hypertonic and non-hypertonic kits. Color map bar units are $\mu \mathrm{m}^{2} / \mathrm{ms}$. 


\section{SUPPLEMENTARY TABLES}

\begin{tabular}{|l|l|l|l|l|l|}
\hline & $\begin{array}{l}\text { Predicted } \\
\text { negative }\end{array}$ & $\begin{array}{l}\text { Predicted } \\
\text { positive }\end{array}$ & $\begin{array}{l}\text { Fisher's exact test, } \\
\text { p-value }\end{array}$ & Sensitivity & Specificity \\
\hline \multicolumn{7}{|c|}{ Any motor deficits at 72 hour after H-I } \\
\hline Logit $\mathrm{P}=-1.550+(0.976 *$ Basal ganglia $)+(1.10 *$ Brain stem $)$ \\
\hline Actual negative & 12 & 2 & & 0.89 \\
\hline Actual positive & 2 & 17 & $<0.001$ & 0.86 \\
\hline \multicolumn{7}{|c|}{ Hypertonia at 72 hour after H-I } \\
\hline Logit $\mathrm{P}=-2.728+(0.682 *$ Thalamus $)+(0.61 *$ Brain stem $)$ \\
\hline Actual negative & 20 & 2 & 0.78 \\
\hline Actual positive & 4 & 7 & 0.002 & 0.83 & 0. \\
\hline
\end{tabular}

Table S3. Logistic regression model and results of classification to predict presence of any motor deficits and hypertonia at $72 \mathrm{~h}$ after $\mathrm{H}-\mathrm{I}$ by presence of abnormally low ADC regions at 24 hours after $\mathrm{H}-\mathrm{I}$. Threshold probability for positive classification: 0.5 . The power of the Fisher's exact test with alpha $=0.05$ was 0.82 for all motor deficits and 0.78 for hypertonia at 72 hours.

\section{SUPPLEMENTARY REFERENCES}

1. Derrick M, Luo NL, Bregman JC, Jilling T, Ji X, Fisher K, et al. Preterm fetal hypoxia-ischemia causes hypertonia and motor deficits in the neonatal rabbit: A model for human cerebral palsy? J. Neurosci. 2004;24:24-34

2. Drobyshevsky A, Derrick M, Prasad PV, Ji X, Englof I, Tan S. Fetal brain magnetic resonance imaging response acutely to hypoxia-ischemia predicts postnatal outcome. Ann. Neurol. 2007;61:307-314

3. Chen JJ, Wu YN, Huang SC, Lee HM, Wang YL. The use of a portable muscle tone measurement device to measure the effects of botulinum toxin type a on elbow flexor spasticity. Arch. Phys. Med. Rehabil. 2005;86:1655-1660

4. Lee HM, Chen JJ, Ju MS, Lin CC, Poon PP. Validation of portable muscle tone measurement device for quantifying velocity-dependent properties in elbow spasticity. J. Electromyogr. Kinesiol. 2004;14:577-589

5. Kakinohana O, Hefferan MP, Nakamura S, Kakinohana M, Galik J, Tomori Z, et al. Development of gaba-sensitive spasticity and rigidity in rats after transient spinal cord ischemia: A qualitative and quantitative electrophysiological and histopathological study. Neuroscience. 2006;141:1569-1583

6. $\mathrm{Wu} \mathrm{YN}$, Hyland BI, Chen JJ. Biomechanical and electromyogram characterization of neuroleptic-induced rigidity in the rat. Neuroscience. 2007; 147:183-196

7. Drobyshevsky A, Derrick M, Wyrwicz AM, Ji X, Englof I, Ullman LM, et al. White matter injury correlates with hypertonia in an animal model of cerebral palsy. J. Cereb. Blood Flow Metab. 2007;27:270-281 
APÊNDICE C-Watanabe IS, Dias FJ, Mardegan Issa JP, dos Santos Haemmerle CA, Cury DP, Takada SH, Sosthenes MC, Pereira da Silva MC, Campos LM, Nogueira $\mathrm{MI}$, Iyomasa MM. Immunohistochemistry and ultrastructural characteristics of nerve endings in the oral mucosa of rat.Microscopy (Oxf). 2013;62(2):259-70. 
Biological: Full-length

\title{
Immunohistochemistry and ultrastructural characteristics of nerve endings in the oral mucosa of rat
}

\author{
Ii-sei Watanabe ${ }^{1, *}$, Fernando José Dias ${ }^{1}$, João Paulo Mardegan Issa ${ }^{2}$, \\ Carlos Alexandre dos Santos Haemmerle ${ }^{1}$, Diego Pulzatto Cury ${ }^{1}$, \\ Silvia Honda Takada ${ }^{1}$, Marcia Consentino Kronka Sosthenes ${ }^{4}$, \\ Marcelo Cavenaghi Pereira da Silva ${ }^{3}$, Leila M. G. Campos ${ }^{1}$, \\ Maria Inês Nogueira ${ }^{1}$ and Mamie Mizusaki Iyomasa ${ }^{2}$ \\ ${ }^{1}$ Institute of Biomedical Sciences, University of São Paulo, São Paulo, Brazil, ${ }^{2}$ Faculty of Dentistry of Ribeirão \\ Preto, University of São Paulo, Ribeirão Preto, Brazil, ${ }^{3}$ Department of Anatomy, Federal University of São \\ Paulo, São Paulo, Brazil and ${ }^{4}$ University Hospital João de Barros Barreto, Federal University of Pará, Belém, \\ Brazil \\ *To whom correspondence should be addressed. E-mail: watanabe@icb.usp.br
}

The sensory nerve endings of the rat tongue, cheek and palate were
studied using immunohistochemical staining and transmission electron
microscopy analysis. The specimens were fixed in modified Karnovsk
solution and embedded in Spurr resin. Substance P, calcitonin gene-
related peptide (CGRP)- and protein gene product 9.5 (PGP b9.5)-contain-
ing nerve fibers in the rat tongue, cheek and palate were examined by
electronic microscopical analysis and immunohistochemical localization.
These fibers run very close to the basal lamina of the epithelium and
extend into the filliform and fungiform papillae. Numerous plexiform
fibers immunoreactive for substance P, CGRP and PGP 9.5 were found in
the connective tissue of mucosa. Electron microscopic observations
showed clearly immunostained nerve fibers, which are located very close
to the basal lamina of epithelial cells. Some electron-dense granules may
be observed in the axoplasms of both substance P and CGRP immunor-
eactive fibers. Several lamellar corpuscles into the subepithelial connect-
ive tissue papillae, Merkel corpuscles and numerous thin unmyelinated
and myelinated axons were observed. The terminal axons revealed nu-
merous mitochondria, neurofilaments, microtubules and clear vesicles in
the base of axoplasmic protrusions. The lamellar cells showed caveolae
and interlamelar spaces filled by amorphous substance. Between the la-
mellar cells and axoplasmic membrane, and in the adjacent lamellae
region, desmosome-type junctions were observed. The quantitative and
morphometric analysis showed nerve endings with an average area of
4.83 $3.4 \mu{ }^{2}$ and 19.4 internal mitochondria in this site and the orga-
nized corpuscles with an average area of $79.24 \pm 27.24 \mu m^{2}$ and 24.23
internal mitochondria in this place. All the structures observed are
involved in the transmission of pain and mechanoreceptors stimulus of
these oral mucosae.
Lamellated corpuscles, nerve endings, immunohistochemistry, mitochon-
dria, TEM, rat 


\section{Introduction}

Several papers have been reported the fine structure of sensory nerve endings in animals [1-11]. Electron microscopic histochemistry of sensory nerve endings in several organs also demonstrated that cholinesterase (ChE) activities are present in the cisternae of rough endoplasmic reticulum, caveolae and the nuclear envelope of lamellar cells [12-21]. Substance P may be contained in nerve fibers of the dental pulp, periodontium and inferior alveolar nerve fibers [22-24]. The presence of substance $\mathrm{P}$-, calcitonin gene-related peptide (CGRP)-containing structures and the PGP9.5 in the vallate and taste buds structures were reported by [25-27], describing the existence of substance P-like immunoreactive structures in the dental pulp of the cat. The coexistence of CGRP and substance P-like peptide in single cells of the trigeminal ganglion of the rat was described [28].

Especially in the oral mucosa, the lamellar sensory nerve endings were reported by [29-42]. Other organized nerve endings such as Meissner corpuscles were reported by [2,9,43-45] and the Pacinian corpuscles were described by $[6,46,47]$ as free or complex structures localized and encapsulated with the connective tissue. The details of these structures were reported by $[11,48,49]$. The sensory corpuscles are formed by numerous cytoplasmic extensions of lamellar cells, and terminal axons.

The sensory nerve endings are responsible for monitoration of internal and external stimuli. Furthermore, it is known that some free nerve endings of myelinated and unmyelinated contain neuropeptides associated with pain and inflammation; thus, knowledge of these nerve endings could promote the pathophysiology understanding of several diseases, such as trigeminal neuralgia. Thus, our study aims to describe, using the Wistar rat as experimental animal model, the fine structure of lamellated, intraepithelial and subepithelial nerve endings of the rat tongue, cheek and palate mucosae with special attention for lamellar corpuscles and free nerve endings cells by transmission electron microscopy, using imunohistochemistry for substance P, CGRP and PGP 9.5.

\section{Materials and methods}

\section{Immunoperoxidase staining}

Five rats (Rattus norvegicus albinus, Wistar), $310 \mathrm{~g}$ and 50 days, were anaesthetized with sodium pentobarbital $\left(20 \mathrm{mg} \mathrm{kg}^{-1}\right.$, Rhobifarma Indústria Farmacêutica Ltd., Hortolândia, São Paulo, Brazil) and perfused through the left ventricle of the heart using $4 \%$ paraformaldehyde and $0.2 \%$ glutaraldehyde in sodium phosphate buffer. Small segments of central portion of the tongue, cheek, gingival and soft palate were removed carefully and sectioned using a vibratome apparatus. Sections of 40-50 $\mu \mathrm{m}$ thickness were obtained. All surgical procedures were approved by the local ethical Research Council (number 11.1.130.53.5) that follows the international laws for animals' procedure.

Sections were placed in small vials with paraformaldehyde (PBS), followed by 50, 70 and 50\% ethyl alcohol. Staining was proceeded by immersion of tissues in 2\% normal sheep serum (NSS) in PBS for $10 \mathrm{~min}$ at room temperature. Various dilutions of the primary antisera were used directly after blocking, without washing in PBS. The incubation time was 24 or $48 \mathrm{~h}$ at room temperature and at $4{ }^{\circ} \mathrm{C}$. After this, sections were washed in PBS for $10 \mathrm{~min}$ and then blocked in 2\% NSS for $10 \mathrm{~min}$. Incubation was performed in anti-rabbit gamma globulin (diluted, 1:100) for $30 \mathrm{~min}$ and then washed in PBS for $10 \mathrm{~min}$. Peroxidase-antiperoxidase diluted 1:1000 was applied for $30 \mathrm{~min}$. Sections were then washed in PBS for $10 \mathrm{~min}$. One hundred and fifty milligrams of 3,3-diamino benzedine tetrahydrochloride (Aldrich Chemical Co., USA) were freshly dissolved in $200 \mathrm{ml}$ of $0.05 \mathrm{M}$ tris buffer. Fourteen microlitres of $30 \% \mathrm{H}_{2} \mathrm{O}_{2}$ solution were added just prior to the immersion of the sections. Sections were stained for $10 \mathrm{~min}$ and then washed in tris buffer solution for $10 \mathrm{~min}$, followed by PBS for $10 \mathrm{~min}$.

The sections were dehydrated, cleared in xylene and mounted with Permount (Fisher). The slides were examined under a Zeiss microscopy (Axioskop-2, Deutsch) equipped with an automatic photomicrographic system. 


\section{Transmission electron microscopy}

For transmission electron microscopy, five rats were anaesthetized with sodium pentobarbital and perfused through the left ventricle of the heart with modified Karnovsky fixative solution containing $2.5 \%$ glutaraldehyde and $2 \%$ paraformaldehyde in a $0.1 \mathrm{M}$ sodium cacodilate buffer ( $\mathrm{pH}$ 7.4) [30]. The tongue, cheek and palate were removed carefully and immersed in the same fixative solution for $3 \mathrm{~h}$ at $4^{\circ} \mathrm{C}$. Specimens were rinsed with $0.1 \mathrm{M}$ sodium cacodilate buffer and post-fixed in $1 \% \mathrm{OsO}_{4}$ for $2 \mathrm{~h}$ at $4^{\circ} \mathrm{C}$. Then, the samples were immersed in $5 \%$ uranyl acetate aqueous solution for $2 \mathrm{~h}$ at room temperature, dehydrated with a graded series of ethanol and embedded in Spurr resin.

Semi-thin sections were cut with a glass knife on an LKB ultramicrotome, mounted and stained with $2 \%$ toluidine blue for light microscopy study. Ultra-thin sections of the selected areas were cut with a Reichert Ultracut Ultramicrotome using diamond knife. The grids were counterstained with uranyl acetate [50] and lead citrate [51] and examined using a JEOL 1010 transmission electron microcopy (Tokyo, Japan).

It was used ultra-thin sections of pre-selected areas (40-50 $\mu \mathrm{m}$ of thickness) for immunohistochemical analysis, using a transmission electron microscope (JEOL 1010). The samples were analyzed using Jeol 1010 transmission electron microscope.

\section{Morphometric and quantification analyses}

The morphometric and quantitative analyses were performed using images obtained by transmission electron microscope. Organized corpuscles area, the mitochondria in organized corpuscles area, the nerve ending area, the lamellae thickness of the organized corpuscles and mitochondria quantification belonging to the organized corpuscles and nerve endings were measured using the Image $J$ software (http://rsb.info.nih.gov/ij, free). Data are presented as mean and standard deviation using a boxplot graph in order to present the data dispersion.

\section{Results}

\section{Immunohistochemistry}

The papillae of the tongue, cheek, gingival and palate of oral mucosae showed immunoreactive nerve fibers (Fig. 1a-d). These nerve fibers were strongly stained by immunohistochemical stain as shown in Fig. 1, the fungiform papilla showed substance P-containing fibers. The single fibers could be observed penetrating into the epithelial layer. In frontal sections of the tongue mucosa, numerous substance P-immunoreactive fibers were seen within the connective tissue into each papilla. The greatest abundance of plexiform fibers immunoreactive for substance $P$ and for CGRP was seen in the connective tissue of fungiform papillae. The subepithelial nerve fibers form a lattice-like arrangement in many areas (Fig. 1c). These are slightly varicose and most of them disposed towards the basement membrane of the epithelial cells. The PGP 9.5-containing nerve fibers were observed into the connective tissue of small papilla or in the subepithelial space (Fig. 1d).

Well-stained substance P-containing fibers were identified using electron micrographies (Fig. 5a). These fibers are very closely located to the basal lamina of epithelial cells (Fig. 5). Axoplasm of the nerve fibers presented numerous electron-dense granules (Fig. 5a-d). Electron-dense granules in neuronal fibers stained by calcitonin-gene-related peptide (CGRP) are shown in Fig. 5.

\section{Morphology of nerve endings}

In the rat oral mucosa, the sensory corpuscles and free nerves endings were identified, which are presented in the subepithelial and intraepithelial localization (Fig. 2a-d). These structures could be observed in the deep portion of dermal papillae and very closely to the basal lamina of epithelial cells. The intraepithelial endings were located in different layers of epithelium. The axon was surrounded by cytoplasmic lamina of Schwann cell and adjacent bundles of collagen fibers (Fig. 2d). Numerous amyelinic and myelinic axons were present in the subepithelial region of oral mucosa (Fig. 3d-g). 

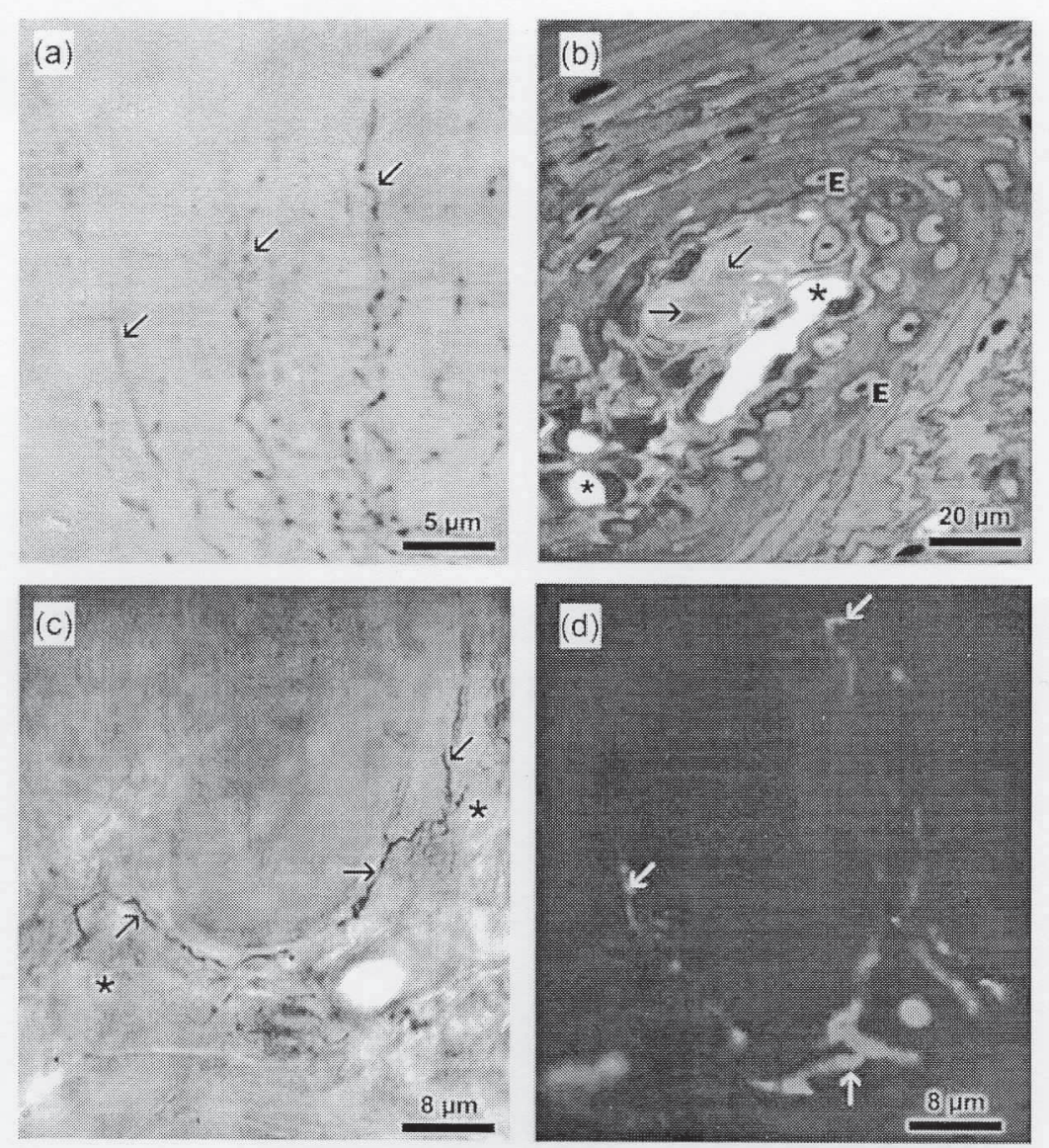

Fig. 1. Immunoreactive light microscopy images of substance P, CGRP and PGP 9.5 and the lamellar corpuscle of semi-thin section stained by toluidin blue. (a) Numerous substance P immunoreactive nerve fibers (arrows) extend a network into the connective tissue of fungiform papilla of the tongue (arrows). Bar: $5 \mathrm{\mu m}$. (b) The semi-thin section of gingiva stained by toluidin blue shows the terminal lamellar corpuscles (arrows), capillary (asterisk) and bundles of collagen fibers. The flat basal epithelial cells (E) are identified. Bar: $20 \mu m$. (c) CGRP immunoreactive of free nerve endings (arrows) extend into the connective tissue (asterisk) which are located very close to the basement membrane of epithelial cells and into the papilla. Bar: $8 \mu \mathrm{m}$. (d) PGP 9.5 Immunoreactive axons are noted in the deep portion of papilla (arrows) and subepithelial portions. Bar: $8 \mathrm{~mm}$.

The thin amyelinic fibers were numerous than myelinated axons (Fig. 3e-g). The axoplasm of unmyelinated axons containing several mitochondria and neurofilaments was clearly identified. The cytoplasm of Schwann cell showed mitochondria and its large nucleus (Fig. 3g).

Subepithelial free nerve endings were placed closely to the basement membrane of epithelial cells and were surrounded by lamina of Schwann cells (Fig. 3h). At the periphery, an afibrillar substance was observed involving the nervous terminations (Fig. 2h).

In the subepithelial regions, numerous unmyelinated terminal axons, capillaries and fibroblast cells were detected (Fig. 3a). Different forms of nerve endings are shown in Fig. 3.

\section{Morphology of organized corpuscles}

The organized corpuscle presented terminal axons in central position, involved by numerous and thin concentric cytoplasmic lamellae (Fig. 4a and b), especially at mucosa of the cheek. At the periphery, a capsule was observed formed by cytoplasmic extensions of perineural cells and bundles of collagen fibers disposed in various directions (Fig. 4a). Scattered mitochondria could be observed at the periphery of the central axon, measuring about 250 $\mathrm{nm}$ in diameter (Fig. 4b). The lamellar corpuscle of soft palate presents numerous mitochondria that were clearly seen (Fig. 4c and d). They also contained neurofilaments and microtubules (Fig. 4c and $d$ ). 

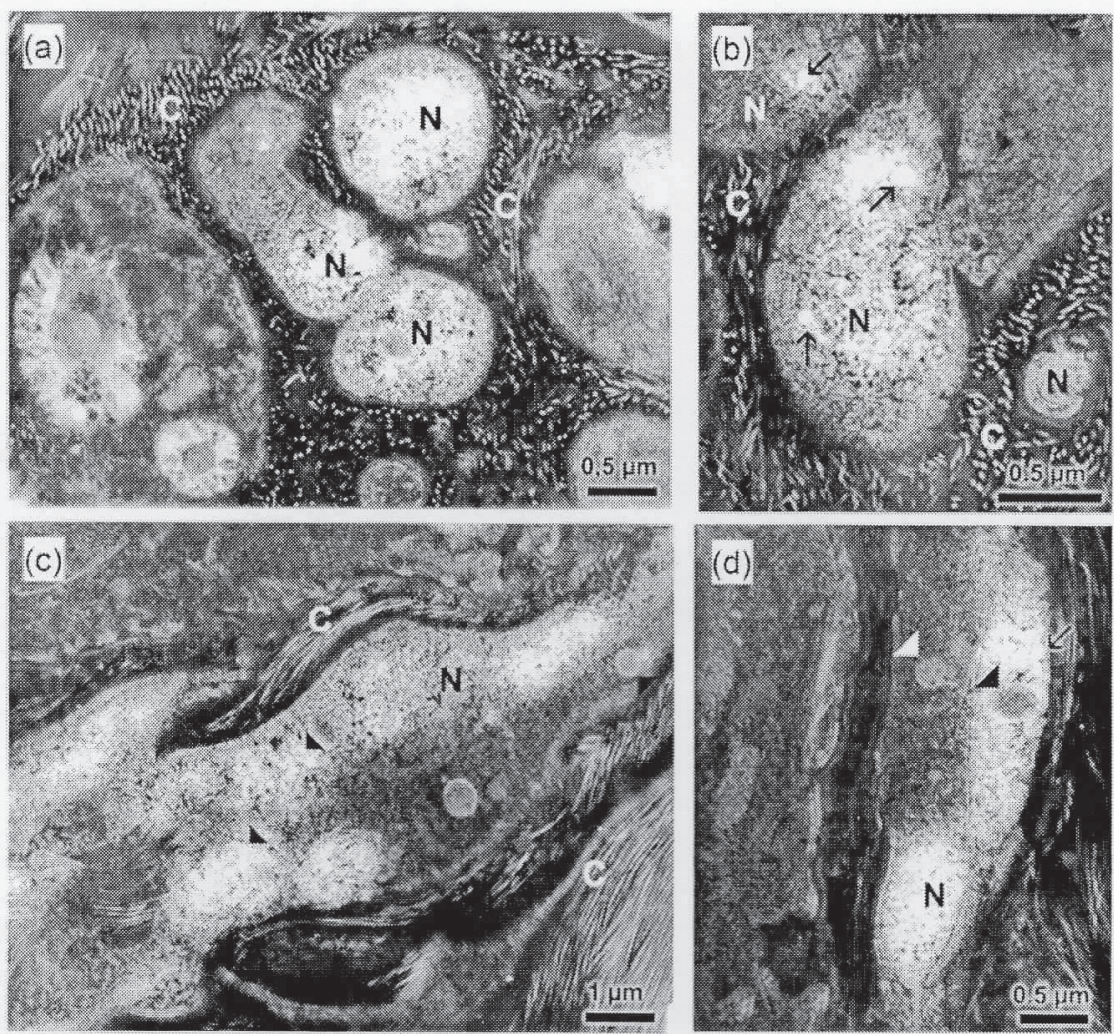

Fig. 2. Transmission electron microscopy images of tissues after immunoreaction with substance P and CGRP. (a) These nerve fibers (N) were marked intensively by substance P immunoreactions. Several substance P-containing fibers are noted and surrounded by collagen fiber bundles (C). Bar: $0.5 \mu \mathrm{m}$. (b) Several substance P-immunoreactive fibers (N) are seen within the connective tissue (C) of the filliform papilla. The small vesicle-like formations are identified (arrows). Bar: $0.5 \mu \mathrm{m}$. (c) Vallate papilla of the tongue presenting CGRP-containing nerve fibers $(\mathrm{N})$ revealing the adjacent collagen fiber bundles (C). The axoplasm is intensively marked by immunoreaction revealing the mitochondria (arrows). Bar: $1 \mu \mathrm{m}$. (d) Well-stained CGRP-containing fibers (N) identifying small vesicles (small arrow) and mitochondria (arrowheads). These fibers are very close to the basal lamina of epithelial cells. Bar: 0.5 um.

Under higher magnification, in the lateral portion of terminal axons, it could be detected the axoplasmic protrusions containing several clear vesicles measuring $25-50 \mathrm{~nm}$ in diameter (Fig. 4d).

The lamellae of cytoplasmatic processes are uniform and disposed bilaterally (Fig. 4a and b). The lamellae of soft palate corpuscles exhibited thin and small aspects near to the axoplasm membrane and become large in diameter at periphery (Fig. 4c and d). The cytoplasm of lamellar cell showed numerous mitochondria, microtubules and filaments (Fig. 4c).

The laminae contained several caveolae (Fig. 4c and d), which were invaginations of the cytoplasmic membrane, and in the interlamellar spaces, it was seen amorphous material and fine collagen fibers. Between the adjacent lamellae and terminal axon, and between the lamellar cells, it was seen desmosome-type junctions, as demonstrated in Fig. 4d.

Merkel cells and associated nerve endings of oral mucosa were characterized by the presence of lobulated nucleus, having one or two intraepithelial nerve endings, on basal layer of epithelial cells (Fig. 5e). Terminal axons contained numerous mitochondria. There were numerous round granules usually accumulated in the cytoplasm facing the nerve terminals (Fig. 5f). It was also observed some desmosome-like membrane on the surface between the keratinocytes and the nerve terminals. The spine-like processes extend into the intercellular spaces.

\section{Morphometry and quantification of nerve endings and organized corpuscles}

Quantitative morphometric analyses were performed related to nerve endings and organized 

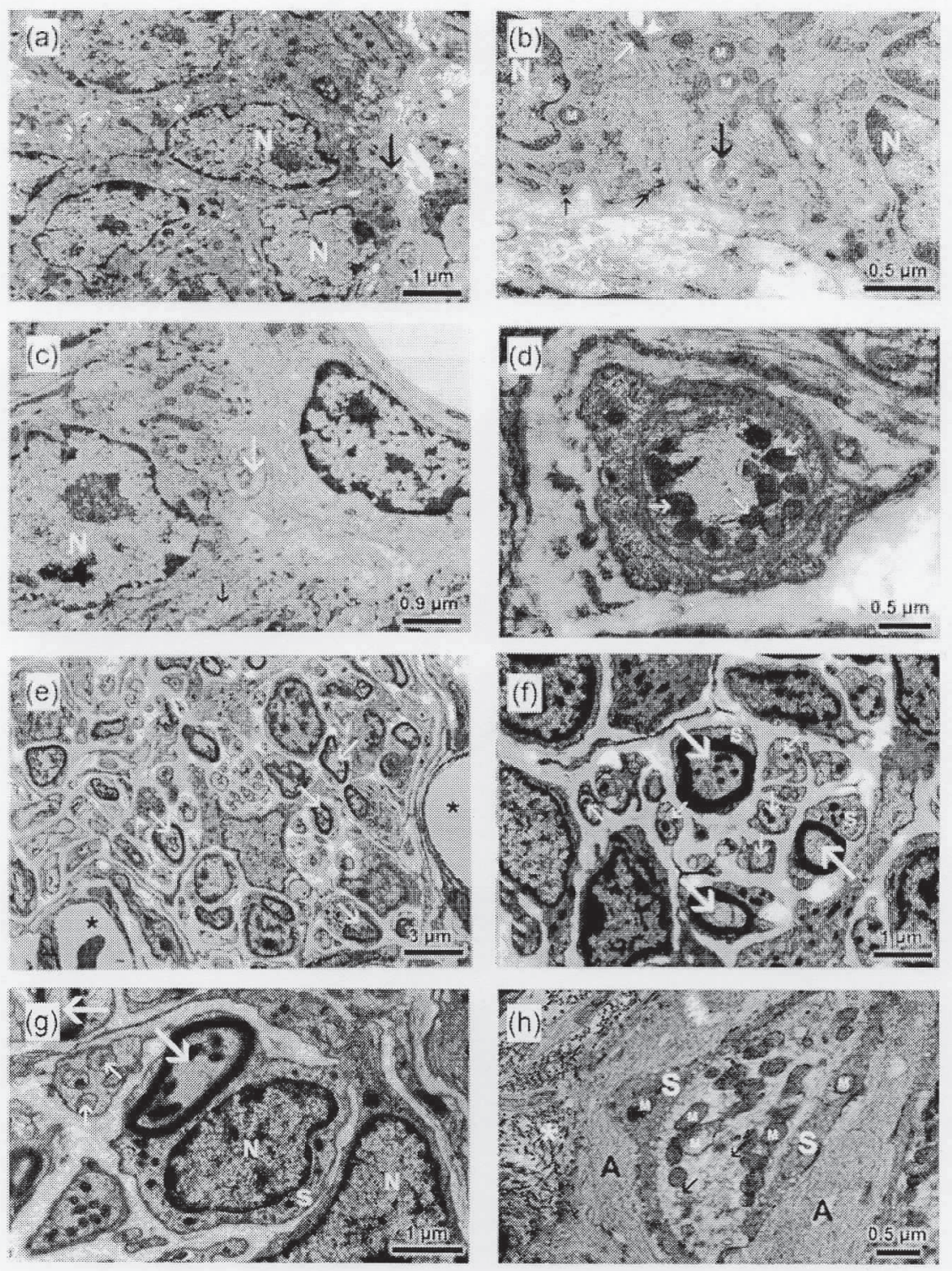

Fig. 3. (a) Pyramidal epithelial cells of basal lamina with nuclei $(\mathrm{N})$ and the nerve ending (small arrow) and basement membrane (large arrow). Bar: 1 un. (b) Cytoplasm of epithelial cell containing several mitochondria (m), nuclei (N) and the intraepithelial nerve ending (large dark arrow). In the axoplasm, mitochondria is observed. The desmosome junction between the epithelial cells (large white arrows) and hemi-desmosomes (white arrowhead) is seen. Bar: $0.5 \mu \mathrm{m}$. (c) Nucleus $(\mathrm{N})$ of epithelial cell, cytoplasm containing the mitochondria and cytoplasmic interdigitations (small arrow) and free nerve ending very close to the basement membrane of epithelial cells (large arrow). Bar: $0.9 \mu \mathrm{m}$. (d) High magnified free nerve endings surrounded by Schwann cell cytoplasm containing the several mitochondria at the periphery (arrows) and neurofilaments in the central portion. Bar: $0.5 \mu \mathrm{m}$. (e) Groupings of thin myelinated fibers (arrows) and numerous unmyelinated fibers very close to the basal lamina. Small capillaries measuring about 3-5 $\mu \mathrm{m}$ are shown (asterisk). Bar: $3 \mu \mathrm{m}$. (f and g) Few myelinated nerve fibers (large arrows) and unmyelinated fibers (small arrows), nuclei (N) and Schwann cell cytoplasm (S), shown at high magnification. Bar: $1 \mu \mathrm{m}$. (h) End bulb of free nerve endings and cytoplasm of Schwann cell present numerous mitochondria (M), clear vesicles (arrows) and neurofilaments. A thin lamina of Schwann cells (S) surround free nerve endings and at the periphery may observe the extense amorphous substance (A) separating the terminal axon and adjacent collagen fibers (asterisk). Bar: $0.5 \mathrm{\mu m}$.

corpuscles in the oral mucosa of rats (Fig. 6). The nerve endings showed an average area of $4.83 \pm 3.4 \mu^{2}$ with 19.4 (mean) of mitochondria inside, the dispersion of nerve endings areas are shown in Fig. 6a and the median area of these nerve endings was $2.99 \mu \mathrm{m}^{2}$. The average area of organized corpuscles was $79.24 \pm 27.24 \mu \mathrm{m}^{2}$ with 24.23 (mean) inside mitochondria, the dispersion of organized corpuscles areas are represented in Fig. $6 \mathrm{~b}$ and the median area of the organized corpuscles was 

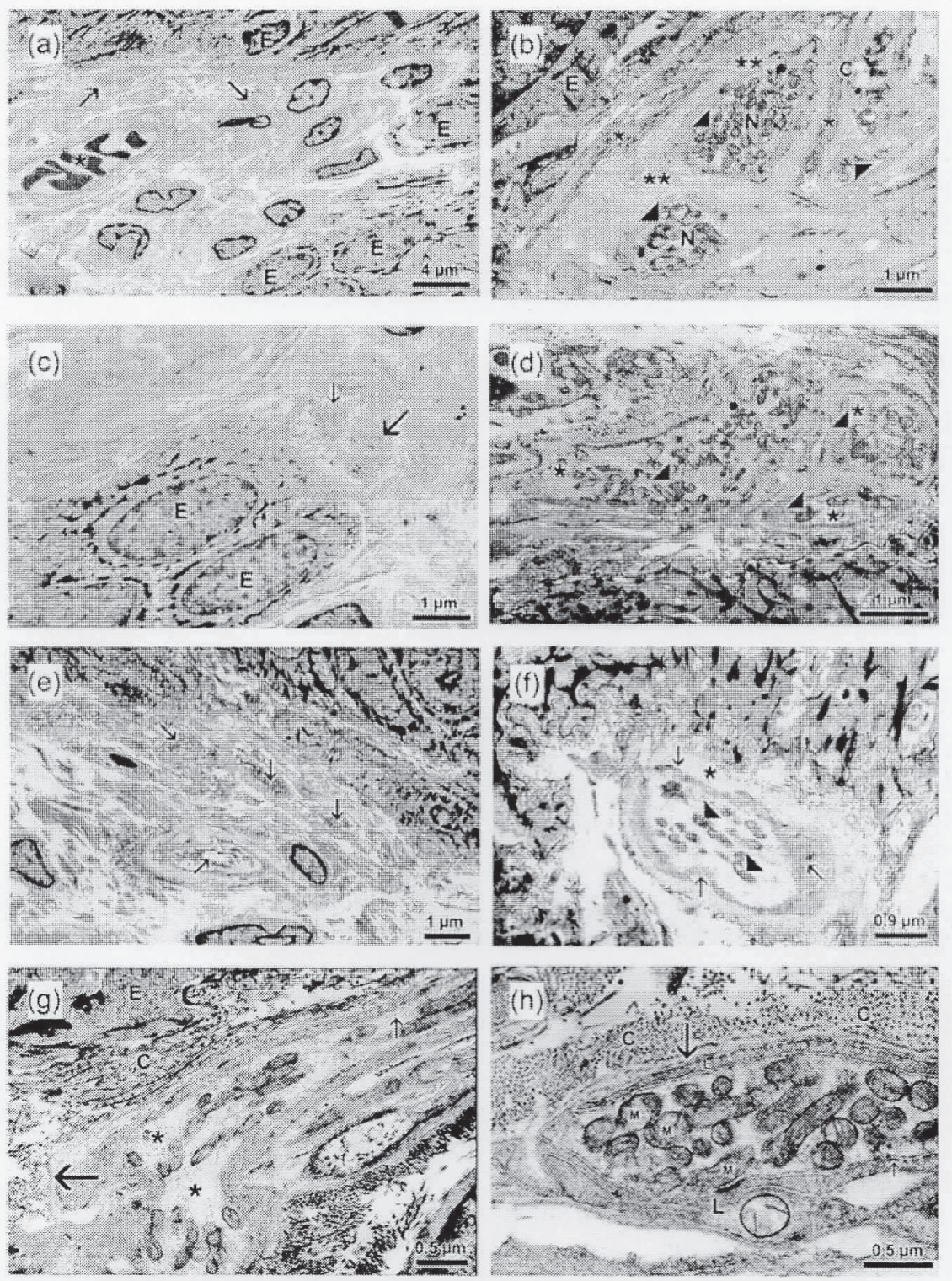

Fig. 4. (a) Subepithelial lamina propria containing several nerve endings (arrows), fibroblasts, capillary (asterisk) and adjacent epithelial cells (E). Bar: $4 \mu \mathrm{m}$. (b) Free nerve endings $(\mathrm{N})$ and a continuous amorphous substance (double asterisk) very close to the basal epithelial cells, shown at high magnification (E). The axoplasm presents numerous mitochondria (arrowheads) and adjacent collagen fibers (C). Bar: $1 \mathrm{\mu m}$. (c) At the base of epithelial cells (E), the free nerve endings (large arrow) containing numerous mitochondria and lamellar ending (small arrow) are identified. Bar: $1 \mathrm{\mu m}$. (d) Several expansions of free nerve endings (asterisk) with numerous mitochondria (arrowheads) and neurofilaments (arrow) are noted. Bar: $1 \mathrm{\mu m}$. (e) The lobulated nervous endings in shape are identified in the subepithelial portion of epithelial cells (arrows). Bar: $1 \mu \mathrm{m}$. (f) At high magnification, small and lobulated form of nerve ending presents its axoplasm surrounded by a thick lamina of Schwann cells (arrows). The axon presenting numerous mitochondria (arrowheads) and amorphous substance (asterisk) is shown. Bar: $0.9 \mathrm{\mu m}$. (g) The filamentous form of free nerve endings may ramified in several small branches (asterisk) containing few mitochondria, neurofilaments (small arrow). In the adjacent area, the basement lamina (large arrow), bundles of collagen fibers (C) and cytoplasm of epithelial cell (E) is identified. Bar: $0.5 \mu \mathrm{m}$. (h) The thin free nerve ending surrounded by a lamina of Schwann cell (S) presents the numerous mitochondria (M). At the periphery, the lamina of Schwann cell (L) and basement membrane of Schawann cell (large arrow) thick bundles of collagen fibers (C) are identified. The desmosome-type junction is observed between the axoplasm membrane and Schwann cell membrane (small arrow). Bar: $0.5 \mu \mathrm{m}$.

$84.24 \mu \mathrm{m}^{2}$. In addition, the mitochondria area and the lamellae thickness of organized corpuscles were also measured. The average area of the corpuscles mitochondria was $0.084 \pm 0.044 \mu \mathrm{m}^{2}$ with the dispersion shown in Fig. 6c and the median area was $0.074 \mu^{2}$. The average thickness of the corpuscles 

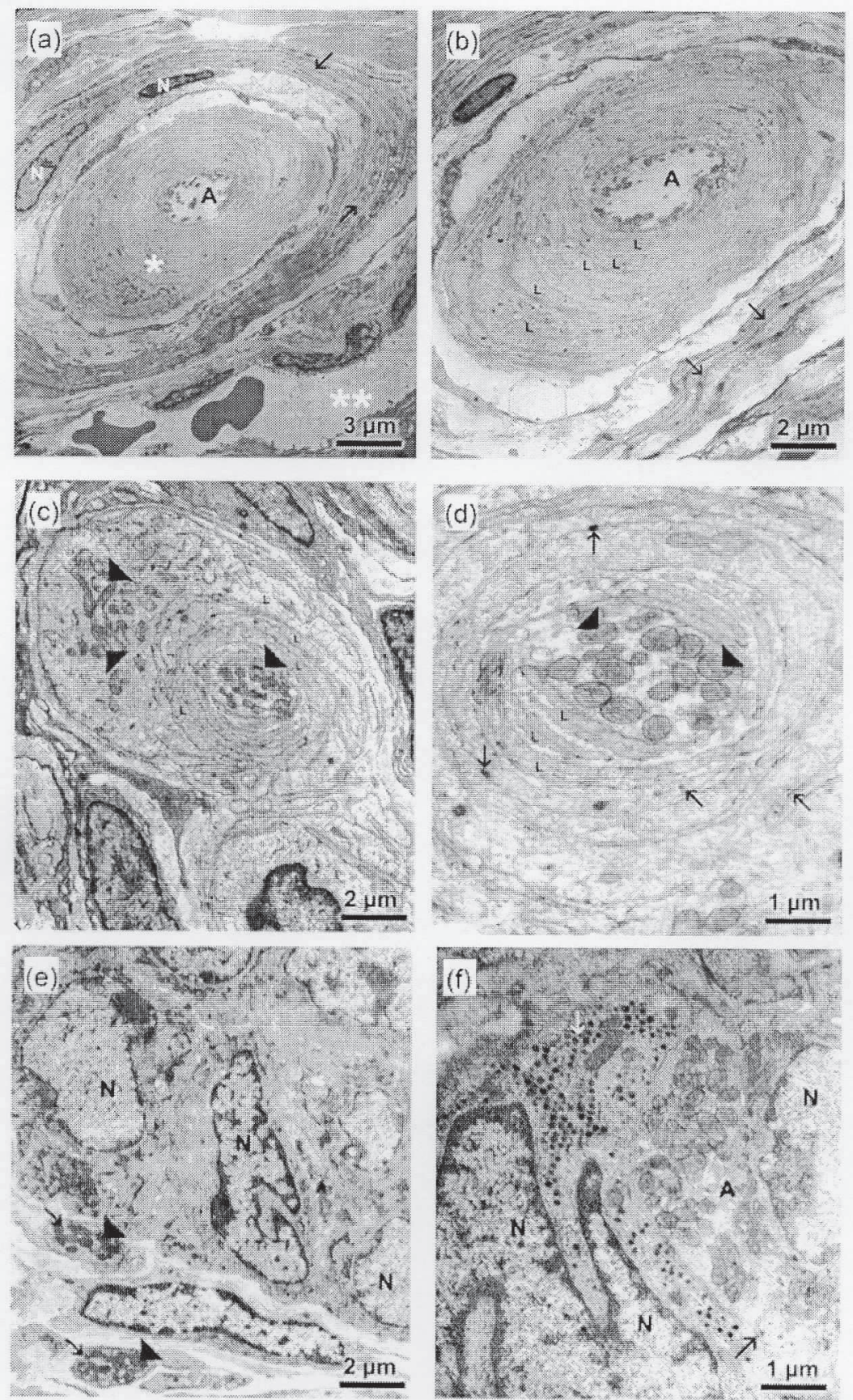

Fig. 5. (a and b) Lamellar corpuscles of cheek. A central axon (A) containing numerous mitochondria was observed. The lamellar cytoplasmic (L) was formed by a concentric disposition of different sizes of laminae. At the periphery, the cytoplamic extensions (arrows) of perineural cells nuclei $(\mathrm{N})$ are observed. The adjacent capillary (double asterisk) is clearly seen. Bar: 3 and $2 \mu \mathrm{m}$, respectively. (c and d) Soft palatine mucosa. Lamellar corpuscles with small and irregular shapes. The cytoplasm of lamellar cells are large, at the periphery, and contain numerous mitochondria (arrowheads), filaments and desmosome-type junctions between the laminae (L). The central axon presents numerous mitochondria (arrowheads). The small desmosome-type junctions are noted between the lamellae (small arrows) Bar: 2 and $1 \mu \mathrm{m}$, respectively. (e and f) Structure of Merkel corpuscles. The lobulated nuclei (N), associated with intra-epithelial axons (A) and dark granules (white arrows), are identified. Between the Merkel cell lamina and axoplasmic membrane, the desmosome-type junction (dark arrow) is observed. Bar: 2 and $1 \mu \mathrm{m}$, respectively. 

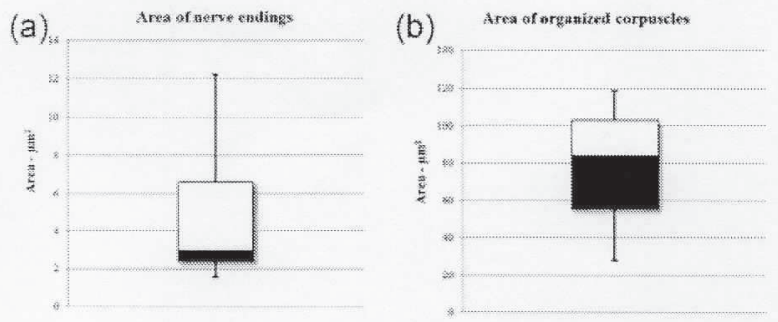

(c)

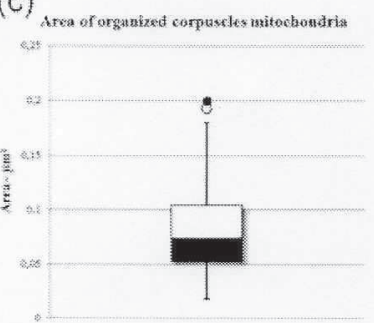

(d)

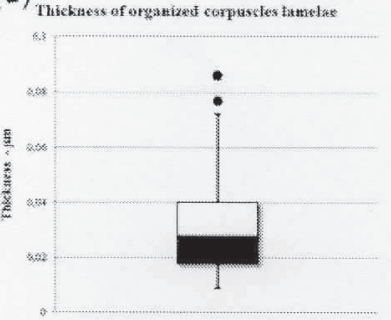

Fig. 6. Morphometry and quantification of nerve endings and organized corpuscles. (a) Data dispersion of nerve ending area. (b) Data dispersion of organized corpuscles area. (c) Data dispersion of mitochondria area inside the organized corpuscles. (d) Data dispersion of lamellae thickness of organized corpuscles.

lamellae was $0.031 \pm 0.015 \mu \mathrm{m}$, the dispersion of these thicknesses are shown in Fig. 6d and the median was $0.028 \mu \mathrm{m}$.

\section{Discussion}

The present findings demonstrated immunoreactivity for substance P-like peptide, CGRP and PGP 9.5 peptide in sensory nerve endings of several types in the subepithelial layer and in the connective tissue of papillae of the rat tongue mucosa.

Substance P, CGRP and PGP 9.5 peptide containing nerve fibers are numerous in the oral mucosa and run as single or ramified fibers in the tissue of every papilla or in subepithelial lamina propria, similar to those found by [24,52-54]. Filiform papillae demonstrated relatively few nerve fibers, and most of them are thin. On the other hand, in the fungiform papilla, our results showed that there are numerous substance P- and CGRP-containing nerve fibers, which are arranged in very complex networks of thin fibrils. These observations were reported in human fungiform papillae [55] and in the rat' fungiform papillae [25]. Although, there is special interest to verify the presence of substance $\mathrm{P}$ - and CGRP-containing fibers in peripheral trigeminal nerve branches supplying the tongue mucosa. Substance $\mathrm{P}$ is released by nervous stimulation from peripheral sensory branches in the dental pulp [27]. Substance P and CGRP represent the neutrophic factors responsible for stimulation of peripheral structures and modulating the threshold of excitability of the nerve endings as the presence was demonstrated by [28] and [56], suggesting that substance $\mathrm{P}$ could serve as neurotransmitter in some sensory afferent fibers, perhaps for pain transmission or for mechanoreceptors [57]. It was also suggested that these substances are related to sensory transmission system [28].

On the other hand, our data demonstrated clearly the fine structure of free sensory nerve endings and organized corpuscles present in the lamina propria of rat oral mucosa. The organized corpuscles are composed by numerous surrounding cytoplasmic extensions of lamellar cells and the central terminal axons. The characteristics of sensory nerve endings were reported in rat gingiva [30]; in the rat cheek mucosa [32] and in primate fungiform papillae [58]. The terminal axon exhibited a large number of mitochondria and small clear vesicles particularly at the base of axoplasmic protrusions. These data are very similar to previous findings in the sheep oral mucosa [56] and in the rat lip [18,37,39]. In the terminal axon, the axoplasmic protrusions were observed, which may provide extra information during the mastication [32,58]. Also, those lamellar corpuscles are generally concerned with rapidly adapting mechanoreception $[30,36,59,60]$.

Our results showed that Merkel cells are found in the palatine and tongue mucosae of Wistar rats. The characteristics are similar to those reported by the literature using different experimental models $[61,62]$, vermillion border and mucosal areas of the rat lip [39], chicken [63], lingual mucosa of the finch, Lonchula striata var. domestica [64], labial ridge epidermis of anuran tadpole [65,66] and labial mucosa of the rabbit $[67,68]$.

Lamellar cells surrounding the terminal axon contained several caveolae, which are invaginations of the cytoplasmic membrane and interlamellar spaces filled by amorphous substance and fine filaments. These structures are important for modulation of the neurosensorial transmission mechanisms. These characteristics were also observed by [18] and [39]. The authors also demonstrated the nonspecific cholinesterase activity mainly in the interlamellar 
spaces, suggesting that lamellar cells can synthesize cholinesterase. Although, the clear vesicles were only stationary pictures of the dynamic metabolic action involving transport, intake and elimination of substances onto the surface of cytoplasm [69]. The presence of desmosome-type junctions between lamellar cell and the terminal axon and adjacent lamellae was also reported by several authors $[29,30,32,36,39,70]$, suggesting the function of mechanoreceptors and pain.

Quantitative and morphometric data of this study showed a great variability in relation to the organized corpuscles area $\left(27-118 \mu \mathrm{m}^{2}\right)$, suggesting varying sizes. The area of nerve endings also showed considerable variability $\left(1.5-12 \mu \mathrm{m}^{2}\right)$, but lower compared with the organized corpuscles. The mitochondrial area inside the corpuscles (0.018$0.2 \mathrm{\mu m}^{2}$ ) and the corpuscles lamellae thickness $(0.009-0.086 \mu \mathrm{m})$ showed a variation in small amplitude.

In literature, there are few studies that performed quantitative and morphometric analyses and in nerve endings and receptors of the oral mucosa. In two studies, the focus was the nerve endings in the periodontal ligament [71,72] and, in another study, the focus was the nerve endings of the tongue [42]. However, in none of these studies, the measured parameters were similar to those presented in this study, thus not allowing comparisons.

\section{Concluding remarks}

In conclusion, lamellar bodies are located in the sensitive region and the subepithelial Merkel corpuscles are located in the basal layer of epithelial cells containing the intraepithelial nerve endings. Ultrastructural details of lamellar cells, myelinated and unmyelinated nerve fibers were evidenced by immunohistochemical staining. These sensory fibers act in the transmission of sensory impulses of pain and mecanoreception of oral mucosa.

\section{Funding}

Japan Society for the Promotion of Science - JSPS/ EP/78191; Sao Paulo State Foundation - FAPESP N. 97/09943-0; Japan International Cooperation Agency - JICA N. 8205491.

\section{References}

1 Pease D C and Quillian T A (1957) Electron microscopy of the Pacinian corpuscle. J. Cell Biol. 3: 331-342.

2 Cauna N and Ross L L (1960) The fine structure of Meissner's touch corpuscles of human fingers. J. Biophys. Biochem. Cytol. 8: $467-482$.

3 Quillian T A and Armstrong J (1963) Mechanoreceptors. Endeavour 22: $55-60$.

4 Yamamoto T (1966) The fine structure of palisade-type sensory ending in relation to hair follicles. J. Elect. Microsc. 15: 158-166.

5 Andersen A E and Nafstad P H J (1968) An electron microscopic investigation of the sensory organs in the hard palate region of the hen (Gallus dormesticus). Z. Zellforsch. 91: 391-401.

6 Chouchkov C (1971) Ultrastructure of Pacinian corpuscles in man and cats. Z. Mikrosk. Anat. Forsch. 83: 17-32.

7 Andres K H and von During M (1973) Morphology of cutaneous receptors sensory. In: IGGO A (ed.), Handbook of Sensory Physiology, vol. II. Somatosensory System, pp 3-8. (Springer, New York).

8 Spencer P S and Schaumburg H H (1973) An ultrastructural study of the inner core of the Pacinian corpuscle. J. Neurocy. 2: 217-235.

9 Castano P and Ventura R G (1978) The Meissner corpuscle of the green-monkey. I. The organization of the nervous component. $J$. Submicr. Cytol. 10: 327-344.

10 Chiba T, Watanabe S, and Shin T (1985) Ultrastructure of the glom erular corpuscular nerve endings in the subepithelium of human epiglottis. Arch. Histol. Jpn. 48: 213-221.

11 Munger B L and Ide C (1988) The structure and function of cutaneous sensory receptors. Arch. Histol. Cytol. 51: 1-34.

12 Rakhawi M and Bourne G H (1960) Cholinesterase in the human tongue. In: Symposium on Histochemistry of Cholinesterase (Basel).

13 Saxod R (1973) Activite cholinesterastique des corpuscles sensoriales cutanes de Herbst et de Grandry. Histochem. 34: 43-63.

14 Ide C and Saito T (1980) Electron microscopic histochemistry of cholinesterase activity of Vater-Pacini corpuscles. Acta Histochem. Cytochem. 13: 298-305.

15 Ide C and Saito T (1980) Electron microscopic cytochemistry of cholinesterase activity of mouse digital corpuscle. Acta Histochem. Cytochem. 13: 218-225.

16 Ide C (1982) Degeneration of digital corpuscles. Am. J. Anat. 163: $59-72$.

17 Toyama Y (1985) The morphology of sensory corpuscles in the joint capsule. Ultrastructural and histochemical study. J. Jpn. Orthop. Ass. 59: 397-407.

18 Watanabe I and Ide C (1987) Cholinesterase activity of lamellated sensory corpuscles in the rat lip. Arch. Oral. Biol. 32: 129-134.

19 Dubovy P (1989) Electron microscopical study of non-specific cholinesterase activity in simple lamellar corpuscles of glabrous skin from cat rhinarium: a histochemical evidence for the presence of collagenase-sensitive molecular forms and their secretion. Acta Histochem. 86: 63-77.

20 Dubovy P (1990) A fine structural localization of the non-specific cholinesterase activity in glomerular nerve formations. Zeit. Mikrosk. Anat. Forsch. 104: 87-96.

21 Loo S K, Halata Z, and Strasmann T (1990) Cholinesterase activity in sensory-nerve endings, capillaries and motor end plates of the facial skin of the Brush-Tailed Possum (Trichosurus vulpecula). Acta Anat. 139: 357-366.

22 Wakisaka S, Ichikawa H, Matsuo S, Yamamopto K, Nakata T, and Arai M (1984) Immunoreactivity in the pulp dentine zone of human molar teeth demonstrated by indirect immunofluorescence. Arch. Oral Biol. 29: 73-75. 
23 Wakisaka S, Nishikawa S, Ichikawa H, Matsuo S, Takano Y, and Arai M (1985) The distribution and origin of substance P-like Immunoreactivity in rats molar pulp and periodontal tissues. Arch. Oral Biol. 30: 813-818

24 Wakisaka S, Ichikawa H, Uchivama T, Matsuo S, Takano Y, and Arai M (1987) Immunohistochemical study on regeneration of substance P-like immunoreactivity in rat molar pulp and periodontal ligament following resection of the inferior alveolar nerve. Arch. Oral Biol. 32: $215-227$.

25 Astback J, Arvidson K, and Johansson O (1997) An immunohistochemical screening of neurochemical markers in fungiform papillae and taste buds of the anterior rat tongue. Arch. Oral Biol. 42: 137-147.

26 Yee CL, Yang R, Bottiger B, Finger T E, and Kinnamon J C (2001) Type III cells of rat taste buds: immunohistochemical and ultrastructural studies of neuron-specific enolase, protein gene product 9.5, and serotonin. J. Comp. Neurol. 440: 97-108.

27 Olgarth L, Gazellius B, Brodin E, and Nilsson G (1977) Release of substance P-like immunoreactive from the dental pulp. Acta Physiol. Scand. 101: 510-512.

28 Lee Y, Shiosaki S, Takami R, Kiyama H, Hillyard C J, Girgis S, Mac Intre I, Emson P C, and Tohyama M (1985) Coexistence of calcitonin gene-related peptide and substance P-like peptide in single cells of the trigemminal ganglion of the rat: immunohistochemical analysis. Brain Res. 330: 194-196.

29 Martinez Z R and Pekarthy J M (1974) Ultrastructure of encapsulated nerve endings in rat gingiva. Am. J. Anat. 140: 135-138.

30 Watanabe I and Yamada E (1983) The fine structure of lamellated nerve endings found in the rat gingiva. Arch. Histol. Jpn. 46: 173-182.

31 Watanabe I and Yamada E (1984) Unusual nerve endings found in the rat palatine mucosa. Arch. Histol. Jpn. 47: 187-196.

32 Watanabe I and Yamada E (1985) A light and electron microscopic study of lamellated nerve endings found in the rat cheek mucosa. Arch. Histol. Jpn. 48: 497-504.

33 Watanabe I and Yamada E (1988) Fine structure of the lamellated corpuscles in the mouse hard palatine mucosa. Z. Mikrosk. Anat. Forsch. 102: 811-816.

34 Watanabe I and Yamada E (1989) Fine structure of lamellated and free nerve endings of the rat soft palate mucosa. Micr. Eletr. Biol. Cel. 13: 139-150.

35 Halata H and Munger B L (1983) The sensory innervation of primate facial skin. II. Vermilion border and mucosa of lip. Bruin Res. Rev. 5: $81-107$.

36 Watanabe I, Usukura J, and Yamada E (1985) Electron microscopy study of the Grandry and Herbst corpuscles found in the palatine mucosa, gingival mucosa and beak skin of the duck. Arch. Hist. Jpn. 48: $1-9$

37 Watanabe I and Semprini M (1985) Light and electron microscopy observations in the rat gingiva nerve endings. A silver impregnation and a transmission electron microscopy study. Rev. Cienc. Morfol. 2: $10-18$

38 Nakamura T K, Nakamura M, Yoshikawa M, Kiyomura H, and Hanai $H$ (1986) Fine structure of probable sensory nerve endings in human periodontal ligaments. Okaj. Folia. Anat. Jpn. 63: 323-330.

39 Tachibana T, Sakakura Y, Ishizeki K, and Nawa T (1987) Nerve endings in the vermillion border and mucosal areas of the rat lip. Arch. Histol. Jpn. 50: 73-85.

40 Tachibana T, Fujiwara N, and Nawa T (1989) Intraperineural localization of lamellated sensory corpuscles in the skin and oral mucosae of the adult cat and miniature pig. J. Neurocitology. 8: 61-69.

41 Tachibana T, Fujiwara N, Sato H, and Nawa T (1990) A comparative electron microscopic analysis of mechanoreceptors in the hard palate of the mouse and the musk shrew (suncus murinus, Insectivora). Arch Oral Biol. 35: 949-956.
42 Watanabe I and Ide C (1991) Ultrastructure of the nerve endings in the rat tongue mucosa. Micr. Electr. Biol. Cel. 15: 159-171.

43 Ide C (1976) The fine structure of the digital corpuscle of the mouse toe pad, with special reference to nerve fibers. Am. J. Anat. 147: $329-356$.

44 Ide C (1977) Development of Meissner corpuscle of mouse toe pad. Anat. Rec. 188: 49-67.

45 Chouchkov C (1973) Further observations of the fine structure of Meissner's corpuscles in human digital skin and rectum. Z. Mikrosk. Anat. Forsch. 87: 33-45.

46 Andres K H (1969) Zur Ultrastruktur verschiedener Mechanorezeptoren von hoheren Wirbeltieren. Anat. Anz. 124: $551-565$

47 Cauna N and Mannan G (1959) Development and postnatal changes of digital Pacinian corpuscles (Corpuscula lamellosa) in the human hand. Anat. Rec. 93: 271-286.

48 Ide C, Yoshida Y, Hayashi S, Takashio M, and Munger B L (1988a) A re-evaluation of the cytology of cat Pacinian corpuscles. I. The inner core and clefts. Cell Tissue Res. 253: 83-93.

49 Ide C, Yoshida Y, Hayashi S, Takashio M, and Munger B L (1988b) A re-evaluation of the cytology of cat Pacinian corpuscles. II. The extreme tip of the axon. Cell Tissue Res. 253: 95-103.

50 Watson M L (1958) Staining of tissue sections for electron microscopy with heavy metals. II. Application for solutions containing lead and barium. J. Biophys. Biochem. Cytol. 4: 475-479.

51 Reynolds E S (1963) The use of lead citrate at high $\mathrm{pH}$ as on electron opaque stain in electron microscopy. J. Cell Biol. 17: 208.

52 Lundberg J M, Hokfelt T, Anggard A, Pernow B, and Emson P (1979) Immunohistochemical evidence for substance $\mathrm{P}$ immunoreactive nerve fibers in the taste buds of the cat. Acta Physiol. Scund. 107. 389-391.

53 Nagy J I, Goedert M, Hunt S P, and Bond A (1982) The nature of the substance P-containing nerve fibers in taste papillae of the rat tongue. Neuroscience 7: 3137-3151.

54 Nishimoto T, Ichikawa H, Wakisaka S, Matsuo S, Yamamoto K, Nakata T, and Arai M (1985) Immunohistochemical observation on substance $\mathrm{P}$ in regeneratiung taste buds of the rat. Anat. Rec. 212: $430-436$.

55 Astback J, Arvidson K, and Johansson O (1995) Neurochemical markers of human fungiform papillae and taste buds. Regul. Pept. 59: 389-398.

56 Jayaraj P, Quilliam T A, and Tilly R (1973) Oral nerve endings in the sheep. J. Physiol. 232: 7-9

57 Otsuka M, Konishi S, Takahashi T, and Saito K (1976) Substance P and primary afferent transmission. Adv. Biochem. Psychopharmacol. 15: $187-191$

58 Toyoshima K, Miyamoto K, and Shimamura A (1987) The ultrastructure of encapsulated sensory corpuscles in the fungiform papillae of monkeys. Arch. Histol. Jpn. 50: 385-392.

59 Maeda T, Kannari K, Sato O, and Iwanaga T (1990) Nerve terminals in human periodontal ligament as demonstrated by immunohistochemistry for neurofilament protein (NFP) and S-100 protein. Arch. Hist. Cytol. 53: 259-265.

60 Malinovsky L (1986) Classification of sensory nerve endings in vertebrates brought up to date. Folia. Morphol. 34: 261-266.

61 Iggo A and Andres K H (1982) Morphology of cutaneous receptors Ann. Rev. Neurosci. 5: 1-31.

62 Zelená I (1994) Nerve and Mechanoreceptors, 1st edn. (Chapman and Hall, London).

63 Saxod R (1978) Ultrastructure of Merkel corpuscles and so-called "transitional" cells in the white Leghorn chicken. Am. J. Anut. 151 $453-473$ 
64 Toyoshima K and Shimamura A (1991) Uranaffin reaction of Merkel corpuscles in the lingual mucosa of the finch, Lonchula striata var. domestica. J. Anat. 179: 197-201.

65 Tachibana T (1978) The Merkel cell in the labial ridge epidermis of anuran tadpole. I. Fine structure, distribution and cytochemical studies. Anat. Rec. 191: 487-502.

66 Tachibana T (1979) The Merkel cell in the labial ridge epidermis of anuran tadpole. II. Electron microscope observations on the appearance and differentiation of the Merkel cell. Arch. Hist. Jpn. 42 : 129-140.

67 Tachibana T and Nawa T (1980) Merkel cell differentiation in the labial mucous epithelium of the rabbit. J. Anat. 131: 145-155.

68 Tachibana T, Sakakura Y, Ishizeki K, Iida S, and Nawa T (1983) An experimental study of the influence of sensory nerve fibers on
Merkel cell differentiation in the labial mucosa of the rabbits. Arch. Histol. Jpn. 46: 469-477.

69 Malinovsky L, Pac L, and Dubovy P (1986) On the problems of clear vesicles in sensory corpuscles. Z. Mikrosk. Anat. Forsch. 100: 213-223.

70 Halata Z, Cooper B Y, Baumann K I, Schwegmann C, and Friedman R M (1999) Sensory nerve endings in the hard palate and papilla incisiva of the goat. Exp. Brain Res. 129: 218-228.

71 Freezer S R and Sims M R (1989) Morphometry of neural structures in the mouse periodontal ligament mesial to the mandibular first molar. Aust. Orthod. J. 11: 30-37.

72 Fukuda M and Tazaki M (1994) Distribution of organized sensory nerve endings in the human periodontal ligament. Bull. Tokyo Dent. Coll. 35: 133-137. 